\title{
The Mallory-head hydroxyapatite coated femoral prosthesis : studies on patient outcome, radiology and bone density
}

Citation for published version (APA):

Gosens, T. (2004). The Mallory-head hydroxyapatite coated femoral prosthesis : studies on patient outcome, radiology and bone density. [Doctoral Thesis, Maastricht University]. Universiteit Maastricht. https://doi.org/10.26481/dis.20041118tg

Document status and date:

Published: 01/01/2004

DOI:

10.26481/dis.20041118tg

Document Version:

Publisher's PDF, also known as Version of record

\section{Please check the document version of this publication:}

- A submitted manuscript is the version of the article upon submission and before peer-review. There can be important differences between the submitted version and the official published version of record.

People interested in the research are advised to contact the author for the final version of the publication, or visit the DOI to the publisher's website.

- The final author version and the galley proof are versions of the publication after peer review.

- The final published version features the final layout of the paper including the volume, issue and page numbers.

Link to publication

\footnotetext{
General rights rights.

- You may freely distribute the URL identifying the publication in the public portal. please follow below link for the End User Agreement:

www.umlib.nl/taverne-license

Take down policy

If you believe that this document breaches copyright please contact us at:

repository@maastrichtuniversity.nl

providing details and we will investigate your claim.
}

Copyright and moral rights for the publications made accessible in the public portal are retained by the authors and/or other copyright owners and it is a condition of accessing publications that users recognise and abide by the legal requirements associated with these

- Users may download and print one copy of any publication from the public portal for the purpose of private study or research.

- You may not further distribute the material or use it for any profit-making activity or commercial gain

If the publication is distributed under the terms of Article 25fa of the Dutch Copyright Act, indicated by the "Taverne" license above, 


\title{
The Mallory-Head hydroxyapatite COATED FEMORAL PROSTHESIS.
}

\begin{abstract}
Studies on patient outcome, radiology and bone density
\end{abstract}

\section{ProefSChrift}

ter verkriiging van de graad van doctor aan de Universiteit Maastricht, op gezag van de Rector Magnificus, Prof. mr. G.P.M.F. Mols,

volgens het besluit van het College van Decanen, in het openbaar te verdedigen op donderdag

18 november 2004 om 12.00 uur

door

Taco Gosens 
Promotor:

Co-promotores:

Manuscript beoordelingscommissie:
Prof. Dr. R.G.T. Geesink

Dr. E.J. van Langelaan

(Rijnland Ziekenhuis Leiderdorp)

Dr. A.J. Tonino

(Atrium Medisch Centrum Heerlen)

Prof. Dr. J.M.A. van Engelshoven

(voorzitter)

Dr. S.K. Bulstra

Prof. Dr. H. van Mameren

Prof. Dr. J.A.N. Verhaar

(Erasmus Universiteit Rotterdam)

Dr. N. Verdonschot

(Academisch Ziekenhuis Nijmegen) 
This work was performed from Rijnland Hospital in Leiderdorp,

Atrium Medical Center in Heerlen and University Hospital in Maastricht, the Netherlands.

The publication of this thesis was supported by:

Biomet NederLand B.V., Dordrecht

NEDERLANDSE ORTHOPAEDISCHE VERENIGING

STRYKER - HOWMEDICA B.V., Waardenburg

Medacta Holland B.V., Nijkerk

TORNIER B.V., Schiedam

DEPUY MITEK, Amersfoort

NTOC MEDISCHE TECHNIEK, Lithoijen

BAUERFEIND BENELUX B.V., Haarlem

Somas Orthopaedie B.V., Sint Anthonis

ND Service N.V., Grimbergen, België

J. VAN LIEROP ORTHOPEDIE, Venlo

IMD B.V., Uden

Defauwes ORTHopaedische Schoentechniek B.V., Heerlen

SANOFI-SYNTHELABO B.V., Maassluis

J.B. IMPLANTS SERVices B.V., Rosmalen

MSD B.V. Haarlem

ZIMMER B.V., Utrecht

SMEETS\&ZONEN, Geleen

SMTTH\&NePHEW B.V., Hoofddorp

van Straten Medical B.V., Nieuwegein

HANSSEN FoOTCARE, Kerkrade

ENDOCARE B.V., Hoogeveen

ANNA-FONDS, Leiden

ISBN 90-9018497-X

Graphic Design:

TVM DESIGN

Eric Elich

Printed by:

DRUKKERIJ

EM. DE JONG B.V.

\section{Gosens, Taco}

The Mallory-Head hydroxyapatite coated femoral prosthesis. Studies on patient outcome, radiology and bone density studies.
Subject headings:

Total hip arthroplasty, cementless, MalloryHead, hydroxyapatite, patient outcome, primary, dysplasia, revision, bone density

(C) T.Gosens, Goirle, the Netherlands All rights are reserved, no part of this publication may be reproduced or transmitted in any form or by any means, electronic or mechanic, including photocopy, recording or any information storage and retrieval system, without the prior permission in writing from the author. 

Opgedragen aan mijn moeder. 



\section{ODE TO TOTAL HIPS.}

I think that I shall never see

$A$ hip as lovely as a tree.

Trees grow and change in ev'ry season, While hips can fail for any reason.

Trees stand up tall, and shade provide, While hips get loose, migrate, subside.

A tree whose roots grow deep and long, To make a base that's broad and strong, Needs no support from bone cement, To which our hips oft sing lament.

It holds the joint, and shock absorbs, Until it cracks, or bone resorbs. Cement or not; a tough decision. We like it less with each revision.

$A$ tree that may in summer wear $A$ nest of robins in her hair Has more appeal than hips that wear By creep, cold flow, or fracture tear, Or stems that fail in varus tilt Causing painful antalgic lilt. Like a tree, hips too have beauty, Relieving pain is their prime duty. Canes are dropped, and patients walk, While media folks hype miracle talk.
Implanting hips is lots of fun, But which of them is number one? Space-age alloys in new designs And metal-backed cups sure look fine. Porous coats, stems without collars, All cost patients many dollars.

The choice of hips can be confusing, And sales campaigns are quite amusing. Yet we must choose which hip to use, And hope our patients do not lose.

It is clear, hips must last longer, Like a sapling, growing stronger. Perhaps someday, my sons will see $A$ hip that lasts as long as a tree.

The moral of this rhyme is clear, And should spread grins from ear to ear. Hips are put in by fools like me, But only God can make a tree.

by William L. Healy, MD. 



\section{The Mallory-Head hydroxyapatite COATED FEMORAL PROSTHESIS}





\section{Contents}

$\begin{array}{llll}\text { Chapter I Introduction } & 13\end{array}$

$\begin{array}{llll}\text { Chapter II History and Background } & 19\end{array}$

Chapter III Translation and validation of the modified "Oxford Heup Score" 41

$\begin{array}{lll}\text { Chapter IV The Mallory-Head prosthesis } & 63\end{array}$

$\begin{array}{lll}\text { Chapter V Primary THA with the Mallory-Head femoral prosthesis } & 73\end{array}$

Chapter VI The Mallory-Head femoral prosthesis in hip dysplasia 95

$\begin{array}{lll}\text { Chapter VII The Mallory-Head femoral prosthesis in revision cases } & 113\end{array}$

$\begin{array}{ll}\text { Chapter VIII Femoral fit predicts radiologic changes } & 135\end{array}$

Chapter IX DEXA study of the Mallory-Head femoral prosthesis 157

$\begin{array}{llll}\text { Chapter X Discussion and Conclusions } & 179\end{array}$

$\begin{array}{lll}\text { Chapter XI Summary in English } & 193\end{array}$

Chapter XII Summary in Dutch / Samenvatting in het Nederlands 201

Chapter XIII Acknowledgements / Dankwoord 209

$\begin{array}{lr}\text { Chapter XIV Curriculum Vitae } & 215\end{array}$ 
INTRODUCTION 


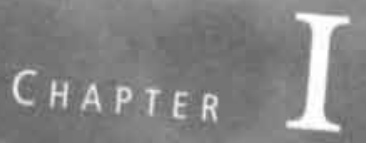

INTRODUCTION 
INTRODUCTION 


\section{INTRODUCTION}

It has been more than four decades since Sir John Charnley introduced the low-friction arthroplasty. Total hip arthroplasty has become one of the most commonly performed procedures in the orthopaedic practice. Its clinical efficacy and cost-effectiveness have both been well documented in the literature (1-7). Total hip arthroplasty has been offered to younger and more active patients with increasing frequency over the last decade as the clinical success of this operation continues to be validated. With reference to age and the choice for cemented or cementless hip replacement the study of Malchau et al. (8) can be mentioned. They described in their annual evaluation of the Swedish Hip Register that the results in terms of survival in younger patient cohorts are nowadays similar for cemented, hybrid and cementless prostheses (a survival percentage of $95.2 \%$ for the cementless prostheses versus $89.9 \%$ for the cemented designs in patients younger than 55 years of age). However the critical period for cemented prostheses has come now and the future will show whether the trend that is already visible that cementless designs have a better survival will stand the test of time or that time will even enhance this difference.

Failure of a total hip prosthesis can be caused by aseptic loosening. Loosening of cemented designs is said to be caused by mechanical degradation of the acrylic bone cement with time (9-11), impairment of the mechanical strength of the cement by entrapment of air, blood and laminations (12) and adverse tissue reactions initiated by the thermal-chemical side-effects of the acrylic cement (13). In cementless designs loosening may be caused by weakening of the bone resulting from bone resorption in particle disease, material strain in the interface of prosthesis and bone, failure of the ingrowth in improperly fitting prostheses and inadequate stress transfer of prosthesis to bone (14). More than in cemented designs, the implantation of a stem in the femoral canal radically alters the stress distribution in the femur and this alteration in the local mechanical situation results in changes of the bony architecture. The stresses that are normally experienced by the femoral trabecular and cortical bone are locally decreased, leading to atrophy of the involved zones of the proximal femur.

Therefore in cementless total hip replacement, this periprosthetic bone loss caused by stress shielding may be an adverse sequel for the long term. Bone loss can affect both the femur and the acetabulum and can seriously compromise the outcome of total hip replacement, although even extensive bone loss may be without any clinical symptoms. However, extensive bone loss can present very serious problems for further reconstruction in revision hip surgery.

Enormous amounts of data on topics related to total hip arthroplasty are presented and published each year. Survival studies, wear performance studies, radiologic studies, patient outcome studies, etc. are all performed for the various hip implants used all over the world. This thesis focuses on only a small part of the topics related to total hip arthroplasty. It contains studies about the patient outcome, the radiologic and the bone remodeling behavior of the cementless porous and hydroxyapatite (HA) coated femoral prosthesis according to Mallory-Head (Biomet, Warsaw, Indiana, USA). This prosthesis is not widely described in literature, especially not with the HA-coating. It is also not mentioned in the Swedish Arthroplasty Register. (15)

Following the introduction in this chapter, the history and background information about total hip replacement in general and more specific the cementless designs are discussed in chapter II. In this chapter also the different items that are important in jud- 
ging the success of a hip prosthesis are discussed. Chapter III presents the validation and translation of the modified "Oxford Heup Score": a questionnaire tailored to the Dutch situation and language based on the 12-item questionnaire by Dawson et al. (16) In my opinion this score reflects the patients' opinion about his or her total hip prosthesis better than the more well-known doctors' opinion based scores such as the Harris Hip Score (17) or the Merle d'Aubigné score. (18) Also, the selected use of patient-completed questionnaires has the potential to substantially reduce the costs of outcome evaluation programs by minimizing doctor input. Therefore, this score will be a part of the analysis performed in the following chapters of this thesis.

In chapter IV the design rational of the Mallory-Head stem and the use of hydroxyapatite as a coating on the prosthesis will be discussed. Finally, the results of the Mallory-Head stem in literature will be reviewed.

Chapters V, VI and VII represent the clinical and radiologic results of the MalloryHead hydroxyapatite coated femoral stem in primary, dysplasia and revision cases respectively after a mean follow up of 6 years. In chapter VII the results of the different operation groups will be compared and the influence of various parameters on the formation of the radiologic remodeling phenomena will be studied. In chapter IX the results of a prospective, randomized study of the ABG versus the Mallory-Head stem using Dual Energy X-ray Absorbtiometry (DEXA) will be presented. DEXA is a twodimensional projection system in which an X-ray tube is used as a source of photons of two energies. The use of a photon-detector and an interface with a computer system for imaging the scanned areas allows for measurement of the bone mineral content and, by calculation, the bone mineral density at axial skeletal sites at which there are varying amounts of overlying soft tissue, such as the hip and spine. The changes in bone density next to these two stems will be discussed. The importance of bone density changes surrounding a hip prosthesis is to determine factors that influence bone remodeling. Progressive bone loss may interfere with the clinical result, the survival of the hip prosthesis and may limit the options in revision hip arthroplasty. Chapter X discusses the results of the studies performed and conclusions will be drawn from them. Chapter XI will contain a summary in English, where as chapter XII will do the same in Dutch. Chapter XIII expresses my thanks to the persons who made this thesis possible and in chapter XIV a summary of my curriculum vitae can be read.

This short description of the contents of this thesis summarizes in fact the aims of this thesis:

1 To evaluate the clinical results more specifically, a more detailed, patient oriented questionnaire was needed. Therefore a modification, a translation into Dutch and validation of the 12-item questionnaire led to the modified "Oxford Heup Score".

2 To describe the clinical and radiologic behavior of the Mallory-Head hydroxyapatite coated femoral prosthesis in different categories of patients.

3 To analyse the factors that cause the radiologic changes that occur around this prosthesis.

4 To more accurately describe the bone density changes around this prosthesis and relate them to the design rational of this prosthesis. 


\section{REFERENCES}

1 Keet JG. (1987) [Cost-benefit analysis of total hip prosthesis]. Ned Tijdschrift Geneeskd 131(44):1965-9.

2 Laupacis A, Bourne R, Rorabeck C, Feeny D, Wong C, Tugwell P, Leslie K, Bullas R. (1994) Costs of elective total hip arthroplasty during the first year. Cemented versus noncemented. J Arthroplasty 9(5):481-7.

3 Bayley KB, London MR, Grunkemeier GL, Lansky DJ. (1995) Measuring the success of treatment in patient terms. Med Care 33(4) (Suppl): AS226-35.

4 Braeken AM, Lochhaas-Gerlach JA, Gollish JD, Myles JD, Mackenzie TA. (1997) Determinants of 6-12 month postoperative functional status and pain after elective total hip replacement. Int J Qual Health Care 9(6):413-8.

5 Fitzpatrick R, Shortall E, Sculpher M, Murray D, Morris R, Lodge M, Dawson J, Carr A, Britton A, Briggs A. (1998) Primary total hip replacement surgery: a systematic review of outcomes and modelling of cost-effectiveness associated with different prostheses. Health Technol Assess 2(20): 1-64.

6 Okhuijsen SY, Dhert WJ, Faro LM, Keet JG, Schrijvers AJ, Verbout AJ. (1998) [An estimate of the intramural costs of the placement of a total hip prosthesis]. Ned Tijdschr Geneeskd 142(25):1450-1455.

7 Mainard D, Guillemin F, Cuny C, Mejat-Adler E, Galois L, Delagoutte JF. (2000) [Quality of life assessment one year after total hip or knee arthroplasty]. Rev Chir Orthop Reparatrice Appar Mot 86(5): 464-73.

8 Malchau H, Herberts P, Eisler T, Garellick G, Soderman P. (2002) The Swedish total hip replacement register. J Bone Joint Surg [Am] 84, suppl 2:1-20.

9 Gates EI, Harris WH.(1984) Comparative fatigue behaviour of different bone cements. Clin Orthop 189:294 299.

10 Krause WR, Krug W, Eng B, Miller J. (1982) Strength of the cementbone interface. Clin Orthop 163:290-299.

11 Lange DR. (1979) The mechanical bonding of methyl-methacrylate to cancellous bone. J Bone Joint Surg 61-A:254-256.

12 Gruen TA, Amstutz HC. (1976). Effects of laminations and blood entrapment on the strength of acrylic bone cement. Clin Orthop 119:250-255.

13 Mjoberg B, Petterson H, Rosenqvist R, Rydholm A. (1984) Bone cement, thermal injury and the radiolucent zone. Acta Orthop Scand 55:597-600.

14 Huiskes R. (1998) [Causes of failure of hip and knee prostheses.] Ned Tijdschr Geneesk 142(37):2035-2040.

15 Malchau H, Herberts P,Garellick G, Soderman P, Eisler T. (2002) Prognosis of total hip replacement. Update of results and risk-ratio analysis for revision and rerevision from the Swedish National Hip Arthroplasty Register 1979-2000.

Presented at the 69th Annual Meeting of the AAOS, february 13-17, 2002, Dallas, USA.

16 Dawson J, Fitzpatrick R, Carr A, Murray D. (1996) Questionnaire on the perceptions of patients about total hip replacement. J Bone Joint Surg [Br] $78(2): 185-90$.

17 Harris WH. (1969) Traumatic arthritis of the hip after dislocation and ace tabular fractures: treatment by mold arthroplasty. An end-result study using a new method of result evaluation. J Bone Joint Surg [Am] 51(4):737-55.

18 Merle d'Aubigné RM, Postel M. (1954) Functional results of hip arthroplasty with acrylic prosthesis. J Bone Joint Surg [Am] 36(3):451-475. 


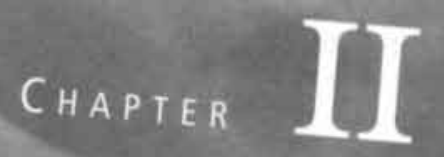

\section{History AND BaCKgROUND}


HISTORY AND BACKGROUND 


\section{History AND BACKGROUND}

The introduction of polymethylmethacrylate (PMMA) as a fixation method for endoprostheses by Haboogh, popularized by Sir John Charnley, was clearly a tidewater mark in the history of reconstructive orthopaedics. (1-3) For the first time, practicing orthopaedic surgeons had at their disposal a reliable, reproducible means of treating the myriad of patients presenting with major hip dysfunction. Early experience was prudently limited to the elderly and the relatively inactive.

By the early 1970 's, more than 100,000 total hip replacements were being performed annually, with many authors reporting spectacular results. (4-9) The number of hip replacements was 500,000 worldwide annually in the early 1990's and is still rising. In 1995 over 17,000 primary and over 1,500 revision hip arthroplasties were performed in the Netherlands. For 2010 the estimates are 25,000 primary and 4,000 revision operations. (10)

By 1975 , it was recognized that early techniques were perhaps deficient, and reports of increasing failure rates with time and activity began to surface. (11-17) By 1978, with the publication of Chandler et al.'s classic article concerning the catastrophic failure rate of cemented total hip replacements in the young and the active, it was beginning to be recognized that cement was not without substantial disadvantages. (18) Many of these early results were obtained using implants and cementing techniques that are considered obsolete nowadays. Increased knowledge of orthopaedic biomechanics (19-22) has led to improvements in implant design, and cementing technique leading to the currently accepted third generation cementing techniques with use of bone lavage, vacuummixing during the preparation of bone cement and femoral plugging with pressurization during injection of the bone cement. These improvements have led to considerably lower failure rates, improving long-term clinical results. (23)

It was in this setting that a number of surgeons thought the answer lay not in improving old fixation techniques, but in developing new methods of fixation, avoiding the use of bone cement: biologically fixed implants. By providing the prosthesis with surface texturing in the form of threedimensional pores of a specific size, one can expect bone to grow into these openings and afford long-term, durable fixation. Galante published his first experimental work on fiber metal. $(24,25)$ Pilliar was working with porous chromecobalt. $(26,27)$ Several European investigators already had substantial experience with press-fit non-ingrowth cementless systems. (28-30) Lord had developed a madreporic (coral-like) prosthesis for biologic fixation. (31-33) Because this was not truly porous coated, the term "ongrowth" is perhaps most appropriate to distinguish it from the smooth press-fit systems.

The earlier problems related with cemented implants thus led to a schism in prosthetic hip surgery: newer generation of cemented prostheses and cementless designs. Of course, it must also be remembered that cementless arthroplasty antedates cemented arthroplasty by several decades. The prostheses of Austin-Moore, Thompson, Boyd and Campbell, Smith-Peterson, MacIntosh, and McKeever are just some of the early pioneers to whom much is owed. $(34,35)$ Frequently, these early prostheses failed because only one side of the articulation was replaced or resurfaced. Even when they failed on the replaced side, that failure was seldom catastrophic in terms of bone loss. The first porous coated Austin-Moore prosthesis was implanted by Cameron in Canada and Lunceford in the United States in 1976. The prosthesis survived as the AML prosthesis and with some modification continues in its use. (36) The cementless implants, nowa- 
days, vary greatly in design philosophy. Cementless fixation of the femoral stem has gone through a period of improvements over the last two decades. More data are being presented with regard to their medium and long-term clinical performance and durability at ten to fifteen years. One of the most recent developments, in 1986, was the development and use of an additional coating of hydroxyapatite onto the prosthesis.

Surface texture is an integral factor influencing the success of cementless fixation of the stem. Evaluation and comparison of the clinical efficacy of the many stem designs over this time-period has been complicated by the extent of surface treatment (proximal or extensive). There is also considerable variety in surface finish and biological coating among the various available designs. The two main types of surfaces that have been in use over the last two decades are porous and hydroxyapatite. Also the variables of stem geometry (straight, curved, tapered, or modular) and biomaterials (titanium alloy or cobalt-chromium alloy) make it difficult to compare the reports in literature concerning the various prostheses, let alone the differences between the study groups.

The pathophysiology of the cementless hip prosthesis should be discussed prior to the identification of influencing factors. The predominant mechanism of aseptic loosening is still uncertain, but in summary, the three main theories currently explaining long term failure by aseptic loosening are:

1 Wear particles migrate around the prosthesis and cause a local macrophagic or sensitivity reaction, leading to the production of osteolytic mediators or local necrosis, respectively. This process is also known as particle disease. (37-46)

2 Micromotion of the prosthesis due to insufficient initial fixation, or loss of fixation, induces the formation of a periprosthetic membrane, which causes progressive loosening. (47-52)

3 Periprosthetic bone is exposed to joint fluid and joint fluid pressure, causing death of exposed osteocytes, and thus osteolysis. (53-55)

Huiskes (56) divided the possible factors which are important for the quality and durability of prosthetic fixation into prosthetic design factors (materials, shape, fixation), surgical factors (surgical skills, experience, patient and device selection, patient instruction) and patient factors (sex, age, weight, level of activity, general condition, local bone condition). Using this differentiation, I will discuss in the next paragraphs the items that are of crucial importance in the evaluation of cementless hip replacement surgery.

\section{Prosthetic Design factors}

The concepts discussed are:

- the concept of difference in elasticity of the prosthesis and the bone and the use of titanium alloy or cobalt-chrome prostheses.

- the concept of proximal bone loading by using tapered or anatomic versus cylindrical prostheses.

- the concept of proximal fixation versus distal fixation of the prosthesis and its influence on bone loading and wear debris migration.

- the concept of effective joint space and how to reduce it by using circumferential porous and/or hydroxyapatite coatings. 


\section{TITANIUM VERSUS COBALT-CHROMIUM PROSTHESES}

Friedman et al. (57) have suggested that titanium is the material of choice for cementless femoral components. One of the primary advantages of using titanium is its superior biocompatibility and lack of known immunogenicity. Another advantage with the use of titanium is its lower modulus of elasticity, which is approximately one-third to one-half that of stainless steel and cobalt-chromium. (58) Low moduli combined with low ductility and relatively high strength make this a relatively brittle alloy. Although the elastic modulus of titanium is still significantly greater than that of cortical bone, stress shielding of the surrounding tissue is less than with the stainless steel and cobalt-chromium alloys. Since implant flexibility has been inversely related to pain $(59,60)$ and stress shielding (61), a titanium-alloy femoral implant should be used to minimize these complications. The significance of this lower elastic modulus is understood after a brief explanation of Wolff's law. It states that bone, whether normal or abnormal, develops the structure most suited to resist the forces acting upon it. Simply put, bone formation occurs along the lines of stress. The arthroplasty-induced reconstruction of diaphyseal bone produces a composite load-sharing system, the result of which is a decrease in the load share or stress transmitted through the bone. When the stress or load is reduced, periprosthetic bone mass is resorbed, leading to lower bone density and decreased stiffness. This process may ultimately contribute to the failure of total joint arthroplasty by diminishing the total surface of ingrowth. The prosthesis is therefore more prone to osteolysis by wear particles, and thus loosening. This results in more difficult revision operations, since less bone stock is available.

Bobyn et al. performed an experimental study using a canine model of stiff versus flexible, fully porous-coated, metallic femoral stems (differing by 3 - to 5 -fold in stiffness characteristics). This study revealed markedly different resorptive bone remodeling patterns. The flexible stem resulted in about $30 \%$ more cortical bone retention adjacent to the implant at one-year postimplantation and larger differences in dogs killed two and three years after surgery. The flexible stem produced a more uniform and more nearly normal strain distribution medially. Differences in cortical bone remodeling were quantified using Dual Energy X-ray Absorptiometry (DEXA). At three years postimplantation, the bone mineral content of the femora with the stiff stem was about $50 \%$ that of the femora with the flexible stem. Clinically, DEXA revealed that $5 \%-15 \%$ changes in bone mineral density at various peri-implant sites were common within the first two years after surgery; these changes were not usually evident radiographically. Serial radiographically distinct bone resorption was usually associated with bone mineral density changes of $20 \%-50 \%$. Five- to 13-year radiographic follow up observations of 213 cases with the Anatomic Medullary Locking prosthesis showed that pronounced bone resorption occurred in $33 \%$ of patients. Larger stems (greater than $13 \mathrm{~mm}$. in diameter) and stems with extensive porous coating had a significantly higher incidence of pronounced bone resorption than smaller stems and those with a proximal coating. The stiffness characteristics of the human femur were established as a function of canal size and compared with those of noncemented hip prostheses. Increased mechanical compatibility was found for stems made of titanium alloy and with design features that reduce crosssectional area and moment of inertia. Clinical data suggest that to reduce the likelihood of pronounced bone resorption, it would be beneficial for the implant to possess a bending stiffness of about one half to one third that of the human femur. $(62,63)$ For titanium stems the critical thickness is reported to be $15 \mathrm{~mm}$. and adjustments should be made, such as hollowing out the stem. (64) A more "isoelastic" femoral stem was deve- 
loped to solve the problem of this stiffness mismatch. However the intermediate term results were not satisfying with high rates of loosening and suboptimal clinical results. (65) A higher elasticity will increase the interface stresses between the prosthesis and the bone and insufficient bone ingrowth will occur because of initial instability.

\section{TAPERED VERSUS NON-TAPERED PROSTHESES}

Tapered stem geometry has received increasing attention over the last years. With a tapered stem one gradually decreases the stiffness of the stem and the possibility of distal stress transfer. The use of a tapered stem led to a decrease in the reported percentages of thigh pain. Thigh pain is also reported to correlate with smoothness and nonincorporation in the host bone of the distal part of the stem by Min et al. (66) The distal stem should, according to them, be incorporated by the femur to prevent thigh pain. With tapered, extensively coated stems, like they used for their study, this is the case, but with tapered, proximally coated stems this correlation is not found. (67)

A tapered prosthesis with a wide spread use around the world and reports in literature is the Porous Coated Anatomic. (68-73) This prosthesis, however, represents the first generation of cementless stems which is characterized by high percentages of thigh pain. The reason for this high percentage of thigh pain with this prosthesis is said to be the rather abrupt step in stiffness at the tip of the prosthesis. The cause for this abrupt step in stiffness is twofold. First, it is an extensively porous coated stem, and although it is dually tapered, it aims for distal ingrowth. Furthermore, it is made of cobalt chrome which has a stiffness that is twice as high as titanium. That rigid fixation does not guarantee a painless hip was shown by Barrack et al. with the retrieval results of six patients. Despite bony ingrowth thigh pain existed. (74) This stem can not be seen as a representative of the tapered stem family of today.

Burkart et al. compared 110 PCA-stems and 105 consecutive Mallory-Head (MH) prostheses using prospectively gathered clinical data and a detailed radiographic analysis. In the PCA group, 13\% of patients experienced thigh pain at 1 year and $23 \%$ at 2 years. Positive radiographic correlates with thigh pain included subsidence, distal cortical hypertrophy, a tight diaphyseal fit, and stem tip sclerosis. In the $\mathrm{MH}$ group, the incidence of thigh pain was $7 \%$ at 1 year and $3 \%$ at 2 years. No radiographic findings correlated positively with thigh pain. The results of this short-term clinical comparison suggest that a long, straight, tapered design offered better initial stability than its anatomic counterpart as reflected in the much lower incidence of thigh pain. (75) McLaughlin and Lee (76) reported on a consecutive series of 108 total hip arthroplasties with use of a tapered design (Taperloc; Biomet, Warsaw, Indiana, USA) in patients less than fifty years old. The mean age of the patients was thirty-seven years, and the mean duration of follow up was 10.2 years. No stem was revised because of loosening, osteolysis was noted in association with $7 \%$, and osseointegration was judged to have been achieved in $98 \%$. Various other authors have described the excellent long-term results with femoral stems with a tapered design, this time without thigh pain or proximal femoral bone loss. (7779)

In a meta-analysis published in 2002, Mallory et al. compared the results of various tapered femoral components after a minimum follow up of 5 years. This study documents a low incidence of thigh pain, radiographic characteristics indicating stable fixation, and an extremely low incidence of revision for aseptic loosening among the tapered designs. More specifically, the proximal to distal dual-tapered geometry of the 
Mallory-Head porous cementless femoral design resulted in low stress shielding, mild thigh pain and minimal distal osteolysis compared with the non-tapered and extensively coated AML stem and the tapered and extensively coated PCA stem. (67)

Another family of total hip prostheses, next to the tapered proximally coated and the non-tapered extensively coated stems is formed by the anatomically designed stems, such as the ABG stem. (80-82) By using left- and right-sided prostheses, the anatomy of the proximal femur is imitated to obtain metaphyseal fit and fill. Hereby stress transfer is said to occur only proximally and proximal bone stock is thus preserved. This group of prostheses usually use an additional coating of hydroxyapatite. The name "anatomic" suggests a perfect fit in the metaphysis with these prostheses. However, the shape of the femur is much more variable than most contemporary designs would suggest or can accommodate. In the face of this variability, line-to-line or surface-to-surface contact is not expected between cementless implants (whether they are tapered, straight, cylindrical or anatomic) and much of the endosteal surface.

\section{Proximally Versus EXTENSIVEly POROUS COATED PROSTHESES}

The rationale behind the use of a porous coating is to minimize the micromotion during the period that the bone has to grow onto the prosthesis. A further advantage of a porous coating is that by the enlargement of the surface the bone can actually grow into the prosthesis and create a locking mechanism. The extent of the porous coating on the stem can vary from proximally coated to fully coated. Examples of extensively porous coated implants are the Zweymuller- or the AML-stem. Proponents of these stems believe that the proximal stress shielding seen in the femur associated with distal biological ingrowth and load transmission is a small price to pay for long-term durability of fixation. These implants which aim for distal fixation and stress transfer have long-term results that can be compared with proximally coated prostheses. $(83,84)$

Others prefer proximally coated femoral components, relying primarily upon metaphyseal fit and fill to stabilize the implant until biological ingrowth occurs. A few examples of these stems are the Omnifit, ABG or Mallory-Head stem. With regard to proximally porous coated stems, there has been concern over the increasing incidence of osteolysis. (85) Extensively porous coated stems probably offer more resistance to the distal migration of particulate wear debris. Most proximally porous coated implants have now been modified so that the coating is circumferential around the area beneath the collar. This was not previously the case, providing smooth pathways for debris to enter the bone-prosthesis interface and migrate distally. These proximally porous coated stems also have good medium and long-term results in terms of survival and function. $(67,79,86-90)$ The addition of hydroxyapatite to the circumferential porous coating has also promising results in the prevention of debris migration. This will be discussed in the part of this chapter about hydroxyapatite.

Proximally coated prostheses with uncoated distal stems load the metaphyseal bone in a more physiologic way than extensively coated components. The stress shielding and femoral bone loss is reduced by comparison. (91) Since the distal stem in proximally coated components is uncoated, there is theoretically less biological ingrowth distally to transfer load distally to the femur and stress shield the proximal bone. Extensively coated stems unload the proximal femur by its distal fixation, which may result in proximal bone loss. Although excellent long-term survival results are described with extensively coated stems, by numerous authors, most of these reports also mention the proximal bone loss. $(63,92-108)$ 


\section{HYDROXYAPATITE COATED VERSUS NON-HYDROXYAPATITE COATED PROSTHESES}

Hydroxyapatite coating of the stem was introduced with the intention to improve the fixation stability and durability. The addition of a hydroxyapatite coating to the femoral stem was described with good results experimentally and clinically by Geesink et al. for the first time. (109-118) Later on, various femoral stems were described to have improved bone ongrowth in retrieval studies by the addition of hydroxyapatite (119$121)$ and to have excellent medium and long-term results $(104-108,115,122-131)$. However some studies report no difference in the use of a hydroxyapatite coating on the femoral stem with reference to clinical outcome, loosening and osteolysis $(104,132)$, while others did find a significant improval in the initial fixation of the prosthesis with hydroxyapatite $(133,134)$. Søballe et al. have studied the positive effects of hydroxyapatite in relation to bone ongrowth to an endoprosthesis in animal research. They found positive effects of hydroxyapatite on gap healing potential, a decrease of micromotion with the use of hydroxyapatite, positive effects concerning ingrowth in osteoporotic bone and bone grafts. (135-142) Kraemer et al. concluded that the use of cement, porous, or HA-coating prevents or delays access of the polyethylene wear debris to the boneimplant interface, but that the percentage bone ingrowth was $8 \%$ for the smooth, $38 \%$ for the porous, and $83 \%$ for the HA-coated sections. (143) The major advantage of HA addition to arthroplasty components seems to be enhanced osteoconductivity around metallic surfaces.

Some authors correlate the use of hydroxyapatite with increased wear. $(144,145)$ The slight increase in particulate load seen in the presence of some HA-coatings (especially the thicker coatings) may contribute to the development of aseptic loosening of arthroplasty components, but is unlikely to be the major causative factor. This was concluded by Anderson et al. after performing an in vivo study with dogs, comparing the histological results of hydroxyapatite coated or non-coated THA. (146) Bauer et al. also studied the degradation effects of the hydroxyapatite coating with laser interference microscopy and found that the chrome-cobalt heads retrieved from patients with a hydroxyapatite coated prosthesis showed significantly less surface roughness and less deep scratches than the heads retrieved from patients in the porous or cemented group. (147)

Moroni et al. (148) stated that the addition of a hydroxyapatite layer to a porous coated titanium prosthesis improved the bone ingrowth percentage and the bone depth penetration into the prosthesis significantly. This implicates stronger fixation and a more complete sealing off of the femoral canal from wear products. Muller et al. (149) performed a prospective randomised Röntgen Stereophotogrammetric Analysis (RSA) trial to study the results of a hydroxyapatite, a fluoroapatite or no extra layer on the porous coated Mallory-Head stem. They found no differences in clinical, radiologic and RSA values after two years. Especially the migration did not differ between the three groups, suggesting no extra effect of the coating on subsidence prevention and fixation. However, the sealing off effect of hydroxyapatite or fluoroapatite could not be studied with this short follow up. Unfortunately, the number of patients lost to follow up is too large to draw conclusions at a longer follow up. 


\section{SURGICAL FACTORS}

Surgical factors such as surgical skills, experience, patient selection and instruction, are important items in view of potential complications. Outcome of total hip arthroplasty was influenced by various surgical factors.

\section{SURGICAL FACTORS AND EXPERIENCE}

A more experienced surgeon has fewer complications and for all surgical procedures a learning curve is present. (150-152) In cementless hip arthroplasty it is mandatory to obtain a press fit of the prosthesis, but nowhere is quantified what press fit means or at what size of prosthesis this is obtained. Differences in the closeness of the fit means will influence the strain in the proximal femur. Accurate metaphyseal fit will prevent subsidence. Whiteside (153), in his study on the effect of stem fit on bone hypertrophy, observed that a tight fit is associated with distal cortical hypertrophy, while a loose fit was not but caused more pain.

The choice of approach is one of the better investigated items with reference to complications. (154) Primary hip prostheses dislocate in 0.4 to $8.7 \%$ of the cases. Revision hip prostheses dislocate in 5 to $20 \%$ of the cases. High age, female sex, co-morbidity and alcoholism increase the risk of dislocation. The surgical approach of the hip and the experience of the surgeon are important factors in the operation technique. Posterior approaches more often result in dislocations than anterior approaches ( $3 \%$ versus $1 \%$ ). The anterior approaches are however more infamous for the increased chances of a Trendelenburg sign and limping. This is caused by muscle and nerve damage to the abductors.

The selected implant also influences the dislocation risk. A smaller head increases the range of motion of the hip, but it also increases the risk for dislocation. Furthermore, the femur must not come too close to the pelvis: a diminished femoral offset leads more often to dislocations. Peri-articular ossifications are also influenced by approach and tissue handling. Also patient related factors such as the male gender and specific conditions such as active ankylosing spondylitis, skeletal hyperostosis or prior heterotopic ossifications increase the incidence of heterotopic ossifications. (155)

\section{Patient selection and instruction}

Furthermore, the selection of patients for total hip arthroplasty will also influence the final result. Young and active patients have more demands and expect more from their hip replacement than the sedentary elderly, who will be satisfied with pain relief. Too high or irrational expectations of the patient can influence the final result, if the proper instruction and explanation is omitted. "Survival is a function of use, not time." This one-liner was the conclusion of an awardwinning paper by Schmalzried et al. (156) Younger patients use their hip prostheses more frequently and thus the wear is proportionally more in younger patients. 


\section{Patient factors}

That the above mentioned patient related factors, such as sex, age, weight, level of activity and general condition are of influence on the final result of the total hip replacement is common knowledge. However, local bone condition is a less commonly known factor.

\section{LOCAL BONE CONDITION}

Especially in cementless hip arthroplasty, where the bone has to grow into the (porous coating of the) prosthesis, a healthy local bone condition is required. However, the use of cementless prostheses in patients with rheumatoid arthritis showed promising results in the medium term follow up. (157-161) Good results are also obtained with cementless implants in patients with Paget disease. $(127,162)$ In patients with Gaucher's disease the loosening seems to be related to the disease and not to a specific type of prosthetic component (163), although more recently equally good results as in standard primary hip replacements were described. (164) The influence of osteoporosis on remodeling processes after total hip arthroplasty is a hot item nowadays. Laporte et al. published in 1999 their opinion about the use of proximally coated hip prostheses in various bone conditions. (165) They saw indications in primary total hip arthroplasty in patients aged $<70$ years with good bone stock. Relative contraindications are based on interference with bone ingrowth or with the ability to achieve a congruent fit, both of which preclude establishment of rigid initial stability. These conditions include metabolic bone diseases such as osteoporosis, osteomalacia, Gaucher's disease, sickle cell disorders, and Paget's diseases; significant anatomical distortion, as seen in developmental dysplasia of the hip with anteversion, prior osteotomy, or intertrochanteric fracture; Dorr type C bone; and current treatment with radiation, chemotherapy, indomethacin, or diphosphonates. The same relative contraindications to use are applicable in revision situations. Most of the aforementioned conditions are without discussion, but the use of cementless implants, especially those with an hydroxyapatite coating, in osteoporotic patients is not without discussion. Earlier in this chapter the good clinical results were mentioned (157-161), but also experimental and retrieval studies by Søballe have shown rigid osseointegration in this patient group. $(136,138)$ Further, proximally porous-coated prostheses should not be used for revision arthroplasty in the setting of massive bone loss, limited life expectancy, or inability to participate in protected weight bearing. These devices may be used successfully in revision arthroplasty when the hip has minimal or moderate bone loss, and occasionally in the setting of severe bone loss.

\section{ANALYSIS OF THE CLINICAL RESULT}

Another patient related factor is that the patient's opinion about his or her total hip replacement does not have to be the same as the surgeon's opinion. Excellent radiographs and a positive opinion of the surgeon are not enough anymore to grade the result of a total hip arthroplasty as excellent. Even the presence of a long survival alone will not be enough to obtain a good result. More often it appears that the opinion of the patient plays an important role. (166) The patient experiences most of the alterations to his or her body and knows like no one else what the influence of these alterations has on his or her life. The surgeon on the other hand can only judge a distinct moment in time with the use of physical examination, radiographs and/or other investigations. The evaluation 
of a patient with a total hip prosthesis would therefore be most complete if the opinions of both the patient and the surgeon are combined. (167) Until now most questionnaires for the result of total hip arthroplasty are based on the opinion of the surgeon, like the Harris Hip Score and the Merle d'Aubigné score. $(168,169)$ The Harris Hip Score is especially very dominated by the pain score. Questionnaires with which specifically the result of a total hip replacement is measured from the scope of the patient are relatively scarce, especially in the Dutch language.

\section{ANALYSIS OF THE RADIOLOGIC RESULT}

The preoperative radiographs are usually judged for osteoporosis grading and femoral morphometrics. The modified Singh trabecular index (170) is a rather crude way to measure osteoporosis. Femoral morphometrics are judged to be champagne flute, normal or stove pipe, according to Dorr. (171) During each follow up visit, an anteroposterior and lateral radiograph is taken of the involved hip. These are evaluated using Gruen zones (172) for signs of bone resorption, subsidence, osteolysis, interface deterioration, cyst formation, radiolucencies, reactive line formation around the HA-coated and the non-coated parts of the femoral prosthesis, cancellous and cortical bone densifications, cortical hypertrophy, tip sclerosis and pedestal formation around the stem tip. In the Mallory-Head femoral prosthesis HA covered the stem in Gruen zones 1 and 7 and the proximal part of zones 2 and 6 . (Figure 1)

\section{Figure 1}

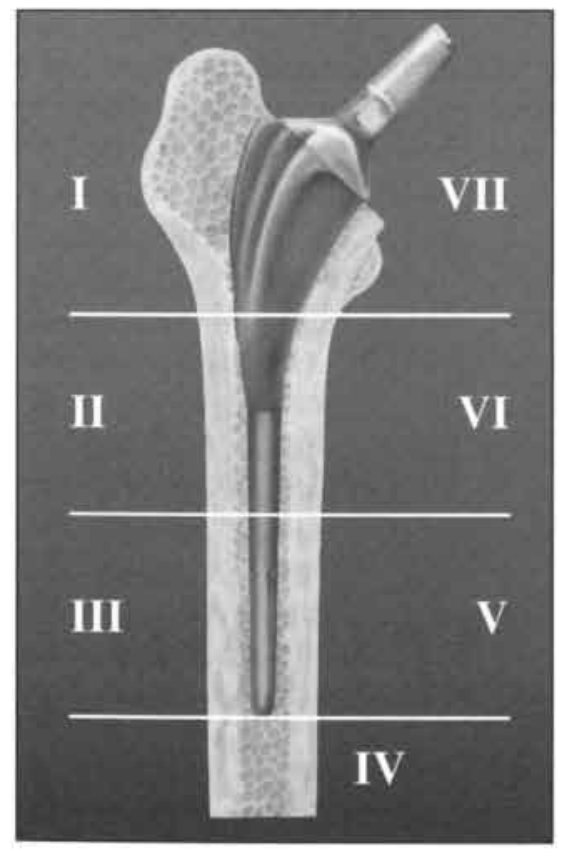

The Mallory-Head femoral prosthesis and its Gruen zones.

All bony changes are estimated by the eye. Resorption of bone is not quantified but graded as present, when loss of trabecular bone density, corticocancellization, or cortical thinning is noted. Cortical hypertrophy (cortical thickening) is recorded when there is an increase in the outside diameter of the cortex at the maximal point of hypertrophy. 
Reactive line formation is defined as a thin radiopaque layer of bone seen parallel and in close proximity to the implant. Between this line and the implant, a radiolucent line is always present. To be recorded, this line has to extend at least $50 \%$ of the zone length. Radiolucency is defined as a radiolucent zone anywhere around the implant with no relation to any radiopacity. A radiolucent line is recorded when it was at least two $\mathrm{mm}$. in width and occupied at least $30 \%$ of any one zone. Osteolysis is defined as a scalloped erosion of more than two $\mathrm{mm}$. in diameter at the bone-prosthesis interface. Femoral cancellous bone densification (spotwelding) is defined as an augmentation in bone mineral content anywhere between the implant and the femoral cortex; cortical bone densification is defined as an augmentation in bone mineral content in the femoral cortex itself. Likewise the position of the implant after surgery is assessed: the stem is assessed as in varus or in valgus when it measures more than two degrees from the neutral. The stem is defined as completely filling the diaphysis when on the AP radiograph the diameter of the stem divided by the distance between the inner cortices at the transition of zone 2 to 3 and zone 5 to 6 is larger than 0.8. The radiograph was chosen only in the AP-direction, instead of also the axial view, because at this level the femoral canal is nearly circular. A measument in one direction thus predicts the amount of femoral canal filling.

The stem is defined as having fixation by bone ongrowth (osseointegration) when there is no subsidence or migration and no formation of a radiolucent or radiodense line along the HA-coated portion of the prosthesis. The presence of spotwelding also suggests bone ongrowth.

The acetabular bone-prosthesis transition is evaluated using the criteria of DeLee and Charnley (173). Especially asymmetry of the head in the liner suggesting PE-wear is recorded and it is correlated with femoral and acetabular osteolysis. Recently, Hui et al. proved that the use of two-dimensional measurements, based solely on an anteroposterior radiograph, may suffice in the clinical setting and a good agreement between the two- and three-dimensional measurements was found. (174) The presence of heterotopic ossification is performed using the system described by Brooker et al. (175) 
1 Haboogh EJ. (1953) A new operation for arthroplasty of the hip based on biomechanics, photoelasticity, fast-setting dental acrylic, and other considerations. Bull Hosp Joint Dis Orthop Inst 14:242.

2 Charnley J. (1960) Anchorage of the femoral head prosthesis to the shaft of the femur. J Bone Joint Surg [Br] 42:28.

3 Charnley J. (1961) Arthroplasty of the hip - a new operation. Lancet 1:1129.

4 Charnley J. (1972) The long-term results of low-friction arthroplasty of the hip performed as a primary intervention. J Bone Joint Surg [Br] 54:61.

5 Coventry MB, Beckenbaugh RD, Nolan DR, Ilstrup DM. (1974) 2,012 total hip arthroplasties: a study of postoperative course and early complications. J Bone Joint Surg [Am] 56:273.

6 Eftekhar NS. (1971) Charnley low friction torque arthroplasty. Clin Orthop 81:93.

7 Eftekhar NS, Stinchfield FE. (1973) Experience with low-friction arthroplasty. Clin Orthop 95:60.

8 Evarts CM, DeHaven KE, Nelson CL, Collins HR, Wilde AH. (1973) Interim results of Charnley-Muller total hip arthroplasty. Clin Orthop 95:193.

9 Nicholson OR. (1973) Total hip replacement. Clin Orthop 95:217.

10 Geesink RGT. (1998) Bewogen zorg. Universitaire Pers Maastricht.

11 Amstutz HC, Markolf KL, McNeice GM, Gruen TA. (1976) Loosening of total hip components, cause and prevention. In: "The Hip, proceedings of the fourth open scientific meeting of the Hip Society. St. Louis: CV Mosby: 102.

12 Beckenbaugh RD, Ilstrup DM. (1978) Total hip arthroplasty. A review of three hundred and thirty-three cases with long follow-up. J Bone Joint Surg [Am] 60:306.

13 Carlsson AS, Gentz CF. (1978)

Mechanical loosening of the femoral head prosthesis in the Charnley total hip arthro- plasty. Clin Orthop 147:262.

14 Coventry MB, Stauffer RN. (1982)

Long-term results of total hip arthroplasty.

Proceedings of the tenth open scientific meeting of the Hip Society. Nelson JP, ed. Princeton: CV Mosby Co:34.

15 McBeath AA, Foltz RN. (1979) Femoral component loosening after total hip arthroplasty. Clin Orthop 141:66.

16 Stauffer RN. (1982) Ten year follow-up study of total hip replacement. J Bone Joint Surg [Am] 64:983.

17 Sutherland CJ, Wilde AH, Borden LS, Marks KE. (1982) A ten year follow-up study of one hundred consecutive Muller curved stem total hip replacement arthroplasties. J Bone Joint Surg [Am] 64:920.

18 Chandler HP, Reineck FT, Wixson RL, McCarthy JC. (1981) Total hip replacements in patients younger than thirty-years old. J Bone Joint Surg [Am] 63:1426.

19 Huiskes, R, Weinans H, Grootenboer HJ, Dalstra M, Fudala B, Slooff TJ. (1987) Adaptive bone remodelling theory applied to prosthetic design analysis. J Biomech 20:1135-1150.

20 Huiskes R, Vroemen W. (1986) A standardized finite element model for routine comparative evaluation of femoral hip prostheses. Acta Orthop Belg 52:258-261.

21 Huiskes R, Chao EYS. (1983) A survey of finite element analysis in orthopaedic biomechanics: the first decade. J Biomech 16:385-409.

22 Huiskes R. (1979) Some fundamental aspects of human joint replacement. Acta Orthop Scand suppl 185.

23 Harris WH. (1984) Advances in total hip arthroplasty, the metal-backed acetabular component. Clin Orthop 183:4-11.

24 Galante JO, Rostoker W. (1973) Fiber metal composites in the fixation of skeletal prostheses. J Biomed Mater Res 7:43.

25 Galante JO, Rostoker W, Lueck R, Ray RD. (1971) Sintered fiber metal composites as a basis for attachment of implants to 
bone. J Bone Joint Surg [Am] 53:101.

26 Pilliar RM, Cameron HU, Macnab I.

(1971) Porous surface layered prosthetic devices. Biomedical Engineering 10:126.

27 Pilliar RM, Cameron HU, Binnington AG. (1979) Bone ingrowth and stress shielding with a porous surface coated fracture fixation plate. J Biomed Mat Res 13:799.

28 Mittelmeier H. (1984) Total hip replacement with the Autophor cement-free ceramic prosthesis. In: Morscher E, ed. The cementless fixation of hip endoprostheses. New York: Springer-Verlag.

29 Morscher EW. (1983) European experience with cementless hip replacements. In: Proceedings in the 11 th open scientific meeting of the Hip Society, CV Mosby, 190.

30 Ring PA. (1973) Total replacement of the hip joint. Clin Orthop 95:34.

31 Lord GA. (1981) Bone ingrowth and uncemented total hip replacement with madreporic stemmed prostheses.

J Bone Joint Surg [Am] 63:383.

32 Lord GA, Bancel P. (1983)

The madreporic cementless total hip arthroplasty. New experimental data and a seven year clinical follow-up study. Clin Orthop 176:67.

33 Lord GA, Hardy JR, Kummer FJ. (1979) An uncemented total hip replacement experimental study and review of 300 madreporic arthroplasties. Clin Orthop 141:2.

34 Engh CA. (1983) Hip arthroplasty with a Moore prosthesis with porous coating - a five year study. Clin Orthop 176:52.

35 Sullivan B, Momsy CA, Woods GW, Tullos HA. (1978)

Stabilization of Thompson femoral head prosthesis with a porous stem coating. Clin Orthop 132:136.

36 Engh CA, Glassman AH, Bobyn JD. (1986) Surgical principles in cementless total hip arthroplasty. Techniques in orthopaedics 1:35.

37 Jasty M, Bragdon C, Jiranek W, Chandler M, Moloney W, Harris WH. (1994) Etiology of osteolysis around porous-coated cementless total hip arthroplasties. Clin Orthop 308:111-126.

38 Willert HG, Semlitsch M. (1977)

Reactions of the articular capsule to wear products of artificial joint prostheses. J Biomed Mater Res 11:157-164.

39 Schmalzried TP, Jasty M, Harris WH. (1992) Periprosthetic bone loss in total hip arthroplasty. Polyethylene wear debris and the concept of the effective joint space. J Bone Joint Surg [Am] 74:849-863.

40 Schmalzried TP, Jasty M, Rosenberg A, Harris WH. (1993) Histologic identification of polyethylene wear debris using Red O stain. J Appl Biomater 4:119-125.

41 Goldring SR, Schiller AL, Roelke M, Rourke CM, O'Neill DA, Harris WH. (1983) The synovial-like membrane at the bone-cement interface in loose total hip replacements and its proposed role in bone lysis. J Bone Joint Surg [Am] 65:575-584.

42 Herman JH, Sowder WG, Anderson D, Appel AM, Hopson CN. (1989)

Polymethylmethacrylate-induced release of bone resorbing factors. J Bone Joint Surg [Am] 71:1530-1541.

43 Murray DW, Rushton N. (1990) Macrophages stimulate bone resorption when they phagocytose particles. J Bone Joint Surg [Br] 72:988-992.

44 Schüller HM, Scholten PE, Lettinga K, Marti RK, Van Noorden CJF. (1993)

High cathepsin B activity in arthroplasty interface membranes. Acta Orthop Scand 64:613-618.

45 Mervyn Evans E, Freeman MAR, Miller AJ, Vernon-Roberts B. (1974) Metal sensitivity as a cause of bone necrosis and loosening of the prosthesis in total joint replacement. J Bone Joint Surg [Br] 56:626-642.

46 Haddad FS, Levell NJ, Dowd PM, Cobb AG, Bentley G. (1995) Cement hypersensitivity: A cause of aseptic loosening? J Bone Joint Surg [Am] 77:329-330.

47 Aspenberg P, Herbertsson P. (1996) Periprosthetic bone resorption. Particles versus movement. J Bone Joint Surg $[\mathrm{Br}]$ 78:641-646. 
48 Mjoberg B. (1991) Fixation and loosening of hip prostheses. A review. Acta Orthop Scand 62:500-508.

49 Mjoberg B. (1994) Theories of wear and loosening in hip prostheses. Acta Orthop Scand 65:361-371.

50 Kärrholm J, Borssen B, Löwenhielm G, Snorrason F. (1994) Does early micromotion of femoral stem prostheses matter? J Bone Joint Surg [Br] 76:912-917.

51 Kobayashi A, Donnelly WJ, Scott G, Freeman MAR. (1997) Early radiological observations may predict the long-term survival of femoral hip prostheses J Bone Joint Surg [Br] 79:583-589.

52 Mjoberg B., Franzen H, Selvik G. (1990) Early detection of prosthetic hip loosening. Acta Orthop Scand 61:273-274.

53 van der Vis HM, Aspenberg P, Marti RK, Tigchelaar W, van Noorden CJF. (1998) Fluid pressure causes bone resorption in a rabbit model of prosthetic loosening. Clin Orthop 350:201-208.

54 Dorr LD, Bloebaum R, Emmanuel J, Meldrum R. (1990) Histologic, biochemi$\mathrm{cal}$, and ion analysis of tissue and fluids retrieved during total hip arthroplasty. Clin Orthop 261:82-95.

55 Nivbrant B, Karlsson K, Kärrholm J. (1999) Cytokine levels in synovial fluid from hips with well-functioning or loose prostheses. J Bone Joint Surg [Br] 81:163166.

56 Friedman RJ, Black J, Galante JO. (1994) Current concepts in orthopaedic biomaterials and implant fixation. In: Heckman, J.D. (ed): Instr Course Lect 43. Rosemont, $\Pi$, The American Academy of Orthopaedic Surgeons.

57 Huiskes R. (1991) Biomechanics of artificial joint fixation. In: Basic Orthopaedic Biomechanics (Ed: Mow VC, Hayes WC). Raven Press, New York:375-442.

58 Pugh J, Dee R. (1988) Properties of musculoskeletal tissues and biomaterials. In: Dee, R., Mango, E., Hurst, L.C. (eds): Principles of Orthopaedic Practice 1. New York, McGraw-Hill:134-46.

59. Franks E, Mont MA, Maar DC. (1992)
Thigh pain as related to bending rigidity of the femoral prosthesis and bone. Trans Orthop Res Soc 17:296.

60. Skinner HB, Curlin FJ. (1990) Decreased pain with lower flexural rigidity of uncemented femoral prostheses. Orthopedics 13(11):1223-8.

61 Skinner HB, Kilgus DJ, Keyak J, Shimaoka EE, Kim AS, Tipton JS. (1994) Correlation of computed finite element stresses to bone density after remodeling around cementless femoral implants. Clin Orthop 305:178-89.

62 Bobyn JD, Glassman AH, Goto H, Krygier JJ, Miller JE, Brooks CE. (1990) The effect of stem stiffness on femoral bone resorption after canine porous-coated total hip arthroplasty. Clin Orthop 2 61:196-213.

63 Bobyn JD, Mortimer ES, Glassman AH, Engh CA, Miller JE, Brooks CE. (1992) Producing and avoiding stress shielding. Laboratory and clinical observations of noncemented total hip arthroplasty. Clin Orthop 274:79-96.

64 Dujovne AR, Bobyn JD, Krygier JJ, Miller JE, Brooks CE. (1993)

Mechanical compatibility of noncemented hip prostheses with the human femur. J Arthroplasty 8(1):7-22.

65 Niinimaki T, Puranen J, Jalovaara P. (1994) Total hip arthroplasty using isoelastic femoral stems. A seven to nine-year follow-up in 108 patients. J Bone Joint Surg [Br] 76(3):413-418.

66 Min B, Longjohn DB, Dorr LD, Wan Z. (2000) Radiographic comparison of diaphyseal grit blasted with smooth surface stems by matched pair analysis. Clin Orthop 381:156-67.

67 Mallory TH, Lombardi AV, Leith JR, Fujita H, Hartman JF, Capps SG, Kefauver CA, Adams JB, Vorys GC. (2002) Why a taper? J Bone Joint Surg [Am] 84;suppl 2:81-9.

68 Kim YH, Kim JS, Cho SH. (1999) Primary total hip arthroplasty with a cementless porous-coated anatomic total hip prosthesis: 10- to 12-year results of 
prospective and consecutive series.

J.Arthroplasty 14(5):538-48.

69 Kim YH, Kim JS, Cho SH. (1999)

Primary total hip arthroplasty with the

AML total hip prosthesis. Clin Orthop 360:147-58.

70 Heekin RD, Callaghan JJ, Hopkinson WJ, Savory CG, Xenos JS. (1993) The porous-coated anatomic total hip prosthesis, inserted without cement. Results after five to seven years in a prospective study [published erratum appears in J Bone Joint Surg [Am] (1993) 75(5):791]. J Bone Joint Surg [Am] 75(1):77-91.

71 Martell JM, Pierson RH 3rd, Jacobs JJ, Rosenberg AG, Maley M, Galante JO. (1993) Primary total hip reconstruction with a titanium fiber-coated prosthesis inserted without cement. J Bone Joint Surg [Am] 75(4):554-71.

72 Xenos JS, Hopkinson WJ, Callaghan JJ, Heekin RD, Savory CG. (1995)

Osteolysis around an uncemented cobalt chrome total hip arthroplasty. Clin Orthop 317:29-36.

73 Xenos JS, Callaghan JJ, Heekin RD, Hopkinson WJ, Savory CG, Moore MS. (1999) The porous-coated anatomic total hip prosthesis, inserted without cement. A prospective study with a minimum of ten years of follow-up. J Bone Joint Surg [Am] 81(1):74-82.

74 Barrack RL, Jasty M, Bragdon C, Haire T, Harris WH. (1992) Thigh pain despite bone ingrowth into uncemented femoral stems. J Bone Joint Surg [Br] 74(4):507-10.

75 Burkart BC, Bourne RB, Rorabeck CH, Kirk PG. (1993) Thigh pain in cementless total hip arthroplasty. A comparison of two systems at 2 years' follow-up. Orthop Clin North Am 24(4):645-53.

76 McLaughlin JR, Lee KR. (2000) Total hip arthroplasty in young patients.

8- to 13-year results using an uncemented stem. Clin Orthop 373:153-63.

77 Yee AJ, Kreder AH, Bookman I, Davey JR. (1999) A randomized trial of hydroxyapatite coated prostheses in total hip arthroplasty. Clin Orthop 366:120-32.

78 D'Antonio JA, Capello WN, Manley

MT, Geesink RGT. (2001)

Hydroxyapatite femoral stems for total hip arthroplasty: 10- to 13-year followup. Clin Orthop 393:101-11.

79 Tonino AJ, Therin M, Doyle C. (1999) Hydroxyapatite coated femoral stems: histology and histomorphometry around five components retrieved at autopsy. J Bone Joint Surg [Br] 81: 148.

80 Sakalkale DP, Eng K, Hozack WJ, Rothman RH. (1999) Minimum 10-year results of a tapered cementless hip replacement. Clin Orthop 362:138-44.

81 Tonino AJ, Rahmy AIA. (2000) The International ABG Study Group. The hydroxyapatite-ABG hip system. J Arthroplasty 11:534-542.

82 Oosterbos CJ, Rahmy AIA, Tonino AJ. (2001) Hydroxyapatite coated hip prosthesis followed up for 5 years. Int Orthop 25(1):17-21.

83 Havelin LI, Espehaug B, Vollset SE, Engesaeter LB. (1995) Early septic loose ning of uncemented femoral components in primary total hip replacement, a review based on the Norwegian arthroplasty register. J Bone Joint Surg [Br] 77(1): 11-17.

84 Korovessis P, Droutsas P, Piperos G, Michael A, Baikousis A, Stamatakis M. (1997) Course of bone mineral content changes around cementless Zweymuller total hip arthroplasty. A 4-year follow up study. Arch Orthop Trauma Surg 116 (1-2):60-65.

85 Smith E, Harris WH. (1995) Increasing prevalence of femoral lysis in cementless total hip arthroplasty. J Arthroplasty 10(4):407-12.

86 Archibeck MJ, Berger RA, Jacobs JJ, Quigley LR, Gitelis S, Rosenberg AG, Galante JO. (2001) Second-generation cementless total hip arthroplasty. Eight to eleven-year results. J Bone Joint Surg [Am] 83(11):1666-73.

87 Brindley GW, Adams R. (1998)

Cementless revision of total hip arthropla- 
sty using proximal porous-coated femoral implants. J South Orthop Assoc 7(4):

246-50.

88 Head WC, Mallory TH, Emerson RH, Jr. (1999) The proximal porous coating alternative for primary total hip arthroplasty. Orthopedics 22(9):813-5.

89 Massat BJ, Miller RT, DeYoung BA, Schiller RA, Aberman HM, DeYoung DJ. (1998) Single-stage revision using an uncemented, porous-coated, anatomic endoprosthesis in two dogs: case report. Vet Surg 27(3):268-77.

90 Bourne RB, Rorabeck CH, Patterson JJ, Guerin J. (2001) Tapered titanium cementless total hip replacements. A 10- to 13-year follow up study. Clin Orthop 393:112-20.

91 Scott DF, Jaffe WL. (1996) Host-bone response to porous-coated cobalt-chrome and hydroxyapatite-coated titanium femoral components in hip arthroplasty. Dual- energy $\mathrm{x}$-ray absorptiometry analysis of paired bilateral cases at 5 to 7 years.

J Arthroplasty 11(4):429-37.

92 Dorr LD, Wan Z, Gruen T. (1997) Functional results in total hip replacement in patients 65 years and older. Clin Orthop 336:143-51.

93 Dorr LD, Luckett M, Conaty JP. (1990) Total hip arthroplasties in patients younger than 45 years. A nine- to ten-year followup study. Clin Orthop 260:215-9.

94 Engh CA, McGovern TF, Schmidt LM. (1993) Roentgenographic densitometry of bone adjacent to a femoral prosthesis. Clin Orthop 292:177-90.

95 Engh CA, Zettl-Schaffer KF, Kukita Y, Sweet D, Jasty M, Bragdon C. (1993) Histological and radiographic assessment of well functioning porous-coated acetabular components. A human postmor tem retrieval study. J Bone Joint Surg [Am]75(6): 814-24.

96 Engh CA, O'Connor D, Jasty M, McGovern TF, Bobyn JD, Harris WH. (1992) Quantification of implant micromotion, strain shielding, and bone resorption with porous-coated anatomic medullary locking femoral prostheses. Clin Orthop 285:13-29.

97 Engh CA, McGovern TF, Bobyn JD, Harris WH. (1992) A quantitative evaluation of periprosthetic bone-remodeling after cementless total hip arthroplasty. J Bone Joint Surg [Am] 74(7):1009-20.

98 Engh CA, Hooten JP jr, Zettl-Schaffer KF, Ghaffarpour M, McGovern TF, Bobyn JD. (1995) Evaluation of bone ingrowth in proximally and extensively porous-coated anatomic medullary locking prostheses retrieved at autopsy. J Bone Joint Surg [Am] 77(6):903-10.

99 Engh CA, Bobyn JD. (1988) The influence of stem size and extent of porous coating on femoral bone resorption after primary cementless hip arthroplasty. Clin Orthop 231:7-28.

100 Engh CA, Bobyn JD, Glassman AH. (1987) Porous-coated hip replacement. The factors governing bone ingrowth, stress shielding, and clinical results. J Bone Joint Surg [Br] 69(1):45-55. 101 Engh CA jr, Culpepper II WJ, Engh CA. (1997) Longterm results of use of the anatomic medullary locking prosthesis in total hip arthroplasty. J Bone Joint Surg [Am] 79:77-84.

102 McAuley JP, Sychterz, CJ, Engh CA. (2000) Influence of porous coating level on proximal femoral remodeling. A postmortem analysis, Clin Orthop 371:146-53.

103 Paprosky WG, Greidanus NV, Antoniou J. (1999) Minimum 10-yearresults of extensively porous-coated stems in revision hip arthroplasty. Clin Orthop 369:230-42.

104 Krishnamurthy AB, MacDonald SJ, Paprosky WG. (1997) 5- to 13-year follow-up study on cementless femoral components in revision surgery.

J Arthroplasty 12(8):839-47.

105 Bohm G, Lintner F, Auterith A, Lester DK, Zweymuller KA. (2001) Morphometric examination of straight, tapered titanium stems: a retrieval study. Clin Orthop 393:13-24.

106 Delaunay C, Kapandji AI. (2001) 
Survival analysis of cementless grit-blasted titanium total hip arthroplasties. J Bone Joint Surg [Br] 83(3):408-13.

${ }_{107}$ Delaunay C, Bonnomet F, North J, Jobard D, Cazeau C, Kempf JF. (2001) Grit-blasted titanium femoral stem in cementless primary total hip arthroplasty: a 5- to 10-year multicenter study. J Arthroplasty 16(1):47-54.

108 Effenberger H, Ramsauer T, Bohm G, Hilzensauer G, Dorn U, Lintner F. (2002) Successful hip arthroplasty using cementless titanium implants in rheumatoid arthritis. Arch Orthop Trauma Surg 122(2):80-7.

109 Geesink RGT, de Groot K, Klein CP. (1987) Chemical implant fixation using hydroxyl-apatite coatings. The development of a human total hip prosthesis for chemical fixation to bone using hydroxylapatite coatings on titanium substrates. Clin Orthop 225:147-70.

110 Geesink RGT, de Groot K, Klein CP. (1988) Bonding of bone to apatite-coated implants. J Bone Joint Surg [Br] 70(1):1722.

111 Geesink RGT. (1989) Experimental and clinical experience with hydroxyapatitecoated hip implants. Orthopedics 12(9): 1239-42.

112 Geesink RGT. (1989) Experimental and clinical experience with hydroxyapatitecoated hip implants [published erratum appears in Orthopedics (1990) 13(2):200]. Orthopedics 12(9):1239-42.

113 Geesink RGT. (1990) Hydroxyapatitecoated total hip prostheses. Two-year clinical and roentgenographic results of 100 cases. Clin Orthop 261:39-58.

114 Geesink RGT. (1993) Clinical, radiologi$\mathrm{cal}$ and human histological experience with hydroxyapatite coatings in orthopaedic surgery. Acta Orthop Belg 59 Suppl 1: 160-4.

115 Geesink RGT, Hoefnagels NHM. (1995) Six-year results of hydroxyapatite-coated total hip replacement. J Bone Joint Surg [Br] 77(4):534-47.

116 Geesink RGT, Hoefnagels NHM. (1997)
Revision total hip arthroplasty using hydroxylapatite-coated implants. Acta Orthop Belg 63 Suppl 1:77-80.

117 Geesink RGT, Hoefnagels NHM. (1997) Eight years results of HA-coated primary total hip replacement. Acta Orthop Belg 63 Suppl 1:72-5.

118 Geesink RGT, Hoefnagels NHM. (1998)

Revision of the femoral component: hydroxyapatite enhancement. The adult hip. JJ Callaghan, AG Rosenberg and HE Rubash. Philadelphia, Lipincott-Raven publishers:1537-1547.

119 Bauer TW, Geesink RGT, Zimmerman R, McMahon JT. (1991). Hydroxyapatitecoated femoral stems. Histological analysis of components retrieved at autopsy. J Bone Joint Surg [Am] 73(10):1439-52.

120 Bloebaum RD, Merrell M, Gustke K Simmons M. (1991) Retrieval analysis of a hydroxyapatite-coated hip prosthesis. Clin Orthop 267:97-102.

121 Bloebaum RD, Bachus KN, Rubman MH, Dorr LD. (1993) Postmortem com parative analysis of titanium and hydroxyapatite porous-coated femoral implants retrieved from the same patient. A case study. J Arthroplasty 8(2):203-11.

122 Capello WN, D'Antonio JA, Feinberg JR, Manley MT. (1997) Hydroxyapatitecoated total hip femoral components in patients less than fifty years old. Clinical and radiographic results after five to eight years of follow-up. J Bone Joint Surg [Am] 79(7):1023-9.

123 Capello WN, D'Antonio JA, Manley MT, Feinberg JR. (1998) Hydroxyapatite in total hip arthroplasty. Clinical results and critical issues. Clin Orthop 355:200-11.

${ }_{124}$ D'Antonio JA, Capello WN, Manley MT, Feinberg JR. (1997) Hydroxyapatite coated implants. Total hip arthroplasty in the young patient and patients with avascular necrosis. Clin Orthop 344:124-38.

125 D'Lima DD, Walker RH, Colwell CW jr. (1999) Omnifit-HA stem in total hip arthroplasty. A 2- to 5-year followup. Clin Orthop 363:163-9.

126 Jaffe WL, Scott DF. (1996) Total hip 
arthroplasty with hydroxyapatite-coated prostheses. J Bone Joint Surg [Am] 78(12):1918-34.

${ }_{127}$ Kirsh G, Kligman M, Roffman M. (2001) Hydroxyapatite-coated total hip replacement in Paget's disease: 20 patients followed for 4-8 years. Acta Orthop Scand 72(2):127-32.

128 Kirsh G, Roffman M, Kligman M. (2001) Hydroxyapatite-coated total hip replacements in patients 65 years of age and over. Bull Hosp Jt Dis 60(1):5-9.

129 Loupasis G, Hyde ID, Morris EW. (1998) The Furlong hydroxyapatite-coated femoral prosthesis. A 4- to 7-year followup study. Arch Orthop Trauma Surg $117(3): 132-5$.

130 Loupasis G, Morris EW, Hyde ID. (1998) The Furlong hydroxyapatite-coated total hip replacement in patients under age 51. A 6-year follow-up study. Acta Orthop Belg 64(1):17-24.

131 McNally SA, Shepperd JA, Mann CV, Walczak JP. (2000) The results at nine to twelve years of the use of a hydroxyapatitecoated femoral stem. J Bone Joint Surg [Br] 82(3):378-82.

132 Rothman RH, Hozack WJ, Ranawat A, Moriarty L. (1996) Hydroxyapatitecoated femoral stems. A matched-pair analysis of coated and uncoated implants. J Bone Joint Surg [Am] 78(3):319-24.

133 Huracek J, Spirig P. (1994) The effect of hydroxyapatite coating on the fixation of hip prostheses. A comparison of clinical and radiographic results of hip replacement in a matched-pair study. Arch Orthop Trauma Surg 113(2):72-7.

134 Dorr LD, Wan Z, Song M, Ranawat A. (1998) Bilateral total hip arthroplasty comparing hydroxyapatite coating to porous-coated fixation. J Arthroplasty 13(7):29-36.

135 Søballe K, Hansen ES, BrockstedtRasmussen H, Pedersen CM, Bunger C. (1990) Hydroxyapatite coating enhances fixation of porous coated implants. A comparison in dogs between press fit and noninterference fit.
Acta Orthop Scand 61(4):299-306.

${ }_{136}$ Søballe K, Gotfredsen K, BrockstedtRasmussen H, Nielsen PT, Rechnagel

K. (1991) Histologic analysis of a retrieved hydroxyapatite-coated femoral prosthesis. Clin Orthop 272:255-8.

137 Søballe K, Hansen ES, BrockstedtRasmussen H, Hjortdal VE, Juhl GI, Pedersen CM, Hvid I, Bunger C. (1991) Gap healing enhanced by hydroxyapatite coating in dogs. Clin Orthop 272:300-7.

138 Søballe K, Hansen ES, BrockstedtRasmussen H, Hjortdal VE, Juhl GI, Pedersen CM, Hvid I Bunger C. (1991) Fixation of titanium and hydroxyapatitecoated implants in arthritic osteopenic bone. J Arthroplasty 6(4):307-16.

139 Søballe K, Hansen ES, BrockstedtRasmussen H, Jorgensen PH, Bunger C. (1992) Tissue ingrowth into titanium and hydroxyapatite-coated implants during stable and unstable mechanical conditions. J Orthop Res 10(2):285-99.

140 Seballe K, Hansen ES, BrockstedtRasmussen $\mathbf{H}$, Jorgensen $\mathbf{P H}$, Bunger C. (1992) Bone graft incorporation around titanium-alloy- and hydroxyapatite- coated implants in dogs. Clin Orthop 274:282-93.

${ }_{141}$ Soballe K, Toksvig-Larsen S, Gelineck J, Fruensgaard S Hansen ES, Ryd L, Lucht U, Bunger C. (1993) Migration of hydroxyapatite coated femoral prostheses. A Roentgen Stereophotogrammetric study. J Bone Joint Surg [Br] 75(5):681-7.

${ }_{142}$ Søballe K., Hansen ES, Brockstedt-

Rasmussen H, Bunger C. (1993)

Hydroxyapatite coating converts fibrous tissue to bone around loaded implants. J Bone Joint Surg [Br] 75(2):270-8.

143 Kraemer WJ, Maistrelli GL, Fornasier V, Binnington A, Zhao JF. (1995)

Migration of polyethylene wear debris in hip arthroplasties: a canine model.

J Appl Biomater 6(4):225-30.

144 Bloebaum RD, Dupont JA. (1993)

Osteolysis from a press-fit hydroxyapatite coated implant: a case study. J Arthroplasty 


\section{8:195-202.}

145 Bloebaum RD, Beeks D, Dorr LD, Savory CG, DuPont JA, Hofmann AA. (1994) Complications with hydroxyapatite particulate separation in total hip arthroplasty. Clin Orthop 298:19-26.

146 Anderson GI, Orlando K, Waddell JP. (2001) Synovitis subsequent to total-hip arthroplasty with and without hydroxyapatite coatings: a study in dogs.

Vet Surg 30(4):311-8.

147 Bauer TW, Taylor SK, Jiang M, Medendorp SV. (1994) An indirect comparison of third body wear in retrieved hydroxyapatite, porous, and cemented components. Clin Orthop 298:11-18.

148 Moroni A, Faldini C, Pegreffi F,

Giannini S. (2002) The effect of hydroxyapatite on bone ingrowth into porous coated titanium implants. Hip Int 12(2):153-7.

149 Muller JC, Nelissen RGHH, Brand R, Valstar ER, Rozing PM. (1997)

The effect of hydroxyapatite or fluoroapatite coating on micromotion of an uncemented hip prosthesis. Personal communication.

150 Fender D, van der Meulen JH, Gregg PJ. (2003) Relationship between outcome and annual surgical experience for the Charnley total hip replacement. Results from a regional hip register. J Bone Joint Surg [Br] 85(2):187-190.

151 Kreder HJ, Deyo RA, Koepsell T, Swiontkowski MF, Kreuter W. (1997) Relationship between the volume of total hip replacements performed by providers and the rates of postoperative complications in the state of Washington.

J Bone Joint Surg [Am] 79:485-494.

152 Espehaug B, Havelin LI, Engesaeter

LB, Vollset SE. (1999) The effect of hospital-type and operating volume on the survival of hip replacements. Acta Orthop Scand 70:12-18.

153 Whiteside LA. (1989) The effect of stem fit on bone hypertrophy and pain relief in cementless total hip arthroplasty, Clin Orthop 247:138-147.
154 van der Grinten M, Verhaar JAN.

(2003) [Dislocation of total hip prostheses; risk factors and treatment.] Ned Tijdschr Geneesk 147(7):286-290.

155 Lewallen DG. (1995) Heterotopic ossification following total hip arthroplasty. Instr Course Lect 44:287-292.

${ }_{156}$ Schmalzried TP, Shepherd EF, Dorey

FJ, Jackson WO, dela Rosa M, Fa'vae F, McKellop HA, McClung CD, Martell J, Moreland JR. (2000)

The John Charnley Award. Wear is a function of use, not time. Clin Orthop 381:36-46.

157 Garcia Araujo C, Fernandez Gonzalez J, Tonino AJ. (1998) Rheumatoid arthritis and hydroxyapatite-coated hip prostheses: five-year results. International ABG Study Group. J Arthroplasty 13(6):660-667.

158 Effenberger H, Ramsauer T, Bohm G, Hilzensauer G, Dorn U, Lintner F. (2002) Succesful hip arthroplasty using cementless titanium implants in rheumatoid arthritis. Arch Orthop Trauma Surg 122(2):80-87.

159 Thomason HC 3rd, Lachiewicz PF.

(2001) The influence of technique on fixation of primary total hip arthroplasty in patients with rheumatoid arthritis.

J Arthroplasty 16(5):628-634.

160 Keisu KS, Orozco F, McCallum JD 3rd, Bissett G, Hozack WJ, Shark PF, Rothman RH. (2001) Cementless femoral fixation in the rheumatoid patient undergoing total hip arthroplasty: minimum 5year results. J Arthroplasty 16(4):415-421.

161 Loehr JF, Munzinger U, Tibesku C. (1999) Uncemented total hip arthroplasty in patients with rheumatoid arthritis.

Clin Orthop 366:31-38.

162 Parvizi J, Schall, DM, Lewallen DG, Sim FH. (2002) Outcome of uncemented hip arthroplasty components in patients with Paget's disease. Clin Orthop 403: 127-134.

163 van Wellen PA, Haentjens P,

Frecourt N, Opdecam P. (1994)

Loosening of a noncemented porouscoated anatomic femoral component in 
Gaucher's disease. A case report and review of literature. Acta Orthop Belg 60(1):119-23.

164 Lebel E, Itzchaki M, Hadas-Halpern I, Zimran A, Elstein D. (2001) Outcome of total hip arthroplasty in patients with Gaucher disease. J Arthroplasty 16(1): 7-12.

165 LaPorte DM, Mont MA, Hungerford

DS. (1999) Proximally porous-coated ingrowth prostheses: limits of use. Orthopedics 22(12):1154-60.

166 Lieberman JR, Dorey F, Shekelle P, Schumacher L, Thomas B, Kilgius D, Finerman GA. (1996) Differences between patients' and physicians' evaluations of outcome after total hip arthroplasty. J Bone Joint Surg [Am] 78(6):835-8.

167 Brokelman RBG, van Loon CJM, Rijnberg WJ. (2003) Patient versus surgeon satisfaction after total hip arthroplasty. J Bone Joint Surg [Br] 85(4):495-498.

168 Harris WH. (1969) Traumatic arthritis of the hip after dislocation and acetabular fractures; treatment by mold arthroplasty. J Bone Joint Surg [Am] 51:737-55.

169 Merle d'Aubigné RM, Postel M. (1954) Functional results of hip arthroplasty with acrylic prosthesis. J Bone Joint Surg [Am] 36:451-75.

${ }_{170}$ Singh M, Nagrath AR, Maini PS.

(1970) Changes in trabecular pattern of the upper end of the femur as an index of osteoporosis. J Bone Joint Surg [Am] 54:457-467.

171 Dorr LD, Takei GK, Conally JP. (1983) Total hip arthroplasties in patients less than forty five years old. J Bone Joint Surg [Am] 65:474.

172 Gruen TA, McNeice JM, Amstutz HC. (1979) Modes of failure of cemented stem type femoral components. A radiographic analysis of loosening. Clin Orthop 141: 17-29.

173 DeLee JG, Charnley J. (1976) Radiological demarcation of cemented soekets in total hip replacement. Clin
Orthop 121:20- 32 .

174 Hui AJ, McCalden RW, Martell JM, MacDonald SJ, Bourne RB, Rorabeck CH. (2003) Validation of two and three-dimensional radiographic techniques for measuring polyethylene wear after total hip arthroplasty. J Bone Joint Surg [Am] 85(3):550-511. 175 Brooker AF, Bowerman JW, Robinson RA, Riley RHJR. (1973) Ectopic ossification following total hip replacement. Incidence and a method of classification. J Bone Joint Surg [Am] 55: 1629-1632. 
Translation AND VALIDATION OF THE MODIFIED "OXFORD HEUP SCORE" 
TRANSLATION AND VALIDATION OF THE MODIFIED "OXFORD HEUP SCORE"

\section{THE MODIFIED “OXFORD HEUP SCORE"}

\section{THE TRANSLATION AND VALIDATION OF A DUTCH QUESTIONNAIRE TO EVALUATE THE RESULTS OF TOTAL HIP ARTHROPLASTY.}

\section{T. Gosens}

N.H.M. Hoefnagels

H.C.W. de Vet

W.J.A. Dhert

E.J. van Langelaan

S.K. Bulstra

R.G.T. Geesink

Study performed at the Academic Hospital Maastricht, the University Medical Center Utrecht and the Rijnland Hospital Leiderdorp, the Netherlands. 
TRANSLATION AND VALIDATION OF THE MODIFIED "OXFORD HEUP SCORE" 


\section{Abstract}

The disease specific 12-item questionnaire, on the perception of patients with total hip replacement, was translated into Dutch. We also investigated the extra value of two specific hip items, "the need for walking aids" and "sexual problems because of the hip", four general items on overal satisfaction and one question about patient classification. The 14 hip specific items were scored, each from 1 (least difficulties) to 5 (most difficulties). The Dutch translation ("Oxford Heup Score") was tested on psychometric quality in a multicenter prospective study. The psychometric results of the "Oxford Heup Score" proved to be adequate. In the first postoperative year, the score was very sensitive for change; in the second year it did not change significantly. The two added hip specific questions were both filled out positively by more than $50 \%$ of the patients and fit therefore perfectly in this hip specific patient outcome questionnaire. The "Oxford Heup Score" proves to be an appropriate instrument to assess the outcome of total hip replacement from the patient's perspective. Together with the judgement of the surgeon it provides useful insights into the question whether this operation has been a success or not.

Keywords:

hip - Oxford Heup Score - translation - validation - patient outcome - questionnaire 


\section{INTRODUCTION}

Excellent radiographs and a positive opinion of the surgeon are not enough anymore to grade the result of a total hip arthroplasty as excellent. More and more it appears that the opinion of the patient plays an important role. (1) The patient experiences most of the alterations to his or her body and knows like no one else what the influence of these alterations is on his or her life. The surgeon on the other hand can only judge a distinct moment in time with the use of physical examination, radiographs and/or eventual other investigations. The evaluation of a patient with a total hip prosthesis would there fore be most complete if the opinions of both the patient and the surgeon are combined. Up till now, most questionnaires for the result of total hip arthroplasty are based on the opinion of the surgeon, like the Harris Hip Score and the Merle d'Aubigné score. $(2,3)$ Questionnaires that measure specifically the result of a total hip replacement from the scope of the patient are relatively scarce, especially in the Dutch language. Therefore in the Netherlands usually generic questionnaires that are validated for Dutch are used, such as the RAND-36, a Visual Analog Scale for pain and the Nottingham Health Profile. (4-7) Generic questionnaires are opposite to disease specific questionnaires aimed to the general health of a patient. These questionnaires can be used in various conditions but are not very sensible for disease specific alterations.

In 1996 we (the departments of Orthopaedics of the Academic Hospital Maastricht, the University Medical Center Utrecht and the Rijnland Hospital in Leiderdorp) decided to translate, modify and validate for the Dutch language the disease specific, "12item questionnaire" for the total hip patient that was published in that same year. (8)

This disease specific questionnaire contained twelve questions with which the patient was able to evaluate pain and function of the hip in relation to various activities. Each question contained five quantifyable answering possibilities, with which a total score could be achieved of 12 (least problems) to 60 (most problems). The 12 -item questionnaire was tested in the English language for psychometric quality. (9-11)

Based on experience with hip patients we also analysed whether the addition of two disease specific items and five general questions to the Dutch version of the 12-item questionnaire would be beneficial to the score. The two disease specific items were "the use of walking aids when walking" and problems because of the hip with sexual activities". (12-14) These were added to the twelve pre-existing items so the total score of the Dutch version varied from 14 to 70 . (Table 1a English and Dutch) Of the five added general questions four gave the general opinion of the patient. (15) The fifth question reflected the division in different Charnley classes. (16) These questions were not included in the total score, because they were not disease specific. (Table ib English and outch) The Dutch version is called the "Oxford Heup Score" (OHS). In this paper the internal consistency, reproducibility, construct validity and sensitivity to change are evaluated. 


\section{METHODS}

The research was divided into two phases: at first the original 12-item questionnaire was translated into Dutch and then this version with the added questions was tested for psychometric quality in a prospective project.

\section{Procedure of TRANSLATion}

Four persons from different centres translated independently the English version of the 12-item questionnaire into Dutch. This version was reviewed to a bilingual person with English as her primaire language. Without knowledge of the original questionnaire, she translated this Dutch version back into English. The similarities and differences between the original, the translated and the re-translated versions were discussed and made into a Dutch-language version. The complete questionnaire was then tested in 15 patients with hip problems divided over the three participating hospitals and processed to the definitive version of the Dutch OHS.

\section{PROSPECTIVE TRIAL OF THE PSYCHOMETRIC QUALITIES}

To test the psychometric quality of the OHS, a prospective trial was performed in 150 patients with hip disease. All patients met the inclusion criteria of this study. (Tab) 2)

\section{Table 2}

\section{Patient inclusion criteria.}

- The patient is admitted for a total hip prosthesis (cemented or cementless)

- The patient is 35 years of age or older

- The diagnosis and indication for the total hip prosthesis is primary osteoarthritis of the hip or secondary osteoarthritis of the hip because of DDH, dislocation, fracture, infection or osteonecrosis

- The patient has no systemic illness that could influence the overall outcome results of this study (for instance rheumatoid arthritis or M. Bechterew)

- The patient is able to read and understand the Dutch language and is able to complete the questionnaire by him-/herself

- The patient is physically and mentally able to be included in the study.

- The patient has understood and signed the informed consent belonging to this study.

The included patients ( 98 females and 52 males) with a mean age of 65.4 (38- 85 years were divided over the Academic Hospital Maastricht ( $n=57)$, the University Medical Center $(n=41)$ and the Rijnland Hospital $(n=52)$. Primary osteoarthritis was the reason for surgery in $78 \%$ of the cases. In $62 \%$ a cemented THA and in $38 \%$ a cementless THA was performed. Different kinds of prostheses were used: SHP 22\%, Osteonics cemented $18 \%$, Osteonics HA-coated $17 \%$, Exeter $20 \%$, Müller 3\%, Mallory-Head HA-coated $12 \%$, AML $3 \%$ and Zweymuller $5 \%$. The OHS was presented to the patients preoperatively and postoperatively at seven weeks, three, six, 12 and 24 months. The Rijnland Hospital was forced to abandon the examination at seven weeks for organizational reasons. All patients gave their informed consent. The OHS was investi- 
gated for reproducibility, internal consistency, constuct validity and sensitivity for change. The same set up and statistical methods were used as with the validation of the original version, with the exception of the follow up period, which was extended in this trial to two years.

\section{REPRODUCIBILITY}

The reproducibility was investigated by calculating the intra class correlation coefficient (ICC, two way random model for agreement) between the test and the re-test. (17) We asked 42 included patients to answer the questionnaire again within 24 hours to see whether they completed the questionnaire with the same answers. We assumed that the hip problems were not changed in between. Also the "borders of similarity" were calculated according to the method of Bland and Altman. (18) We included these, because it provides insight to the site of the noise. An ICC is a coefficient between 0 and 1 and does not tell how many points on a scale a repeated measure may differ. Although the Bland and Altman method was originally designed to compare different methods, it can be well applied to measure reproducibility of a measurement.(19)

\section{INTERNAL CONSISTENCY}

The internal consistency was calculated via Cronbach's alpha. (20) This is a summarising value (range 0.0 to 1.0 ) that is based on the correlations amongst the separate questions and the overall score. With this test we also investigated whether the alpha could increase by removing individual questions.

\section{CONSTRUCT VALIDITY}

The validity of the OHS was determined by comparing its results with the generic RAND-36 (because we lacked a disease specific questionnaire in the Dutch language) and the VAS for pain, to test whether the OHS actually measured the problems of the patient with a THA. Spearman mark correlation coefficients were calculated. The VAS for pain was filled in by the patient at every follow up moment; the RAND-36 was filled in preoperatively as well as postoperatively at 6 months. To investigate whether the OHS of satisfied patients differed from the OHS of dissatisfied patients, the scores of every postoperative follow up moment were compared with each other. Convergent and divengent validity were measurde by investigating the strength of the correlation coefficients. The OHS should converge with similar metrics (e.g., VAS for pain, physical, functioning), and diverge from dissimilar domains from the RAND-36 (e.g., general perception of health, mental health).

\section{Sensitivity}

The sensitivity of the score for changes is expressed in effect size (difference in means/SD of the baseline score), calculated by the method of Kazis, between the preoperative score and the postoperative score of six months, one year and two years follow-up. (21) An effect size above 0.8 is considered as large, between 0.5 and 0.8 as moderate, and below 0.5 as small. (22)

This comparison was also made between the pre- and the postoperative RAND-36 score of six months follow up. 


\section{RESUlts}

During the total follow-up period the OHS was not completed 25 times, in 20 questionnaires the total score could not be calculated since not all questions were answered. In 18 cases it concerned the question about "problems because of the hip with sexual activity".

The mean preoperative OHS was 40 and the mean postoperative OHS was at seven weeks 31 , at three months 25 , at six months 21 , at one year 19 and at two years 19 . The mean total score of the 12 questions of the original version followed a comparable trend, when the two extra questions were added. The OHS 's were $47,36,29,25,22$, and 22 respectively. (figure 1)

\section{Figure 1}

\section{Mean total OHS}

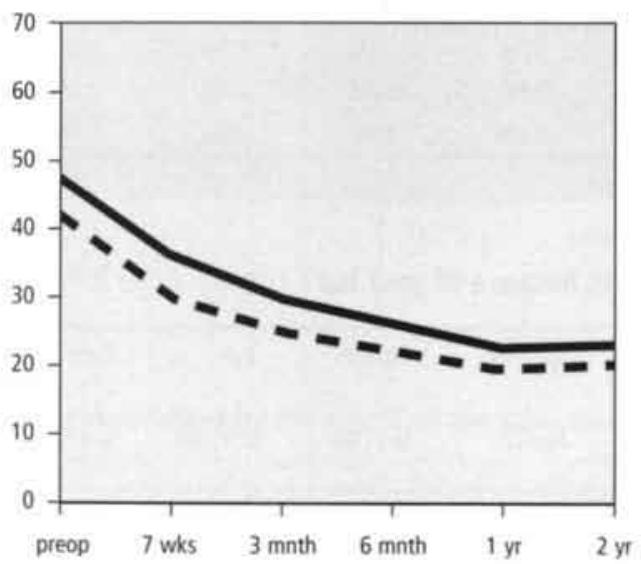

Mean modified Oxford Heup Score and 12-item questionnaire per follow-up.

\section{- 12-item questionnaire \\ - "Oxford Heup Score"}

\section{Figure 2}

\section{Mean total OHS}

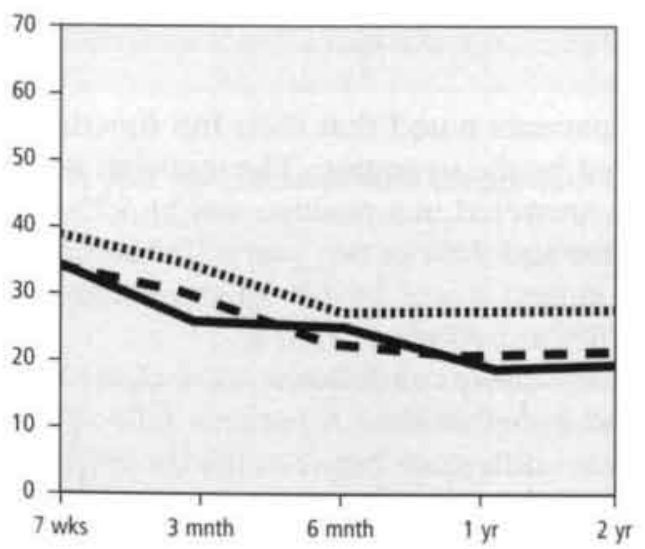

Mean modified Oxford Heup Score per follow-up per Charnley class.

- - Charnley A

- Charnley B

"..... Charnley C 
Preoperatively $65 \%$ of the patients some times to always used a walking aid, while postoperatively at six months this figure dropped to $45 \%$, at one year to $31.5 \%$ and finally at two years increases a little to $35 \%$. Problems because of the hip with sexual activity were noticed preoperatively by $57 \%$ of the patients and postoperatively at six months by $22 \%$, at one year $18 \%$ and at 2 years follow up $24 \%$ (Tab) 3 )

Table 3

Answers to the added disease specific questions: percentage per follow up.

Have you been using walking aids (cane(s), crutch(es) or a walker) when walking?

\begin{tabular}{|l|rrrrrrr|}
\hline & preop & 7 wks & 3mnth & 6 mnth & $1 \mathrm{yr}$ & $2 \mathrm{yrs}$ \\
& $\mathrm{N}=150$ & $\mathrm{~N}=91$ & $\mathrm{~N}=142$ & $\mathrm{~N}=148$ & $\mathrm{~N}=141$ & $\mathrm{~N}=139$ \\
\hline Never & $35.3 \%$ & $4.4 \%$ & $26.1 \%$ & $54.7 \%$ & $69.5 \%$ & $65.5 \%$ \\
Sometimes & $19.3 \%$ & $17.6 \%$ & $24.6 \%$ & $20.3 \%$ & $12.8 \%$ & $18.0 \%$ \\
Often & $6.0 \%$ & $14.3 \%$ & $7.7 \%$ & $6.1 \%$ & $3.5 \%$ & $5.0 \%$ \\
Most of the time & $12.7 \%$ & $25.3 \%$ & $12.0 \%$ & $10.8 \%$ & $6.4 \%$ & $2.9 \%$ \\
All of the time & $26.7 \%$ & $38.5 \%$ & $29.6 \%$ & $8.1 \%$ & $7.8 \%$ & $8.6 \%$ \\
& & & & & & \\
\hline
\end{tabular}

Have you had problems with your sexual activities because of your hip?

\begin{tabular}{|l|rrrrrrr|}
\hline & preop & 7 wks & 3mnth & 6 mnth & $1 \mathrm{yr}$ & 2 yrs \\
& $\mathrm{N}=146$ & $\mathrm{~N}=90$ & $\mathrm{~N}=141$ & $\mathrm{~N}=144$ & $\mathrm{~N}=138$ & $\mathrm{~N}=138$ \\
\hline Never / not applicable & $43.2 \%$ & $61.1 \%$ & $66.7 \%$ & $77.8 \%$ & $81.9 \%$ & $76.1 \%$ \\
Sometimes & $15.8 \%$ & $15.6 \%$ & $20.6 \%$ & $15.3 \%$ & $13.8 \%$ & $17.4 \%$ \\
Often & $6.2 \%$ & $2.2 \%$ & $3.5 \%$ & $0.7 \%$ & $0 \%$ & $2.9 \%$ \\
Most of the time & $12.3 \%$ & $6.7 \%$ & $1.4 \%$ & $3.5 \%$ & $2.2 \%$ & $0.7 \%$ \\
Always & $22.6 \%$ & $14.4 \%$ & $7.8 \%$ & $2.8 \%$ & $2.2 \%$ & $2.9 \%$ \\
& & & & & & \\
\hline
\end{tabular}

Up to 2 years follow up the majority of the patients noted that their hip function had increased and that their hip pain had decreased by the operation. The question whether the patient was satisfied by the operation was answered in a positive way by $92 \%$ of the patients at 6 months follow up, $94 \%$ at one year and $90 \%$ at two years. The comparison of the hip with the previous follow up was judged worse by $6 \%$ of the patients at 6 months follow up, by $4 \%$ at one year and by $8 \%$ at two years. (Table 4)

The patients were divided into the Charnley classes as follows: $42 \%$ class $\mathrm{A}, 24 \%$ class B and $34 \%$ class C. The mean OHS was better in class A patients followed by B and C. From 3 months on there was a significant difference between the three Charnley classes for their mean total OHS. This significant difference was seen between class A and $\mathrm{C}$ and between class $\mathrm{B}$ and $\mathrm{C}$, but not between class A and B. (Figure 2) The mean VAS score for pain was preoperatively 6.7 and postoperatively 2.01 at six months, 1.64 at one years and 1.6 at two years follow up. 
Table 4

Answers to the added disease specific questions: percentage per follow up.

Has the function or range of motion of your hip been improved by the operation?

\begin{tabular}{|l|rrrrr|}
\hline & 7wks & 3mnth & 6 mnth & $1 \mathrm{yr}$ & 2yrs \\
& $\mathrm{N}=91$ & $\mathrm{~N}=141$ & $\mathrm{~N}=148$ & $\mathrm{~N}=141$ & $\mathrm{~N}=140$ \\
\hline Yes & $87.9 \%$ & $90.1 \%$ & $93.2 \%$ & $94.3 \%$ & $91.4 \%$ \\
No & $11 \%$ & $9.9 \%$ & $6.8 \%$ & $5.7 \%$ & $8.6 \%$ \\
Yes and no & $1.1 \%$ & $0 \%$ & $0 \%$ & $0 \%$ & $0 \%$ \\
\hline
\end{tabular}

Has the pain in / around your hip been improved by the operation?

\begin{tabular}{|l|rrrrrr|}
\hline & 7 wks & 3mnth & 6 mnth & $1 \mathrm{yr}$ & $2 \mathrm{yrs}$ \\
& $\mathrm{N}=91$ & $\mathrm{~N}=141$ & $\mathrm{~N}=147$ & $\mathrm{~N}=141$ & $\mathrm{~N}=140$ \\
\hline Yes & $87.9 \%$ & $92.9 \%$ & $93.2 \%$ & $94.3 \%$ & $92.9 \%$ \\
No & $12.1 \%$ & $6.4 \%$ & $6.8 \%$ & $5.7 \%$ & $7.1 \%$ \\
Yes and no & $0 \%$ & $0.7 \%$ & $0 \%$ & $0 \%$ & $0 \%$ \\
\hline
\end{tabular}

Are you satisfied by the result of the operation?

\begin{tabular}{|l|rrrrr|}
\hline & 7 wks & 3mnth & 6 mnth & $1 \mathrm{yr}$ & $2 \mathrm{yrs}$ \\
& $\mathrm{N}=90$ & $\mathrm{~N}=141$ & $\mathrm{~N}=148$ & $\mathrm{~N}=141$ & $\mathrm{~N}=139$ \\
\hline Yes & $91.1 \%$ & $95.0 \%$ & $91.9 \%$ & $94.3 \%$ & $89.9 \%$ \\
No & $6.7 \%$ & $4.3 \%$ & $7.4 \%$ & $5.7 \%$ & $10.1 \%$ \\
Yes and no & $2.2 \%$ & $0.7 \%$ & $0.7 \%$ & $0 \%$ & $0 \%$ \\
\hline
\end{tabular}

How is your hip compared with the previous time you completed this questionnaire?

\begin{tabular}{|l|rrrrr|}
\hline & 7wks & 3mnth & 6 mnth & $1 \mathrm{yr}$ & $2 \mathrm{yrs}$ \\
& $\mathrm{N}=89$ & $\mathrm{~N}=141$ & $\mathrm{~N}=146$ & $\mathrm{~N}=141$ & $\mathrm{~N}=139$ \\
\hline Better & $88.8 \%$ & $80.9 \%$ & $69.2 \%$ & $56.7 \%$ & $40.3 \%$ \\
The same & $10.1 \%$ & $17 \%$ & $24.7 \%$ & $39 \%$ & $51.8 \%$ \\
Worse & $1.1 \%$ & $2.1 \%$ & $6.2 \%$ & $4.3 \%$ & $7.9 \%$ \\
Not applicable & $0 \%$ & $0 \%$ & $0 \%$ & $0 \%$ & $0 \%$ \\
\hline
\end{tabular}




\section{REPRODUCIBILITY}

The test-retest $(n=42)$ showed an ICC of 0.97 (95\% CI: $0.095-0.98) .95 \%$ Of the differences in the scores were between -2.7 and +2.7 on a scale of 12 to 60 points.

\section{INTERNAL CONSISTENCY}

Cronbach's alpha varied preoperatively from 0.84 to postoperatively 0.89 at six months, 0.93 at one year and 0.92 at two years follow up. All questions correlated with the total score from $\mathrm{r}=0.4$ to $\mathrm{r}=0.9$, except the question about problems because of the hip with sexual activity (range $\mathrm{r}=0.2-0.4$ ). The alpha was however not influenced by removal of this question.

\section{ConstruCt VALIDITY}

The pre- as well as the postoperative OHS at 6 months correlated significantly with the scores of the RAND-36. Low correlations, or divergent validity, $(<0.35)$ were preoperatively obtained on the items: decrease of emotional role, perception of general health and changes in general health and postoperatively on mental health, vitality and perception of general health. High correlations, or convergent validity, $(r \geq 0.7)$ were obtained preoperatively as well as postoperatively on the items physical function and pain and postoperatively also on decrease of physical role. The correlation between the OHS and the VAS for pain was also very high at all moments of follow up $(r \geq 0.7)$. At every moment of follow up a significant difference was found between the total score of satisfied patients and those that were dissatisfied about the result of the operation. The same difference was found between patients who judged that their hip pain had decreased and those who judged the pain had not decreased. Satisfied patients and patients with less pain had a higher OHS. This significant difference was also seen between those patients who thought the mobility of their hip had increased and those who thought it had not, with the exception of the result at seven weeks follow up. With these results one should remark that most patients were satisfied (between $89 \%$ and $95 \%$ ), so the groups to be compared are unevenly divided.

\section{SENSITIVITY}

The "effect size" in the OHS between the pre- and postoperative follow up moments of six months, one year and two years were respectively $2.38,2.68$ and 2.65. An effect size above 0.8 is considered as large, between 0.5 and 0.8 as moderate and below 0.5 as small (22) For the items of the RAND-36 these were at six months: physical functioning 1.63; social functioning 1.01; role decrease (physical problem) 1.59; role decrease (emotional problem) 0.84 ; mental health 0.54 ; vitality 0.63 ; pain 2.28 ; general perception of health 0.04 and change of health 1.69 .

\section{Discussion}

The results presented here concern the validation of the into Dutch translated modified "Oxford Heup Score". It is insufficient solely to translate a questionnaire into a 
foreign language, without validating the translated version. $(28,29)$ The translation process followed the general guidelines given by Guillemin et al. (28) The complete questionnaire appeared to be completed by the patients quite easily, which resulted in a small amount of missing values. (23) The two added questions about "the use of walking aids" and "problems because of the hip with sexual activity" were positively answered before the operation by more than half of the patients. This illustrates the importance of these items for total hip arthroplasty patients and therefore these questions should be included in a disease specific questionnaire for total hip arthroplasty patients. The internal consistency dropped a little by the low correlation between the question about "problems because of the hip with sexual activity" and the total score. A possible explanation might be that the physical stress in this item is different than in the other items of the OHS. Another argument for not including this question in the score is that $18 / 150$ cases did not complete this specific question. On the other hand Cronbach's alpha hardly increased by removing this question. When comparing the OHS with the items of the RAND-36 the largest correlation was seen with the items "physical functioning", "pain" and "decrease of role by physical problems". With the VAS for pain also a high correlation was seen. With this it was proven that these important parameters were measured by the OHS. $(24,25)$

The four general questions proved that satisfied patients had a higher OHS than dissatisfied patients. The only exception was the question whether the patient thought hip mobility had increased by the operation. At seven weeks follow up no significant difference in OHS was found between these two answers. A possible explanation is that after such a short follow up a less mobile hip joint does not influence daily life as much as it does in the long run.

The total OHS showed an improvement with time. The largest change was seen in the first year, while the score reached a plateau after the first year of follow up. This trend was also seen with the general questions for improved hip function and decreased pain. Longer follow up will be necessary to see how the score develops after two years. The fact that the mean total score has neither its maximal nor its minimal score is a psychometric advantage: it leaves space for developments in both positive and negative directions. Ceiling- and floor effects are prevented. Compared with the RAND-36 the OHS was more sensitive for alterations in time, which is to be expected since the RAND-36 is a generic tool. (26) The reliability and the validity of the twelve translated questions of the 12-item questionnaire match with those of the original version. This is important when research results measured with the Dutch OHS are compared with those measured with the original 12-item questionnaire. This investigation has proven that the OHS is a useful instrument to judge the result of a total hip arthroplasty from the patient's point of view. By using the original questionnaire and interpretation of the results McMurray stated that the use of walking aids, the use of medication and comorbidity could cause distortion of the actual situation. (27) It appears difficult for the patient to imagine the situation without walking aids, medication or comorbidity. This phenomenon can also be seen in our population. The patients in Charnley class $\mathrm{C}$ had a significantly worse mean OHS than the patiens in class A or B. Therefore the answers to the activity questions should not be interpreted as the absolute, but the relative capability of the patient. Since this is a problem of the validity of almost all disease specific questionnaires, it is an item that needs to be evaluated more thoroughly.

The use of the OHS has many advantages. Firstly for the patient, since specific problems can be evaluated. Secondly for the surgeon, since the questionnaire can be a guide in the conversation with the patient. Thirdly, repeated assessments are facilitated, 
since this questionnaire can be sent and returned by mail. Finally, one should bear in mind that when using the OHS that it is meant to be used in combination and as an additive to the evaluation by the surgeon. It is not meant to be a substitution. The combination of the opinions of the patient and the surgeon will give a fair evaluation of a total hip replacement. 


\section{REFERENCES}

1 Lieberman JR, Dorey F, Shekelle P, Schumacher L, Thomas B, Kilgius D, Finerman GA. (1996) Differences between patients' and physicians' evaluations of outcome after total hip arthroplasty. J Bone Joint Surg [Am] 78(6):835-8.

2 Harris WH. (1969) Traumatic arthritis of the hip after dislocation and acetabular fractures; treatment by mold arthroplasty. J Bone Joint Surg [Am] 51:737-55.

3 Merle d'Aubigné RM, Postel M. (1954) Functional results of hip arthroplasty with acrylic prosthesis. J Bone Joint Surg [Am] 36:451-75.

4 Van der Zee K, Sanderman R. (1993) [RAND-36 een handleiding. Noordelijk Centrum voor Gezondheids vraagstukken.] Rijksuniversiteit Groningen.

5 Van der Zee K, Sanderman R, Heyink J. (1993) Psychometrische kwaliteit van de MOS 36-item Short Form Health Survey (SF-36) in een Nederlandse populatie.] Tijdschr Soc Gezondheidsr 71:183-91.

6 Carlsson AM. (1983) Assessment of chronic pain. Aspects of the reliability and validity of the visual analog scale.

Pain 16:87-101.

7 Erdman RAM, Passchier J.

[Nottingham Health Profile de geauthoriseerde Nederlandse versie Handleiding.]

Centrum voor Pschychometrisch en Psychotherapeutisch Onderzoek

Rotterdam. Instituut Medische

Psychologie-Psychotherapie, Erasmus Universiteit Rotterdam.

8 Dawson J, Fitzpatrick R, Carr A, Murray D. (1996) Questionnaire on the perceptions of patients about total hip replacement. J Bone Joint Surg [Br] 78:185-90.

9 Dawson J, Fitzpatrick R, Murray D, Carr A. (1996) The problem of "noise" in monitoring patient-based outcomes: generic, disease-specific and site-specific instruments for total hip replacement.
J Health Serv Res Policy 4:224-31.

10 Dawson J, Fitzpatrick R, Murray D, Carr A. (1996) Comparison of measures to assess outcomes in total hip replacement surgery. Qual Health Care 5:81-8.

11 Fitzpatrick R, Dawson J. (1997) Health-related quality of life and the assessment of outcomes of total hip replacement surgery. Psychol Health 12:793-803.

12 Wright JG, Rudicel S, Feinstein AR. (1994) Ask patients what they want: evaluation of individual complaints before total hip replacement. J Bone Joint Surg [Br] 76:229-35.

13 Currey HLF. (1997) Osteoarthritis of the hip and sexual activity. Ann Rheum Dis 29:488-93.

14 Stern SH, Fuchs MD, Ganz SB, Classi P, Sculco T, Salvati E. (1991) Sexual function after total hip arthroplasty. Clin Orthop 269:228-35.

15 Johnston RC, Moines D, Fitzgerald RH, Harris WH, Poss R, Muller M, Sledge CB. (1990) Clinical and radiographic evaluation of total hip replacement. J Bone Joint Surg [Am] 72(2):161-8.

16 Charnley J. (1972) The long-term results of low-friction arthroplasty of the hip performed as a primary intervention. J Bone Joint Surg [Br] 54:61-7.

17 Mc Graw KO, Wong SP (1996) Forming is references about some intraclass correlation coefficients Psych. Methods 1: 30-46.

18 Bland JM, Altman DG. (1996) Statistical methods for assessing agreement between two methods of clinical measurement. Lancet 8:307-10.

19 Bland JM, Altman DG. (1996) Measurement error BMJ 312:1654

20 Cronbach LJ. (1951) Coefficient alpha and the internal structure of tests. Psychometrika 16(3):297-334.

21 Kazis LE, Anderson JJ, Meenam RF. (1989) Effect sizes for interpreting changes in health status. Med Care Suppl.27:178-89. 
22 Cohen. J. (1977) Statistical poven analysis for the behavioural sciences, New York: Academic Press.

23 Fitzpatrick R, Morris R, Hajat S, Reeves B, Murray DW, Hannen D, Rigge M, Williams O, Gregg P. (2000) The value of short and simple measures to assess outcomes for patients of total hip replacement surgery. Qual Health Care 9:146-50.

24 Britton AR, Murray DW, Bulstrode CJ, McPherson K, Denham RA. (1997) Painlevels after total hip replacement. J Bone Joint Surg [Br]79 (1):93-8.

25 Liang MH, Cullen KE, Poss R. (1982) Primary total joint replacement: evaluation of patients. Annual Intern Med 97:735-9.

26 Wright JG, Young NL. (1977) A comparison of different indices of responsiveness. J Clin Epidemiol 50:239-46.

27 MCMurray R, Heaton J, Sloper P, Nettleton S. (1999) Measurement of patient perceptions of pain and disability inrelation to total hip replacement: the place of the Oxford Hip Score in mixed methods. Qual Health Care 8:229-33.

28 Guillemin F, Bombardier C, Beaton D. (1993) Cross-cultural adaptation of health-related quality of life measures: literature review and proposed guidelines [see comments]. J Clin Epidemiol 46(12):1417-1432.

29 Guyatt GH. (1993) The philosophy of health related quality of life translation. Qual Life Res 2(6):461-5. 
Ta b le 1 a - the English version.

The 14 specific questions of the modified Oxford Heup Score ( 12 from the original questionnaire and 2 added questions)

During the last 4 weeks:

1. How would you describe the pain you usually had from your hip?

- None

- Very mild

- Mild

- Moderate

- Severe

2. Have you had any trouble with washing and drying yourself (all over) because of your hip?

- No trouble at all

- Very little trouble

- Moderate trouble

- Extreme difficulty

- Impossible to do

3. Have you had any trouble getting in and out of a car or using public transport because of your hip? (whichever you tend to use)

- No trouble at all

- Very little trouble

- Moderate trouble

- Extreme difficulty

- Impossible to do

4. Have you been able to put on a pair of socks, stockings or tights?

- Yes, easily

- With little difficulty

-With moderate difficulty

- With extreme difficulty

- No, impossible

5. Could you do the household shopping on your own?

- Yes, easily

-With little difficulty

- With moderate difficulty

-With extreme difficulty

- No, impossible
6. For how long have you been able to walk before the pain from your hip became severe? (with or without a stick)

- No pain $/>30$ minutes

- 16 to 30 minutes

- 5 to 15 minutes

- Around the house only

- Not at all

7. Have you been able to climb a flight of stairs? - Yes, easily

- With little difficulty

- With moderate difficulty

- With extreme difficulty

- No, impossible

8. After a meal (sat at a table), how painful has it been for you to stand up from a chair because of your hip?

- Not at all painful

- Slightly painful

- Moderately painful

- Very painful

- Unbearable

9. Have you been limping when walking because of your hip?

- Rarely / never

- Sometimes or just at first

- Often, not just at first

- Most of the time

- All of the time

10. Have you had any sudden, severe pain 'shooting', 'stabbing' or 'spasms' - from the affected hip?

- No days

- Only 1 or 2 days

- Some days

- Most days

- Every day 
11. How much has pain from your hip interfered with your usual work (including housework)?

- Not at all

- A little bit

- Moderately

- Greatly

- Totally

12. Have you been troubled by pain from your hip in bed at night?

- No nights

- Only 1 or 2 nights

- Some nights

- Most nights

- Every night

13. Have you been using walking aids (cane(s), crutch(es) or a walker) when walking?

- Never

- Sometimes

- Often

- Most of the time

- All of the time

14. Have you had problems with your sexual activities because of your hip?

- Never / not applicable

- Sometimes

- Often

- Most of the time

- Always

\section{T a b l e 1 b}

\section{The 5 general questions}

1. Pick from the three situations below the situation that is most applicable to your situation:

- I have hip problems and/or a hip prosthesis at one side, but no other health problems that influence my daily life.

- I have hip problems and/or a hip prosthesis on both sides, but no other health problems that influence my daily life.

- I have hip as well as other health problems that influence my daily life (for instance : back- or knee problems, rheumatoid arthritis, breathing problems, heart problems, neurological problems, etc.).

2. Has the function or range of motion of your hip been improved by the operation?

- yes

- no

3. Has the pain in / around your hip decreased by the operation?

- yes

- no

4. Are you satisfied by the result of the operation?

- yes

- no

5. How is your hip compared with the previous time you completed this questionnaire?

- better

- the same

- worse

- not applicable 
Ta ble 1 a - the Dutch version.

\section{De 14 specifieke vragen van de gemodificeerde Oxford Heup Score}

(12 vanuit de originele vragenlijst en 2 toegevoegde vragen)

Gedurende de afgelopen 4 weken

1. Hoe zou u de pijn omschrijven die u normaal in/rond uw heup heeft?

- Geen pijn

- Heel licht

- Licht

- Matig

. Ernstig

2. Heeft $u$, door uw heup, moeite met het wassen en afdrogen van uw hele lichaam?

- Helemaal geen moeite

- Beetje moeite

- Nogal wat moeite

- Veel moeite

- Onmogelijk om te doen

3. Heeft $u$, door uw heup, moeite bij het in en uitstappen van de auto, trein, bus of ander openbaar vervoer?

- Helemaal geen moeite

- Beetje moeite

- Nogal wat moeite

- Veel moeite

- Onmogelijk om te doen

4. Kunt u zelf uw sokken, kousen of panty's aantrekken?

- Ja, gemakkelijk

- Met een beetje moeite

- Met nogal wat moeite

- Met veel moeite

- Nee, onmogelijk

5. Kunt u zelf uw dagelijkse boodschappen doen?

- Ja, gemakkelijk

- Met een beetje moeite

- Met nogal wat moeite

- Met veel moeite

- Nee, onmogelijk
6. Hoe lang kunt u lopen (met of zonder stok) voordat de pijn in/rond uw heup ernstig wordt?

- Langer dan 30 minuten

- 16 tot 30 minuten

- 5 tot 15 minuten

- Alleen in en om het huis

- Helemaal niet

7. Kunt u trappen lopen?

- Ja, gemakkelijk

- Met een beetje moeite

- Met nogal wat moeite

- Met veel moeite

- Nee, onmogelijk

8. Hoe pijnlijk is uw heup, als u na het eten aan tafel, uit uw stoel opstaat?

- Helemaal niet pijnlijk

- Beetje pijnlijk

- Nogal pijnlijk

. Erg pijnlijk

. Ondraaglijk

9. Trekt $u$, vanwege uw heup, met uw been tijdens het lopen (afgelopen 4 weken)?

- Zelden / nooit

- Soms (bv. de eerste passen)

- Vaak (bv. niet alleen de eerste paar passen)

- Meestal

- Altijd

10. Heeft u wel eens dagen waarop u plotselinge, ernstige pijn (scheuten, steken en/of krampen)in/rond uw heup heeft?

- Nee, nooit

- 1 - 2 dagen

- Een aantal dagen

- Meeste dagen

- Elke dag 
11. In hoeverre beĭnvloedt de pijn in uw heup uw dagelijks werk (inclusief huishoudelijk werk)?

- Helemaal niet

- Een beetje

- Nogal

- Veel

- Totaal

12. Heeft $u$ wel eens nachten waarop $u$ in bed last heeft van pijn in/rond uw heup?

- Nooit

. 1 - 2 nachten

- Een aantal nachten

- Meeste nachten

- Elke nacht
13. Gebruikt u hulpmiddelen (stok(ken), kruk(ken), looprek) bij het lopen?

- Nooit

- Soms

- Vaak

- Meestal

- Altijd

14. Wordt $\mathrm{u}$ bij uw seksuele activiteiten belemmerd door uw heup?

- Nooit / niet van toepassing

- Soms

- Vaak

- Meestal

- Altijd

Table 1 b

De 5 algemene vragen

1. Geef aan welke van de volgende drie situaties het beste bij u past:

- Ik heb aan één kant: heupproblemen en/of een heupprothese, maar geen andere gezondheidsproblemen die van invloed zijn op mijn dagelijks functioneren.

- Ik heb aan beide kanten: heupproblemen en/of een heupprothese, maar geen andere gezondheidsproblemen die van invloed zijn op mijn dagelijks functioneren.

- Ik hebzowel heup-als andere gezondheidsproblemen die van invloed zijn op mijn dagelijks functioneren (bijvoorbeeld: rug-of knieproblemen, reuma, nierziekte, hartaandoening, neurologische aandoening etc.).

2. Is door de operatie de beweeglijkheid of functie van uw heup beter geworden?

- ja

- nee

3. Is door de operatie de pijn in/rond uw heup minder geworden?

- ja

- nee

4. Bent $u$ tevreden met het resultaat van de operatie?

- ja

- nee

5. Hoe is uw heup vergeleken met de vorige keer dat u deze vragenlijst heeft ingevuld?

- beter

- hetzelfde

- slechter

- niet van toepassing 


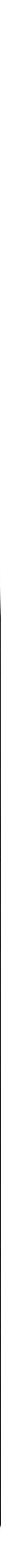


THE MALLORY-HEAD PROSTHESIS 


\section{The Mallory-Head Prosthesis}

\section{The Mallory-Head FEMORAL PROSTHESIS: DESIGN RATIONAL}

Proximal loading of the femur to recreate near-normal bone stresses is the primary goal of the Mallory-Head porous femoral stem (figure 1).

Figure 1

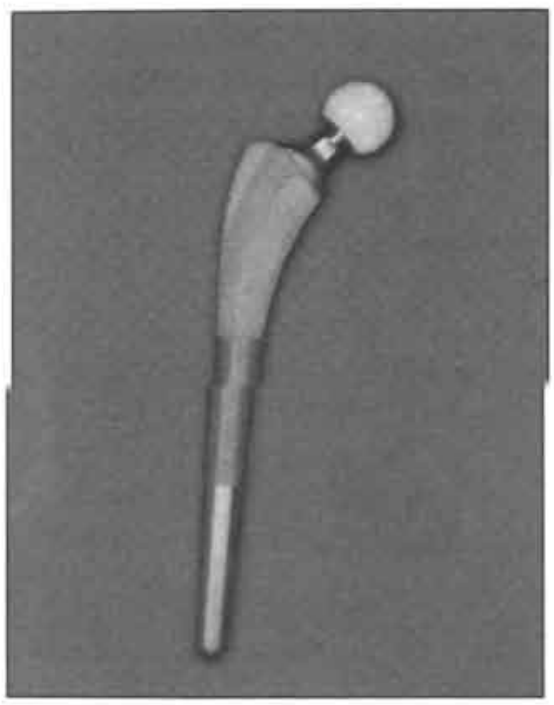

The Mallory-Head cementless femoral stem with a proximal hydroxyapatite coating and a ceramic head.

This concept has proven to deliver excellent clinical results since its conception in 1984 . (1-22) The proximal geometry of the Mallory-Head porous component is designed to promote filling of the metaphysis and proximal off-loading. This is achieved through quadrilateral fixation in the proximal femur. The quadrilateral fixation is created by an anterior and a posterior flange, a wide lateral fin and the shape of the medial aspect of the stem (figure 2). This proximal configuration will ensure that normal circumferential or

Figure 2

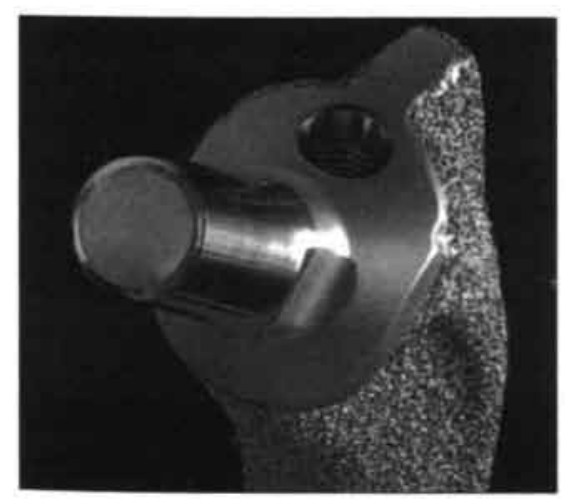

Cranial view of the cementless Mallory-Head femoral prosthesis, showing in more detail the unique proximal design with its fins for rotational stability. 
hoop stresses will be exerted on the femur, while bending and rotational forces are resisted.

The Mallory-Head porous primary stem features a bi-planer taper. The lateral-tomedial taper, augmented with the finned geometry, enhances proximal stress off-loading and initial stability. Unlike fully porous coated cylindrical stems that tend to transmit most of the load distally and may stress shield proximally, the Mallory-Head porous implant taper from proximal-to-distal paralleling the natural contours of the canal and allowing a gradual decrease in the stresses transferred to the bone (Figure 3).

\section{Figure 3}

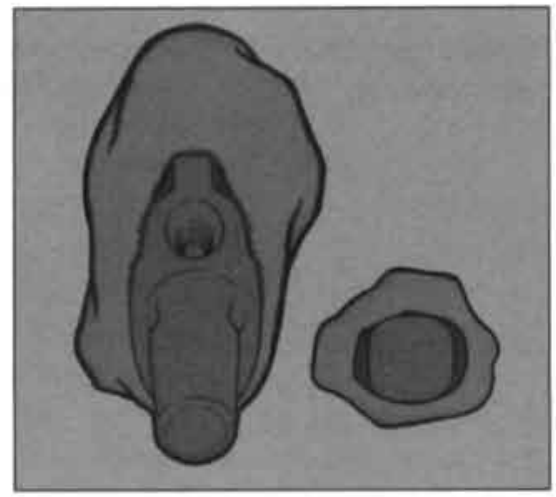

Quadrilateral fixation is shown with maximal canal filling in the proximal regions and close contact with the bone in the distal regions.

This three degree taper allows the prosthesis to achieve three point fixation for immediate stem stability, and contributes to the reported low incidence of thigh pain and stress shielding with this implant. $(5,16,20)$ The Mallory-Head porous stem is a straight stem given the fact that there are so many variables within the femur itself. The femur is a curved helix and, by inserting a straight stem, multiple contact points throughout the geometry of any given femur are created.

The metal of choice for the porous primary stem is titanium alloy (Ti-6Al-4V), chosen for its biocompatibility. Titanium also possesses a modulus of elasticity which more closely approximates that of actual bone as compared to cobalt-chrome and stainless steel. This allows the stem to transfer stresses to the proximal portion of the bone, resulting in a femur that bears load and preserves cortical density. Titanium alloy, not only as a porous coating but also as a substrate, plays a critical role in implant performance. A titanium substrate and titanium closed-pore, circumferential porous coating designed to lock in the femoral implant and create a seal to particulate debris migration may help to reduce osteolysis and improve long-term fixation. $(24,25)$ The surface treatments of the primary porous system are consistent with its design objective, which is a gradual decrease in the forces transferred to the bone from proximal to distal. The surface areas are treated independently to provide secure fixation where it is most needed to restore normal stresses in the bone. The proximal area is circumferentially porous coated with a titanium alloy plasma spray, which greatly increases the surface area of the stem for improved fixation. This circumferential porous coating is a "closed pore" design that acts as a barrier to the migration of particulate debris. The middle one-third has a roughened finish created through a blasting technique allowing firm fixation in the diaphysis to prevent torsional stresses. The distal portion of the stem is smooth, allowing the majority of forces to be off-loaded proximally. 
By using a HA-coating added to the porous proximal third of the femoral prosthesis the in- and ongrowth of bone to the prosthesis is stimulated. In this way the initial fixation of the prosthesis in the proximal femur and the sealing effect to prevent particulate debris is optimized. The coating is characterized by a coating thickness of $55 \mu \mathrm{m}$ $\pm 15 \mu \mathrm{m}$, a HA crystalline content of more than $98 \%$ with a cristallinity of $50 \%-70 \%$ and a tensile adhesion of more than $15 \mathrm{MPa}$. The Mallory-Head porous prostheses are proportionally sized, ranging from 6 to $19 \mathrm{~mm}$ in width and from 135 to $180 \mathrm{~mm}$ in length with a neck angle of 135 degrees.

\section{The Mallory-Head Femoral PROSTHESIS: LITERATURE.}

Most reports in literature were published by the inventors of the Mallory-Head femoral prosthesis themselves, although others also presented medium and long-term results. (1-23) From 1984 onwards the Mallory-Head cementless proximally porous coated femoral prosthesis was used by the designers, Mallory and Head. In 1990 the early results of fifty primary total hip arthroplasties were published. (1) The average age of the patients was 53 years; the follow-up range was 24 to 52 months. The predominant preoperative diagnosis was osteoarthritis $(88 \%)$. Using the Harris Hip Score, an noted improvement was seen in the preoperative score of 37 to a postoperative score of 94 . Ninety-seven percent of the patients reported no pain or discomfort. Using Engh's fixation scale, all femoral components were rated as optimum with signs of bone ingrowth. Radiographic evaluation showed no subsidence or shift of the femoral components. All were asymptomatic and fully functional in daily living activities.

In 1996 various papers described the medium term results of the Mallory-Head femoral prosthesis. The designers presented their medium term results of 177 non-consecutive, primary total hip arthroplasties performed in 150 patients using the MalloryHead porous coated component. $(4,5)$ The average time to follow-up evaluation for the entire population (including all early revisions) was 76 months ( 6.3 years). There were 10 revisions $(6 \%)$ with an average time to revision of 50 months (4.2 years). Two revisions were for component undersizing; three revisions were for aseptic loosening; four revisions were for acetabular component failure and one revision was due to a femoral fracture secondary to trauma. The average Harris Hip Score for all hips increased from 41.5 before surgery to $86.8(p<0.001)$. Radiographic assessments yielded an average Engh fixation score of 20.7. The survival estimate for the average time to follow-up evaluation was $98 \%$. Mulliken et al. (non-designers) published their results of 416 total hip arthroplasties performed in 372 patients. (6-9) The average duration of clinical and radiographic follow-up was 3.7 years (range, 2.0 to 6.5 years). They performed no revisions. Although the clinical results were excellent, they noticed that radiographic evaluation of stability of this stem is clearly different from that of chromium-cobalt stems, particularly extensively coated anatomic medullary locking stems, in that so-called spot-welds and severe resorptive bone changes were uncommon and distal cortical hypertrophy was common. Although this study was performed retrospectively, it still describes the largest series with the use of this prosthesis.

Long term results were described only recently by Bourne et al. (11) The 10 to 13 year performance of 283 Mallory-Head cementless tapered total hip replacements was assessed. Eighty-five percent of patients had a diagnosis of osteoarthritis. Fifty-one percent of patients were women. The mean patient age was $64+/-10$ years. The Hex Loc 
cementless acetabular component and titanium alloy femoral heads were used in each patient. At final follow up, $37(13 \%)$ patients died, $32(10 \%)$ had revision surgery, and two $(1 \%)$ were lost to follow up. No femoral stem was revised for aseptic loosening, but one was revised because of sepsis and one was revised because of a periprosthetic fracture. Wear, osteolysis, and loosening were problems with the Hex Loc cementless acetabular components and $31(10 \%)$ acetabular components required revision because of these mechanisms. The mean Harris Hip Score at final follow up of the remaining patients was $87+/-14$ points. Three percent of these patients had thigh pain. Radiographic assessment revealed that no femoral stem or acetabular socket was definitely or probably loose. The Mallory-Head cementless, tapered femoral component performed well in the patients in this study, but unfortunately, the clinical results were compromised by the use of a suboptimal cementless acetabular component, the use of polyethylene that was gamma-irradiated in air, and by the use of titanium alloy femoral heads. Also Mallory et al. published in 2001 and 2002 their long-term results after a minimum follow up of 10 years. $(16,22)$ They found a $97.5 \%$ survival of the stem.

They found high percentages for calcar remodeling $(71.7 \%)$ and spot-weld formation $(88.3 \%)$. Cortical thickening was absent in most cases $(87.5 \%)$, as well as pedestal formation (77.5\%). Proximal stress shielding was observed in $18.3 \%$ of the patients. The study of Mallory et al. published in 2002 is a meta-analysis of various tapered femoral stems. (22) The Mallory-Head stem appears to be one of the best performing stems in this family.

All cited studies however discuss the use of the femoral prosthesis without the use of an additional layer of hydroxyapatite. No literature is published up till now about the hydroxyapatite coated version of the Mallory-Head femoral prosthesis, except by Emerson et al. who compared the results of the Mallory-Head stem with and without hydroxyapatite in similar patient populations. (14). He could demonstrate no clinical difference at one-year follow up. However the HA group progressed more rapidly when comparing clinical scores at 6 months $(p=0.0058)$ and appeared to demonstrate more rapid bone remodeling at 6 months on the femoral side, although this observation did not make statistical significance $(p=0.0618)$. A comparison between these two groups at a later stage of follow up was not published. The extra value of this hydroxyapatite layer in terms of a barrier to wear debris products or improved fixation over the non-hydroxyapatite coated prosthesis can be extrapolated from retrieval studies concerning other hydroxyapatite coated stems. Retrieval studies of the hydroxyapatite coated MalloryHead femoral prosthesis are not published. Whiteside et al. (26) studied fixation of two femoral specimens, one Mallory-Head specimen and one AML (DePuy, Warsaw, IN) specimen, that were retrieved after 2-8 years of successful use in active patients. Both implants had radiographic signs of bone ingrowth. No permanent rotational displacement was found in either specimen during torsional load testing, but rotational and axial micromotion were found in both. These findings indicate excellent fixation of implant to bone, and no slippage at the bone-implant interface. The Mallory-Head implant had much greater elastic displacement than the AML, and histological examination showed cancellous bone ingrowth into the porous-coated portion of the Mallory-Head stem.

The AML implant, which withstood much higher torsional loads, was found upon histological evaluation to have dense cortical-cancellous bone ingrowth. Strength of attachment of the metal implant to bone was good in both specimens, and neither had slippage at this interface. No other retrievals concerning the Mallory-Head femoral stem were published. To further optimise the design of the Mallory-Head cementless porous coated femoral prosthesis Camino created a three dimensional finite element model. 
(27) With this model he studied the design parameters of the stem: the depth of the lateral, anterior and posterior fins, the stem taper angle, the elastic modulus and the length. It was calculated that the fins have little effect on proximal stress overall, but they should be retained to promote initial stability. The stiffness of the stem should be minimized by reducing the modulus and the cross section (i.e, increasing the taper angle). Finally, the stem length must be minimized with assurance that bone stock is adequate for stability. These proposed changes to the design were however never made. Tanner et al (28) did finite element and mechanical tests of different stem lengths and found that the longer the stem the lower the interface contact stress levels were under the proximal femoral neck. His results indicate that the use of a stem is important to resist varus/ valgus stress, but it should be as short as possible and with a flexibility as close to that of the femur as possible to decrease the compressive stresses to the lateral femoral cortex. 


\section{REFERENCES}

1 Mallory TH, Mitchell MB. (1990)

Results of total hip replacement using porous coating as a fixation mode. Semin Arthroplasty 1(1):70-6.

2 Emerson RH, Head WC, Peters PC. (1991) Comparison of the early healing course of porous titanium with hydroxy apatite-coated porous titanium hip implants: clinical considerations for the use of hydro-xyapatite coating in total hip replacement. Semin Arthroplasty 2 (4):295-301.

3 Head WC, Bauk DJ, Emerson RH. (1995) Titanium as the material of choice for cementless femoral components in total hip arthroplasty. Clin Orthop 311:85-90.

4 Mallory TH. (1996) Porous-coated fixation: the experience. Orthopedics 19(9): 736-8.

5 Mallory TH, Head WC, Lombardi AV, Emerson RH, Eberle RW, Mitchell MB. (1996) Clinical and radiographic outcome of a cementless, titanium, plasma spraycoated total hip arthroplasty femoral component. Justification for continuance of use. J Arthroplasty 11(6):653-60.

6 Mulliken BD, Bourne RB, Rorabeck CH, Nayak N. (1996) A tapered titanium femoral stem inserted without cement in a total hip arthroplasty. Radiographic evaluation and stability. J Bone Joint Surg [Am] 78(8):1214-25.

7 Mulliken BD, Bourne RB, Rorabeck CH, Nayak N. (1996) Results of the cementless Mallory-Head primary total hip arthroplasty: a 5 to 7 year review. Iowa Orthop J 16:20-34.

8 Mulliken BD, Rorabeck CH, Bourne RB. (1996) Uncemented revision total hip arthroplasty: a 4-to-6-year review. Clin Orthop 325:156-62.

9 Mulliken BD, Nayak N, Bourne RB, Rorabeck CH, Bullas R. (1996) Early radiographic results comparing cemented and cementless total hip arthroplasty. J Arthroplasty 11(1):24-33.
10 Mallory TH, Head WC, Lombardi AV. (1997) Tapered design for the cementless total hip arthroplasty femoral component. Clin Orthop 344:172-8.

11 Bourne RB, Rorabeck CH, Patterson JJ, Guerin J. (2001) Tapered titanium cementless total hip replacements. A 10- to 13-year follow up study. Clin Orthop 393:112-20.

12 Dowdy PA, Rorabeck CH, Bourne RB. (1997) Uncemented total hip arthroplasty in patients 50 years of age or younger. J Arthroplasty 12(8):853-62.

13 Bourne RB, Rorabeck CH. (1998) A critical look at cementless stems. Clin Orthop 365:212-23.

14 Emerson RH, Sanders SB, Head WC, Higgins L. (1999) Effect of circumferntial plasma-spray porous coating on the rate of femoral osteolysis after total hip arthro-plasty. J Bone Joint Surg [Am] 81(9):1291-8.

15 Emerson RH, Head WC, Emerson CB, Rosenfelt W, Higgins LL. (2002)

A comparison of cemented and cementless components used for primary total hip arthroplasty. J Arthroplasty 17(5): 584-91

16 Mallory TH, Lombardi AV, Leith JR, Fujita H, Hartman JF, Capps SG, Kefauver CA, Adams JB, Vorys GC. (2001) Minimal 10-year results of a tapered cementless femoral component in total hip arthroplasty. J Arthroplasty 16(8) suppl 1:49-54.

17 Vaughn BK, Lombardi AV, Mallory TH. (1991) Clinical and radiographic experience with a hydroxyapatite-coated titanium plasma-sprayed porous implant. Semin Arthroplasty 2(4):309-16.

18 Vaughn BK, Lombardi AV, Mallory TH. (1992) Clinical and radiographic experience with a hydroxyapatite-coated titanium plasma-sprayed porous implant. Dent Clin North Am 36(1):263-72.

19 Bourne RB, Rorabeck CH, Burkart 
BC, Kirk PG. (1994) Ingrowth surfaces. Plasma spray coating to titanium alloy hip replacements. Clin Orthop 298:37-46.

20 Burkart BC, Bourne RB, Rorabeck CH, Kirk PG. (1993) Thigh pain in cementless total hip arthroplasty. A comparison of two systems at 2 years' follow-up. Orthop Clin North Am 24(4):645-53.

21 Head WC, Mallory TH, Emerson RH, Jr. (1999) The proximal porous coating alternative for primary total hip arthroplasty. Orthopedics 22(9):813-5.

22 Mallory TH, Lombardi AV, Leith JR, Fujita H, Hartman JF, Capps SG, Kefauver CA, Adams JB, Vorys GC. (2002) Why a taper? J Bone Joint Surg [Am] 84;suppl 2:81-9.

23 Park MS, Choi BW, Kim SJ, Park JH. (2003) Plasma spray-coated Ti femoral component for cementless total hip arthroplasty. J Arthroplasty 18(5):626-630.

24 Tanzer M, Maloney WJ, Jasty M, Harris WH. (1992) The progression of femoral cortical osteolysis in association with total hip arthroplasty without cement. J Bone Joint Surg [Am] 74(3):404-10.

25 Tanzer M, Kantor S, Rosenthall L, Bobyn JD. (2001) Femoral remodeling after porous-coated total hip arthroplasty with and without hydroxyapatite-tricalcium phosphate coating: a prospective randomized trial. J Arthroplasty 16(5):552-8.

26 Whiteside LA, White SE, Engh CA, Head WC. (1993) Mechanical evaluation of cadaver retrieval specimens of cementless bone-ingrown total hip arthroplasty femoral components. J Arthroplasty 8(2):147-55.

27 Camino TS. (1993) Design optimization of the Mallory-Head prosthesis using the finite element method. Master of Science dissertation, Ohio State University, Columbus, Ohio.

28 Tanner KE, Yettram AL, Loeffler M, Goodier WD, Freeman MAR, Bonfield W. (1995) Is stem length important in uncemented endoprostheses? Med Eng Phys 17(4):291-296. 


\section{CHAPTER}

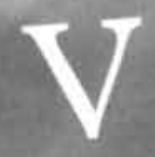

MALLORY-HEAD FEMORAL PROSTHESIS

\section{Primary THA WITH THE}


PRIMARY THA WITH THE MALLORY-HEAD FEMORAL PROSTHESIS 


\section{Primary THA with The Mallory-Head FEMORAL PROSTHESIS}

Cementless Mallory-Head HA-CoATed femoral PROSTHESIS IN PRIMARY TOTAL HIP ARTHROPLASTY.

Clinical AND RADIOLOGIC RESUlts OF A FOUR TO NINE YEARS PROSPECTIVE STUDY.

T. Gosens

E.J. van Langelaan 
PRIMARY THA WITH THE MALLORY-HEAD FEMORAL PROSTHESIS 


\section{Abstract}

We prospectively studied 152 hips in 126 patients with a proximally porous and hydroxyapatite coated double tapered straight femoral prosthesis. The follow up period was 4.2 to 9.6 years. All but two prostheses showed osseointegration. The mean Harris Hip Score increased from 40 to 92 points and $97 \%$ of the patients had no or only mild pain. Limping and the use of walking aids decreased substantially after the operation. The morphology of positive bone remodeling with either endosteal bone formation or periosteal bone formation was correlated with the stem fit in the medullary canal $(p=0.0001)$. Negative bone remodeling features could not be demonstrated. There was no correlation between the clinical parameters and the radiologic phenomena.

Keywords:

hip - primary - cementless - remodeling - clinical result - radiologic result 


\section{INTRODUCTION}

Tanzer et al. (1) and Harris (2) claim that cementless femoral stems may present a pathway for polyethylene particles to permeate distally and cause osteolysis, because they lack the defense that cemented stems have. Hydroxyapatite (HA) coatings have been shown to provide a secure and reliable bond between prosthesis and bone even under loaded conditions over long periods of time, without the formation of an intermediate layer of fibrous tissue over long periods of time (3-11). Also evidence has been shown that a HA-coated femoral stem may prevent peri implant particle migration (1217) and has superior potential in sealing the proximal femur over the use of cement (18). Clinical results with HA-coated prostheses have shown reliable osseointegration with neglegible midthigh pain (19-21). The long term success of most prostheses is closely related to the distribution of stress transfer, which mainly depends on prosthetic design and bonding characteristics $(22,23)$. Predominance of stress transfer more distally in the femur caused by a tight diaphyseal fit leads to an infavorable stem-to-bone stiffness ratio, which is thought to be a reason for a higher incidence of thigh pain (22-26) and leads to augmented proximal stress shielding-induced bone resorption, which may start a failure scenario (27).

This prospective study presents the clinical and radiographic results after a mean follow up of 6.4 years of 152 consecutive primary total hip arthroplasties (THA) with the cementless Mallory-Head HA-coated femoral prosthesis (Biomet, Warsaw, Indiana, USA). Primarily, our goal is to describe the clinical and radiographic features of osseointegration and stress shielding. Secondly, we tried to confirm the hypothesis that a proximal circumferential HA-coating prevents distal bone resorption by wear debris. Finally, we also report the statistical correlations between various radiologic phenomena and clinical parameters.

\section{Patients AND Methods}

\section{GEOMETRY OF THE PROSTHESIS}

Proximal loading of the femur to recreate near-normal bone stresses is the primary goal of the Mallory-Head porous femoral stem. This concept has proven to deliver excellent clinical results since its conception in 1984 (28-31). The proximal geometry of the stem is designed to promote filling of the metaphysis and proximal off-loading. It has a double three degree taper that allows the prosthesis to achieve three point fixation for immediate stem stability, and contributes to the reported low incidence of thigh pain and stress shielding with this implant (29). The Mallory-Head porous stem is a straight stem given the fact that there are so many variables within the femur itself. The metal of choice for the porous primary stem is titanium alloy (Ti-6Al-4V), chosen for its biocompatibility and elasticity. A titanium closed-pore, circumferential plasma sprayed porous coating on the proximal third of the stem designed to lock in the femoral implant and create a seal to particulate debris migration may help to reduce osteolysis and improve long-term fixation $(1,28,32)$. It has a surface roughness $(\mathrm{Ra})$ of 21 microns, a thickness of 635 to 889 microns and a porosity of $43.6 \%$. The middle third has a grit blasted finish. The distal third is smooth. Osteoinduction is stimulated by a HA-coating 
on the proximal third of the stem. The hydroxyapatite has a cristalline content of more than $98 \%$ with a cristallinity of $50 \%-70 \%$, a tensile adhesion of more than $15 \mathrm{MPa}$ and a thickness of about $55 \mu \mathrm{m} \pm 15 \mu \mathrm{m}$ and is applied by plasma spraying in vacuum. The Mallory-Head porous prostheses are proportionally sized, ranging from 6 to $19 \mathrm{~mm}$ in width and from 135 to $180 \mathrm{~mm}$ in length with a neck angle of 135 degrees.

\section{PATIENT AND IMPLANT CHARACTERISTICS}

Between 1991 and 1997152 primaryTHA's in 126 patients, 87 right and 65 left were performed. We operated 65 male and 87 female hips, 26 patients had bilateral surgery. The Mallory-Head stem was primarily combined with the HG cup (Zimmer, Warsaw, Indiana, USA) and a $\mathrm{CoCr}$ head $(\mathrm{n}=102)$, later on with the Ringlock cup (Biomet, Warsaw, Indiana, USA) and a ceramic head $(n=49)$. A $32 \mathrm{~mm}$. head in combination with a HG cup was used in the first twelve cases, later on we only used $28 \mathrm{~mm}$. heads. The mean age at surgery was 55.7 years (range: $20-68$ years). The diagnosis at surgery is summarized in rable 1 . In 28 patients a total of 44 previous procedures were performed.

\section{Table 1}

\section{Diagnosis at surgery}

$\begin{array}{lr}\text { Primary osteoarthritis } & 68 \\
\text { Secondary osteoarthritis } & 84 \\
\text { - rheumatoid arthritis } & 1 \\
\text { - congenital hip disease } & 63 \\
\text { - femoral head necrosis after fracture } & 8 \\
\text { - protrusio acetabuli } & 5 \\
\text { - M. Legg-Calve-Perthes } & 2 \\
\text { - acetabular fracture } & 3 \\
\text { - synovitis villonodularis pigmentosa } & 2\end{array}$

\section{SURGICAL TECHNIQUE}

All patients were operated by the senior author (EJvL) by a straight lateral approach. Routine postoperative management included 24 hours of antibiotic prophylaxis and peri- and postoperative anticoagulation. To inhibit distal stem contact we routinely performed distal overreaming of at least one $\mathrm{mm}$. with flexible reamers over a guiding rod. After inserting the prosthesis optimal prosthesis-bone contact (metaphyseal fit) was mostly the case. Where this was not the case, the femoral seal was created in combination with the HA-coating by impacting morselized autologous bone chips into the remaining space. Postoperatively protected weight bearing with crutches was used for six weeks.

\section{Patient assessments}

All patients were included in a prospective follow up schedule and were evaluated preoperatively, and postoperatively at three, six and 12 months and yearly thereafter 
using the Harris Hip Score (33) and specific questions about functional items such as pain, limping and use of walking aids.

\section{RADIOGRAPHIC ASSESSMENTS}

The preoperative radiographs were judged for osteoporosis grading and femoral morphometrics. The modified Singh trabecular index (34) showed severe osteoporosis in $4.6 \%$, moderate osteoporosis in $25.2 \%$ and normal bone quality in $70.2 \%$ of all cases. Femoral morphometrics were judged to be champagne flute in $14.6 \%$, normal in $77.5 \%$ and stove pipe in $7.9 \%$ of all cases (35).

During each follow up visit, an anteroposterior and lateral radiograph was taken of the involved hip. These were evaluated using Gruen zones (36) for signs of bone resorption, subsidence, osteolysis, interface deterioration, cyst formation, radiolucencies, reactive line formation around the HA-coated and the non-coated parts of the femoral prosthesis, cancellous and cortical bone densifications, cortical hypertrophy, tip sclerosis and pedestal formation around the stem tip. HA covered the stem in Gruen zones 1 and 7 and the proximal part of zones 2 and 6 . All bony changes were estimated by the eye by an observer who was not the surgeon (TG). Resorption of bone was not quantified but graded as present, when loss of trabecular bone density, corticocancellization, or cortical thinning was noted. Cortical hypertrophy (cortical thickening) was recorded when there was an increase in the outside diameter of the cortex at the maximal point of hypertrophy. Reactive line formation was defined as a thin radiopaque layer of bone seen parallel and in close proximity to the implant. Between this line and the implant, a radiolucent line was always present. To be recorded, this line had to extend at least $50 \%$ of the zone length. Radiolucency was defined as a radiolucent zone anywhere around the implant with no relation to any radiopacity. A radiolucent line was recorded when it was at least two mm. in width and at least $30 \%$ of any one zone. Osteolysis was defined as a scalloped erosion of more than two $\mathrm{mm}$. in diameter at the bone-prosthesis interface. Femoral cancellous bone densification (spotwelding) was defined as an augmentation in bone mineral content anywhere between the implant and the femoral cortex; cortical bone densification was defined as an augmentation in bone mineral content in the femoral cortex itself. Likewise the position of the implant after surgery was assessed: the stem was assessed as in varus or in valgus when it measured more than two degrees from the neutral. The stem was defined as completely filling the diaphysis when on the AP radiograph the diameter of the stem divided by the distance between the inner cortices at the transition of zone 2 to 3 and zone 5 to 6 was larger than 0.8 . The stem was defined as having fixation by bone ongrowth (osseointegration) when there was no subsidence or migration and no formation of a radiolucent or radiodense line along the HAcoated portion of the prosthesis. The presence of spotwelding also suggests bone ongrowth.

The acetabular bone-prosthesis transition was evaluated using the criteria of DeLee and Charnley (37). We especially recorded asymmetry of the head in the liner suggesting PE-wear and tried to correlate this with femoral and acetabular osteolysis.

\section{Statistical anAlysis}

After a mean follow up of $6.4(4.2$ - 9.6) years a clinical and radiologic evaluation was performed. Statistical analysis of the results was performed and the influences of clini- 
cal and radiographic variables were studied using the chi-square tests, the one-way ANOVA test or ordinal logical regression testing, depending on group characteristics. Statistical significance was set at $\mathrm{p}<0.05$. Survival was calculated using stem revision or stem revision pending because of aseptic loosening as the definition of failure. Wilson quadratic $95 \%$ confidence intervals were calculated using the method described by Rothman. (38)

\section{RESUlts}

Five patients (seven hips) died during this ongoing study after they had completed a follow up of one, two, three, four, five (two patients) and seven years respectively: all died of causes not related to the arthroplasty and had shown radiographic osseointegration of the prosthesis and had no complaints at the last follow up before they died. No permission was obtained for a retrieval study.

\section{Complications}

In the immediate postoperative period three patients developed a wound hematoma and six patients had a prolonged wound drainage. None of these patients were reoperated. In one patient with congenital hip dysplasia and epiphysary dwarfism the leg was lengthened with five $\mathrm{cm}$. An ischiadic nerve palsy was found postoperatively, which resolved spontaneously within three months. Dislocations were seen before discharge in three hips and could be solved with closed reduction. Two hips progressed however to recurrent dislocations and were managed by acetabular revision. Once we saw a peroperative femoral fracture that was treated by bed rest during six weeks. One patient sustained a subprosthetic femoral fracture four years after the operation and was managed surgically. One male patient developed PAO, Brooker grade IV, (39) despite prophylactic treatment with indomethacine. An arthrolysis was performed. Failure of osseointegration of the stem (radiolucent line formation in all zones) was seen in two patients.

\section{IMPLANT REVISION}

Acetabular revision for instability was performed in two patients as mentioned above. We exchanged two liners for augmented PE wear without loosening of the HG cup after four and six years respectively and three patients required acetabular revision for augmented PE wear with acetabular cyst formation after eight, eight and nine years respectively. One patient is waiting for acetabular revision for aseptic loosening at this moment. In all cases no signs of femoral osteolysis were seen. (figure 1)

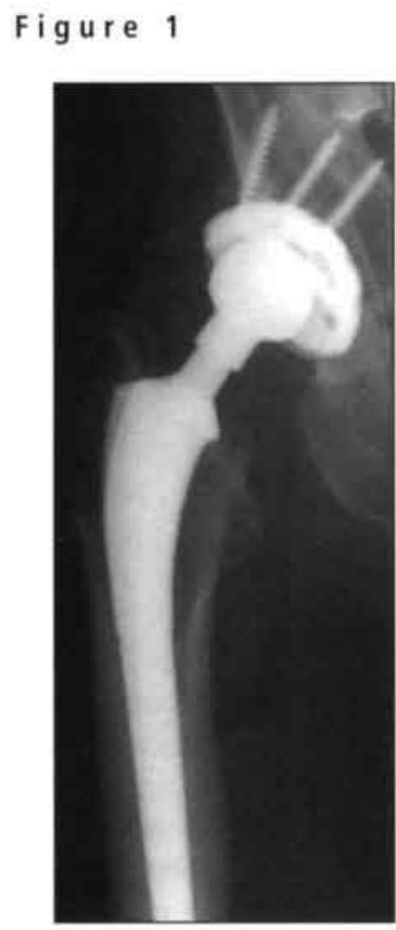

No signs of femoral osteolysis despite massive PE wear, suggesting a tight prosthesis-bone contact. 
Stem revision was performed in two patients. In a 54-year old female patient with failed osteosynthesis after a subcapital femoral head fracture leading to avascular femoral head necrosis and a disuse osteoporosis grade III according to Singh (34) osseointegration of the stem failed to occur. After two years the femoral prosthesis was removed and a cemented stem was inserted. The other stem revision was in a male patient with osteoarthritis of the hip joint who sustained an ipsilateral subtrochanteric fracture of the femur. We tried to treat the fracture and the arthritis in one session using the primary HA-coated stem and bed rest during six weeks. However a pseudarthrosis developed and the stem failed to incorporate and after two years we revised the femur using a calcar replacement stem. No stem revisions were performed after the second year of follow up or were pending at the last follow up.

\section{Clinical Results}

The mean preoperative Harris Hip Score was $40(16$ - 48) points. The Harris Hip Score at the latest follow up was $92(10-100)$. Pain, limping and the use of walking aids decreased in comparison to preoperative values. (таble 2) There was a low incidence in thigh pain at the latest follow up when asked specifically: $3.2 \%$, although in the first and second year of follow up this percentage was higher: $5.8 \%$.

\section{Table 2}

Distribution of pain, limping and the use of walking aids.

[Values at final follow up (before the operation)]

\begin{tabular}{|lll|ll|lll|}
\hline Pain & & Limping & & Walking aids & \\
\hline No & $75 \%$ & $(0 \%)$ & No & $69 \%$ & $(0 \%)$ & No & $73 \%(35 \%)$ \\
Very mild & $18 \%$ & $(0 \%)$ & Some times & $15 \%$ & $(0 \%)$ & Some times & $14 \%(15 \%)$ \\
Mild & $4 \%$ & $(2 \%)$ & At long walks & $5 \%$ & $(2 \%)$ & At long walks & $6 \%(35 \%)$ \\
Moderate & $2 \%$ & $(30 \%)$ & Most times & $4 \%$ & $(30 \%)$ & Most times & $4 \%(10 \%)$ \\
Severe & $1 \%$ & $(68 \%)$ & Always & $7 \%$ & $(68 \%)$ & Always & $3 \%(5 \%)$ \\
\hline
\end{tabular}

\section{RADIOLOGIC RESULTS}

Acetabulum. Except for the patients mentioned before with aseptic loosening of the HG cup due to excessive PE-wear, analysis of the acetabular bone showed no progressive radiolucent line formation and all prostheses showed osseointegration. Thirteen acetabular inserts (twelve $32 \mathrm{~mm}$. and one $28 \mathrm{~mm}$.) showed asymmetry, suggesting PEwear, progressing from six years of follow up and onward. Especially the first twelve cases in which we used $32 \mathrm{~mm}$. heads showed earlier and more asymmetry of the liner than the cases in which we used $28 \mathrm{~mm}$. heads. This resulted in one liner breakage necessitating exchange after six years and one other liner exchange and three complete acetabular revisions and one patient awaiting acetabular revision. The remaining patients with liner asymmetry are monitored closely.

Femur. The femoral stem position was within two degrees varus or valgus in all patients. We could not detect stem migration or subsidence in the first three months 
postoperatively, neither in further follow up. Structural changes of the femoral bone became apparent between three and six months (Table 3.4 and 5), starting with the formation of densifications of the cancellous bone.

Table 3

Radiologic phenomena of bone remodeling in time: cancellous densifications [percentage (number of hips)]

\begin{tabular}{|l|llllllll|}
\hline & Gruen zones & $\mathbf{1}$ & $\mathbf{2}$ & $\mathbf{3}$ & $\mathbf{4}$ & $\mathbf{5}$ & $\mathbf{6}$ & $\mathbf{7}$ \\
\hline Follow up & no of hips & & & & & & & \\
6 months & 152 & 0 & $19.7(30)$ & 0 & 0 & 0 & $21.1(32)$ & 0 \\
1 year & 152 & 0 & $29.6(45)$ & 0 & 0 & 0 & $30.2(46)$ & 0 \\
2 years & 151 & 0 & $29.1(44)$ & $2.0(3)$ & 0 & $3.2(5)$ & $32.4(49)$ & 0 \\
3 years & 148 & 0 & $31.0(46)$ & $4.1(6)$ & 0 & $4.1(6)$ & $35.1(52)$ & 0 \\
4 years & 147 & 0 & $30.6(45)$ & $4.1(6)$ & 0 & $4.1(6)$ & $34.7(51)$ & 0 \\
5 years & 133 & 0 & $30.1(40)$ & $4.5(5)$ & 0 & $4.5(6)$ & $36.8(49)$ & 0 \\
6 years & 96 & 0 & $31.3(30)$ & $5.2(5)$ & 0 & $5.2(5)$ & $36.5(35)$ & 0 \\
7 years & 67 & 0 & $31.3(21)$ & $6.0(4)$ & 0 & $7.5(5)$ & $37.3(25)$ & 0 \\
8 years & 33 & 0 & $36.1(13)$ & $8.3(3)$ & 0 & $8.3(3)$ & $38.8(14)$ & 0 \\
9 years & 15 & 0 & $46.7(7)$ & $20.0(3)$ & 0 & $13.3(2)$ & $40.0(6)$ & 0 \\
\hline
\end{tabular}

Table 4

Radiologic phenomena of bone remodeling in time: cortical thickening [percentage (number of hips)]

\begin{tabular}{|l|lllccccc|}
\hline & Gruen zones & $\mathbf{1}$ & $\mathbf{2}$ & $\mathbf{3}$ & $\mathbf{4}$ & $\mathbf{5}$ & $\mathbf{6}$ & $\mathbf{7}$ \\
\hline Follow up & no of hips & & & & & & & \\
$\mathbf{6}$ months & 152 & 0 & 0 & $25.0(38)$ & 0 & $32.2(49)$ & 0 & 0 \\
$\mathbf{1}$ year & 152 & 0 & 0 & $32.8(50)$ & 0 & $35.5(34)$ & 0 & 0 \\
$\mathbf{2}$ years & 151 & 0 & $1.3(2)$ & $35.1(53)$ & 0 & $37.7(57)$ & $1.9(3)$ & 0 \\
3 years & 148 & 0 & $1.4(2)$ & $35.1(52)$ & $2.0(3)$ & $39.2(58)$ & $2.7(4)$ & 0 \\
4 years & 147 & 0 & $2.7(4)$ & $35.1(52)$ & $2.0(3)$ & $40.8(60)$ & $3.4(5)$ & 0 \\
5 years & 133 & 0 & $3.8(5)$ & $35.3(47)$ & $2.2(3)$ & $46.6(60)$ & $4.5(6)$ & 0 \\
6 years & 96 & 0 & $5.2(5)$ & $43.7(42)$ & $2.1(2)$ & $52.0(50)$ & $6.3(6)$ & 0 \\
7 years & 67 & 0 & $5.9(4)$ & $50.7(34)$ & $3.0(2)$ & $53.7(36)$ & $7.5(5)$ & 0 \\
8 years & 33 & 0 & $5.6(2)$ & $52.7(19)$ & $2.8(1)$ & $55.6(20)$ & $8.3(3)$ & 0 \\
9 years & 15 & 0 & $13.3(2)$ & $53.3(8)$ & $6.6(1)$ & $46.7(7)$ & $13.3(2)$ & 0 \\
\hline
\end{tabular}

At the same time calcar rounding became visible, which remained stable after two years. We saw this as maturation of the osteotomy site and not as negative bone remodeling. Densifications of cancellous bone were seen along the femoral stem at the point of transition between the coated and non-coated parts of the stem in Gruen zones 2 and 6, from three months and onwards. These bone densifications were progressive in fre- 
Table 5

Radiologic phenomena of bone remodeling in time: reactive line formation [percentage (number of hips)]

\begin{tabular}{|l|lllccccc|}
\hline & Gruen zones & $\mathbf{1}$ & $\mathbf{2}$ & $\mathbf{3}$ & $\mathbf{4}$ & $\mathbf{5}$ & $\mathbf{6}$ & $\mathbf{7}$ \\
\hline Follow up & no of hips & & & & & & & \\
6 months & 152 & 0 & 0 & 0 & 0 & 0 & 0 & 0 \\
$\mathbf{1}$ year & 152 & 0 & 0 & 0 & $8.6(13)$ & 0 & 0 & 0 \\
2 years & 151 & 0 & 0 & $4.0(6)$ & $10.6(16)$ & $3.3(5)$ & 0 & 0 \\
3 years & 148 & 0 & 0 & $8.8(13)$ & $20.3(30)$ & $8.1(12)$ & 0 & 0 \\
4 years & 147 & 0 & 0 & $10.2(15)$ & $21.8(32)$ & $10.2(15)$ & 0 & 0 \\
5 years & 133 & 0 & 0 & $10.4(14)$ & $22.5(30)$ & $7.8(13)$ & 0 & 0 \\
6 years & 96 & 0 & 0 & $8.3(8)$ & $19.8(19)$ & $6.3(6)$ & 0 & 0 \\
7 years & 67 & 0 & 0 & $7.5(5)$ & $17.9(12)$ & $4.5(3)$ & 0 & 0 \\
8 years & 33 & 0 & 0 & $5.5(2)$ & $16.7(6)$ & $2.8(1)$ & 0 & 0 \\
9 years & 15 & 0 & 0 & $6.6(1)$ & $18.3(3)$ & 0 & 0 & 0 \\
& & & & & & & & \\
\hline
\end{tabular}

quency and, from two years onwards, the areas of bone apposition slowly expanded distally into the upper parts of Gruen zones 3 and 5. Endosteal reactive lines became visible on radiographs in Gruen zone 4 between six months and the first year postoperatively. The incidence increased until the fifth year after which a slight decline in frequency was seen due to expansion of the bone apposition from the more proximal zones. Resorption of bone was not observed, especially not in Gruen zones 1 and 7, and the same accounts for radiolucent line formation, except in the two previous mentioned stem failures, which had a line of more than two $\mathrm{mm}$. around the entire stem. Densification of cortical bone was observed in Gruen zones 2, 3, 5 and 6 from one year onwards and progressing distally in further follow up. The pattern of peripheral thickening of the femoral cortex followed that of cortical bone densification. Observed from the second postoperative year onwards it was also progressing distally like the densifications of the cortical bone, some times even reaching the region that previously showed a reactive line. These mostly symmetrical bone reactions were mainly seen in hips in which there was a tight fit of the stem in the femoral canal. When a relatively smaller size stem was used or when the femoral canal had a wider appearence, cortical thickening was hardly seen but cancellous densifications even more.

Periarticular ossifications were recorded using the Brooker grading system (39). At the time of review $8 \%$ hips had grade I ossifications, 3\% grade II, $0 \%$ grade III and $0 \%$ grade IV. One patient however had undergone arthrolysis before review for grade IV PAO.

\section{Statistical analysis}

Statistical analysis showed correlations between tight femoral canal fit and the existence of cortical hypertrophy and the non-existence of spot-welding. The correlation between the stem filling the medullary canal completely in the radiographs and symmetrical cortical thickening was significant $(p<0.001$ chi-square test). Vice versa: the correlation between the stem not filling the medullary canal completely and cancellous den- 
sifications (spot-welding) was also significant ( $\mathrm{p}<0.001$ chi-square test). Osteoporotic femora with a stovepipe appearance and a tight femoral canal fit showed an equal small percentage of cortical hypertrophy and spot-welding compared to normal femora with a tight fit. However the number of patients with a tight fit in an osteoporotic femur was too small to reach significance.

No correlations were found between the clinical parameters and the radiologic phenomena, especially the attempt to correlate the presence of thigh pain with cortical thickening or reactive line formation failed to demonstrate a correlation.

With two stem revisions in 152 hips replaced a survival percentage of $98.7 \%$ can be calculated after a follow up of 6.4 (range: 4.2 to 9.6 ) years. (Table 6 and figure 2)

Table 6

Life table for the femoral prosthesis

\begin{tabular}{|c|c|c|c|c|c|c|c|c|c|}
\hline Year & $\begin{array}{l}\text { Number of } \\
\text { prostheses } \\
\text { surviving } \\
\text { as a success }\end{array}$ & $\begin{array}{l}\text { Number of } \\
\text { hips with } \\
\text { drawn due } \\
\text { s to death }\end{array}$ & $\begin{array}{l}\text { Number of } \\
\text { hips with } \\
\text { drawn due } \\
\text { to failure }\end{array}$ & $\begin{array}{l}\text { Number } \\
\text { of } \\
\text { failures }\end{array}$ & $\begin{array}{l}\text { Number } \\
\text { at risk }\end{array}$ & $\begin{array}{l}\text { Failure } \\
\text { rate } \\
(\%)\end{array}$ & $\begin{array}{l}\text { Survival } \\
\text { rate } \\
(\%)\end{array}$ & $\begin{array}{l}\text { Cum. } \\
\text { Survival } \\
\text { rate }(\%)\end{array}$ & $\begin{array}{l}95 \% \\
\text { confidence } \\
\text { interval }(\%)\end{array}$ \\
\hline 1 & 152 & 0 & 1 & 0 & 151.5 & 0.0 & 100 & 100 & 2,5 \\
\hline 2 & 151 & 0 & 1 & 2 & 150.5 & 1.3 & 98.7 & 98.7 & 3,0 \\
\hline 3 & 148 & 0 & 1 & 0 & 147.5 & 0.0 & 100 & 98.7 & 3,1 \\
\hline 4 & 147 & 13 & 1 & 0 & 140 & 0.0 & 100 & 98.7 & 3,1 \\
\hline 5 & 133 & 35 & 2 & 0 & 114.5 & 0.0 & 100 & 98.7 & 3,1 \\
\hline 6 & 96 & 29 & 0 & 0 & 81.5 & 0.0 & 100 & 98.7 & 3,6 \\
\hline 7 & 67 & 33 & 1 & 0 & 50 & 0.0 & 100 & 98.7 & 4,2 \\
\hline 8 & 33 & 18 & 0 & 0 & 24 & 0.0 & 100 & 98.7 & 5,1 \\
\hline 9 & 15 & 15 & 0 & 0 & 7.5 & 0.0 & 100 & 98.7 & 6.4 \\
\hline
\end{tabular}

\section{Figure 2}

Cumulative survival percentage (\%)

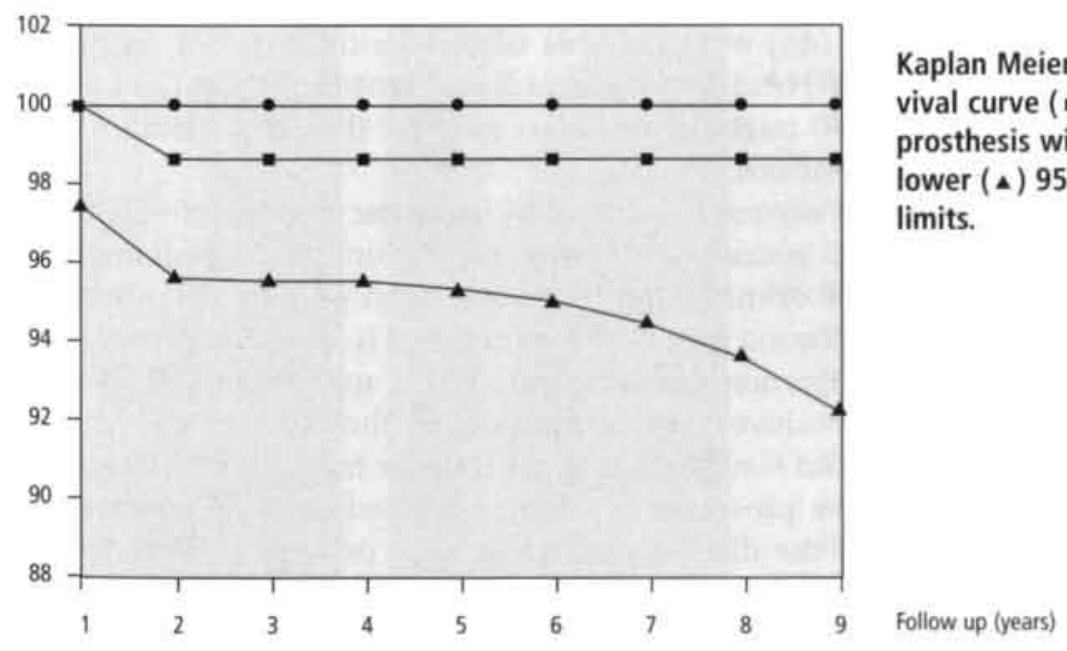


These figures represent the worst case scenario as no patient was lost to follow up. It also represents the mechanical failure rate since no stem was revised for other reasons than aseptic loosening and no patient has signs of radiographic loosening. The survival rate has remained the same $(98.7 \%)$ up to the 9 th year, but the confidence intervals have widened as the numbers at risk have decreased.

\section{Discussion}

The overall result after 6.4 years is excellent in this first European, prospective, noninventor related study. The pain relief, function and survival of the cementless HAcoated Mallory-Head femoral prosthesis can be compared with several other cementless prostheses $(14,16,19,20,40-45)$. The low frequency of thigh pain, seen in the first generation cementless stems, has been shown with the same prosthesis $(44,45)$, although in those series no HA-coating was used.

In the first two years of follow up the percentage of thigh pain was higher than in further follow up. This might be explained by a mismatch in stiffness between the femur and the prosthesis. In the two years following implantation a remodeling process of the femur will eradicate this mismatch. In this series however, no significant relation was found between thigh pain and radiologic remodeling.

The presence of 50 patients ( 63 hips) with congenital hip disease in this series shows that with this proximally relatively slim and straight prosthesis also dysplastic femora with hyperanteversion and narrow femoral canals can be treated (46). An extreme example is visible in figure 3a and 3b. Another example of inappropriate femoral morphometrics is a patient with a history of reconstruction of a subtrochanteric pseudarthrosis with allograft. After consolidation the hip was replaced and an uneventful osseointegration took place even without optimal metaphyseal contact. (figure 4a and 4b)

The use of a titanium plasma-sprayed HA-coated femoral prosthesis leads to a tight bondage between the metaphyseal bone and the prosthesis creating a barrier for PE debris migrating distally. That this seal in combination with the HA-coating is effective is shown by a patient with marked PE-wear without any sign of proximal or distal bone resorption. (figure 1) Yee et al. (46) were not able to show a difference in using a HAcoating or not on the Mallory-Head femoral prosthesis. However their (and our own) follow up length (4.4-4.9 years) might be too short to judge the extra effect of HA with respect to longevity of the prosthesis.

Although only $70.2 \%$ had a normal bone stock by using the modified Singh index this did not compromise clinical success and osseointegration: no correlation existed between an osteoporotic grade of the Singh index and thigh pain or the overall result, although in one severly osteoporotic patient the stem failed to osseointegrate.

The radiographic osseointegration is characterized by a specific pattern of remodeling in the proximal femur. Positive bone remodeling in the form of endosteal bone apposition in Gruen zones 2 and 6 suggests that the transfer from stem to femoral bone occurs in this area and that the prosthesis is securely bonded there. When transferring stresses from the proximal to the distal prosthesis, a slow process of bone resorption (negative bone remodeling) in the region of the lesser and greater trochanter should be expected. We could not detect any sign of femoral resorption or atrophy in our study which is explained by the fact that a substantial percentage of the bone mineral content has to be resorbed before it is visual on plain radiographs. On the other hand, numerous 
Figure 3

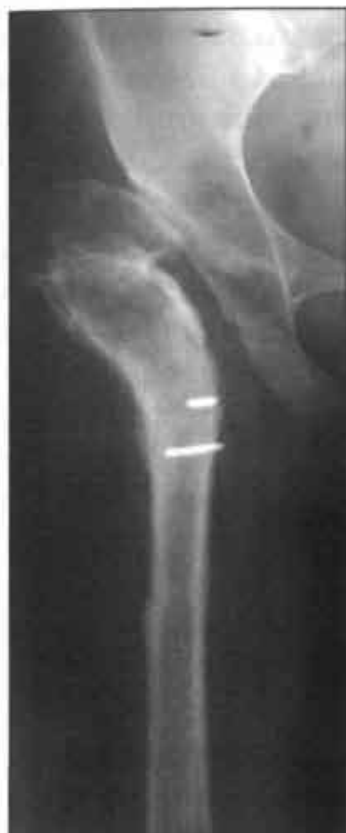

A

Figure 4

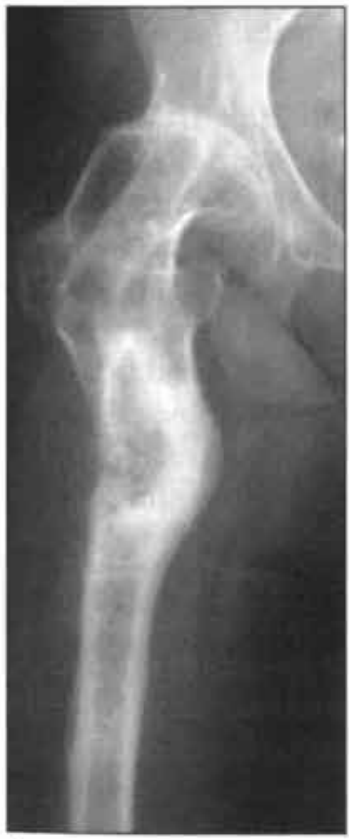

A

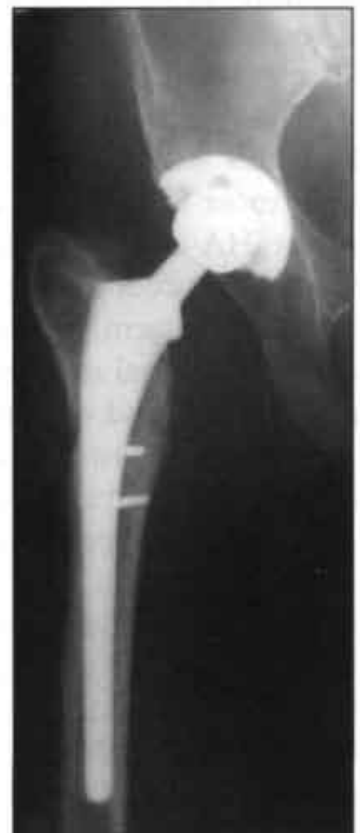

B

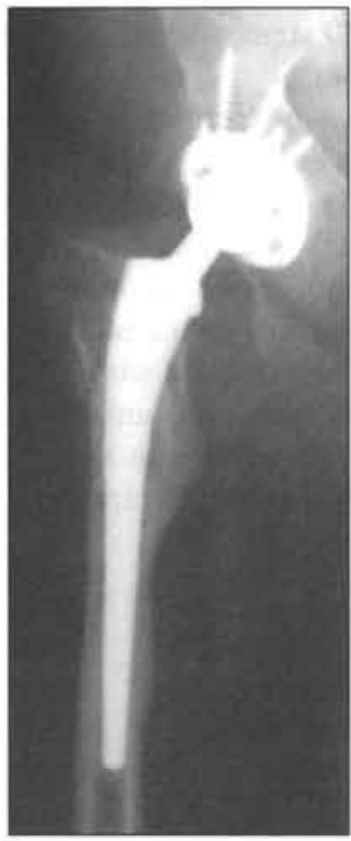

B

Example of inappropriate femoral morphometrics in a patient with a Schanz osteotomy performed thirty years ago with screw fragments in situ.

A - Preoperative radiograph.

B - Radiograph 5 years after THA where a combined vertical splitting osteotomy and transversal osteotomy were performed to obtain the desired metaphyseal contact. The gaps remaining after the osteotomies were filled with autogeneous bone graft from the femoral head.

Example of inappropriate morphometrics of the femur in a patient with a subtrochanteric fracture pseudarthrosis that was reconstructed with allograft five years before the index total hip replacement.

A - Preoperative radiograph showing the severely deformed femoral canal; the fixation material was removed before.

B - Postoperative radiograph showing the result after six years. A vertical splitting osteotomy was performed to adapt the metaphysis to the prosthesis. The remaining gaps were filled with autogeneous bone graft from the femoral head. 
series reported proximal bone resorption after this length of follow up $(14,19,20,44)$. A DEXA study providing more information about bone mineral density changes next to this prosthesis is in preparation. The formation of a reactive line around the distal part of the stem in Gruen zones 3, 4 and 5 is explained by the presence of a fibrous interface as a result of micromotion in this area. These three characteristic radiographic phenomena confirm the rational design behind this stem that osseointegration should occur mainly proximally. In fact, after 6.4 years most of the bone apposition occurs adjacent to that part of the femoral stem where the HA-coating ends, the so-called transitional zone. We would have expected the apposition to occur more proximally since the coating was present only on the proximal one third of the stem. Instead we found that the region in which the most prominent cancellous and cortical densifications were observed gradually shifted from proximally in Gruen zones 2 and 6 to more distally in these same zones. Formation of new bone in the area near the lower edge of HA-coatings was predicted by Huiskes et al. (22) using finite element analysis. The explanation was that particularly in this area endosteal stress concentrations are caused by the abrupt transition from a bonded to a loose interface.

The incidence of cortical thickening (35.8-40.2\%) and cortical densification, mainly symmetrically distributed around the stem in zones 3 and 5, is the same as reported in literature. D'Antonio et al. (19) observed $47 \%$ cortical thickening in Gruen zone 5 along with $63 \%$ calcar resorption after nearly 6 years with a proximally HA-coated stem. Geesink and Hoefnagels (20) using the same design of prosthesis as d'Antonio reported nearly the same figures. The phenomenon of cortical hypertrophy was also noted with non-cemented, non-HA-coated stems: Mulliken et al. (44) reported distal cortical hypertrophy in $35 \%$ and $38 \%$ proximal bone loss of their patients. Tonino et al. (14) however reported a cortical thickening rate of only $3 \%$ to $5 \%$ with a $27 \%$ calcar resorption. He advised, in contrast to most other authors, not to obtain a complete fill of the diaphysis. In his study he used the ABG stem, which has an anatomical stem design with a short stem.

This paper statistically proves that the concept of transitional load transfer from proximal to distal can morphologically be predicted by the way the stem fills the medullary canal. Whiteside (48), in his study on the effect of stem fit on bone hypertrophy, observed that a tight fit is associated with distal cortical hypertrophy, while a loose fit did not and caused more pain. We could not prove the relation between stem fit and pain, but we could prove the relation between femoral canal fit and the radiologic remodeling pattern. In theory proximal bone loss is correlated with a tight femoral canal fit and therefore we advise to overream the diaphysis and aim for perfect metaphyseal fit. One should not try to use a smaller prosthesis and skip the process of overreaming of the femoral canal, because there will be no perfect metaphyseal press fit and the prosthesis will subside to obtain a good fixation.

\section{Conclusions}

Our results confirm that fixation by means of osseointegration of a proximally HAcoated hip prosthesis is very reliable irrespective of factors such as age, sex, weight, activity or quality of bone stock and diagnosis. Secondly, we found that the morphology of the positive bone remodeling around the stem, with either endosteal bone formation or periosteal bone formation, was dependent on the way the stem filled the medullary 
canal. The radiologic phenomena are in our opinion not prosthesis-dependent but femoral canal fit dependent. We showed that in a less tightly fitted prosthesis spotwelding is in essence the endosteal equivalent of cortical hypertrophy. 


\section{REFERENCES}

1 Tanzer M, Maloney WJ, Jasty $\mathbf{M}$, Harris WH. (1992) The progression of femoral cortical osteolysis in association with total hip arthroplasty without cement. J Bone Joint Surg [Am] 74:404-410.

2 Harris WH. (1995) The problem is osteolysis. Clin Orthop 311:46-53.

3 Bauer TW, Geesink RGT, Zimmerman R, McMackon JT. (1991) Hydroxyapatite coated femoral stems. J Bone Joint Surg [Am] 74:1439-1452.

4 Donnelly WJ, Kobayashi A, Freeman MAR, Chin TW, Yeo H, West $M$,

Scott G. (1997) Radiological and survival comparison of four methods of fixation of a proximal femoral stem. J Bone Joint Surg [Br] 79:351-360.

5 Frayssinet P, Hardy D, Conte P, Delince P, Guilhem A, Bonel G. (1993) Histological analysis of the bone-prosthesis interface after implantation in humans of prostheses coated with hydroxy-apatite. J Orthop Surg 7:246-253.

6 Geesink RGT, Groot K, Klein CPAT. (1988) Bonding of bone to apatite coated implants. J Bone Joint Surg [Br] 70:17-22.

7 Hardy DCR, Frayssinet P, Guilhem A, Lafontaine MA, Delince PE. (1991)

Bonding of hydroxyapatite-coated femoral prostheses. Histopathology of specimens from four cases. J Bone Joint Surg [Br] 73:732-740.

8 Overgaard $\mathbf{S}$, Lind $\mathbf{M}$, Glerup $\mathbf{H}$, Grundvig S, Bunger C, Seballe K. (1995) Hydroxyapatite and fluorapatite coatings for fixation of weight loaded implants. Clin Orthop 336:286-296.

9 Søballe K, Hansen ES, BrockstedtRasmussen H, Bunger C. (1993) Hydroxyapatite coating converts fibrous tissue to bone around loaded implants. J Bone Joint Surg [Br] 75:270.

10 Tonino AJ, Therin M, Doyle C. (1999) Hydroxyapatite coated femoral stems: histology and histomorphometry around five components retrieved at autopsy. J Bone Joint Surg [Br] 81:148.

11 Søballe K, Hansen ES, BrockstedtRasmussen H, Hjortdal VE, Juhl GI, Pedersen CM, Hvid I, Bunger C. (1991) Gap healing enhanced by hydroxyapatite coating in dogs. Clin Orthop 272:300-7.

12 Rahbek O, Overgaard S, Søballe K, Bunger C. (1996) Hydroxyapatite coating might prevent peri-implant particle migration: a pilot study in dogs. Acta Orthop Scand 67(suppl 267):58-9.

13 Rahbek O, Overgaard S, Lind $\mathbf{M}$, Bendix I, Bunger C, Søballe K. (2001) Sealing effect of hydroxyapatite coating on peri-implant migration of particles. An experimental study in dogs. J Bone Joint Surg [Br] 83:441-447.

14 Tonino AJ, Rahmy AIA. (2000) The International ABG Study Group. The hydroxyapatite-ABG hip system. J Arthroplasty 11:534-542.

15 Kraemer WJ, Maistrelli GL, Fornasier V, Binnington A, Zhao JF. (1995) Migration of polyethylene wear debris in hip arthroplasties: a canine model. J Appl Biomater 6(4):225-230.

16 Hellman EJ, Capello WN, Feinberg JR. (1999) Omnifit cementless total hip arthroplasty. A 10 year average follow up. Clin Orthop 364:164-174.

17 Coathup MJ, Blunn GW, Flynn N, Williams C, Thomas NP. (2001)

A comparison of bone remodelling around hydroxyapatite-coated porous-coated and grit-blasted hip replacements retrieved at post-mortem. J Bone Joint Surg [Br] 83:118.

18 Kadoya Y, Kobayashi A, Ohashi H. (1998) Wear and osteolysis in total joint replacements. Acta Orthop Scand 278:1.

19 D'Antonio JA, Capello WN, Jaffe WL. (1992) Hydroxylapatite-coated hip implants: multicentre three year clinical 
and roentgenographic results. Clin Orthop 285: 102-115.

20 Geesink RGT, Hoefnagels NHM. (1995) Six-year results of hydroxyapatite-coated total hip replacement. J Bone Joint Surg [Br] 77:534-547.

21 Jaffe WL, Scott DF. (1993) Rationale and clinical application of hydroxyapatite coatings in press fit total hip arthroplasty. Semin Arthroplasty 3:159.

22 Huiskes R, Weinans H, Dalstra M. (1989) Adaptive bone remodelling and biomechanical design considerations. Orthopaedics 12:1255-1267.

23 Huiskes R. (1990) Various stress patterns of press-fit, ingrowth and cemented femoral stems. Clin Orthop 261:27.

${ }_{24}$ Skinner HB, Curlin FJ. (1990) Decreased pain with lower flexural rigidity of uncemented femoral prostheses.

Orthopaedics 13:1223.

25 Franks E, Mont MA, Maar DC. (1992) Thigh pain as related to bending rigidity of the femoral prosthesis and bone. Trans Orthop Res Soc 38:296-300.

26 Mont MA, Hungerford DS. (1997) Proximally coated ingrowth prostheses: a review. Clin Orthop 344:139.

27 Huiskes R. (1993) Failed innovation in total hip replacement: diagnosis and proposals for a cure. Acta Orthop Scand 64:699.

28 Head WC. (1993) Mallory-Head porous press-fit primary hip replacement.

Presented at the tenth annual international symposium: New Developments in Total Joint Reconstruction, Lake Tahoe, Nevada.

29 Burkart BC, Bourne RB, Rorabeck CH, Kirk PG. (1993) Thigh pain in cementless total hip arthroplasty. Orthop Clin North Am 24(4): 645-653.

30 Mallory TH, Head WC. (1988) A total hip replacement system: clinical experience and recommendations.

Contemp Orthop 17(4):21-28.

31 Mallory TH, Head WC. (1994) Two to seven year follow-up of 311 proximal one-third plasma spray coated, monolithic femoral components in total hip arthro- plasty. Presented at the AAOS, New Orleans, Louisiana.

32 Lemons JE. (1993) Moderator of the symposium: Porous coating methods: the pros and cons. Contemp Othop 27(3):363-368.

33 Harris WH. (1969) Traumatic arthritis of the hip after dislocation and acetabular fractures: treatment by mold arthroplasty. An end result study using a new method of result evaluation. J Bone Joint Surg [Am] 51:737.

34 Singh M, Nagrath AR, Maini PS. (1970) Changes in trabecular pattern of the upper end of the femur as an index of oste oporosis. J Bone Joint Surg [Am] 54:457-467.

35 Dorr LD, Takei GK, Conally JP. (1983) Total hip arthroplasties in patients less than forty five years old. J Bone Joint Surg [Am] 65:474.

36. Gruen TA, McNeice JM, Amstutz HC. (1979) Modes of failure of cemented stem type femoral components. A radiographic analysis of loosening. Clin Orthop 141:17-29.

37 DeLee JG, Charnley J. (1976)

Radiological demarcation of cemented soekets in total hip replacement. Clin Orthop 121:20- 32 .

38 Rothman KJ. (1978) Estimation of confidence limits for the cumulative propability of survival in life table analysis. J Chronic Dis 31:557-560.

39 Brooker AF, Bowerman JW, Robinson RA, Riley RHJR. (1973) Ectopic ossification following total hip replacement. Incidence and a metbod of classification. J Bone Joint Surg [Am] 55:1629-1632.

40 Ang KC, Das De S, Goh JCH, Low SL, Bose K. (1997) Periprosthetic bone remodelling after cementless total hip replacement. A prospective comparison of two different implant designs. J Bone Joint Surg [Br] 79:675-679.

41 Bourne RB, Rorabeck CH, Ghazal ME, Lee MH. (1994) Pain in the thigh following total hip replacement with a porous coated anatomic prosthesis for osteoarthrosis. J Bone Joint Surg [Am] 
76:1464-1470.

42 Engh CA, Bobyn JD, Glassman AH. (1987) Porous coated hip replacement.

The factors governing bone ingrowth, stress shielding and clincal results. J Bone Joint Surg [Br] 69:44-55.

43 Malchau H, Herberts P, Ahnfelt L. (1993) Prognosis of total hip replacement in Sweden. Acta Orthop Scand 64:497506.

44 Mulliken BD, Bourne RB, Rorabeck CH, Nayak N. (1996)

A tapered titanium femoral stem inserted without cement in a total hip arthroplasty. J Bone Joint Surg [Am] 78:1214- 1225.

45 Mallory TH, Mitchell MB. (1990) Results of total hip replacement using porous coating as a fixation mode. Sem Arthroplasty 1:70.

46 Gosens T, van Langelaan EJ, Tonino AJ. (2003) Cementless Mallory-Head HA-coated hip arthroplasty for osteoarhtritis in hip dysplasia. J Arthroplasty 18(4):401-410.

47 Yee AJM, Kreder HK, Bookman I, Davey JR. (1999) A randomised trial of hydroxyapatite coated prostheses in total hip arthroplasty. Clin Orthop 366:120.

48 Whiteside LA. (1989) The effect of stem fit on bone hypertrophy and pain relief in cementless total hip arthroplasty.

Clin Orthop 247:138-147. 
The Mallory-Head Femoral PROSTHESIS IN HIP DYSPLASIA 
ThE MALLORY-HEAD FEMORAL PROSTHESIS IN HIP DYSPLASIA 


\section{The MALlory-Head FeMoral PROSTHESIS IN HIP DYSPLASIA}

\section{Cementless Mallory-Head HA-CoATed PROSTHesis IN HIP DYSPLASIA}

\section{T. Gosens}

E.J. van Langelaan

A.J. Tonino 
The Mallory-Head fEMORAL PROSTHESIS IN hip dYSPLASIA 


\section{Abstract}

Sixty-three cementless Mallory-Head HA-coated femoral prostheses were used in primary total hip arthroplasty in fifty patients with osteoarthritic hips due to congenital hip dysplasia. Also the implanted cup was cementless ( $41 \mathrm{HG}$ and 22 Ringlock). The patients were followed for a mean period of 75.1 (range $44-110$ ) months. Clinical and radiologic analyses were performed. The Harris Hip Score increased from 42 to 90 points; $97 \%$ of the patients had no or only mild pain, while limping decreased from $90 \%$ to $20 \%$. Complications were marginal: no infections, one habitual dislocation, one peroperative fracture of the femur and one transient ischiadic nerve palsy. Two HG cups were revised for augmented PE-wear. Radiographically no subsidence of the prosthesis nor any bone atrophy of the proximal femur could be detected. No correlations were found between the radiologic phenomena and the clinical outcome, but the tightness of the fit of the prosthesis had a definitive influence on the radiographic bone remodeling pattern. The cementless Mallory-Head HA-coated femoral prosthesis shows excellent clinical and radiologic mid term results in osteoarthritic hip dysplasia patients. There was no need for the use of a specially designed dysplasia femoral prosthesis.

Keyzords:

hip - dysplasia - cementless - remodeling - clinical result - radiologic result 


\section{INTRODUCTION}

Total hip replacement for osteoarthrosis in hip dysplasia can provide technical problems while complications occur more often than in standard hip replacements. $(1,2,3,4)$ Attention is usually drawn to the restoration and grafting of the dysplastic acetabulum. However a dysplastic femur can also give considerable technical difficulties, especially when the proximal femur is markedly anteverted and the greater trochanter retroverted. In these cases the metaphysis and the proximal diaphysis are mostly straight, oval in cross-section, with the greatest diameter being in the sagittal plane. $(1,2)$ The medullary canal can be very narrow and previous osteotomies may have further distorted the anatomy, like in cases where a Schanz osteotomy has been performed to improve gait. For these reasons miniature stems have been designed. $(5,6)$

Most series describe cemented techniques $(1,2,3,4)$, but from 1990 onwards cementless techniques are also published. (7) Very few studies have been published from noninventor institutions about the Mallory-Head HA-coated femoral component. In this study this prosthesis was used because the stem is straight and proximally relatively slim which makes it very suitable for dysplastic femora. We present here the clinical and radiologic results with special emphasis on correlations between these measured parameters.

\section{Patients and methods}

The cementless Mallory-Head femoral component (Biomet, Warsaw, IN) is made of a titanium alloy ( $\mathrm{Ti}-6 \mathrm{Al}-4 \mathrm{~V})$ and coated with a plasma sprayed porous titanium coating (Higure 1) over its proximal one third. This closed-pore, circumferential porous coating is designed to lock in the femoral implant and create a seal to particulate debris migration may help to reduce osteolysis and improve long-term fixation $(8,9)$. It has a surface roughness $(\mathrm{Ra})$ of 21 microns, a thickness of 635 to 889 microns and a porosity of $43.6 \%$ (10). The middle third has a 30 microns grit blasted Interlok $\mathbb{R}$ finish (Biomet, Warsaw, Indiana) which allows ingrowth in the diaphysis. The distal third is smooth. Osteoinduction is stimulated by a HA-coating on the proximal third of the stem. The hydroxyapatite has a density of $95 \%$, a thickness of about $55 \mu \mathrm{m}$ and a cristallinity of $62 \%$ and is applied by plasma spraying in vacuum. Initial stability is provided by the proximal geometry of the prosthesis, a bi-planer taper of 3 degrees and a posterior and anterior flange, which is designed for metaphyseal filling. The Mallory-Head femoral stem is available in 14 diameters (6 to $19 \mathrm{~mm}$ ) and 10 lengths (135 to $180 \mathrm{~mm}$.), in which the diameters from $15 \mathrm{~mm}$. on have a length of $180 \mathrm{~mm}$.

The results of this femoral prosthesis were prospectively studied in sixty-three hips in fifty consecutive patients, twenty males and thirty females, with dysplastic hips and secondary osteoarthritis. Thirteen patients had bilateral Mallory-Head total hip replacement. Two patients (four hips) with spondylo epiphyseal dysplasia (dwarfism) were included. The indication for total hip arthroplasty was severe, disabling pain, marked functional impairment and radiological evidence of hip joint destruction. In $90 \%$ of them a limp was present and $16 \%$ regularly used a walking aid. The mean age was 52.7 (range: 20-68) years, sixteen patients (twenty hips) were younger than fifty years. We operated on thirty-one right and thirty-two left hips. At the time of operation the patients were subdivided in the categories according to Charnley (11): thirteen patients were 
classified as class A (unilateral hip disease), thirty six patients as class B (bilateral hip disease) and fourteen patients as class C (hip disease with comorbidity). All procedures were primary hip replacements performed by a direct lateral approach by EJvL between 1991 and 1997. Previous operations have been performed in eighteen patients: a Schanz osteotomy (1), derotation varisation osteotomy (11), acetabular shelf plasty (9), Salter or Chiari pelvic osteotomy (4) and tenotomy of the hip adductors (2). All patients were assessed by the researcher (TG).

After a mean period of follow up of 75.1 (range: 44-110) months a clinical and radiologic analysis was performed. All patients attended at the outdoor clinic visits at regular intervals. At these visits a Harris Hip Score was calculated (12). A modified and to Dutch conditions validated "Oxford Heup outcome score" was available from 1998 onwards and was added to this study. $(13,14)$ So there is only a postoperative modified "Oxford Heup Score", but there are pre- and postoperative Harris Hip Scores. This modified "Oxford Heup Score" includes a Visual Analogue Scale for pain, a question to determine the Charnley class of the patient, questions about the patients satisfaction with the operation and relieve of pain and restoration of range of motion by the operation and fourteen questions about functional aspects in daily life. Questions can be answered by choosing one out of five possibilities, where option 1 is a good result and option 5 is a bad result. The added scores of all categories result in the modified "Oxford Heup Score", which can range from fourteen points (optimal result) to seventy points (worst result). Also standardized radiographs of the standing pelvis were taken and compared with the immediate postoperative radiograph. The radiographs were analyzed by an independent researcher (TG).

\section{OPERATIVE TECHNIQUE}

The surgical approach used in all cases was a direct lateral anterior approach without a trochanteric osteotomy. The acetabulum was reamed until spongious bone appeared and the acetabular cup could be inserted press fit. The mean cup size was 56 (range 50-64) $\mathrm{mm}$. In forty-one cases a cementless HG acetabular cup (Zimmer, Warsaw, Indiana) was used, in twenty-two cases a cementless Ringlock cup (Biomet, Warsaw, Indiana).

The femoral canal was prepared by manual broaching and proximal reaming guided by preoperative planning. The intention of the surgeon when reaming the femoral canal was to obtain an overreaming of $1 \mathrm{~mm}$ to prevent distal bone prosthesis contact. The mean stem size was 12 (range 7-17). In two cases with a champagne flute femur we had to perform a longitudinal splitting osteotomy of the proximal femur to adjust the proxi- 
mal geometry of the femur to obtain optimal metaphyseal stem fit. No prophylactic cerclage was needed in these cases. In all patients the femur was sealed proximally by a spongiosaplasty of autologous bone from the femoral head. One hip (status after Schanz osteotomy) needed a cuneiform osteotomy of the proximal femur to optimize the fitting of the prosthesis. No other osteotomies of the femur to optimize fitting or to create shortening to facilitate reduction were necessary. A cobalt-chromium $28 \mathrm{~mm}$. head was used in the first thirty six cases while a ceramic $28 \mathrm{~mm}$. head was used in the other twenty two cases. With both heads a PE liner was used. In the first five cases we still used 32 $\mathrm{mm}$. cobalt-chrome heads. All patients received prophylactic antibiotics and anticoagulants. To prevent heterotopic ossifications NSAIDS were prescribed. Postoperatively patients were initially mobilized non-weight bearing for six weeks, but later on by direct progressive weight bearing.

\section{FEMORAL RADIOLOGY}

According to Dorr's classification of femoral morphometrics (15) most patients had a "champagn flute" type femur ( $n=42$ or $66.7 \%)$. A minority had a normal femur $(n=16$ or $25.4 \%$ ) and a few patients had a "stove pipe" type femur ( $\mathrm{n}=5$ or $7.9 \%$ ). Quality of bone stock was evaluated by grading the presence of osteoporosis of the proximal femur by the modified Singh index. (16) Five patients $(7.9 \%)$ suffered from mild osteoporosis, while the remainder had good bone quality. Tightness of femoral canal fit was measured on the AP-radiograph at the transition of zones 2 and 3 and 5 and 6 . When the diameter of the stem divided by the distance between the inner cortices at that level (femoral canal index) produced a number smaller than 0.8 , the stem was judged to be non-tightly fitted. Vice versa, a number larger than 0.8 indicated a tightly fitted stem. Femoral subsidence was analysed by measuring the distance between a fixed point at the prosthesis and the lesser trochanter on the most recent radiograph and comparing it with the same measurement on the immediate postoperative film. More sophisticated methods for measuring subsidence, like RSA, were not available. The presence of radiolucencies around the stem, cortical hypertrophy, endosteal densifications or reactive lines were analyzed using the Gruen zones as a reference for location. (17) The presence of heterotopic ossifications was classified using the system of Brooker. (18)

\section{Acetabular Radiology}

Acetabular dysplasia was classified using the system of Crowe. (1) Most patients had moderate acetabular dysplasia classified as I ( $n=30$ hips) or II ( $n=18$ hips), some were classified as III ( $n=14$ hips) and one patient as class IV ( $n=1$ hip). The acetabular bone around the cup was analysed for radiolucencies and radiodense lines according to the zones described by DeLee and Charnley. (19) Asymmetry of the head in the liner indicating PE-wear was searched for on consecutive radiographs.

\section{Statistical analysis}

The clinical results and radiologic phenomena were analyzed statistically using the twotailed Pearson correlation test (SPSS 10.0 for Windows). Statistical significance was set at $\mathrm{p}<0.01$. Survival was calculated using revision or impending revision of one of the components of the total hip arthroplasty because of aseptic loosening as the definition of failure. 


\section{RESULtS}

\section{Clinical analysis}

The mean duration of stay in the hospital was 22.7 (range 9-50) days. In the early 90 's a considerable period for rehabilitation was included in the hospital stay in contrary to the current practice. There were no infections but four other complications. One patient developed a recurrent dislocation which was solved by revision of the acetabular liner with a twenty degree elevated rim. One patient fell one week after the operation and sustained a fracture at the tip of the stem which was treated by plating. One peroperative fracture of the femur was treated conservatively. One temporary ischiadical nerve palsy after lengthening the leg nearly five $\mathrm{cm}$. resolved spontaneously within four months. The mean HHS rose from 42 preoperatively to 90 points at follow up. The modified "Oxford Heup Score" was completed by all patients. The results are summarized in table, The mean score was 20.9 points (range 14-48). All patients were satisfied with the operation, all reported an improvement in function after the operation and all reported a decrease in pain after the operation. No or only mild pain was reported by $97 \%$ of all patients. (categories 1,2 and 3 in rable 1 ) Limping was reported by $20 \%$ of all patients and $84 \%$ walked without crutches or cane. Preoperatively these rates were $90 \%$ and $86 \%$ respectively. Most patients using a cane after the operation $(16 \%)$ did so when walking longer than half an hour and those patients who used a cane before surgery, did so after surgery. Two patients did not use a walking aid anymore but two others (one patient with vascular claudicatio intermittens and another after a femoral fracture which healed with a leg shortening of two $\mathrm{cm}$.) started to use a walking aid after surgery. The Visual Analogue Scale for pain at follow up was 1.70 (range 0-7) $\mathrm{cm}$.

Table 1

Results of the modified "Oxford Heup Score" ( 1 is a good result and 5 is a bad result)

\begin{tabular}{|c|c|c|c|c|c|c|c|c|c|c|}
\hline $\begin{array}{l}\text { Results . } \\
\text { Questions V }\end{array}$ & $\begin{array}{r}1 \\
\text { hips }\end{array}$ & & $\begin{array}{r}2 \\
\text { hips }\end{array}$ & & $\begin{array}{r}3 \\
\text { hips }\end{array}$ & $\%$ & $\begin{array}{r}4 \\
\text { hips }\end{array}$ & & $\begin{array}{r}5 \\
\text { hips }\end{array}$ & \\
\hline Pain in/around the hip? & 41 & 65 & 11 & 18 & 9 & 14 & 2 & 3 & 0 & 0 \\
\hline Difficulty washing/drying whole body? & 46 & 73 & 10 & 16 & 5 & 8 & 2 & 3 & 0 & 0 \\
\hline Difficulty in using public transport? & 32 & 51 & 26 & 41 & 4 & 6 & 1 & 2 & 0 & 0 \\
\hline Able to put on socks? & 41 & 65 & 16 & 25 & 3 & 5 & 3 & 5 & 0 & 0 \\
\hline Able to perform daily shopping? & 48 & 76 & 11 & 18 & 4 & 6 & 0 & 0 & 0 & 0 \\
\hline How long walking before stopping? & 46 & 73 & 12 & 19 & 2 & 3 & 3 & 5 & 0 & 0 \\
\hline Able to climb stairs? & 43 & 68 & 16 & 25 & 3 & 5 & 1 & 2 & 0 & 0 \\
\hline Painful when getting up from a chair? & 48 & 76 & 14 & 22 & 1 & 2 & 0 & 0 & 0 & 0 \\
\hline Limping? & 40 & 63 & 13 & 22 & 4 & 6 & 1 & 2 & 5 & 8 \\
\hline Severe pain/cramps? & 51 & 81 & 7 & 11 & 4 & 6 & 1 & 2 & 0 & 0 \\
\hline Pain influence on daily life? & 41 & 65 & 15 & 24 & 3 & 5 & 4 & 6 & 0 & 0 \\
\hline Nightpain? & 50 & 79 & 7 & 11 & 3 & 5 & 1 & 2 & 2 & 3 \\
\hline Use of cutches or cane? & 41 & 65 & 8 & 13 & 6 & 10 & 4 & 6 & 4 & 6 \\
\hline Hindered in sexual activities? & 39 & 62 & 18 & 28 & 3 & 5 & 0 & 0 & 3 & 5 \\
\hline
\end{tabular}




\section{RADIOLOGIC ANALYSIS}

Varus or valgus malalignment of more than three degrees in either direction was not found, neither directly after the operation, nor at follow up. We also did not observe any subsidence of the femoral prosthesis. The femoral canal fit was found to be "tight" (a femoral canal index of more than 0.8$)$ in $63.5 \%(n=40)$ of the patients and "non-tight" (a femoral canal index of less than 0.8$)$ in $36.5 \%(n=23)$ of the patients.

Gruen zone analysis was performed. No progressive radiodense or radiolucent lines surrounding the prosthesis were observed. No proximal osteolysis or bone atrophy of the proximal femur (Gruen zones 1 and 7) was observed. Cortical hypertrophy was found in Gruen zones 3 and 5 in $46 \%$ but none was observed in Gruen zones 2 and 6 . This cortical hypertrophy ("ballooning") started to appear after six months to one year after surgery, did not disappear after longer follow up, but only augmented in frequency. (Figure 2) Endosteal spot-welds were only infrequently seen $(7.9 \%)$ in Gruen zones 3 and 5, while in Gruen zones 2 and 6 spot-welding was present in $28.6 \%$ of all cases. Reactive line formation in Gruen zone 4 was observed in $13 \%$ of all cases. No shedding of the titanium porous coating or stem breakage was noted nor was there any clinically relevant heterotopic ossification (Brooker III and IV was $0 \%$ ).

The acetabular bone surrounding the cup was assessed as described by DeLee and Charnley. (17) There were no progressive radiolucent or radiodense lines but in two

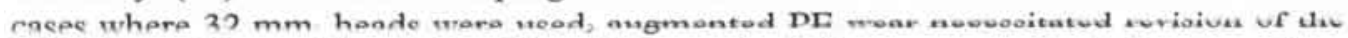
PE inlay and femoral head after 58 and 77 months follow up respectively. In one patient the severely worn liner was broken and in the other the wear was progressive on consecutive radiographs leading to more than three $\mathrm{mm}$. wear. The three other patients who also had $32 \mathrm{~mm}$. cobalt chromium heads only showed minor asymmetry of the liner. These patients are under strict surveillance. In none of these five patients the PE-wear was accompanied by osteolysis of the acetabular bone.

The anatomical centre of rotation could be restored in all patients except for one, who had had the Schanz osteotomy before. (Figure 3) In fifteen patients with a leg length difference of more than $3 \mathrm{~cm}$. (all Crowe class III and IV) leg length could be balanced with in $1 \mathrm{~cm}$ of the contralateral leg and limping disappeared in nine of them.

\section{Statistical ANALYSIS}

We calculated the survival of the stem using a life table. Three cup revisions and no stem revisions in sixty three hips lead to a cumulative survival rate of $91.3 \%$ (SE: $5 \%$ ) of the total hip arthroplasty and a $100 \%$ survival of the stem after a mean follow up of 75 months. We found correlations with a statistical significance level set at $\mathrm{p}<0.01$ between various clinical and radiologic parameters. (Table 2)

Correlations between the femoral morphometrics and the modified Singh index point out that the mildly osteoporotic femora had a stovepipe appearance, although there were only five of them. Stovepipe femora needed larger stem sizes and produced a radiographic less tight femoral canal fit. They showed significantly more endosteal spotwelding than did the champagn flute femora which needed smaller stem sizes and produced a more tight femoral canal fit and showed more cortical hypertrophy. Significant correlations showed the femoral canal fit with some radiologic phenomena: a negative correlation with p-value of 0.0001 (resp. 0.002) between spotwelding in zone 2 and 6 (resp. 3 and 5) and a tight fit of the prosthesis in the femoral canal. A positive correlation with a p-value of 0.0001 was found between cortical hypertrophy in zone 3 and 5 and a tight 
Figure 2

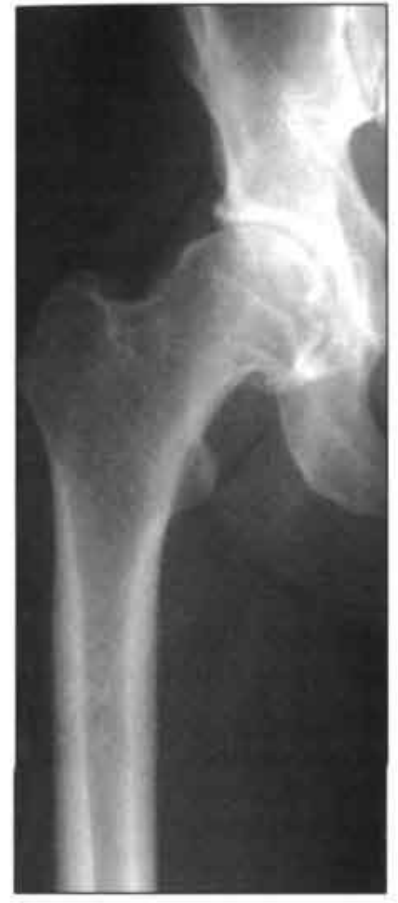

A

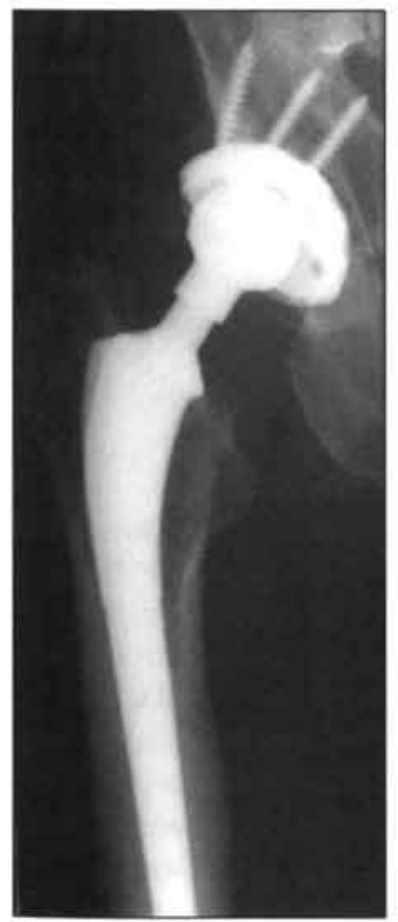

D

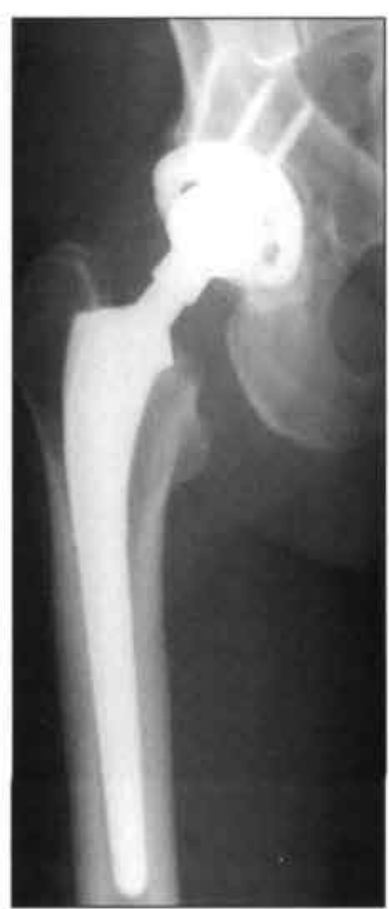

B

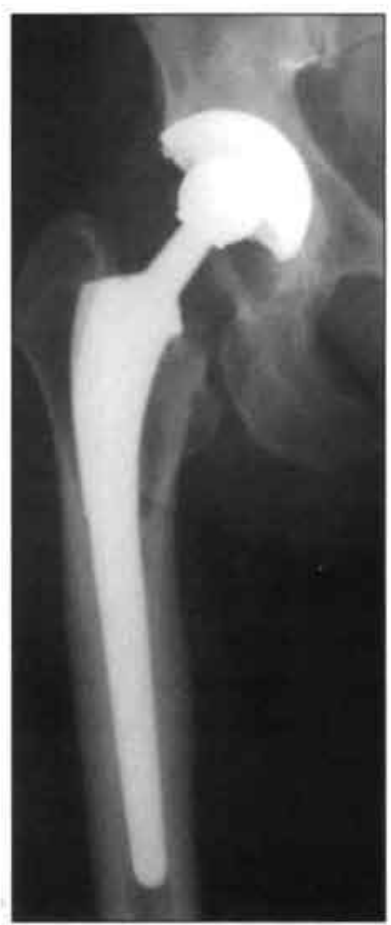

E

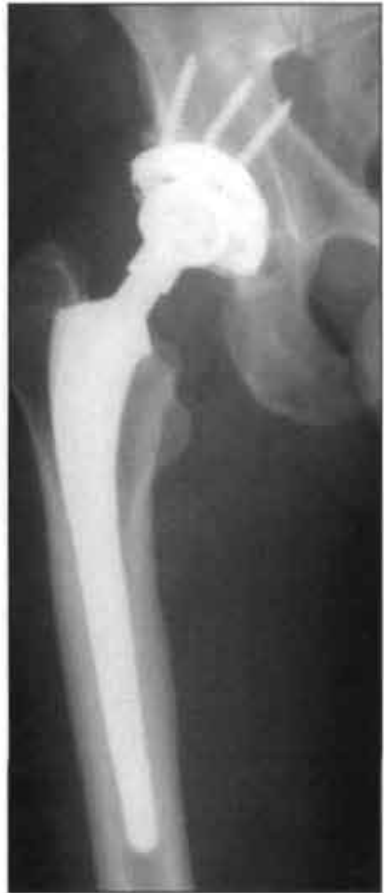

C

Ballooning of the femoral shaft at different stages of follow up in a 37-year-old patient at operation. In this patient with marked PEwear at later stages of follow up there is no proximal femoral osteolysis:

an illustration of proximal osseo-integration of the prosthesis.
A preoperative
B 1 year postoperative
C 2 years postoperative
D 7 years postoperative
E post cuprevision 
Figure 3

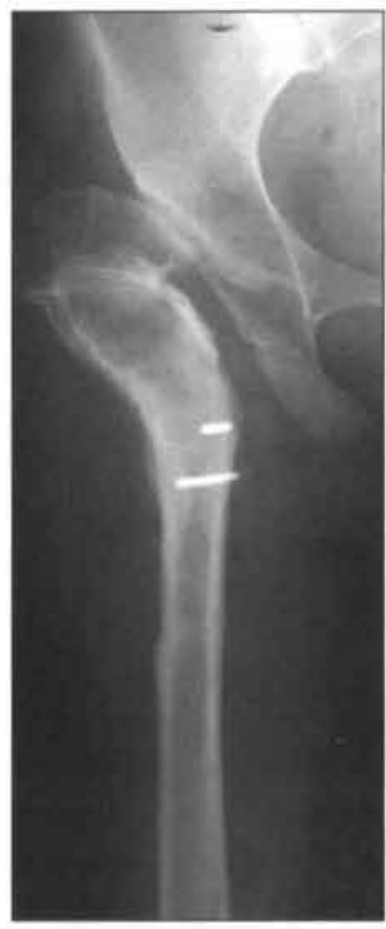

A

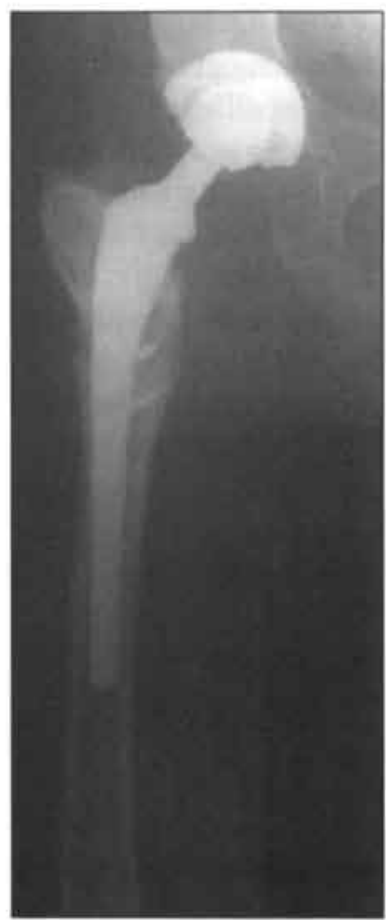

C

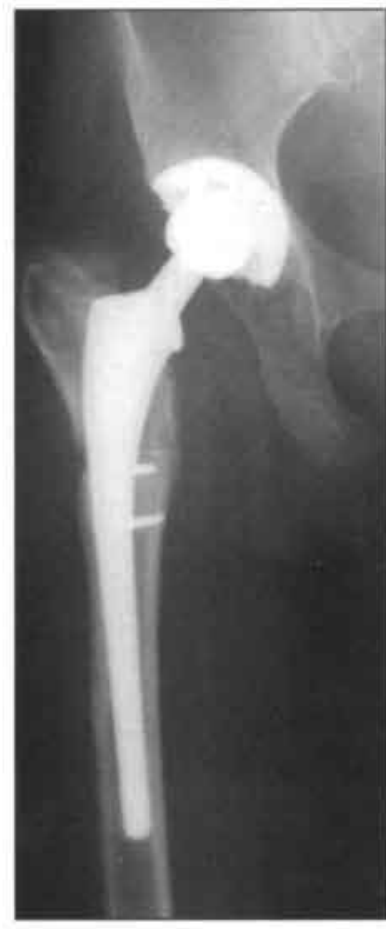

B

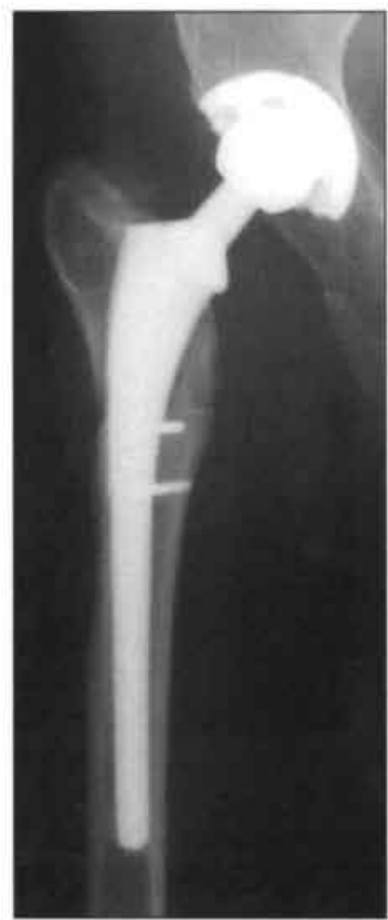

D
Patient after Schanz osteotomy.
A preoperative
B immediate postoperative
C 1.5 years postoperative
D 4 years postoperative 
Table 2

Correlations between the various clinical and radiological parameters according to the two-tailed Pearson test with the significance (p) set at $<0.01$.

\begin{tabular}{|l|l|l|l|l|l|l|l|l|l|l|}
\hline & B & C & D & E & F & G & H & I & J & K \\
\hline A & -.413 & -.241 & .684 & -.172 & -.202 & -.068 & -.273 & .265 & .413 & -.344 \\
& $(.001)$ & $(.058)$ & $(.000)$ & $(.178)$ & $(.112)$ & $(.594)$ & $(.031)$ & $(.036)$ & $(.001)$ & $(.006)$ \\
\hline B & & .387 & -.262 & .161 & .134 & .172 & .179 & .464 & -.566 & .271 \\
& & $(.002)$ & $(.038)$ & $(.208)$ & $(.295)$ & $(.177)$ & $(.159)$ & $(.000)$ & $(.000)$ & $(.038)$ \\
\hline C & & & .015 & -.064 & .041 & .160 & .058 & -.834 & -387 & .700 \\
& & & $(.907)$ & $(.617)$ & $(.751)$ & $(.211)$ & $(.650)$ & $(.000)$ & $(.002)$ & $(.907)$ \\
\hline D & & & & .158 & -.296 & .048 & -.256 & -.066 & .168 & .071 \\
& & & & $(.217)$ & $(.018)$ & $(.707)$ & $(.043)$ & $(.606)$ & $(.189)$ & $(.580)$ \\
\hline E & & & & & .584 & .326 & .643 & .086 & .007 & -.047 \\
& & & & & $(.000)$ & $(.009)$ & $(.000)$ & $(.503)$ & $(.959)$ & $(.713)$ \\
\hline F & & & & & & .423 & .707 & -.220 & -.134 & -.002 \\
& & & & & & $.001)$ & $(.000)$ & $(.083)$ & $(.295)$ & $(.985)$ \\
\hline G & & & & & & & .713 & -237 & -.187 & .067 \\
& & & & & & & $(.000)$ & $(.062)$ & $(.142)$ & $(.604)$ \\
\hline H & & & & & & & & -.246 & -.172 & .131 \\
& & & & & & & & $(.052)$ & $(.177)$ & $(.308)$ \\
\hline I & & & & & & & & & .464 &. .584 \\
& & & & & & & & & $(.000)$ & $(.000)$ \\
\hline J & & & & & & & & & & -.271 \\
& & & & & & & & & & $(.032)$ \\
\hline
\end{tabular}

Legends to Table 2

A - femoral morphometrics according to Dorr (15)

B - modified oseoporosis index according to singh (16)

C - femoral canal fit (tight or non-tight) depending on femoral canal index

D - stem size

E - limping postoperatively

F - use of crutches or cane postoperatively

G - Visual Analogue Scale for pain postoperatively

H - modified Oxford Heup Score postoperatively

I - spotwelding in zone 2 and 6

J - spotwelding in zone 3 and 5

$\mathrm{K}$ - cortical hypertrophy in zone 3 and 5

femoral canal fit. Spot-welding in zone 2 and 6 was correlated with the absence of cortical thickening in zone 3 and 5 .

Also highly significant correlations were found between the total of the modified "Oxford Heup Score" and the Visual Analogue Scale for pain, the use of crutches or cane and limping. However no correlations were found between the clinical and the radiologic parameters.

\section{Discussion}

The cementless porous coated Mallory-Head femoral prosthesis is designed for proximally loading of the femur in order to recreate near-normal bone stresses. (20)

The stem is proximally relatively small and very suitable for the narrow isthmus and tight medullary canal of osteoarthritic hip dysplasia patients. Other studies describe the use of a specially designed dysplasia stem or a modular prosthesis like the S-ROM femoral stem. Especially the ability to correct the anteversion of the prosthesis to the hyperanteversion often seen in dysplastic femora is mentioned (21). We think that with the Mallory-Head femoral stem most of time a good metaphyseal contact is obtained, even in cases with hyperanteversion, and we did see no need for such a specially designed prosthesis in our series $(6,21)$ However we had to perform a proximal femur splitting 
osteotomy in two cases. Our series contained mostly class I or II dysplastic hips, but also a quarter of them was class III or IV. We did not encounter any patients in our clinic that could not be treated by the prosthesis here described. In the Netherlands these higherclass dysplasia patients are very rare, undoubtedly thanks to the neonatal screening program.

We used the HA-coated version of the cementless porous coated Mallory-Head femoral prosthesis for two reasons. Apart from the advantage of accelerated ongrowth of bone, the ability of sealing off the proximal femur by creating a tight barrier for PE debris can be essential for longevity. $(22,23)$ This can be a hot item especially in highly active young patients as in this patient group. We enforced this effect by putting in spongious bone chips in the larger entrance of the proximal femur which was caused by reaming and broaching. This has also been propagated by Kadoya et al. (24). Søballe $(25,26)$ reported the existence of a ring of bone fixed at the titanium HA-coated prosthesis sealing off the effective joint space. In our series we did not observe proximal or distal osteolysis. This is in accordance with the results of Kadoya, Rahbek and Søballe. $(24,22,26)$ Very recently, Coathup et al. (27) showed that prostheses coated with HA had a more even distribution of bone over the implant. This might have implications in reducing stress shielding and limiting osteolysis induced by wear products. The study of Emerson et al. (28) however showed that only a porous proximal coating, without HA, already succeeded in preventing proximal osteolysis, although the survival is larger for HA-coated stems in comparison to only porous coated stems. (29). Yee et al. (30) showed no clinical or radiologic difference in a Mallory-Head femoral prosthesis whether or not HA-coated. However, the limitation of their study is the short length of follow up (4.4 to 4.9 years) which is not sufficient to judge the sealing mechanism of HA for PE-debris and so might be our study (3.7 to 9.1 years), although the two patients which were revised for augmented PE-wear did not show any proximal femoral osteolysis at operation. (figure 2) To judge subsidence we used the distance of the lesser trochanter to the transition of the neck to the body of the prosthesis. Walker et al. (31) criticised these marker points as being inaccurate. We agree that the golden standard in judging subsidence is RSA but it was not available in our hospital. Minor subsidence can thus be missed in this series, but all prostheses showed osseointegration.

The survival rate of $95.3 \%$ for the total hip arthroplasty is approximately the same as Mulliken et al. (32) described for primary total hip replacement with the same prosthesis in a cohort of non-dysplastic patients after a shorter period of follow up ( 3.7 years). The stem survival in our series is however $100 \%$ up till now.

The reason for this relatively high percentage of patients with limping $(20 \%)$ or use of a crutch of cane when walking more than half an hour $(16 \%)$ is fourfold. Firstly, the abductor strength is slightly reduced in dysplastic patients. Secondly, eight out of the ten patients who complained about limping had had multiple previous hip surgery even further compromising abductor strength. Thirdly, there are the cases with concomitant morbidity such as vascular claudicatio and a femoral fracture. Fourthly, we did not succeed to obtain perfectly equal leg length in all patients, although the differences were within $1 \mathrm{~cm}$. of the contralateral leg. Nevertheless it is remarkable that Mulliken et al. (32) noted exactly the same percentage for limping in his series with "normal" primary procedures. Paavilainen et al. (7) described a limp in respectively $17 \%$ and $18 \%$ in two dysplasia groups, of which the first consisted of relatively mild cases (Crowe class I and II) and the other of relatively severe cases (Crowe class III and IV). Seven of their sixty patients $(12 \%)$ still used a walking aid after the operation, compared to $14 \%(10 / 63$ hips or $7 / 50$ patients) in our series. The question about hindrance in sexual activities was 
added to the "Oxford Heup Score". This symptom is prominent when (mostly) younger female patients complain about limited hip abduction. After total hip replacement $90 \%$ of them reported no or only mild problems.

Radiographic bone remodeling around the stem showed $46 \%$ of cortical hypertrophy in Gruen zone 3 and 5; 7.9\% of spot-welding in Gruen zone 2 and 6 and $28.6 \%$ of spotwelding in Gruen zone 3 and 5 and $13 \%$ of reactive line formation in Gruen zone 4. These phenomena have also been described in the radiologic analysis of the MalloryHead prosthesis by Mulliken et al. (32) and Mallory and Mitchell (33) and are also seen in various other cementless prostheses with different percentages varying from study to study even with the same prosthesis. The fact that also zones 3 and 5 showed endosteal spot-welding suggests a more distal bone ongrowth and load transfer than in the area of the HA-coating alone. We found a positive correlation between tight femoral canal fit and cortical hypertrophy in Gruen zone 3 and $5(\mathrm{p}<0.0001)$, while the correlation between tight femoral canal fit and spot-welding in Gruen zone 2 and $6(p<0.0001)$ and 3 and $5(\mathrm{p}<0.002)$ were negative. So spot-welding can be a sign of fixation of a prosthesis (34), but it is rather a sign of stress transfer and in essence the endosteal equivalent of periosteal/cortical hypertrophy. When a tight fit leaves no space between the inner cortex and the prosthesis no endosteal spot-welds can develop, although a bony union is present, but the stresses are transferred to the outer cortex leading to cortical hypertrophy. Therefore osteoporotic femora showed reactions that are in accordance with this femoral canal fit theory: with their less tight fit enough space is left for endosteal spot-welding and no cortical thickening developed. The remodeling patterns of the bone can thus be predicted by femoral canal fit: champagne flute femora are more likely to develop cortical hypertrophy because tight femoral canal fit is easier obtained than in stovepipe femora, while stovepipe femora show more spot-welding and no cortical hypertrophy. However, around a non-tightly fitted stem in a champagne flute femur or in a femur where distal prosthesis-bone contact is inhibited by overreaming the femoral canal, endosteal spot-welds will be seen more often than cortical hypertrophy. These same phenomena have been observed by Tonino et al. for the cementless ABG prosthesis. (22) We were not able to find a highly significant relation between the radiologic phenomena to stem size (read: stem stiffness) when corrected for femoral canal fit.

When stresses are transferred from the metaphysis to the proximal diaphysis atrophy of the metaphysis (Gruen zones 1 and 7) should be a logical sequence. The reason for not observing this phenomenon is that at least $70 \%$ of the bone must be resorbed before it becomes visible on a radiograph. A more precise DEXA study on the Mallory-Head femoral prosthesis in another cohort of patients has been carried out by us and does indeed show some lower proximal bone density values three years after surgery (35).

\section{Conclusions}

We conclude that the cementless Mallory-Head HA-coated femoral prosthesis shows excellent clinical and radiologic mid-term results in the treatment of secondary osteoarthritis in hip dysplasia cases. We did not see a need for a specially designed dysplasia stem in our series. We conclude that the so-called "radiologic phenomena of fixation" are correlated with femoral canal fit and not solely with stem size and the shape of the femoral canal according to Dorr (15). Radiologic phenomena could not be correlated with clinical outcome parameters. 


\section{REFERENCES}

1. Crowe JF, Mani VJ, Ranawat CS. (1979) Total hip arthroplasty in congenital dislocation and dysplasia of the hip. J Bone Joint Surg [Am] 61:15-23.

2. Dunn HK, Hess WE. (1976) Total hip reconstruction in chronically dislocated hips. J Bone Joint Surg [Am] 58:838.

3. Hartofilakides G, Stamos K, Ioannidis TT. (1988) Low friction arthroplasty for old untreated congenital dislocation of the hip. J Bone Joint Surg [Br] 70:182.

4. Linde F, Jensen J, Pilgaard S. (1988) Charnley arthroplasty in osteoarthritis secondary to congenital dislocation or subluxation of the hip. Clin Orthop 227:164.

5. Rahimtoola ZO, Finger $\mathbf{S}$, Imrie $\mathbf{S}$, Goodman SB. (2000) Outcome of total hip arthroplasty in small proportioned patients. J Arthroplasty 15:27.

6. Woolson ST, Harris WH. (1983) Complex total hip replacement for dysplastic or hypoplastic hips using miniature or microminiature components. J Bone Joint Surg [Am] 65:1099.

7. Paavilainen T, Hoikka V, Paavolainen P. (1993) Cementless total hip arthroplasty for congenitally dislocated or dysplastic hips. Technique for replacement with a straight femoral component. Clin Orthop 297:71.

8. Tanzer M, Maloney WJ, Jasty M, Harris WH. (1992) The progression of femoral cortical osteolysis in association with total hip arthroplasty without cement. J Bone Joint Surg [Am] 74:404-4.

9. Head WC. (1993) Mallory-Head porous press-fit primary hip replacement.

Presented at the tenth annual international symposium: New Developments in Total Joint Reconstruction, Lake Tahoe, Nevada.

10. Luedemann RE. (1993) Plasma sprayed porous Ti-6Al-4V coating. Porous coating technology. Biomet product information.
11. Charnley J. (1968) The numerical grading of hips. Internal Publication no. 20, Centre for Hip Surgery, Wrightington Hospital, England.

12. Harris WH. (1969) Traumatic arthritis of the hip after dislocation and acetabular fractures: treatment by mold arthroplasty. An end-result study using a new method of result evaluation. J Bone Joint Surg [Am] 51:737.

13. Dawson J, Fitzpatrick R, Carr A, Murray D. (1996) Questionnaire on the perceptions of patients about total hip replacement. J Bone Joint Surg [Br] 78:185.

14. Hoefnagels NHM, Dhert WJA, Ockhuijsen S, Gosens T, van Langelaan EJ, Geesink RGT, Bulstra SK. (1999) Translation and validation of the 12 item questionnaire on the perceptions of patients about total hip replacement. Acta Orthop Scand (suppl 284):70.

15. Dorr LD, Takei GK, Conally JP. (1973) Total hip arthroplasties in patients less than forty five years old. J Bone Joint Surg [Am] 65:474.

16. Singh M, Riggs BL, Bibout JW, Jowsey J. (1973) Femoral trabecularpattern index for evaluation of spinal osteoporosis. Detailed methodologic description. Mayo Clinic Proceed 48:184.

17. Gruen TA, McNeice GM, Amstutz HC. (1979) "Modes of failure" of cemented stem-type femoral components. A radio graphic analysis of loosening. Clin Orthop 141:17.

18. Brooker AF, Bowerman JW, Robinson RA. (1973) Ectopic ossification following total hip replacement. Incidence and a method of classification. J Bone Joint Surg [Am] 55:1629.

19. DeLee JG, Charnley J (1976) Radiological demarcation of cemented sockets in hip replacement. Clin Orthop 121:20.

20. Mallory TH, Head WC, Lombardi AV jr, Emerson RH jr, Eberle RW, 
Mitchell MB. (1996) Clinical and radiographic outcome of a cementless, titanium, plasma spray coated total hip arthroplasty femoral component. Justification for continuance of use. J Arthroplasty 11(6): 653.

21 Christie MJ, DeBoer DK, Trick LW, Brothers JC, Jones RE, Vise GT, Gruen TA. (1999) Primary total hip arthroplasty with use of the modular S-ROM prosthesis. J Bone Joint Surg [Am] 81:1707-1716.

22. Rahbek O, Overgaard S, Jensen TB, Bendix K, Søballe K. (2000) Sealing effect of hydroxyapatite coating: a 12month study in canines. Acta Orthop Scand 71(6):563.

23. Tonino AJ, Rahmy AIA, and the international ABG study group. (2000) The hydroxyapatite-ABG hip system. 5- to 7-years results from an international multicentre study. J Arthroplasty 15(3):274

24. Kadoya Y, Kobayashi A, Ohashi H. (1998) Wear and osteolysis in total joint replacements. Acta Orthop Scand 278:1.

25. Søballe K, Hansen ES, BrockstedtRasmussen H, Pedersen CH, Bunger C. (1990) Hydroxyapatite coating enhances fixation of porous coated implants - a comparison in dogs between pressfit and noninterference fit. Acta Orthop Scand 61(4):299.

26. Søballe K, Brockstedt-Rasmussen $\mathbf{H}$, Hansen ES, Bunger C. (1992)

Hydroxyapatite coating modifies implant membrane formation. Controlled micromotion studied in dogs. Acta Orthop Scand 63(2):128.

27. Coathup MJ, Blunn GW, Flynn N, Williams C, Thomas NP. (2001):

A comparison of bone remodelling around hydroxyapatite-coated, porous-coated and grit-blasted hip replacements retrieved at post-mortem. J Bone Joint Surg [Br] 83:118.
28. Emerson RH, Sanders SB, Head WC, Higgins L. (1999) Effect of circumferential plasma-spray porous coating on the rate of femoral osteolysis after total hip arthroplasty. J Bone Joint Surg [Br] 81:1291.

29. Havelin LI, Engesaeter LB, Espehaug B, Furnes O, Lie SA, Vollset SE. (2000): The Norwegian Arthroplasty Register. 11 years and 73,000 arthroplasties. Acta Orthop Scand 71(4):337.

30. Yee AJM, Kreder HK, Bookman I, Davey JR. (1999) A randomised trial of hydroxyapatite coated prostheses in total hip arthroplasty. Clin Orthop 366:120.

31. Walker PS, Mal SF, Cobb AG, Bentley G, Hua J. (1995) Prediction of clinical outcome of THR from migration measurements on standard radiographs. J Bone Joint Surg [Br] 77:705-714.

32. Mulliken BD, Bourne RB, Rorabeck CH, Nayak N. (1996)

A tapered titanium femoral stem inserted without cement in a total hip arthroplasty. Radiologic evaluation and stability. J Bone Joint Surg [Am] 78:1214.

33. Mallory TH, Mitchell MB. (1990) Results of total hip replacement using porous coating as a fixation mode. Sem Arthroplasty 1:70.

34. Engh CA, Massin P, Suthers KE. (1990) Roentgenographic assessment of the biologic fixation of porous-surfaced femoral components. Clin Orthop 257:107.

35. Rahmy AIA, Gosens T, Blake GM, Tonino AJ, Fogelman I. (2003)

Periprosthetic bone remodelling of two types of uncemented femoral implants with a proximal hydroxyapatite coating: a 3-year follow up study addressing the influence of prosthesis design and preoperative bone Osteoporosis Int (in press) 
The Mallory-Head FEMoral PROSTHESIS IN REVISION CASES 
THE MALLORY-HEAD FEMORAL PROSTHESIS IN REVISION CASES 


\section{The Mallory-Head femoral PROSTHESIS IN REVISION CASES}

The STANDard Mallory-Head HA-COATEd femoral STEM USED IN REVISION HIP ARTHROPLASTY.

Clinical AND RADIOLOGIC RESULTS AFTER 4 TO 9.3 YEARS.

T. Gosens

E.J. van Langelaan 
THE MALLORY-HEAD FEMORAL PROSTHESIS IN REVISION CASES 


\section{Abstract}

We prospectively studied 48 hips in 47 patients with a mean age of 59.6 years and reviewed the results after a mean period of follow up of 6.1 (range 4 -9.3) years following revision arthroplasty for aseptic loosening using a primary HA-coated femoral stem. 1.8 Previous operations per patient were performed, ranging from 1 to 8 , all patients had a femoral defect class 1 or 2 according to Paprosky.

Clinical outcome was good with a mean postoperative HHS of 90 points. Pain was absent in $89 \%$, a limp was present in $36 \%$ and $41 \%$ used a walking aid. There were 5 reoperations: 4 recurrent dislocations and 1 progressive PE wear necessitated cup revision. At 6 years, 39\% cancellous densifications were seen, especially in non-tightly fitted prostheses, mainly in zone 2 and 6 . Cortical thickening was seen in $30 \%$, especially in tightly-fitted prostheses, mainly in zone 3 and 5 . These differences in bone behavior were significant $(p<0.001)$ and were not related with various clinical parameters. These phenomena started to appear from 6 months onwards with increasing frequency with longer follow up.

The stem survival up til 6.1 years is $100 \%$, no stem is pending revision at the latest follow up. We conclude that the primary Mallory-Head HA-coated femoral prosthesis is a suitable prosthesis to use in revision procedures with a lower class femoral defect.

We also noticed that the radiologic remodeling phenomena are not prosthesis related but femoral canal fit dependent.

Keywords:

revision hip arthroplasty - clinical outcome - radiologic - Mallory-Head - hydroxyapatite 


\section{INTRODUCTION}

Revision hip arthroplasty after aseptic loosening of the previous arthroplasty is more expensive, can provide more technical problems and complications occur more often than in primary hip replacements. (1) The results of revision hip arthroplasty are less good than primary hip replacement, but revision operations give a significant improval in the quality of life (2) and a survivorship of $95 \%$ at ten years has been reported. (3) Especially with cemented revisions high re-revision rates are reported, even with improved cementing techniques. (4-7) A femur after non-septic loosening does not have the trabecular structure anymore that is needed for interdigitation of the cement. This flat endosteal surface of the femur is said to lead to reduced cement-bone interface shear strength. $(8,9)$ For this reason, cementless femoral revision prostheses have been recommended. Specially designed revision prostheses with longer stems and an extensive porous coating have been engineered to bypass the damaged part of the femur and to provide stability by distal fixation. (10-16)

In contrast to these extensively damaged femora where a standard prosthesis may not provide enough stability, lower class femoral deficiencies do not need the extra long stemmed and extensively porous coated prostheses and a standard proximally porous coated prosthesis can provide sufficient stability. (17) The minor damages of these femora can be countered by using hydroxyapatite to obtain good bone ingrowth, sealing of the proximal femur to create a small effective joint space and prevent subsidence.

This prospective study presents the clinical and radiographic results after a mean follow up of 6.1 years of 48 consecutive revision procedures for aseptic loosening using the standard cementless Mallory-Head HA-coated femoral prosthesis (Biomet, Warsaw, Indiana, USA).

Primarily, our goal is to describe the clinical and radiographic features of osseointegration and stress shielding. The second goal is to judge the additional value of a proximal circumferential HA-coating preventing distal bone resorption and enhancing bone ongrowth even in a damaged and sclerotic proximal femur so that mildly damaged femora can be treated with a standard primary prosthesis like the Mallory-Head stem. To our best knowledge this stem is never before described when used in revision situations. Geesink et al. published about proximally HA-coated prostheses in revision cases with good results. (18) Thirdly, we test the hypothesis that the appearance of radiologic remodeling of the femur is a function of stem fit.

\section{Patients AND methods}

\section{Patient Characteristics}

Between 1991 and 199748 revision procedures in 47 patients with a mean age of 59.6 (range 37 - 72) years and reviewed the results after a mean period of follow up of 6.1 (range 4 - 9.3) years. We operated on 15 male and 32 female patients, 1 female patient had bilateral surgery. The diagnosis at surgery was aseptic loosening in all cases, in 46 cases a cementless prosthesis and in 2 cases a cemented prosthesis was revised. In 47 patients 73 previous operations were performed, ranging from 1 to 8 (rab) 1) and for 42 patients this was their first revision, for 5 patients their second and for 1 patient his 
Table 1

\section{Previous operations in revision cases}

Iso-elastic total hip prosthesis and Mecron cup 36

Iso-elastic total hip prosthesis and HG cup 9

Mittelmeyer ceramic prosthesis 3

Zimmer cemented prosthesis $\quad 2$

Judet acrylic prosthesis 1

acetabular reconstruction $\quad 4$

acetabular revision $\quad 5$

shelf plasty $\quad 5$

ORIF for femoral fracture $\quad 5$

arthrolysis 2

Girdlestone for infection 1

Total

73

third revision. Most $(n=46)$ cases had a femoral defect class 1 or 2 , although 2 cases had a type $3 \mathrm{~A}$ femoral defect according to Paprosky. (16) Higher Paprosky classes were operated on using a different prosthesis with a longer stem and calcar replacement. (13) At the time of the index operation 14 patients had a contralateral hip prosthesis, at the time of review this was the case in 19 patients. The selection criteria for these patients to enter the study group included an aseptic loosening of a femoral component at a relatively young age ( $<75$ years of age) with a good proximal bone stock.

\section{GEOMETRY OF THE PROSTHESIS}

Proximal loading of the femur to recreate near-normal bone stresses is the primary goal of the Mallory-Head porous femoral stem. (figure 1) This implant has proven to deliver excellent clinical results since its conception in 1984 in primary cases. (19-22)

Unlike fully porous coated cylindrical stems that tend to transmit most of the load distally and may stress shield proximally, the Mallory-Head porous implant tapers from proximal to distal. This three degree taper allows the prosthesis to achieve three point fixation for immediate stem stability, and contributes to the reported low incidence of thigh pain and stress shielding with this implant. (19) The porous primary stem is made of titanium alloy (Ti-6Al-4V), chosen for its biocompatibility and modulus of elasticity. The Mallory-Head porous prostheses are proportionally sized, ranging from 6 to $19 \mathrm{~mm}$ in width and from 135 to $180 \mathrm{~mm}$ in length with a neck angle of 135 degrees.

The proximal area is circumferentially porous coated with a titanium alloy plasma spray, which greatly increases the surface area of the stem for improved fixation. The circumferential porous coating is a "closed pore" design which acts as a barrier to the migration of particulate debris. (23) Tanzer (24) and Harris (25) have hypothesized that this barrier may help prevent osteolysis clinically reported for other stem designs. The middle one-third has a roughened finish created through a blasting technique. The distal portion of the stem is smooth, allowing the majority of forces to be off-loaded proximally.

By using a HA-coating added to the porous proximal third of the femoral prosthesis the in- and ongrowth of bone to the prosthesis is stimulated. In this way the sealing effect 
to prevent distal migration of particulate debris is optimized. Especially a femur with a sclerotic and irregular endosteal surface, bone ingrowth can be stimulated by the presence of a HA-layer. The coating is characterized by a coating thickness of $55 \mu \mathrm{m} \pm 15 \mu \mathrm{m}$, a HA cristalline content of more than $98 \%$ with a cristallinity of $50 \%-70 \%$ and a tensile adhesion of more than $15 \mathrm{MPa}$.

\section{SURGICAL TECHNIQUE}

All patients were operated on by the senior author (EJvL) by a straight lateral approach without a trochanteric osteotomy. Most patients had class I or II femoral defects. After careful extraction of the loose prosthesis and meticulous removal of fibrous membranes and cement the femoral canal was reamed to cortical contact. To inhibit distal stem contact we routinely performed distal overreaming of at least $1.0 \mathrm{~mm}$. with flexible reamers over a guiding rod. Postoperatively, protected weight bearing with crutches was used in all cases.

The Mallory-Head stem was primarily combined with the HG cup (Zimmer, Warsaw, Indiana, USA) and a $\mathrm{CoCr} 28 \mathrm{~mm}$. head $(n=42)$, later on with the Ringlock cup (Biomet, Warsaw, Indiana, USA) and a ceramic $28 \mathrm{~mm}$. head $(\mathrm{n}=8)$. We used screw fixation of the cup in 40 cases. The medial acetabular wall was reinforced with spongious allograft bone chips in 37 cases, in 11 cases a bulky allograft was used.

\section{Patient assessments}

All patients were included in a prospective follow up schedule and were evaluated preoperatively, and postoperatively at 3,6 and 12 months and yearly thereafter using the Harris Hip Score (HHS) (26) and specific questions about functional items such as pain, limping and use of walking aids. At the latest follow up the modified "Oxford Heup Score" (OHS) (27) was added to the assessment. This questionnaire is based on the translation of the "12-item questionnaire" (28) and was extended with two questions about specific problems of the hip patient, e.g. "the use of crutches or cane" and "problems with sexual intercourse". These specific questions were included in the total score, so this OHS ranges from 14 points (optimal clinical result) to 70 points (worst clinical result). Another part of the analysis was the use of a Visual Analogue Scale for pain $(0$ 10) and a question to determine whether the patients belonged to Charnley class A, B, or $\mathrm{C}$ at the time of analysis. Three further questions about overall satisfaction of the patient were added: whether the mobility of the hip has improved by the operation, whether the pain in the hip has decreased by the operation and whether the patient is satisfied by the result of the operation. These questions are not included in the total score of the OHS. 


\section{RADIOGRAPHIC ASSESSMENTS}

During each follow up visit, an anteroposterior and lateral radiograph was taken of the involved hip. These were evaluated using Gruen zones (29) for signs of bone resorption, subsidence, osteolysis, interface deterioration, cyst formation, radiolucencies, reactive line formation around the HA-coated and the non-coated parts of the femoral prosthesis, cancellous and cortical bone densifications, cortical hypertrophy, tip sclerosis and pedestal formation around the stem tip. Changes in these radiographic parameters with time were noted with special attention to stress-shielding induced bone resorption and osteolysis resulting from particulate debris. HA covered the stem in Gruen zones 1 and 7 and the proximal part of zones 2 and 6 . All bony changes were estimated by the eye by an independent observer (TG). Resorption of bone was not quantified but graded as present, when loss of trabecular bone density, corticocancellization, or cortical thinning was noted. Cortical hypertrophy (cortical thickening) was present when there was an increase in the outer diameter of the cortex. Reactive line formation was defined as a thin radiopaque layer of bone seen parallel and in close proximity to the implant. Between this line and the implant, a radiolucent line is always present. To be recorded, this line had to extend at least $50 \%$ of the zone length. Radiolucency was defined as a radiolucent zone anywhere around the implant with no relation to any radiopacity. A radiolucent line was recorded when it was at least $2 \mathrm{~mm}$. in width and at least $30 \%$ of any one zone. Osteolysis was defined as a scalloped erosion of more than $2 \mathrm{~mm}$. in diameter at the bone-prosthesis interface. Femoral cancellous bone densification (spotwelding) was defined as an augmentation in bone mineral content anywhere between the implant and the femoral cortex; cortical bone densification was defined as an augmentation in bone mineral content in the femoral cortex itself. Likewise the position of the implant after surgery was assessed: the stem was assessed as in varus or in valgus when it measured more than 2 degrees from the neutral. The stem was defined as complete filling the diaphysis when less than $1 \mathrm{~mm}$. was measured on either side between the stem and the cortex on the AP radiograph.The stem was defined as having fixation by bone ongrowth (osseointegration) when there was no subsidence or migration and no formation of a radiolucent or radiodense line along the HA-coated portion of the prosthesis.

The acetabular bone-prosthesis transition was evaluated using the criteria of DeLee and Charnley. (30) We especially recorded asymmetry of the head in the liner suggesting PE-wear and tried to correlate this with femoral and acetabular osteolysis.

\section{STATISTICAL ANALYSIS}

After a mean follow up of $6.1(4-9.3)$ years a clinical and radiologic evaluation was performed. Statistical analysis of the results was performed and the influences of clini$\mathrm{cal}$ and radiographic variables were studied using chi-square test, two-tailed Student's ttest or logistic regression, depending on group characteristics. Statistical significance was set at $\mathrm{p}<0.05$.

\section{RESUlts}

All but one patients were available for follow up. One patient died 6.2 years after the operation from heart failure. The stem had shown radiographic osseointegration and she 
had no pain and was satisfied at the 6 years follow up visit before she died. No permission was obtained for a retrieval study.

\section{Complications}

In the immediate postoperative period 3 patients had a prolonged wound drainage. None of these patients were reoperated. Recurrent dislocations were seen in 4 cases and they were managed by acetabular revision. One acetabular revision was performed for progressive polyethylene wear, and 3 other patients showed liner asymmetry and they are screened every half year for progression. In these patients no osteolytic changes in the acetabulum or femur were seen. No stem related problems were seen and no stem revisions were performed or were pending at the latest follow up.

\section{Clinical Results}

The mean preoperative HHS was $39(16-48)$ points. The mean HHS at the latest follow up was $90(51-100)$. The results of the postoperative OHS are seen in rabie 2. No or only very mild pain was scored by $89 \%$ of the patients. In $36 \%$ of the patients limping was present in varying intensity. Walking aids were regularly used by $41 \%$ of the patients. These figures decreased in comparison to preoperative values. (rable 3) The use of a walking aid is recommended by the senior author in prolonged walking after revision procedures. The average Visual Analogue Scale for pain amounted 1.65 (range: 0 8) at the latest review.

\section{RADiOLOGIC RESUlTS}

\section{Acetabulum.}

Except for the patients mentioned before with asymmetric liners due to PE wear, analysis of the acetabular bone showed no progressive radiolucent line formation.

\section{Femur.}

The femoral stem position was within two degrees varus or valgus in all patients. We could not detect stem migration or subsidence in the first 3 months postoperativerly, neither in further follow up. Structural changes of the femoral bone became apparent at 6 months (Tabte 4,5 and 6 ), starting with the formation of densifications of the cancellous bone. At the same time calcar rounding became visible, which remained stable at $34 \%$ of the femora after 2 years. Because it remained stable we consider this as maturation at the previous osteotomy site and not as negative bone remodeling due to stress shielding. Densifications of cancellous bone were seen along the femoral stem at the point of transition between the coated and non-coated parts of the stem in Gruen zones 2 and 6, from 6 months and onwards. These cancellous densifications were progressive in frequency to $39 \%$ at 6 years and, from 2 years onwards, the areas of bone apposition slowly expanded distally into the upper parts of Gruen zones 3 and 5 to $22 \%$ at 6 years. Endosteal reactive lines became visible on radiographs in Gruen zone 4 between 6 months and the first year postoperatively. The incidence increased until the fifth year in zone 3,4 and $5(9 \%, 17 \%$ and $4 \%$ respectively) after which a slight decline in frequency was seen due to expansion of the bone apposition from the more proximal zones. Progressive resorption of bone was not observed, especially not in Gruen zones 1 and 7, and the same accounts for radiolucent line formation. Densification of cortical bone was observed in Gruen zones 2, 3, 5 and 6 from 1 year onwards and progressing distally in 
Table 2

Results of the modified "Oxford Heup Score" in 48 revision cases (\%). Answer 1 is the answer corresponding with the best result and answer 5 corresponds with the worst result.

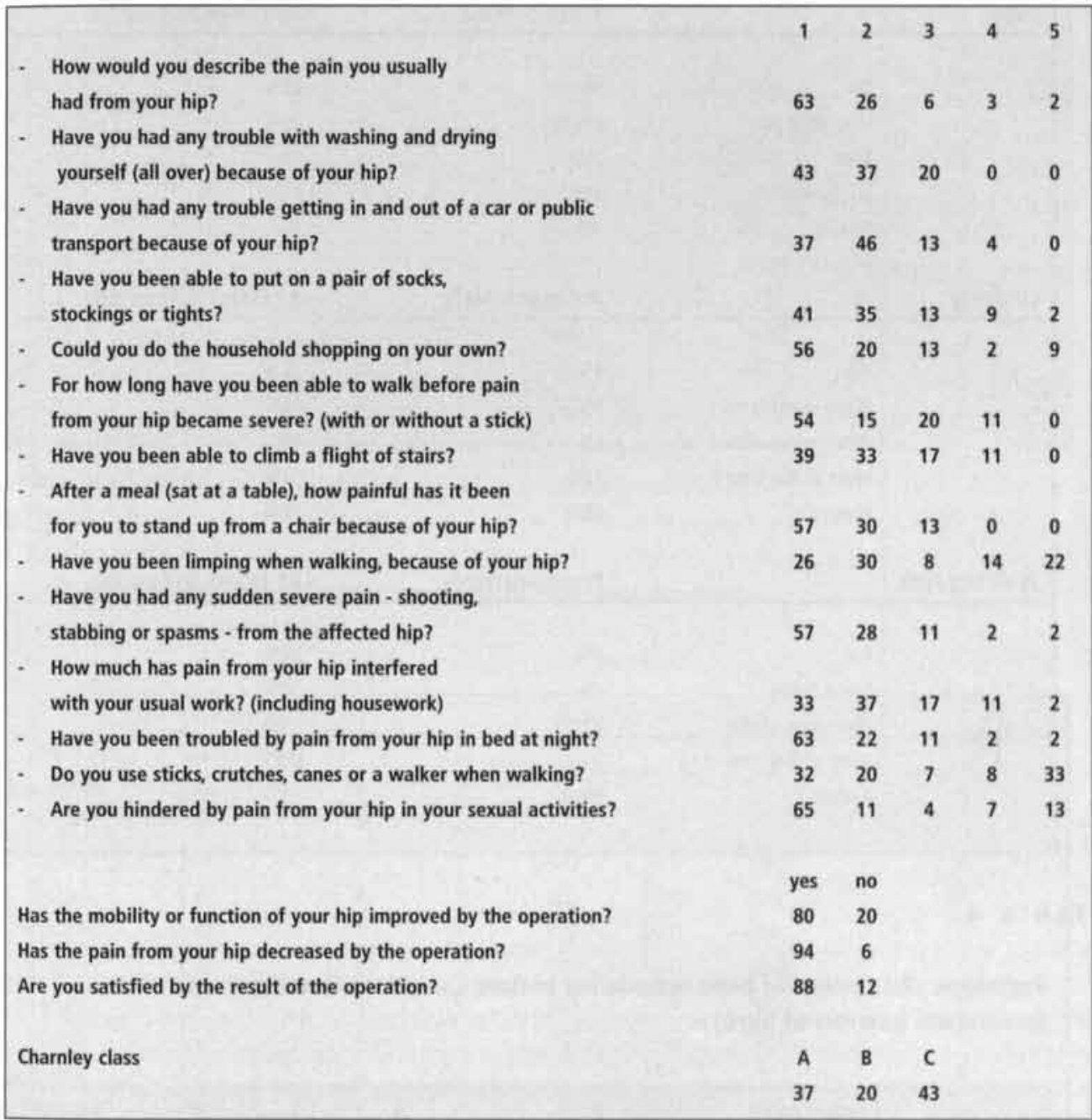

further follow up to $9 \%, 30 \%, 28 \%$ and $9 \%$ at 6 years in zones $2,3,5$ and 6 respectively. The pattern of peripheral thickening of the femoral cortex followed that of cortical bone densification. Observed from the second postoperative year onwards it was also progressing distally like the densifications of the cortical bone, some times even reaching the region that previously showed a reactive line. At 4 years follow up all 48 stems were still available for follow up. A total of 13 stems $(27 \%)$ was tightly fitted in the femoral canal. Symmetrical cortical thickening was seen in $69 \%$ of the stems with a tight femoral canal fit, but only in $18 \%$ of the stems with a non-tight fit. With a non-tight fit of the stem cancellous densifications predominated $(51 \%)$. In tightly fitted stems cancellous densifications were hardly seen (8\%). (Tabie 7 )

Periarticular ossifications were recorded using the Brooker grading system. (31) 
Table 3

Distribution of pain, limping and the use of walking aids preoperatively and postoperatively.

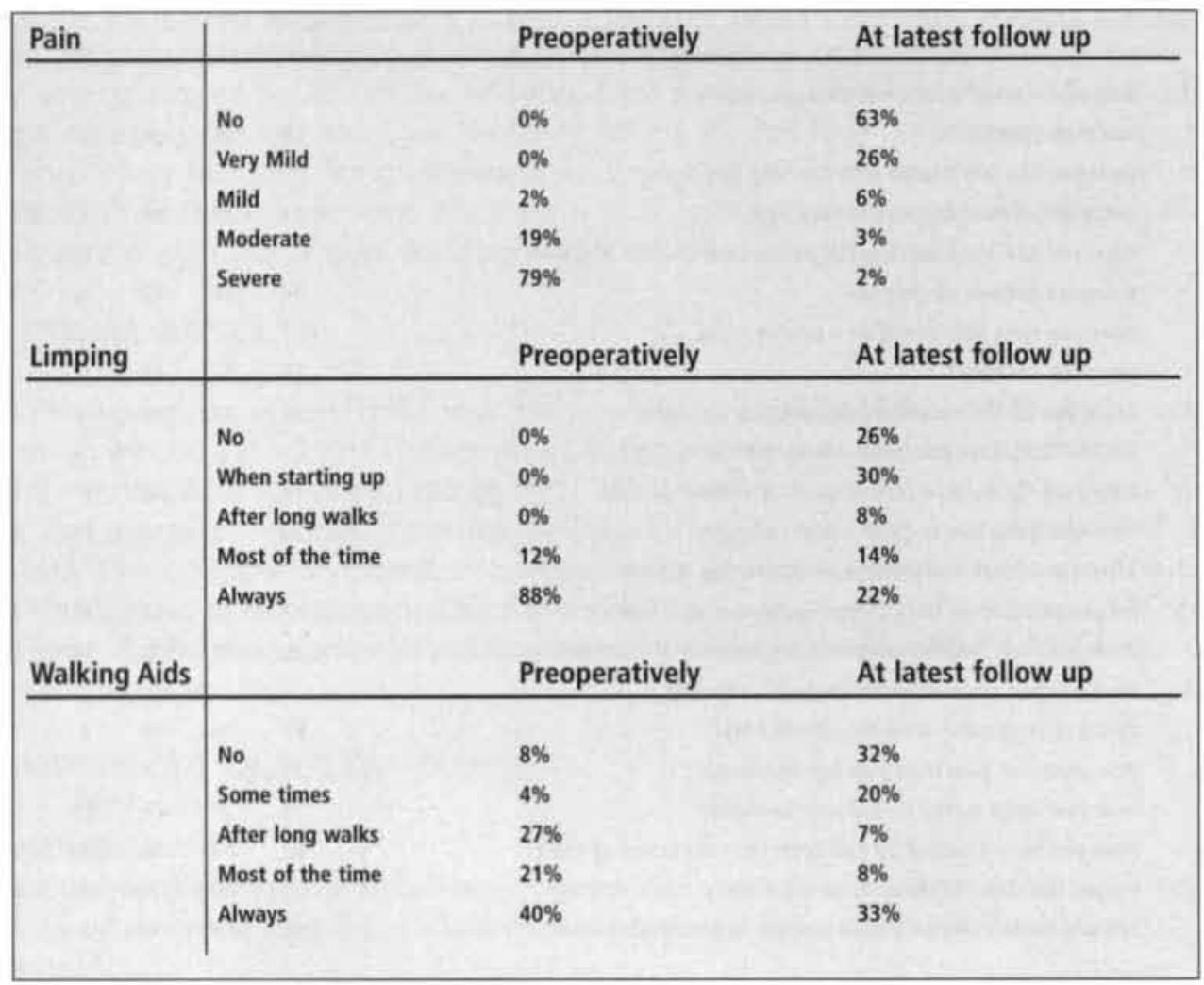

Table 4

Radiologic phenomena of bone remodeling in time: cancellous densifications [percentage (number of hips)]

\begin{tabular}{|l|llcccccc|}
\hline & Gruen zones & $\mathbf{1}$ & $\mathbf{2}$ & $\mathbf{3}$ & $\mathbf{4}$ & $\mathbf{5}$ & $\mathbf{6}$ & $\mathbf{7}$ \\
\hline Follow up & no of hips & & & & & & & \\
6 months & 48 & 0 & $15(7)$ & 0 & 0 & 0 & $17(8)$ & 0 \\
1 year & 48 & 0 & $21(10)$ & $4(2)$ & 0 & $6(3)$ & $19(9)$ & 0 \\
2 years & 48 & 0 & $25(12)$ & $10(5)$ & 0 & $12(6)$ & $25(12)$ & 0 \\
3 years & 48 & 0 & $31(15)$ & $14(7)$ & 0 & $17(7)$ & $33(16)$ & 0 \\
4 years & 48 & 0 & $35(17)$ & $16(8)$ & 0 & $16(8)$ & $40(19)$ & 0 \\
5 years & 41 & 0 & $37(15)$ & $17(7)$ & 0 & $20(9)$ & $41(17)$ & 0 \\
6 years & 23 & 0 & $39(9)$ & $22(5)$ & 0 & $22(5)$ & $35(8)$ & 0 \\
7 years & 10 & 0 & $40(4)$ & $20(2)$ & 0 & $30(3)$ & $50(5)$ & 0 \\
8 years & 3 & 0 & $67(2)$ & $33(1)$ & 0 & $33(1)$ & $67(2)$ & 0 \\
9 years & 1 & 0 & $100(1)$ & $100(1)$ & 0 & $100(1)$ & $100(1)$ & 0 \\
\hline
\end{tabular}




\section{Table 5}

Radiologic phenomena of bone remodeling in time: cortical thickening [percentage (number of hips)]

\begin{tabular}{l|llcccccc|}
\hline & Gruen zones & $\mathbf{1}$ & $\mathbf{2}$ & $\mathbf{3}$ & 4 & 5 & 6 & $\mathbf{7}$ \\
\hline Follow up & no of hips & & & & & & & \\
6 months & 48 & 0 & 0 & $8(4)$ & 0 & $6(3)$ & 0 & 0 \\
7 year & 48 & 0 & 0 & $10(5)$ & 0 & $8(4)$ & 0 & 0 \\
2 years & 48 & 0 & 0 & $17(8)$ & 0 & $15(7)$ & 0 & 0 \\
3 years & 48 & 0 & 0 & $21(10)$ & 0 & $21(10)$ & 0 & 0 \\
4 years & 48 & 0 & $2(1)$ & $25(12)$ & 0 & $27(13)$ & $2(1)$ & 0 \\
5 years & 41 & 0 & $5(2)$ & $20(12)$ & 0 & $27(11)$ & $5(2)$ & 0 \\
6 years & 23 & 0 & $9(2)$ & $30(7)$ & 0 & $28(6)$ & $9(2)$ & 0 \\
7 years & 10 & 0 & $10(1)$ & $50(5)$ & 0 & $50(5)$ & 0 & 0 \\
8 years & 3 & 0 & 0 & $67(2)$ & 0 & $67(2)$ & $33(1)$ & 0 \\
9 years & 1 & 0 & 0 & $100(1)$ & 0 & $100(1)$ & 0 & 0 \\
\hline
\end{tabular}

Table 6

Radiologic phenomena of bone remodeling in time: reactive lines [percentage (number of hips)]

\begin{tabular}{|l|lllccccc|}
\hline & Gruen zones & $\mathbf{1}$ & $\mathbf{2}$ & $\mathbf{3}$ & $\mathbf{4}$ & $\mathbf{5}$ & $\mathbf{6}$ & $\mathbf{7}$ \\
\hline Follow up & no of hips & & & & & & & \\
6 months & 48 & 0 & 0 & 0 & 0 & 0 & 0 & 0 \\
1 year & 48 & 0 & 0 & 0 & $8(4)$ & 0 & 0 & \\
2 years & 48 & 0 & 0 & $2(1)$ & $10(5)$ & $2(1)$ & 0 & 0 \\
3 years & 48 & 0 & 0 & $6(3)$ & $13(6)$ & $8(4)$ & 0 & 0 \\
4 years & 48 & 0 & 0 & $8(4)$ & $15(7)$ & $8(4)$ & 0 & 0 \\
5 years & 41 & 0 & 0 & $10(4)$ & $15(6)$ & $10(4)$ & 0 & 0 \\
6 years & 23 & 0 & 0 & $9(2)$ & $17(4)$ & $4(1)$ & 0 & 0 \\
7 years & 10 & 0 & 0 & $20(2)$ & $30(3)$ & $10(1)$ & 0 & 0 \\
8 years & 3 & 0 & 0 & $33(1)$ & $33(1)$ & 0 & 0 & 0 \\
9 years & 1 & 0 & 0 & 0 & $100(1)$ & 0 & 0 & 0 \\
& & 0 & & & & & & \\
\hline
\end{tabular}

At the time of review $12 \%$ hips had grade I ossifications, $4 \%$ grade II, $2 \%$ grade III and $0 \%$ grade IV.

\section{STATISTICAL ANALYSIS}

Statistical analysis showed correlations between tight femoral canal fit and the existence of cortical hypertrophy and the non-existence of spotwelding. (Table n) The correlation between the stem filling the medullary canal completely on the AP radiograph and symmetrical cortical thickening was significant $(p<0.0001$ chi-square test). Vice versa: 


\section{Table 7}

Distribution of the radiologic phenomena with regards to the tightness of the fit of the femoral stem in the femoral canal [number of cases (percentage of the cases)]

\begin{tabular}{|l|lll|}
\hline & $\begin{array}{l}\text { Tight fit } \\
13(27 \%)\end{array}$ & $\begin{array}{l}\text { Non-tight fit } \\
35(73 \%)\end{array}$ & $\begin{array}{l}\text { All stems } \\
48(100 \%)\end{array}$ \\
\hline No reactions & $3(23 \%)$ & $13(37 \%)$ & $16(33 \%)$ \\
Cancellous densfication & $1(8 \%)$ & $18(51 \%)$ & $19(40 \%)$ \\
Cortical thickening & $9(69 \%)$ & $4(11 \%)$ & $13(27 \%)$ \\
\hline
\end{tabular}

the correlation between the stem not filling the medullary canal completely and cancellous densifications (spotwelding) was also significant ( $\mathrm{p}<0.0001$ chi-square test). No correlations were found between the clinical parameters (OHS, Charnley class and the VAS for pain) and the radiologic phenomena. Especially the presence of thigh pain failed to demonstrate a correlation with cortical thickening or reactive line formation. Up to the latest review no stems were loose or revised. At a follow up of 6.1 (range: 4 9.3) years with all patients surviving a survival percentage of $100 \%$ is still the case.

\section{Discussion}

The overall result after 6.1 years is excellent in this prospective, non-inventor related study. The pain relief $(89 \%)$ and survival of the cementless HA-coated Mallory-Head femoral prosthesis $(100 \%)$ can be compared with several other cementless prostheses $(17,32-37)$, although these studies described primary cementless hip replacements. The functionality of the hip (limping and the use of walking aids) in these revision cases is less good than in the mentioned primary procedures. Studies with the same prosthesis $(38,39)$ (but without the HA-coating and also primary replacements) also show better results in terms of function, but pain relief and survival are comparable. These differences in functionality can be explained by multiple surgery and less function of the abductor muscles, resulting in limping even before the index operation. Preoperatively, all patients had a limp and postoperatively $36 \%$ of the patients still limped and $41 \%$ used walking aids regularly. (table 3) Moreover, revision patients are recommended to use walking aids after their operation, especially when they are limping or feeling they are unstable when walking. Adding the OHS to our study illustrated the patients opinion better than the HHS in our opinion. The mean postoperative HHS was 90 points, which is the usual score after total hip replacement. The OHS shows that besides the already mentioned limping and use of walking aids, the ability to do household shopping and sexual activities, the latter especially in women, are frequently noted items.

We showed better results in our study compared with the proximally porous coated revision procedures in literature. (13,40-45) These authors describe loosening and rerevision rates above $10 \%$ but they studied the use of proximally porous coated in more extensively (class 3 and worse) damaged femora. Woolson and Delaney (45) however noted $48 \%$ of their prostheses subsiding in a study population with only class 1 and 2 femoral defects, a study population comparable to our study. Hydroxy-apatite-coated 
femoral exchange arthroplasty for mechanical lossening has shown satisfying results and the restoration of bone stock is promising for long-term implant survival. $(18,46)$ Specially designed revision prostheses with longer stems and an extensive porous coating have been engineered to bypass the damaged part of the femur and to provide stability by distal fixation. $(7,10-15)$ We do not recommend the use of proximally porous coated prostheses in these grossly damaged femora, but use calcar replacing or distal fixation prostheses instead.

Tanzer et al. (24) and Harris (25) claim that cementless femoral stems may present a pathway for polyethylene particles to permeate distally and cause osteolysis, because they lack the suggested cement barrier for particles. On the contrary, it has been shown that a HA-coated femoral stem may prevent peri implant particle migration $(35,47-51)$ and has superior potential in sealing the proximal femur over the use of cement. (52) Hydroxyapatite (HA) coatings have been shown to provide a secure and reliable bond between prosthesis and bone even under loaded conditions over long periods of time, without the formation of an intermediate layer of fibrous tissue. (53-61) Clinical results with HA-coated prostheses have shown reliable osseointegration with negligible midthigh pain. $(52,62,63)$ The use of a titanium plasma-sprayed HA-coated femoral prosthesis leads to a tight bondage between the metaphyseal bone and the prosthesis and the HA diminishes the "jumping distance" for osteocytes to create a circumferential seal of the diaphysis that leaves a smaller effective joint space, preventing the migration of particulate debris downwards along the interface and preventing the formation of linear lesions creating a barrier for PE-debris migrating distally. The bone ongrowth even occurs in a damaged and sclerotic proximal femur as in revision operations is often the case as a result of bone resorption and relative movement between bone and the loosened implant. That this seal in combination with the HA-coating is effective is shown by various patients with $\mathrm{PE}$-wear without any sign of proximal or distal bone resorption. Although Yee et al. (64) were not able to show a difference in using a HA-coating or not on the Mallory-Head femoral prosthesis, their follow up length (4.4-4.9 years) might be too short to judge the extra effect of HA with respect to longevity of the prosthesis.

The long term success of most prostheses is closely related to the distribution of stress transfer, which mainly depends on prosthetic design and bonding characteristics. $(17,51)$ Predominance of stress transfer more distally in the femur caused by an infavorable stem-to-bone stiffness ratio, which is thought to be a reason for a higher incidence of thigh pain (65-70) and leads to augmented proximal stress shielding-induced bone resorption, which may start a failure scenario. (68) The morphology of this stress transfer (cancellous densification or cortical thickening) is not related to stem size but to stem fit. The radiographic femoral osseointegration is characterized by a specific pattern of remodeling of the proximal femur. (figure 2) Positive bone remodeling in the form of endosteal bone apposition in Gruen zones 2 and 6 suggests that the transfer from stem to femoral bone occurs in this area and that the prosthesis is securely bonded there. When transferring stresses from the proximal to the distal prosthesis, a slow process of bone resorption (negative bone remodeling) in the region of the lesser and greater trochanter should be expected. We could not detect any sign of femoral resorption or atrophy in our study which can be explained by the fact that a substantial percentage of the bone mineral content has to be resorbed before it is visual on plain radiographs.

We think that the calcar rounding in $34 \%$ of the patients is not the same process as resorption of the proximal femur, because it remained stable after 2 years and proximal femoral resorption should not be stable with ongoing femoral remodeling. On the other hand, numerous series reported proximal bone resorption to occur after this length of 


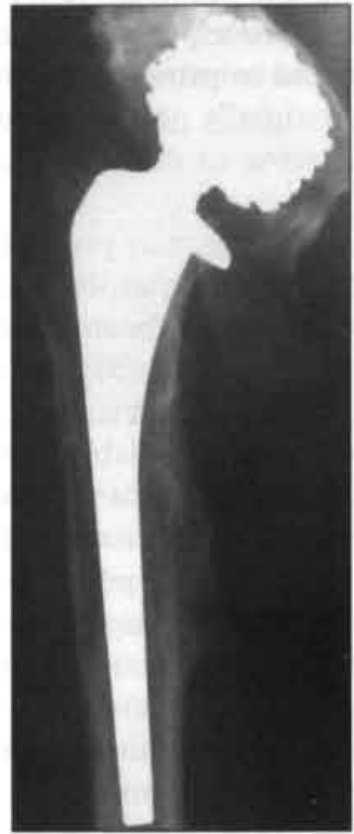

A

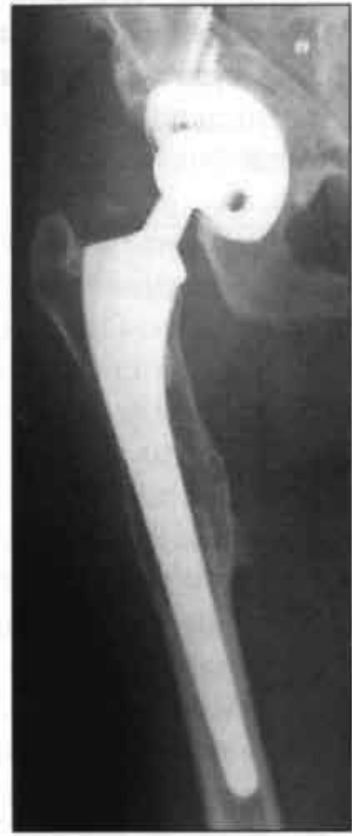

B
Preoperative (A) and nine year postoperative (B) radiographs of a 40 -year old lady at operation. This patient has suffered the sequellae of a central hip dislocation and a proximal femoral fracture, necessitating three previous operations including a total hip replacement at the age of $\mathbf{3 6}$ years. Painful aseptic loosening led to a revision with the Mallory-Head standard femoral stem and Harris Galante acetabular cup. After nine years of follow up no osteolytic lesions of the proximal or distal femur and a quiet femoral remodeling are shown. The patient has no pain, is not limping, uses no walking aids and has a HHS of 100 .

follow up based on the interpretation of radiographs. $(39,51,61,62)$ We performed a DEXA study providing more information about bone mineral density changes next to this prosthesis. (71) The formation of a reactive line around the distal part of the stem in Gruen zones 3, 4 and 5 is explained by the presence of a fibrous interface as a result of micromotion in this area. In fact, after 6.1 years most of the bone apposition occurs adjacent to that part of the femoral stem where the HA coating ends, the so-called transitional zone. We would have expected the apposition to occur more proximally since the coating was present only on the proximal one third of the stem. Instead we found that the region in which the most prominent cancellous and cortical densifications were observed gradually shifted from proximally in Gruen zones 2 and 6 to more distally in these same zones. Formation of new bone in the area near the lower edge of HA-coatings was predicted by Huiskes et al. (66) using finite element analysis. The explanation was that particularly in this area endosteal stress concentrations are caused by the abrupt transition from a bonded to a loose interface.

The incidence of cortical thickening at six years (30\%) is mainly symmetrically distributed around tight fitting stems in zones 3 and 5 . Cortical densification at six years (37\%) is mainly symmetrically distributed around non tightly fitted stems in zones 2 and 6. This is different from other studies. D'Antonio et al. (34) observed $47 \%$ cortical thickening in Gruen zone 5 along with $63 \%$ calcar resorption after nearly 6 years with a proximally HA-coated stem. Geesink and Hoefnagels (62) using the same design of prosthesis as d'Antonio reported nearly the same figures. The phenomenon of cortical hypertrophy was also noted with non-cemented, non-HA coated stems: Mulliken et al. (39) reported distal cortical hypertrophy in 35\% and $38 \%$ proximal bone loss of their patients. Tonino et al. (51) however reported a cortical thickening rate of only $3 \%$ to $5 \%$ with a $27 \%$ calcar resorption. They advised, in contrast to most other authors, not to 
obtain a complete fill of the diaphysis and they both advocated overreaming the diaphysis. We think that these widely variating numbers quoted for periosteal or endosteal bone appositions are merely a function of the tightness of the fit of the stem, a fact that is not reported in most of the literature concerning radiographic changes next to the femoral stem. This paper suggests that the concept of transitional load transfer from proximal to distal can morphologically be predicted by the way the stem fills the medullary canal. Whiteside (72), in his study on the effect of stem fit on bone hypertrophy, observed that a tight fit is associated with distal cortical hypertrophy, while a loose fit, did not and caused more pain. In our study the relation between stem fit and pain was non significant, but we could prove the relation between femoral canal fit and the radiologic remodeling pattern. We could not show that proximal bone loss is correlated with with a tight distal fit but in theory it should. Therefore we too advise to overream the diaphysis, widening the diaphysis, and aim for perfect metaphyseal fit. One should not try to use a smaller prosthesis and skip the process of overreaming of the femoral canal, because there will be no perfect metaphyseal press fit and the prosthesis might subside.

\section{Conclusions}

The osseointegration of a proximally HA-coated hip prosthesis is very reliable in mildly damaged femora (up to class $3 \mathrm{~A}$ according to Paprosky) in revision cases irrespective of factors such as age, sex, weight, activity and diagnosis. These mildly damaged femora can be treated more or less the same as primary hip replacement with the same results. We noted that the HA-coating effectively prevented distal femoral osteolysis in cases with excessive PE-wear.

Our results confirm our hypothesis that the morphology of the positive bone remodeling around the stem, with either endosteal bone formation or periosteal bone formation, was dependent on the way the stem filled the medullary canal. The radiologic phenomena are in our opinion not prosthesis-dependent but femoral canal fit-dependent. We showed that in a less tightly fitted prosthesis spotwelding is in essence the endosteal equivalent of cortical hypertrophy in a tightly fitted prosthesis. 


\section{REFERENCES}

1. Barrack A. (1995) Economics of revision hip arthroplasty. Clin Orthop 319:209-214.

2. Robinson AHN, Palmer CR, Villar RN. (1999) Is revision as good as primary hip replacement? A comparison of quality of life. J Bone Joint Surg [Br] 81:42-45.

3. Izquerdo RJ, Northmore-Ball MD. (1994) Long-term results of revision hip arthroplasty: survival analysis with special reference to the femoral component. J Bone Joint Surg [Br] 76:34-39.

4. Estok DM, Harris WH. (1994) Longterm results of cemented femoral revision using second generation techniques. An average 11 year follow up evaluation. Clin Orthop 299:190-202.

5. Katz RP, Callaghan JJ, Sullivan PM, Johnston RC. (1995) Results of cemented femoral revision total hip arthroplasty using improved cementing techniques. Clin Orthop 319:178-183.

6. Pierson JL, Harris WH. (1995) Effect of improved cementing techniques in the longevity of fixation in revision cemented femoral arthroplasties. Average 8.8 year follow up period. J Arthroplasty 10:581-591.

7. Rubash HE, Harris WH. (1998)

Revision of non-septic, loose, cemented femoral components using modern cementing techniques. J Arthroplasty 3:241-248.

8. Dohmae Y, Bechtold JE, Sherman RE, Puno RM, Gustilo RB. (1988)

Reduction in cement-bone interface shear strength between primary and revision arthroplasty. Clin Orthop 236:214-220.

9. Krause WR, Krug W, Miller J. (1992) Strength of the cement-bone interface. Clin Orthop 163:290-299.

10. Aribindi R, Barba M, Solomon MI, Arp P, Paprosky WG. (1998) Bypass fixation. Orth Clin North Am 29:319-329.

11. Engh CA, Culpepper II WJ, Kassapidis E. (1998) Revision of loose cementless femoral prostheses to larger porous coated components. Clin Orthop 347:168-178.

\section{Engh CA, Glassman AH, Griffin WL,} Mayer JG. ( 1988) Results of cementless revision for failed cemented total hip arthroroplasty. Clin Orthop 235:91-110.

13. Head WC, Wagner RA, Emerson jr RH, Malinin TI. (1994) Revision total hip arthroplasty in the deficient femur with aproximal load bearing prosthesis. Clin Orthop 298:119-126.

14. Lawrence JM, Engh CA, Macalino GE. (1993) Revision total hip arthroplasty. Long term results without cement. Orthop Clin North Am 24:635-644.

15. Moreland JR, Bernstein ML. (1995) Femoral revision hip arthroplasty with uncemented, porous coated stems. Clin Orthop 319:141-150.

16. Paprosky WG, Greidanus NV, Antoniou J. (1999) Minimum 10-year results of extensively porous-coated stems in revision hip arthroplasty. Clin Orthop 369:230-242.

17. Taylor JW, Rorabeck CH. (1999) Hip revision arthroplasty: Approach to the femoral side. Clin Orthop 369:208-222.

18. Geesink RGT. (2002) Osteoconductive coatings for total joint arthroplasty. Clin Orthop 395:53-65.

19. Burkart BC, Bourne RB, Rorabeck CH, Kirk PG. (1994) Thigh pain in cementless total hip arthroplasty. Orthop Clin North Am 24(4):645-653.

20. Head WC. (1993) Mallory-Head porous press-fit primary hip replacement. Presented at the tenth annual international symposium: New Developments in Total Joint Reconstruction, Lake Tahoe, Nevada.

21. Mallory TH, Head WC. (1988) A total hip replacement system: clinical experience and recommendations.Contemp Orthop 17 (4).

22. Mallory TH, Head WC. (1994)

Two to seven year follow-up of 311 proximal one-third plasma spray coated, monolithic femoral components in total hip arthroplasty. Presented at the AAOS, New Orleans, Louisiana. 
23. Lemons JE. (1993) Moderator of the symposium: Porous coating methods: the pros and cons. Contemp Othop 27(3).

24. Tanzer M, Maloney WJ, Jasty $\mathbf{M}$, Harris WH. (1992) The progression of femoral cortical osteolysis in association with total hip arthroplasty without cement. J Bone Joint Surg [Am] 74:404-410.

25. Harris WH. (1995) The problem is osteolysis. Clin Orthop 311:46-26.

26. Harris WH. (1969) Traumatic arthritis of the hip after dislocation and acetabular fractures: treatment by mold arthroplasty. An end result study using a new method of result evaluation. J Bone Joint Surg [Am] 51:737.

27. NHM, Dhert WJA, Ockhuijsen S, Gosens T, van Langelaan EJ, Geesink RGT, Bulstra SK. (2000) Translation and validation of the 12 item questionnaire on the perceptions of patients about total hip replacement. Acta Orthop Scand suppl 284:70.

28. Dawson J, Fitzpatrick R, Carr A, Murray D. (1996) Questionnaire on the perceptions of patients about total hip replacement. J Bone Joint Surg $[\mathrm{Br}]$ 78:185.

29. Gruen TA, McNeice JM, Amstutz HC. (1979) Modes of failure of cemented stem type femoral components. A radiographic analysis of loosening. Clin Orthop 141:1729.

30. DeLee JG, Charnley J. (1976) Radiological demarcation of cemented soekets in total hip replacement. Clin Orthop 121:20-32.

31. Brooker AF, Bowerman JW, Robinson RA, Riley RHJR. (1973) Ectopic ossification following total hip replacement. Incidence and a metbod of classification. J Bone Joint Surg [Am] 55:1629-1632.

32. Bourne RB, Rorabeck CH, Ghazal ME, Lee MH. (1994) Pain in the thigh following total hip replacement with a porous coated anatomic prosthesis for osteoarthrosis. J Bone Joint Surg [Am] 76:1464-1470.

33. Engh CA, Bobyn JD, Glassman AH.
(1987) Porous coated hip replacernent. The factors governing bone ingrowth, stress shielding and clincal results. J Bone Joint Surg [Br] 69:44-55.

34. D'Antonio JA, Capello WN, Jaffe WL. (1992) Hydroxylapatite-coated hip implants: multicentre three year clinical and roentgenographic results. Clin Orthop 285: 102-115.

35. Hellman EJ, Capello WN, Feinberg JR. (1999) Omnifit cementless total hip arthroplasty. A 10 year average follow up. Clin Orthop 364:164-174.

36. Ang KC, Das De S, Goh JCH, Low SL, Bose K. (1997) Periprosthetic bone remodelling after cementless total hip replacement. A prospective comparison of two different implant designs. J Bone Joint Surg [Br] 79:675-679.

37. Malchau H, Herberts $P$, Ahnfelt $L$. (1993) Prognosis of total hip replacement in Sweden. Acta Orthop Scand 64:497506.

38. Mallory TH, Mitchell MB. (1990)

Results of total hip replacement using porous coating as a fixation mode. Sem Arthroplasty 1:70.

39. Mulliken BD, Bourne RB, Rorabeck CH, Nayak N. (1996) A tapered titanium femoral stem inserted without cement in a total hip arthroplasty. J Bone Joint Surg [Am] 78:1214-1225.

40. Berry DJ, Harmsen S, Ilstrup D, Lewallen DG, Cabanela ME. (1995) Survivorship of uncemented proximally porous coated-femoral components. Clin Orthop 319:168-177.

41. Hedley AK, Gruen TA, Ruoff DP. (1988) Revision of failed total hip arthroplasties with uncemented porous coated anatomic components. Clin Orthop 235:75-90.

42. Malkani AL, Lewallen DG, Cabanela ME, Walrichs SL. (1996) Femoral component revision using an uncemented, proximally coated, long-stem prosthesis. J Arthroplasty 11:411-418.

43. Mulliken BD, Rorabeck CH, Bourne RB. (1996) Uncemented revision total hip arthroplasty: a 4- to 6-year review. 
Clin Orthop 1996;325:156-162.

44. Peters CL, Rivero DP, Kull LR, Jacobs J, Rodsenberg AG, Galante JO. (1995) Revision total hip arthroplasty without cement: subsidence of proximally porous coated femoral components. J Bone Joint Surg [Am] 67:1217-1226.

45. Woolson ST, Delaney TJ. (1994) Failure of proximally porous coated femoral prostheses in revision total hip arthroplasty. J Arthroplasty 10(suppl): S22-S28.

46. Walker PS, Culligan SG, Hua J, Muirhead-Allwood SK, Bentley G. (2000) Stability and bone preservation in custom designed revision hip stems. Clin Orthop 373:164-173.

47. Capello WN, D'Antonio JA, Manley MT, Feinberg JR. (1998) Hydroxyapatite in total hip arthroplasty. Clinical results and critical issues. Clin Orthop 355:200211.

48. Coathup MJ, Blunn GW, Flynn N, Williams C, Thomas NP. (2000)

A comparison of bone remodelling around hydroxyapatite-coated porous-coated and grit-blasted hip replacements retrieved at post-mortem. J Bone Joint Surg $[\mathrm{Br}]$ 83:118,

49. Rahbek O, Overgaard S, Søballe K, Bunger C. (1996) Hydroxyapatite coating might prevent peri-implant particle migration: a pilot study in dogs. Acta Orthop Scand 67(suppl 267):58-9.

50. Rahbek O, Overgaard S, Lind $\mathbf{M}$, Bendix, Bunger C, Seballe K. (2001) Sealing effect of hydroxyapatite coating on peri-implant migration of particles. An experimental study in dogs. J Bone Joint Surg [Br] 83:441-447.

51. Tonino AJ, Rahmy AIA. (2000)

The International ABG Study Group. The hydroxyapatite-ABG hip system. J Arthroplasty 11:534-542.

52. Kadoya Y, Kobayashi A, Ohashi H. (1998) Wear and osteolysis in total joint replacements. Acta Orthop Scand 278:1.

53. Bauer JD, Geesink RGT, Zimmerman R, McMackon JT. (1991) Hydroxyapatite coated femoral sterns. J Bone Joint Surg [Am] 74:1439-1452.

54. Donnelly WJ, Kobayashi A, Freeman MAR, Chin TW, Yeo H, West M, Scott G. (1997) Radiological and survival comparison of four methods of fixation of a proximal femoral stem. J Bone Joint Surg [Br] 79:351-360.

55. Frayssinet $\mathbf{P}$, Hardy D, Conte $\mathbf{P}$, Delince P, Guilhem A, Bonel G. (1993) Histological analysis of the bone-prosthesis interface after implantation in humans of prostheses coated with hydroxy-apatite. J Orthop Surg 7:246-253.

56. Geesink RGT, Groot K, Klein CPAT. (1988) Bonding of bone to apatite coated implants. J Bone Joint Surg [Br] 70:17-22.

57. Hardy DCR, Frayssinet P, Guilhem A, Lafontaine MA, Delince PE. (1991) Bonding of hydroxyapatite-coated femoral prostheses. Histopathology of specimens from four cases. J Bone Joint Surg [Br] 73:732-740.

58. Overgaard S, Lind $\mathbf{M}$, Glerup $\mathbf{H}$, Grundvig S, Bünger C, Soballe K. (1995) Hydroxyapatite and fluorapatite coatings for fixation of weight loaded implants. Clin Orthop 336:286-296.

59. Soballe K, Hansen ES, BrockstedtRasmussen H, Hjortal VE, Juhl GI, Pedersen CM, Hvid I, Bunger C. (1991) Gap healing enhanced by hydroxyapatite coatings in dogs.

Clin Orthop 272:300.

60. Søballe K, Hansen ES, BrockstedtRasmussen H, Bunger C. (1993) Hydroxyapatite coating converts fibrous tissue to bone around loaded implants. J Bone Joint Surg [Br] 75:270.

61. Tonino AJ, Therin M, Doyle C. (1999) Hydroxyapatite coated femoral stems: histology and histomorphometry around five components retrieved at autopsy. J Bone Joint Surg [Br] 81:148.

62. Geesink RGT, Hoefnagels NHM. (1995) Six-year results of hydroxyapatite-coated total hip replacement. J Bone Joint Surg [Br] 77:534-547.

63. Jaffe WL, Scott DF. (1993) Rationale 
and clinical application of hydroxyapatite coatings in press fit total hip arthroplasty. Semin Arthroplasty 3:159.

64. Yee AJM, Kreder HK, Bookman I, Davey JR. (1999) A randomised trial of hydroxyapatite coated prostheses in total hip arthroplasty. Clin Orthop 366:120.

65. Franks E, Mont MA, Maar DC. (1992) Thigh pain as related to bending rigidity of the femoral prosthesis and bone. Trans Orthop Res Soc 38:296.

66. Huiskes R, Weinans H, Dalstra M. (1989) Adaptive bone remodelling and biomechanical design considerations. Orthopaedics 12:1255-1267.

67. Huiskes R. (1990) Various stress patterns of press-fit, ingrowth and cemented femoral stems. Clin Orthop 261:27.

68. Huiskes R. (1993) Failed innovation in total hip replacement: diagnosis and proposals for a cure. Acta Orthop Scand 64:699.

69. Mont MA, Hungerford DS. (1997) Proximally coated ingrowth prostheses: a review. Clin Orthop 344:139.

70. Skinner HB, Curlin FJ. (1990)

Decreased pain with lower flexural rigidity of uncemented femoral prostheses. Orthopaedics 13:1223.

71. Rahmy AIA, Gosens T, Blake GM, Tonino AJ, Fogelman I. (2004)

Periprosthetic bone remodeling of two types of uncemented femoral implants with a proximal hydroxyapatite coating: a 3-year follow up study addressing the influence of prosthesis design and preoperative bone quality on periprosthetic bone loss. Osteoporosis Int, 15: 281-284.

72. Whiteside LA. (1989) The effect of stem fit on bone hypertrophy and pain relief in cementless total hip arthroplasty. Clin Orthop 247:138-147. 
FEMORAL FIT PREDICTS RADIOLOGIC CHANGES 


\section{FEMORAL FIT PREDICTS RADIOLOGIC CHANGES, BUT NOT CLINICAL RESULT, IN MALLORY-HEAD TOTAL HIP ARTHROPLASTY}

T. Gosens

J.C. Sluimer

A. D. Kester

E. J. van Langelaan 
FEMORAL FIT PREDICTS RADIOLOGIC CHANGES 


\section{Abstract}

Radiologic remodeling phenomena, such as cancellous densification and cortical thickening, around a hip prosthesis have various incidences in the literature, even when studied with the same prosthesis. Also relations between these features and clinical items, such as pain and limping, are described.

We prospectively studied the clinical and radiologic results in 3 patient groups: 89 standard primary THRs, 63 primary THRs in patients with hip dysplasia, and 48 revision THRs. We describe the differences in clinical behavior of a titanium HA-coated stem with variations in tightness of the fit of the prosthesis in the femoral canal, operative group, stem size, grade of osteoporosis and femoral morphometry.

The clinical results in all three groups are slightly favorable for the standard primary group. The pain relief and stem survival in the three groups were similar to that reported in other studies regarding cementless prostheses. Nontight femoral fit significantly positively influenced the development of cancellous densification; however the presence of osteoporosis also contributed to the formation of cancellous densification.

Only tight femoral canal fit significantly positively influenced the development of cortical thickening independent of other parameters. There was no correlation between clinical parameters and the radiologic phenomena in either of the groups.

Keywords:

femoral fit - remodeling - hip arthroplasty - Mallory-Head 


\section{INTRODUCTION}

Proximally HA-coated femoral components have been used in primary total hip replacements (THRs) with good results. (1-16) Their use in patients with hip dysplasia previously were described with successful results. (17) Hip replacement in dysplastic hips and in hips that were revised cause more technical problems and complications than primary hip replacement. $(14,18-22)$ The results of revision hip arthroplasty are not as good as the results of primary hip replacement; however the quality of life (23) and satisfying survival rates (24) have been reported for patients having revision surgery. The first goal of this study is to compare the clinical results of a proximally HAcoated femoral component in these three groups. We therefor analyzed the results of a prospective series of 200 consecutive THRs, using the cementless Mallory-Head HAcoated femoral prosthesis (Biomet, Warsaw). The prosthesis was used in 89 standard primary THRs, 63 primary THRs in patients with hip dysplasia and in 48 moderately damaged femora in patients who had revision surgery.

The second goal of this study is to study the radiologic reactions (cancellous densifications, cortical thickening, reactive line formation, calcar resorption) around this proximally HA-coated femoral prosthesis. The radiologic reactions have variable incidences in literature. For instance, the presence of cortical thickening varies from only $3 \%$ to $5 \%$ with $27 \%$ calcar resorption in one study 8 to $47 \%$ with $63 \%$ calcar resorption after approximately 6 years in an other study. (15) Even when using the same prosthesis (Mallory-Head) various percentages in different studies are reported (2,3,11-14). Mulliken et al. (14) describe only $6 \%$ of their population showed cancellous densifications and nearly $50 \%$ with cortical hypertrophy, while Mallory et al. (12) found $88.3 \%$ cancellous densifications in their population, with in $87.5 \%$ absence of cortical thickening. Therefore it does not seem logical that these reactions are described as features of the prosthesis. Using the three groups of patients, we test the hypothesis that the radiologic reactions depend on the tightness of the fit of the prosthesis in the femoral canal and therefore can be predicted. Variations in femoral fit then would explain the variability of the radiologic reactions around cementless prostheses in various studies and therefore are a reflection of operative technique. According to our hypothesis, all femurs should have a predictable radiologic reaction depending on the tightness of the fit. We also try to identify other factors that could have an influence on the radiologic behavior of this femoral prosthesis, such as osteoporosis or femoral morphometry. The third goal of this study is to relate the clinical results to the radiologic results. Whiteside (25) described a relation between tight femoral canal fit and cortical hypertrophy and the absence of pain, whereas a nontight fit did not cause cortical hypertrophy but was associated with pain.

The clinical and radiologic results of this prosthesis were studied previously $(2,3,11$ 14), but not with the additional HA-coating we used in this study. 


\section{MATERIALS AND METHODS}

\section{PATIENT CHARACTERISTICS}

Between 1991 and 1997200 consecutive THRs, 89 standard primary THRs, 63 THRs in patients with hip dysplasia, and 48 revision THRs were done. The study has been approved by the local institutional review board and all subjects gave informed consent. In the primary group, we operated on 45 men and 57 women with a mean age of 55.7 years (range, 20 - 68 years); 26 patients had bilateral surgeries. Ninety-one percent of patients had no previous hip surgery. Five percent had one previous operation and $4 \%$ had two or more operations. The primary group of patients with hip dysplasia consisted of 63 hips in 50 patients; 20 men and 30 women with a mean age of 52.7 years (range, 20 - 68 years); 13 patients had bilateral THRs. In this group, $81 \%$ has not had a previous operation, $11 \%$ had one previous hip operation, and $8 \%$ had two or more operations. In the revision group, we operated on 15 men and 32 women, with a mean age of 59.6 years (range, 37 - 72 years); 1 woman had bilateral surgeries. In the revision group, $88 \%$ had one previous hip operation and $12 \%$ had two or more operations.

The data were collected prospectively before the operation and at standardized follow up periods. We reviewed the results after a mean postoperative period of 6.4 years (range, 4.0 - 9.6 years). All patients were operated on by the senior author (EJvL) using a straight lateral approach. Routine postoperative treatment included 24 hours of antibiotic prophylaxis and perioperative anticoagulation. To inhibit distal stem contact, we routinely did distal overreaming of one $\mathrm{mm}$. with flexible reamers over a guide rod and reamed until the distal reamers achieved cortical contact. Postoperatively, protected weightbearing with crutches was used for 6 weeks in the patients in the standard primary group and in most of the patients with hip dysplasia having primary surgery. In some of the patients with hip dysplasia having primary surgery and all of the patients having revision surgery concomitant osteotomies and/or the soft tissue condition necessitated a 2- to 6-week period of bed rest, after which weightbearing was commenced. In the patients having standard primary surgery and in the patients with hip dysplasia having primary surgery the Mallory-Head stem primarily was combined with the cementless Harris Galante (HG) shell (Zimmer, Warsaw) and a CoCr head $(n=102)$, and later, the cementless Ringlock shell (Biomet, Warsaw) and a ceramic head $(n=49)$ were used. A $32-\mathrm{mm}$. head in combination with a HG shell was used in the first 12 cases; later, we only used $28-\mathrm{mm}$. heads. In patients having revision surgery we used $42 \mathrm{HG}$ acetabular shells with $28-\mathrm{mm}$. CoCr heads and 8 Ringlock shells with a $28-\mathrm{mm}$. ceramic head.

Six patients ( 8 hips $)$ died during this ongoing study after they had completed follow ups of $1,2,3,4,5(\mathrm{n}=2), 6$, and 7 years, respectively. All patients died of causes not related to the arthroplasty, had radiographic osseointegration of the prosthesis, and had no complaints at the last follow up. In none of the patients was permission obtained for an autopsy retrieval study.

\section{GEOMETRY OF THE PROSTHESIS}

The proximal geometry of the Mallory-Head porous component is designed to promote filling of the metaphysis and proximal off-loading. Unlike fully porous-coated cylindrical stems that tend to transmit most of the load distally and may stress shield proximally, the Mallory-Head porous implant tapers from proximal to distal allowing a 
gradual decrease in the stresses transferred to the bone. The metal of choice for the porous primary stem is titanium alloy (Ti-6Al-4V), chosen for its biocompatibility and its modulus of elasticity.

The proximal surface area is circumferentially porous-coated with a titanium alloy plasma spray, which greatly increases the surface area available of the stem for improved fixation. The middle $1 / 3$ has a roughened finish created through a blasting technique, which allows firm fixation in the diaphysis to prevent torsional stresses. The distal portion of the stem is smooth, allowing the majority of forces to be off-loaded proximally.

The ingrowth and ongrowth of bone to the prosthesis is stimulated by the addition of a HA-coating to the porous proximal $1 / 3$ of the femoral prosthesis. In this way, the initial fixation of the prosthesis in the proximal femur and the sealing effect to prevent migration of particulate debris are optimized.

\section{Patient assessments}

All patients were included in a prospective follow up schedule and were evaluated preoperatively, and postoperatively at 3,6 and 12 months and yearly thereafter using the Harris Hip Score (26) and specific questions about functional items such as pain, limping, and use of walking aids. At the latest followup, the modified "Oxford Heup Score" $(27,28)$ was added to the assessment. This questionnaire is based on the translation into Dutch and validation of the original 12-item questionnaire. (29) The questionnaire was extended with two questions about specific problems of the patient (the use of crutches or cane and problems with sexual intercourse). These specific questions were included in the total score, so this modified "Oxford Heup Score" ranges from 14 points (the best score) to 70 points (the worst score). Another part of the assessment was the use of a Visual Analogue Scale for pain $(0-10)$ and a question to determine whether the patients belonged to Charnley Class A, B, or C (30) at the time of analysis. Three additional questions about overall satisfaction of the patient were added: whether the mobility of the hip has improved by the operation, whether the pain in the hip has decreased by the operation, and whether the patient is satisfied by the result of the operation. These questions are not included in the total score of the modified "Oxford Heup Score" .

\section{RADIOGRAPHIC ASSESSMENTS}

The preoperative radiographs were graded for osteoporosis using the Singh scale (31) and the morphometry of the femur was classified using the method described by Dorr at al. (32) The femurs with dysplasia were classified according to Crowe et al. (18) The femurs in the patients having revision surgery were classified according to Paprosky et al. (33) During each follow up, AP and lateral radiographs were taken of the involved hip. These radiographs were evaluated using Gruen zones (34) for signs of bone resorption, subsidence, osteolysis, interface deterioration, cyst formation, radiolucencies, reactive line formation around the HA-coated and the noncoated parts of the femoral prosthesis, cancellous bone densifications, cortical hypertrophy, tip sclerosis and pedestal formation around the stem tip. Hydroxyapatite covered the stem in Gruen zones 1 and 7 and the proximal part of zones 2 and 6. Changes in these radiographic parameters with time were observed. Special attention was given to stress-shielding induced bone resorption and osteolysis resulting from particulate debris. All bony changes were estimated by an observer who was not the surgeon (TG). Resorption of bone was not quantified but graded as present, when loss of trabecular bone density, cor- 
ticocancellization, or cortical thinning were observed. Cortical hypertrophy (cortical thickening) was recorded when there was an increase in the outside diameter of the cortex at the maximal point of hypertrophy. Reactive line formation was defined as a thin radiopaque layer of bone seen parallel and in close proximity to the implant. Between this line and the implant, a radiolucent line always was present. To be recorded, this line had to extend at least $50 \%$ of the zone length. Radiolucency was defined as a radiolucent zone anywhere around the implant with no relation to any radiopacity. A radiolucent line was recorded when it was at least $2 \mathrm{~mm}$ in width and at least $30 \%$ of any one zone. Osteolysis was defined as a scalloped erosion of more than $2 \mathrm{~mm}$ in diameter at the bone-prosthesis interface.

Femoral cancellous bone densification (spot-welding) was defined as an augmentation in bone mineral content anywhere between the implant and the femoral cortex. The position of the implant after surgery was also assessed: the stem was assessed as in varus or in valgus when it deviated more than $2^{\circ}$ from the anatomic axis of the femur. The femoral canal fit (stem fill of the femoral canal) was defined on the AP radiograph as tight when the stem diameter in the midstem zones ( 3 and 5) divided by the inner diameter of the femoral cortex was more than 0.8. A nontight fit was defined when this was less than 0.8 . Fit was determined to be tight or nontight based on the radiograph taken immediately postoperative. The stem was defined as having fixation by bone ongrowth (osseointegration) when there was no subsidence or migration and no formation of a radiolucent or radiodense line along the HA-coated portion of the prosthesis. The presence of cancellous bone densifications also suggested bone ongrowth.

The acetabular bone-prosthesis transition was evaluated using the criteria of DeLee and Charnley. (35) We recorded asymmetry of the head in the liner suggesting PE-wear.

\section{Statistical ANALYSIS}

Statistical analysis was done using SPSS ${ }^{*} 10.0$ software (SPSS, Chicago, IL). Descriptive statistics, including mean, median, standard deviation, minimum and maximum for continuous variables, and frequency distributions for categorical variables were determined. Three operative groups (primary, dysplasia, and revision) were compared on clinical and radiologic parameters. A one-way ANOVA was done for quantitative parameters, logistic regression analysis for dichotomous parameters, and ordinal logistic regression for ordinal parameters. Linear regression was used for continuous parameters. In some continuous parameters, the frequency distribution was not normal. A logtransformation was applied and the resulting, normally distributed parameter was used in a linear regression analysis. In some ordinal parameters the frequency distribution was such that dichotomization was done to obtain more reliable statistics. Post-hoc comparisons were made by Tukey's HSD test or Bonferroni correction. Logistic regression was done to determine the influence of femoral canal fit, operative group, osteoporosis, femoral morphometry, and stem size on cancellous densification, cortical thickening, and reactive line formation. Dummy variables were used for all categorical parameters with more than two categories or groups. The category with the largest frequency was set as reference. Spearman correlation coefficients were calculated to determine the relationship between the aforementioned radiologic parameters and pain, limping, use of walking aids and stem size. The Spearman correlation between these clinical parameters and the number of previous operations also was determined. Statistical significance was set at $\mathrm{p} \leq 0.05$. 


\section{RESULts}

We had 9 patients with prolonged wound drainage ( 6 in the standard primary group and 3 in the revision group), 3 patients developed a wound hematoma (all in the standard primary group). None of these patients had revision surgery. In the patients with hip dysplasia no such problems were seen. No infections occurred. Dislocations were seen in 8 cases ( 3 in the standard primary group, 1 in the dysplasia group and 4 in the revision group). All were treated with closed reduction, but 6 progressed to having recurrent dislocations and were treated by acetabular revision. We exchanged 3 liners ( 1 in every group) for augmented PE wear without loosening of the cup. We did 3 acetabular revisions ( 2 in the standard primary group and 1 in the dysplasia group) for augmented $\mathrm{PE}$ wear with acetabular cyst formation. One patient is currently waiting for acetabular revision for aseptic loosening and 10 additional patients ( 3 having standard primary surgery, 4 with hip dysplasia, and 3 having revision surgery) had liner asymmetry. These patients are screened for progression every 6 months. In none of the patients signs of femoral osteolysis were seen.

Stem revision was done in 2 patients having standard primary surgery. One patient had a subtrochanteric fracture and osteoarthritis. Both problems were tried to solve in one stage but extensive preparation of the proximal femur led apperently to non-ingrowth. The other patient had severe osteoporosis after a failed screw fixation of a femoral neck fracture. This situation also led to failure of ingrowth. No stem revisions were done after the second year of follow up or were pending at the last follow up. One patient with hip dysplasia fell 1 week after the operation and sustained a fracture at the tip of the stem, which was treated by plating. One peroperative fracture in a patient with hip dysplasia was treated conservatively. One temporary ischiadic nerve palsy after lengthening the leg approximately $5 \mathrm{~cm}$. resolved spontaneously within 4 months in a patient with dwarfism who had hip dysplasia.

The clinical results are shown in table 1 . We did not find a difference in Charnley class ( $p=0.05$, ordinal logistic regression), femoral morphometrics $(p=0.73$, ordinal logistic regression) or grade of osteoporosis $(p=0.70$, logistic regression) between the three groups. An age difference between the three groups was observed $(p=0.02$, one way ANOVA). Post hoc multiple comparisons by Tukey HSD showed no significant difference between the revision group and the standard primary group $(p=0.11)$ or between the standard primary and the hip dysplasia group $(p=0.56)$, but a significant difference was seen between patients having revision surgery and those with hip dysplasia having primary surgery $(\mathrm{p}=0.02)$.

No significant difference in Harris Hip Score change was observed between the groups. The $\mathrm{p}$ values were 0.18 (revision surgery versus standard primary surgery), 0.13 (revision surgery versus primary surgery in patients with hip dysplasia) and 0.93 (standard primary surgery versus primary surgery in patients with hip dysplasia), respectively. The visual analogue scale for pain was $1.27,1.70$ and 1.65 , respectively at the latest review. No significant differences in pain between the groups was found. The p values were 0.17 (revision surgery versus standard primary surgery), 0.22 (revision surgery versus primary surgery in patients with hip dysplasia) and 0.94 (standard primary surgery versus primary surgery in patients with hip dysplasia), respectively. A specific question for thigh pain was answered identically by all patients: after 6 years only 3 standard primary surgery patients, 2 patients with dysplasia and 1 patient who had a revision operation had thigh pain. This number is too low for reliable statistics. 
Table 1

Summary of clinical statistics.

Answer 1 corresponds with the best possible situation and answer 5 with the worst possible situation.

\begin{tabular}{|c|c|c|c|}
\hline parameter scored & primary & dysplasia & revision \\
\hline \multicolumn{4}{|l|}{ preoperative function } \\
\hline preop pain ( 1 to 5 in \%) & $0 / 0 / 2 / 30 / 68$ & $0 / 0 / 8 / 32 / 60$ & $0 / 0 / 2 / 19 / 79$ \\
\hline preop limping ( 1 to 5 in $\%$ ) & $0 / 0 / 2 / 30 / 68$ & $0 / 2 / 8 / 20 / 70$ & $0 / 0 / 0 / 12 / 88$ \\
\hline preop use walking aids ( 1 to 5 in $\%$ ) & $35 / 15 / 35 / 10 / 5$ & $2 / 5 / 7 / 46 / 40$ & $8 / 4 / 27 / 21 / 40$ \\
\hline \multicolumn{4}{|l|}{ Harris Hip Score" } \\
\hline preop HHS $(0-100)$ & $42(10-48)$ & $42(10-60)$ & $39(16-48)$ \\
\hline postop HHS $(0-100)$ & $92(10-100)$ & $90(40-100)$ & $89(51-100)$ \\
\hline \multicolumn{4}{|l|}{ modified Oxford Heup Score ${ }^{p a}$} \\
\hline postop pain (1 to 5 in \%) & $76 / 16 / 2 / 2 / 2$ & $74 / 16 / 6 / 4 / 0$ & $64 / 26 / 6 / 2 / 2$ \\
\hline postop wash and dry (1 to 5 in \%) & $72 / 21 / 5 / 1 / 1$ & $73 / 16 / 8 / 3 / 0$ & $43 / 37 / 2 / 0 / 0$ \\
\hline postop public transport ( 1 to 5 in \%) & $47 / 47 / 4 / 1 / 1$ & $51 / 41 / 6 / 2 / 0$ & $37 / 46 / 13 / 9 / 2$ \\
\hline postop putting socks on ( 1 to 5 in $\%$ ) & $66 / 24 / 5 / 3 / 2$ & $65 / 25 / 5 / 5 / 0$ & $41 / 35 / 13 / 9 / 2$ \\
\hline postop daily shopping (1 to 5 in \%) & $78 / 16 / 4 / 1 / 1$ & $76 / 18 / 8 / 0 / 0$ & $56 / 20 / 13 / 2 / 9$ \\
\hline postop walking distance ( 1 to 5 in $\%$ ) & $71 / 17 / 8 / 3 / 1$ & $73 / 19 / 3 / 5 / 0$ & $54 / 15 / 20 / 11 / 0$ \\
\hline postop stair walking ( 1 to 5 in $\%$ ) & $61 / 31 / 5 / 2 / 1$ & $68 / 25 / 5 / 2 / 0$ & $39 / 33 / 17 / 11 / 0$ \\
\hline postop raise from chair ( 1 to 5 in $\%$ ) & $75 / 20 / 3 / 2 / 0$ & $76 / 22 / 2 / 0 / 0$ & $57 / 30 / 13 / 0 / 0$ \\
\hline postop limping ( 1 to 5 in \%) & $72 / 14 / 5 / 4 / 5$ & $63 / 15 / 7 / 6 / 9$ & $26 / 30 / 8 / 14 / 22$ \\
\hline postop sudden severe pain ( 1 to 5 in \%) & $82 / 9 / 5 / 1 / 2$ & $81 / 11 / 6 / 2 / 0$ & $57 / 28 / 11 / 2 / 2$ \\
\hline postop work interference ( 1 to 5 in $\%$ ) & $65 / 25 / 5 / 5 / 1$ & $65 / 24 / 5 / 6 / 0$ & $33 / 37 / 17 / 111 / 2$ \\
\hline postop nightpain ( 1 to 5 in $\%$ ) & $79 / 11 / 6 / 3 / 2$ & $79 / 11 / 5 / 2 / 3$ & $63 / 22 / 11 / 2 / 2$ \\
\hline postop use of walking aids ( 1 to 5 in \%) & $76 / 14 / 3 / 4 / 3$ & $66 / 15 / 9 / 7 / 3$ & $32 / 20 / 7 / 8 / 33$ \\
\hline postop sexual activities ( 1 to 5 in $\%$ ) & $73 / 21 / 3 / 1 / 2$ & $62 / 28 / 5 / 0 / 5$ & $65 / 11 / 4 / 7 / 13$ \\
\hline mean total postop mOHS (14 - 70) & $20.1(14-60)$ & $20.6(14-48)$ & $27(14-50)$ \\
\hline postop VAS for pain $(0-10)$ & $1.27(0-10)$ & $1.70(0-7)$ & $1.65(0-8)$ \\
\hline Charnley class" (A/B/C in \%) & $28 / 30 / 42$ & $21 / 57 / 22$ & $37 / 20 / 43$ \\
\hline
\end{tabular}

The total modified "Oxford Heup Score" for the revision group differed significantly from the standard primary group $(\mathrm{p}=0.001)$ and the group of patients with hip dysplasia having primary surgery $(p=0.001)$. No differences were observed between the standard primary group and the group of patients with hip dysplasia having primary surgery $(p=0.64)$. Statistical analysis of categorical parameters is not considered reliable when categories are (almost) empty. Therefore, categories are grouped according to frequency distributions. Pain was dichotomized to pain and no pain. No significant differences in pain between patients having standard primary surgery, patients having revision surgery, and patients with hip dysplasia having primary surgery were observed using logistic regression $(p=0.43)$.

The same procedure was followed for limping and the use of walking aids. Significant differences in limping between the groups were observed using logistic regression 
$(\mathrm{p}=0.001)$. Bonferroni-corrected post-hoc testing showed a significant difference between the revision surgery group and the standard primary surgery group $(p=0.001)$ and between the patients having revision surgery and the patients with hip dysplasia having primary surgery $(\mathrm{p}=0.001)$, but no difference between the patients having standard primary surgery and the patients with hip dysplasia having primary surgery $(\mathrm{p}=$ $0.98)$. Significant differences in the use of walking aids between the groups were observed using logistic regression $(\mathrm{p}=0.001)$. Bonferroni-corrected post-hoc testing showed a significant difference between the revision surgery group and the standard primary surgery group $(\mathrm{p}=0.001)$ and between the patients having revision surgery and the patients with hip dysplasia having primary surgery $(p=0.01)$, but not between the patients having standard primary surgery and the patients with hip dysplasia having primary surgery $(p=0.71)$. Most patients using a cane after the operation did so when walking longer than half an hour and those patients, who used a cane before surgery, did so after surgery.

A positive, but weak, Spearman correlation could be established between the use of walking aids and the Charnley class $(r=0.4)$ in the revision surgery group. No significant correlation could be determined in patients having standard primary surgery and patients with hip dysplasia having primary surgery. In the patients who had revision surgery limping and the use of walking aids correlated significantly $(p=0.001)$ with the number of previous operations ( $r=0.32$ and 0.37 , respectively). Similarly, these correlations also were significant $(p=0.001)$ in patients with hip dysplasia having primary surgery $(r=0.45$ and 0.55$)$ and in patients having standard primary surgery $(r=0.47$ and 0.56 ). In addition, in patients having standard primary surgery a positive correlation was observed between pain and previous operations $(p=0.001, r=0.43)$.

The modified Singh trabecular index showed severe osteoporosis in $4.6 \%$, moderate osteoporosis in $25.2 \%$ and normal bone quality in $70.2 \%$ in all patients having standard primary surgery. In the patients with hip dysplasia having primary surgery these indices were $0 \%, 7.9 \%$, and $92.1 \%$, respectively. Femoral morphometrics were judged to be champagne flute in $14.6 \%$, normal in $77.5 \%$ and stove pipe in $7.9 \%$ in all patients having standard primary surgery. In the patients with hip dysplasia having primary surgery these values were $66.7 \%, 25.4 \%$, and $7.9 \%$, respectively. In the patients having revision surgery the values for osteoporosis and the morphometry of the femur were not possible to measure, although no champagne flutes were seen. The Crowe classification (18) was used to classify the hip abnormalities in the patients with hip dysplasia: most patients had moderate dysplasia classified as 1 ( $n=30$ hips) or II ( $n=18$ hips), but also grade III ( $\mathrm{n}=14$ hips) and grade IV ( $\mathrm{n}=1 \mathrm{hip})$ were present. The femoral abnormalities in the revision patients were mostly Paprosky (33) grade I or II ( $n=46$ hips), but 2 cases were classified as grade IIIA. Higher class abnormalities were not treated with a standard HA-coated stem.

The femoral stem position was within $2^{\circ}$ varus or valgus in all patients. We could not detect stem migration or subsidence in the first 3 months postoperatively, nor in additional follow up and we conclude that all stems were well-fixed. Periarticular ossifications were recorded using the grading system of Brooker et al. (36) At the time of review $8 \%$ of the hips in patients having standard primary surgery had Grade I ossifications, 3\% Grade II ossifications and no hips had Grade III or IV ossifications. One patient, however, had arthrolysis before review for Grade IV PAO. In the patients with hip dysplasia having primary surgery and in the patients having revision surgery these percentages were $12 \%, 6 \%, 0 \%$, and $0 \%$ and $12 \%, 4 \%, 2 \%$, and $0 \%$ respectively. 
Radiologic changes of the femoral bone became apparent at 6 months, starting with the formation of densifications of the cancellous bone. The radiologic changes are shown in rabie 2. Calcar rounding was $30 \%$ to $34 \%$. No changes in these percentages were seen from 2 years.

Densifications of cancellous bone were seen along the femoral stem at the point of

Table 2

Distribution of the radiologic phenomena at 6 years follow up with regards to the tightness of the fit of the femoral stem in the femoral canal.

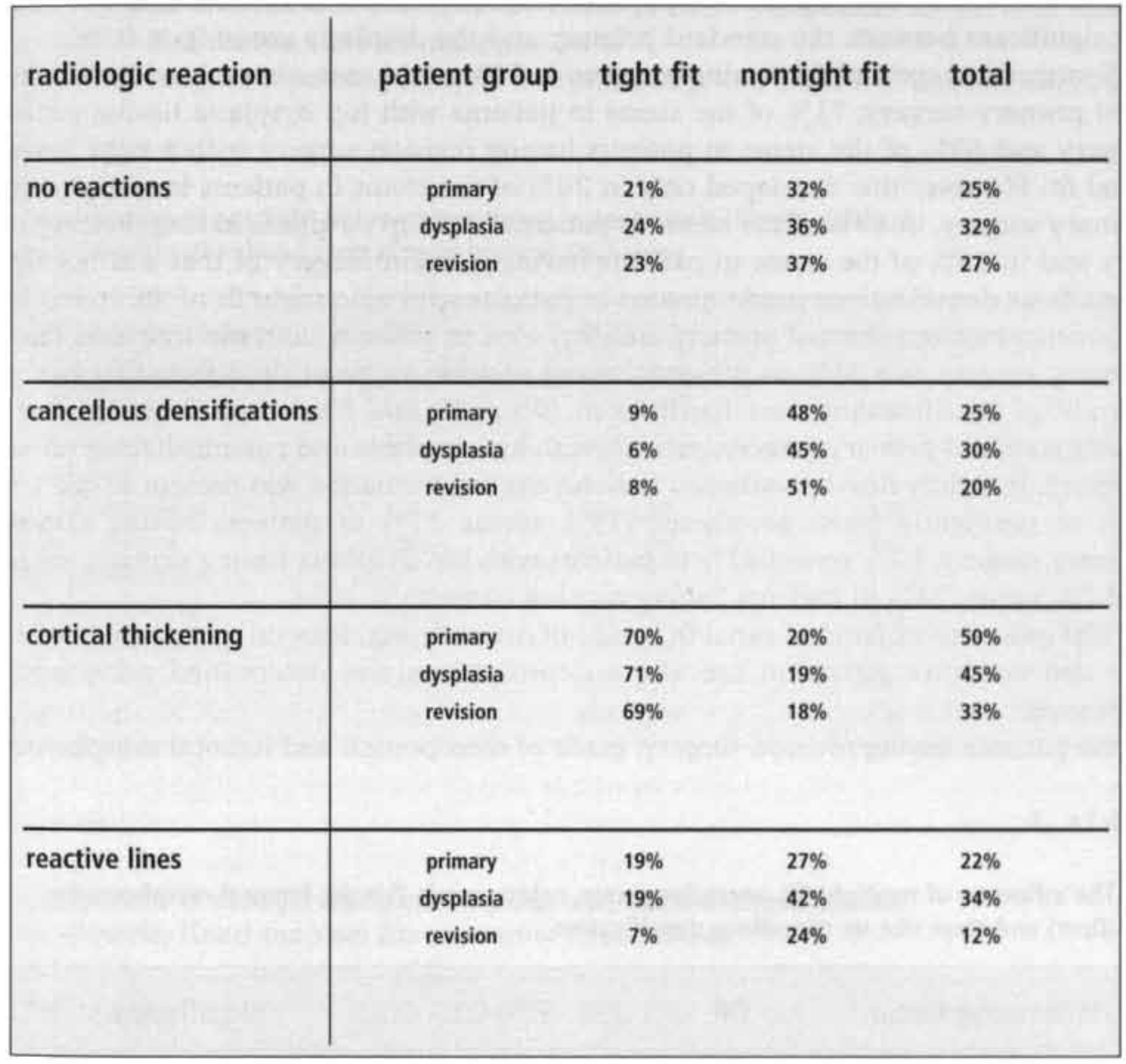

transition between the coated and non coated parts of the stem (Gruen zones 2 and 6), from 6 months. These cancellous densifications were progressive in frequency in all groups. They reached $30 \%$ to $39 \%$ in the midstem zones 2 and 6 at 6 years. From 2 years, the area of bony apposition slowly expanded distally into the upper parts of Gruen zones 3 and 5 . Endosteal reactive lines became visible on radiographs at the tip of the stem (mostly Gruen zone 4, some times zones 3 and 5) between 6 months and the first year postoperatively. The incidence increased until the fifth year after which a slight decline in frequency was seen attributable to expansion of the bone apposition from the more proximal zones. Thickening of cortical bone was observed in the mid- and distal 
stem areas (Gruen zones 2, 3, 5, and 6) in $30 \%$ to $52 \%$ from 1 year and progressing distally in additional follow up. The cortical thickening sometimes expanded into the region that previously showed a reactive line.

The femoral canal fit was tight in 36 stems in patients having standard primary surgery $(40 \%), 40$ stems in patients with hip dysplasia having primary surgery $(63.5 \%)$, and 13 stems in patients having revision surgery $(27 \%)$. The remaining cases were not fitted tightly. Logistic regression analysis showed a difference in fit with reference to the operative groups $(p=0.01)$. Bonferroni corrected post-hoc testing showed that there was a significant difference between the patients having revision surgery and those having standard primary surgery $(\mathrm{p}=0.01)$ and between patients having standard primary surgery and those with hip dysplasia having primary surgery $(p=0.01)$. The difference in fit was not significant between the standard primary and the dysplasia group $(p=0.09)$.

Symmetrical cortical thickening was seen in $70 \%$ of the stems in patients having standard primary surgery, $71 \%$ of the stems in patients with hip dysplasia having primary surgery and $69 \%$ of the stems in patients having revision surgery with a tight femoral canal fit. However this developed only in $20 \%$ of the stems in patients having standard primary surgery, in $19 \%$ of the stems in patients with hip dysplasia having primary surgery and in $18 \%$ of the stems in patients having revision surgery fit that was not tight. Cancellous densifications predominated in patients with a nontight fit of the stem ( $48 \%$ in patients having standard primary surgery, $45 \%$ in patients with hip dysplasia having primary surgery and $51 \%$ in patients having revision surgery). In tightly fitted stems, cancellous densifications were hardly seen $(9 \%, 6 \%$, and $8 \%$, respectively in patients having standard primary surgery, patients with hip dysplasia and patients having revision surgery). In tightly fitted prostheses, radiolucent line formation was present in less cases than in nontightly fitted prostheses $(19 \%$ versus $27 \%$ in patients having standard primary surgery, $19 \%$ versus $42 \%$ in patients with hip dysplasia having primary surgery and $7 \%$ versus $24 \%$ in patients having revision surgery). (Table 2)

The influence of femoral canal fit, grade of osteoporosis, femoral morphometry, stem size and operative group on cancellous densifications was determined using logistic regression. (Table 3)

In the patients having revision surgery, grade of osteoporosis and femoral morphometry

Table 3

The influence of nontight fit, operative group, osteoporosis (Singh), femoral morphometry (Dorr) and stem size on cancellous densification

\begin{tabular}{|l|lll|}
\hline Influencing factor & OR & $95 \%$ C.I. & Significance \\
\hline $\begin{array}{l}\text { nontight fit } \\
\text { operative group } \\
\text { osteoporosis }\end{array}$ & 54.7 & {$[15.82 ; 189.18]$} & 0.00 \\
$\begin{array}{l}\text { moderate versus no } \\
\text { severe versus no }\end{array}$ & 3.71 & {$[0.63 ; 4.62]$} & 0.29 \\
femoral morphometry & 9.12 & {$[1.09 ; 8.74]$} & 0.04 \\
flute versus normal & 4.12 & {$[0.95 ; 87.61]$} & 0.06 \\
stovepipe versus normal & 0.25 & {$[0.68 ; 25.08]$} & 0.13 \\
stem size & 1.11 & {$[0.04 ; 1.78]$} & 0.17 \\
age & 1.01 & {$[0.86 ; 1.43]$} & 0.42 \\
\hline
\end{tabular}


could not be determined. Therefore the operative group consisted of only two classes: patients having standard primary surgery and patients with hip dysplasia having primary surgery. The formation of cancellous densifications was influenced by the grade of osteoporosis ( $\mathrm{p}=0.04$ for no osteoporosis versus moderate osteoporosis). Femoral morphometry, stem size, and operative group did not significantly influence the formation of cancellous densification ( $p$ values $>0.05$ in tabie 3 ). The femoral canal fit affected the formation of cancellous densification formation significantly $(p=0.001)$. Nontight femoral fit gave significantly more cancellous densification, but osteoporosis also contributed to the formation of cancellous densifications. The Odds Ratio (OR) of 54.7 indicated that cancellous densifications are very probable when femoral canal fit was nontight. A similar analysis was done for the effect of these parameters on cortical thickening (rable 4) and reactive line formation. (Table s)

Operative group, osteoporosis, femoral morphometry, and stem size did not affect cor-

Table 4

The influence of nontight fit, operative group, osteoporosis (Singh), femoral morphometry (Dorr) and stem size on cortical thickening

\begin{tabular}{|l|ccc|}
\hline Influencing factor & OR & $95 \%$ C.I. & Significance \\
\hline $\begin{array}{l}\text { nontight fit } \\
\text { operative group } \\
\text { osteoporosis }\end{array}$ & 0.03 & {$[0.01 ; 0.09]$} & 0.00 \\
$\begin{array}{l}\text { moderate versus no } \\
\text { severe versus no }\end{array}$ & 1.82 & {$[0.33 ; 2.03$} & 0.66 \\
femoral morphometry & 1.90 & {$[0.35 ; 2.88]$} & 1.00 \\
flute versus normal & 1.31 & {$[0.13 ; 1.21]$} & 0.64 \\
stovepipe versus normal & 0.38 & {$[0.32 ; 5.41]$} & 0.71 \\
stem size & 0.85 & {$[0.05 ; 3.14]$} & 0.37 \\
age & 0.98 & {$[0.67 ; 1.07]$} & 0.17 \\
\hline
\end{tabular}

Table 5

The influence of nontight fit, operative group, osteoporosis (Singh), femoral morphometry (Dorr) and stem size on reactive line formation

\begin{tabular}{|l|ccc|}
\hline Influencing factor & OR & $95 \%$ C.I. & Significance \\
\hline nontight fit & 1.76 & {$[0.75 ; 4.14]$} & 0.20 \\
operative group & 1.35 & {$[0.61 ; 1.64]$} & 0.46 \\
$\begin{array}{l}\text { osteoporosis } \\
\text { moderate versus no }\end{array}$ & 0.65 & {$[0.27 ; 1.56]$} & 0.33 \\
severe versus no & 0.41 & {$[0.06 ; 2.86]$} & 0.37 \\
femoral morphometry & & & \\
flute versus normal & 0.64 & {$[0.18: 2.23]$} & 0.48 \\
stovepipe versus normal & 0.52 & {$[0.11 ; 2.40]$} & 0.40 \\
stem size & 1.09 & {$[0.89 ; 1.34]$} & 0.41 \\
age & 0.98 & {$[0.94 ; 1.03]$} & 0.46 \\
\hline
\end{tabular}


tical thickening significantly. Only femoral canal fit significantly influenced the development of cortical thickening $(p=0.001)$ independently of other parameters. Cortical thickening was not likely to develop when femoral fit was nontight $(\mathrm{OR}=0.03)$. Reactive line formation was not affected significantly by any of the afore-mentioned factors.

No Spearman correlation ( $r$ ) was observed between stem size, the formation of cancellous densifications, cortical thickening or reactive lines and pain, limping, or use of walking aids. A negative correlation was observed between the formation of cancellous densification and cortical thickening in patients having primary surgery, those with hip dysplasia having primary surgery, and those having revision surgery $(p=0.001)$. These correlations were $-0.38,-0.63$, and -0.38 , respectively. In patients with hip dysplasia cancellous densifications were significantly associated $(p=0.001)$ with a reactive line in the distal part and tip of the stem $(r=0.38)$.

\section{Discussion}

The clinical result for patients having standard primary surgery, those with hip dysplasia having primary surgery, and those having revision surgery after 6.4 years was excellent in this prospective, comparative, and noninventor related study. The pain relief $(93 \%, 97 \%$, and $89 \%)$ and stem survival $(98.7 \%, 100 \%$, and $100 \%)$ in the three groups were similar to the same prosthesis and several other cementless prostheses. $(1-4,7,8)$ Remarkably, because these studies only described primary cementless hip replacements and our study also included patients with hip dysplasia and patients having revision surgery. Also the complications are equally divided over the three groups. Both the excellent result and the small difference in complication rate is undoubtedly caused by the fact that neither the dysplasia patients, nor the revision patients had high grade femoral abnormalities, which is illustrated by the classifications of Crowe (18) and Paprosky (33). Higher class abnormalities were not treated using a standard prosthesis. Compared with the patients having standard primary surgery and patients with hip dysplasia having primary surgery in this study and in the cited studies, hip function (limping and the use of walking aids) was not as good in our patients having revision surgery. These differences in functionality could be explained by the fact that patients who had revision surgery have had multiple previous operations. There may have been difficulties in reattaching the damaged abductors, which resulted in limping even before the index operation. Preoperatively all patients who had revision surgery were limping and postoperatively $36 \%$ of these patients limped always or most of the time. (Table 1) Forty-one percent regularly used walking aids, usually a cane. The patients with hip dysplasia who had primary surgery had a poor function before the operation $(90 \%$ were limping and $86 \%$ used walking aids), but achieved a postoperative functional level comparable with standard primaries. This could be explained by the reorientation of the center of rotation and the tensioning of the abductor muscles. After surgery, walking aids were recommended to patients having revision surgery, especially when they were limping or feeling unstable when walking.

The radiographic osseointegration is characterized by a specific pattern of remodeling in the proximal femur. Positive bone remodeling in the form of endosteal bone apposition in mid-stem regions suggests that stress transfer from stem to femoral bone occurs in this area and that the prosthesis is bonded securely. The incidences of cancellous densifications ( $30 \%$ to $39 \%$ at 6 years) and cortical thickening (30\% to $52 \%$ at 6 
years) are in accordance with the wide range of percentages reported in literature. $(3,13-$ 15) When transferring stresses from the proximal to the distal prosthesis, a slow process of bone resorption (negative bone remodeling) in the region of the lesser and greater trochanters should be expected. Especially in those patients with a tight femoral canal fit, the cortical thickening of the midstem zones suggests stress transfer to these zones, unloading the more proximal zones. However, we were not able to find a relationship between cortical thickening and proximal bone resorption. We suspect that the calcar rounding observed in $34 \%$ of the patients is not this proximal femur resorption. We observed ongoing femoral remodeling and it would be expected that the extent of proximal femoral resorption increased correspondingly. Ongoing femoral resorption or atrophy remained undetected in this study, but proximal negative remodeling should be expected when positive midstem remodeling is present. This is attributable to the fact that a substantial percentage of the bone mineral content will have to be resorbed before it is visual on plain radiographs. However, numerous series reported proximal bone resorption after this length of followup. (3,13-15) A Dual Energy Xray Absorptiometry (DEXA) study providing more information about bone mineral density changes surrounding this prosthesis is currently being done.

The results of radiologic remodeling in response to the transitional load transfer from proximal to distal can be predicted morphologically by the way that the stem fills the medullary canal. Whiteside (25), in his study on the effect of stem fit on bone hypertrophy, observed that a tight fit is associated with distal cortical hypertrophy and thickening, whereas a loose fit, was not associated with distal cortical hypertrophy and thickening and caused more pain. In his study he used CoCr prostheses, whereas we use a titanium alloy stem, a material that has an elasticity modulus that is closer to that of bone than that of CoCr. We could not show the relation between stem fit and pain, nor cortical thickening or reactive line formation and pain, nor stem size and pain, but we were able to show the relation between femoral canal fit and the radiologic remodeling pattern in this study. The relation between cortical hypertrophy and tight femoral fit and between endosteal spot-welding and nontight femoral fit are shown clearly in figure 1 and 2 . For reactive line formation, these relations were not shown. Parameters as femoral morphometrics, grade of osteoporosis, stem size and operative group can be of influence on the remodeling pattern. However, the design of this study is not suitable to study the possibility that femoral canal fit may act as an intermediate factor for the afore-mentioned factors.

All stems appear to be well-fixed, however only the nontightly fitted stems demonstrate a high incidence of cancellous densification. Tightly fitted stems tend to show cortical hypertrophy, a sign negatively valued in the fixation scale designed by Engh et al. (6) This can be explained by the fact that this fixation scale is not suitable for a titanium, tapered, proximally coated femoral stem and is in fact designed on the radiographic appearance of a cylindrical, fully coated $\mathrm{CoCr}$ femoral stem. Because the grading of osteoporosis according to Singh is not very reliable, this is a weakness in this study. To definitively judge the role of osteoporosis in radiologic remodeling and bone density changes around this prosthesis, DEXA analysis was performed. (37) Also the judging of femoral morphometry according to Dorr is not validated and prone to intra- or interobserver variations. However, both indices are used frequently in orthopaedic literature and we are not aware of a better classification of femoral morphometry.

Although we were not able to classify the grade of osteoporosis or the form of the femur in revision patients we still still included these patients into our analysis, because we can still judge the clinical result, the femoral fit, and the subsequent radiological phe- 
Figure 1 and 2

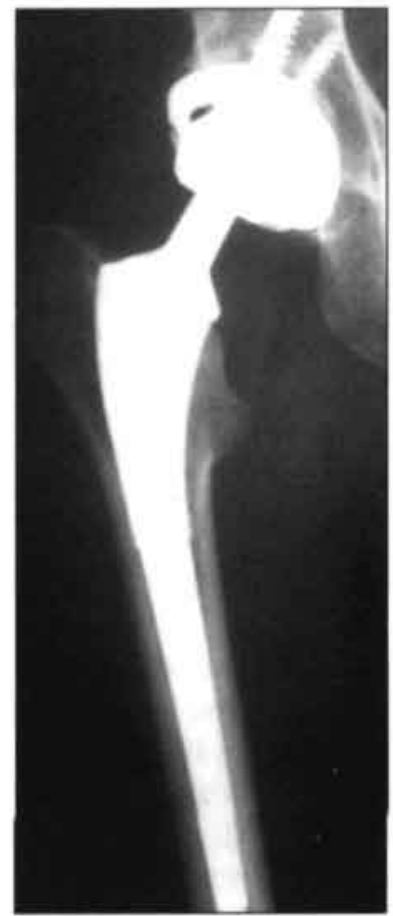

A

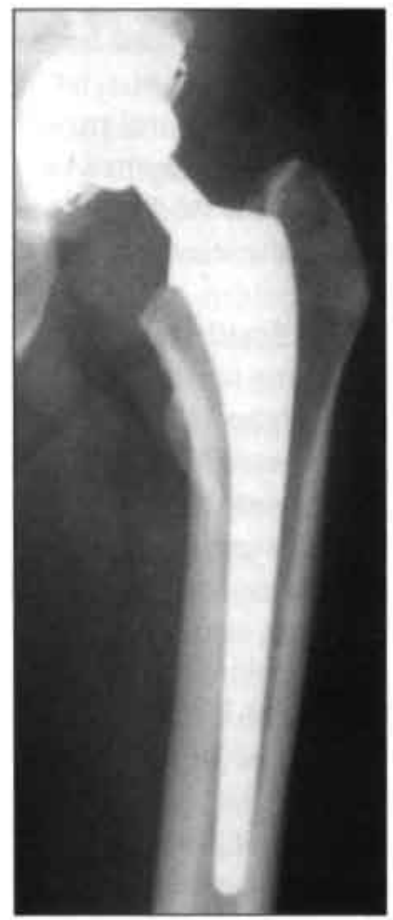

A

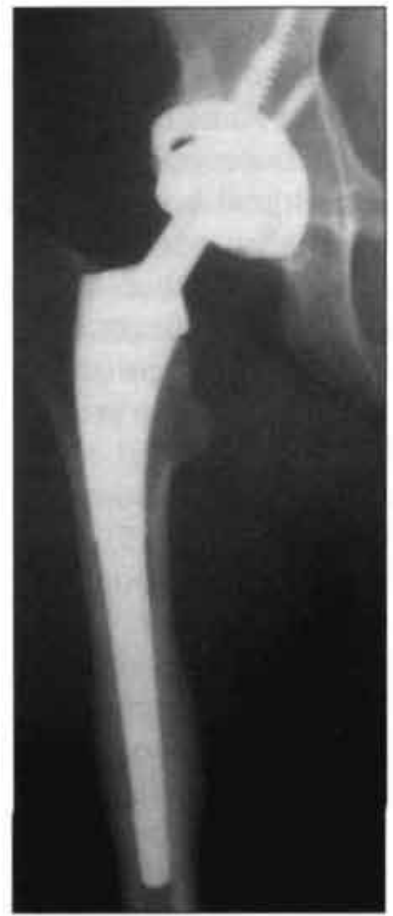

B

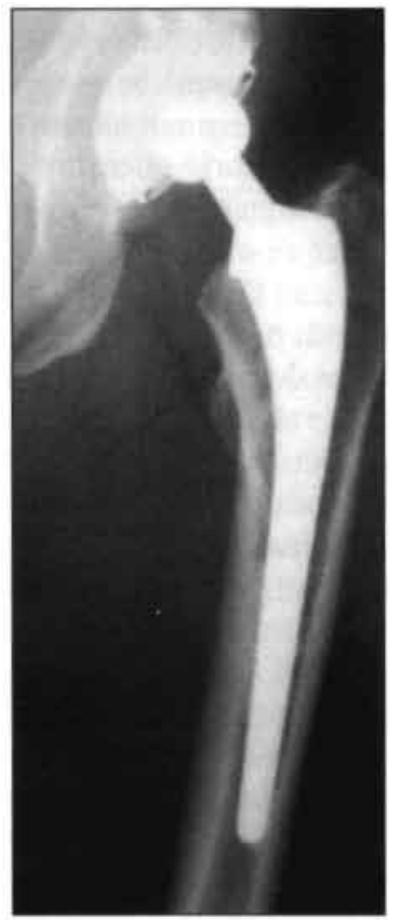

B
An example of the relation between tight femoral canal fit and the development of cortical thickening.

A - immediate postoperative radiograph, showing tight femoral canal fit.

B - radiograph 6 years after the operation, showing symmetrical cortical thickening in zones 3 and 5.
An example of the relation between nontight femoral canal fit and the development of cancellous densifications.

A - immediate postoperative radiograph, showing nontight femoral canal fit.

B - radiograph 6 years after the operation, showing cancellous densifications in zones $2,3,5$, and 6 . 
nomena in these patients. The role of osteoporosis and the sclerosis of the endosteal surface often seen in revision femora are however unknown factors in this analysis.

We conclude that the clinical results confirm the current opinion that standard primary surgery achieves better results in terms of hip function than primary surgery in dysplasia or revision patients. The modified "Oxford Heup Score" shows that primary THRs have a better result than revision total hip arthroplasties, but no difference could be demonstrated between standard and dysplastic primary cases. The bone remodeling process essentially is the same in all three groups. We showed that the morphologic features of the positive bone remodeling around the stem, with either endosteal bone formation or periosteal bone formation, was dependent on the way the stem filled the medullary canal. We showed that in nontightly fitted prostheses spot-welding is obvious and in tightly-fitted prostheses, cortical thickening occurs more frequently. Spot-welding is the endosteal equivalent of cortical thickening. No correlation was seen between the radiologic remodeling pattern and the clinical parameters. 
1. Ang KC, Das De S, Goh JC, Low SL, Bose K. (1997) Periprosthetic bone remodelling after cementless total hip replacement. A prospective comparison of two different implant designs. J Bone Joint Surg [Br] 79:675-9.

2. Bourne RB, Rorabeck CH, Ghazal ME, Lee MH. (1994) Pain in the thigh following total hip replacement with a porous-coated anatomic prosthesis for osteoarthrosis. A five-year follow-up study. J Bone Joint Surg [Am] 76:1464-70.

3. Burkart BC, Bourne RB, Rorabeck CH, Kirk PG. (1993) Thigh pain in cementless total hip arthroplasty. A comparison of two systems at 2 years follow-up. Orthop Clin North Am 24:645-53.

4. D'Antonio JA, Capello WN, Manley MT, Geesink R. (2001) Hydroxyapatite femoral stems for total hip arthroplasty: 10- to 13-year followup. Clin Orthop 393:101-11.

5. D'Antonio JA, Capello WN, Jaffe WL. (1992) Hydroxylapatite-coated hip implants. Multicenter three-year clinical and roentgenographic results. Clin Orthop 285:102-15.

6. Engh CA, Bobyn JD, Glassman AH. (1987) Porous-coated hip replacement. The factors governing bone ingrowth, stress shielding, and clinical results. J Bone Joint Surg [Br] 69:45-55.

7. Geesink RGT. (2002) Osteoconductive Coatings for Total Joint Arthroplasty. Clin Orthop 395:53-65.

8. Gosens T, van Langelaan EJ. (2002) Cementless Mallory-Head HA-coated femoral prosthesis in primary total hip arthroplasty. Hip Int 12(4):345-56.

9. Hellman EJ, Capello WN, Feinberg JR. (1999) Omnifit cementless total hip arthroplasty. A 10-year average followup. Clin Orthop 164-74.

10. Malchau H, Herberts P, Ahnfelt L. (1993) Prognosis of total hip replacement in Sweden. Follow-up of 92,675 operations performed 1978-1990. Acta Orthop Scand 64:497-506.

11. Mallory TH, Head WC. (1988) A total hip replacement system: clinical experience and recommendations. Contemp Orthop 17(4):15-22.

12. Mallory TH, Lombardi AV jr, Leith JR, et al. (2002) Why a taper? J Bone Joint Surg 84-A, suppl 2:81-89.

13. Mallory TH, Mitchell MB. (1990) Results of total hip replacement using porous coating as a fixation mode. Semin Arthroplasty 1:70-6.

14. Mulliken BD, Bourne RB, Rorabeck CH, Nayak N. (1996) A tapered titanium femoral stem inserted without cement in a total hip arthroplasty. Radiographic evaluation and stability. J Bone Joint Surg [Am] 78:1214-25.

15. PaavilainenT, HoikkaV, Paavolainen $P$. (1993) Cementless total hip arthroplasty for congenitally dislocated or dysplastic hips. Technique for replacement with a straight femoral component. Clin Orthop 71-81.

16. Yee AJ, Kreder HK, Bookman I, Davey JR. (1999) A randomized trial of hydroxyapatite coated prostheses in total hip arthroplasty. Clin Orthop 120-32.

17. Gosens T, van Langelaan EJ,Tonino AJ. (2003) Cementless Mallory-Head HAcoated hip arthroplasty for osteoarhtritis in hip dysplasia. J Arthroplasty 18(4): 401-410,

18. Crowe JF, Mani VJ, Ranawat CS. (1979) Total hip replacement in congenital dislocation and dysplasia of the hip. J Bone Joint Surg [Am] 61:15-23.

19. Dunn HK, Hess WE. (1976) Total hip reconstruction in chronically dislocated hips. J Bone Joint Surg [Am] 58:838-45.

20. Hartofilakidis G, Stamos K, Ioannidis TT. (1988) Low friction arthroplasty for old untreated congenital dislocation of the hip. J Bone Joint Surg [Br] 70:182-6.

21. Linde F, Jensen J, Pilgaard S. (1988) 
Charnley arthroplasty in osteoarthritis secondary to congenital dislocation or sub luxation of the hip. Clin Orthop 227: 164-71.

22. Barrack RL. (1995) Economics of revision total hip arthroplasty. Clin Orthop 319:209-14.

23. Robinson AH, Palmer CR, Villar RN. (1999) Is revision as good as primary hip replacement? A comparison of quality of life. J Bone Joint Surg [Br] 81:42-5.

24. Izquierdo RJ, Northmore-Ball MD. (1994) Long-term results of revision hip arthroplasty. Survival analysis with special reference to the femoral component. J Bone Joint Surg [Br] 76:34-9.

25. Whiteside LA. (1989) The effect of stem fit on bone hypertrophy and pain relief in cementless total hip arthroplasty. Clin Orthop 138-47.

26. Harris WH. (1969) Traumatic arthritis of the hip after dislocation and acetabular fractures: treatment by mold arthroplasty. An end-result study using a new method of result evaluation. J Bone Joint Surg [Am] 51:737-55.

27. Hoefnagels NH, DhertWJ, Ockhuijsen S, Gosens T, van Langelaan EJ, Geesink RG. (2000) Translation and validation of the 12 item questionnaire on the preceptions of patients about total hip Replacement. Acta Orthop Scand Suppl 284:30.

28. Hoefnagels NH, Dhert WJ, Gosens T, Bulstra SK, Vet RCK, van Langelaan EJ, Ockhuijsen S, Geesink RG. (2002) [The Oxford hip score : A Dutch patient outcome questionnaire to evaluate the results of a total hip replacement based on the translation of "the 12-item questionnaire on the perceptions of patients about THR"]. Ned Tijdschr Orthop 9(2) : 5-16. Dutch.

29. Dawson J, Fitzpatrick R, Carr A, Murray D. (1996) Questionnaire on the perceptions of patients about total hip replacement. J Bone Joint Surg $[\mathrm{Br}]$ 78:185-90.

30. Charnley J. (1972) The long-term results of low-friction arthroplasty of the hip per formed as a primary intervention. J Bone Joint Surg [Br] 54:61-76.

31. Singh M, Riggs BL, Beabout JW, Jowsey J. (1973) Femoral trabecular pattern index for evaluation of spinal osteoporosis. A detailed methodologic description. Mayo Clin Proc 48:184-9.

32. Dorr LD, Takei GK, Conaty JP. (1983) Total hip arthroplasties in patients less than forty-five years old. J Bone Joint Surg [Am] 65:474-9.

33. Paprosky WG, Greidanus NV, Antoniou J. (1999) Minimum 10-year results of extensively porous-coated stems in revision hip arthroplasty. Clin Orthop 369:230-242.

34. Gruen TA, McNeice GM, Amstutz HC. (1979) "Modes of failure" of cemented stem-type femoral components: a radiographic analysis of loosening. Clin Orthop 141:17-27.

35. DeLee JG, Charnley J. (1976) Radiological demarcation of cemented sockets in total hip replacement. Clin Orthop 20-32.

36. Brooker AF, Bowerman JW, Robinson RA, Riley LH, Jr. (1973) Ectopic ossification following total hip replacement. Incidence and a method of classification. J Bone Joint Surg [Am] 55:1629-32.

37. Rahmy AIA, Gosens T, Blake GM, Tonino AJ, Fogelman I. (2004) Periprosthetic bone remodeling of two types of uncemented femoral implants with a proximal hydroxyapatite coating: a 3-year follow up study addressing the influence of prosthesis design and preoperative bone quality on periprosthetic bone loss. Osteoporosis Int, 15: 281-284. 


\section{THE MALLORY-HEAD FEMORAL PROSTHESIS}


DEXA STUDY OF THE MALLORY-HEAD FEMORAL PROTHESIS 


\section{DEXA STUdy OF THE MALlory-Head FEMORAL PROSTHESIS}

PERIPROSTHETIC BONE REMODELING OF TWO TYPES OF UNCEMENTED FEMORAL IMPLANT WITH PROXIMAL HYDROXYAPATITE COATING. A 3-YEAR FOLLOW UP STUDY ADDRESSING THE INFLUENCE OF PROSTHESIS DESIGN AND PREOPERATIVE BONE DENSITY ON PERIPROSTHETIC BONE LOSS.
A.I.A. Rahmy
T. Gosens
G.M. Blake
A.J. Tonino
I. Fogelman 
DEXA STUDY OF THE MALLORY-HEAD FEMORAL PROTHESIS 


\section{Abstract}

Periprosthetic bone loss is a major cause of concern in patients undergoing total hip arthroplasty (THA). Further studies are required to identify the factors determining the pattern of bone remodeling following THA and obtain improvements in the design and durability of prostheses.In this study we monitored the periprosthetic bone loss around two different types of femoral implant over a 3-year period to evaluate their design and investigate the relationship with the preoperative bone mineral density (BMD) at the spine, hip and radius.

Sixty patients ( 35 female, 25 male, mean age 63 (range, 46-75) years undergoing THA were randomised to either the ABG or $\mathrm{MH}$ femoral stem. Preoperative Dual Energy Xray Absorptiometry (DEXA) scans were acquired of the posteroanterior (PA) and lateral lumbar spine, the contralateral hip and the non-dominant forearm. Postoperative DEXA scans were performed to measure periprosthetic BMD at 10 days (treated as baseline), 6 weeks, and 3, 6, 12, 24 and 36 months after THA using a standard Gruen zone analysis. Results were expressed as the percentage change from baseline and the data examined for the differences in bone loss between the different Gruen zones, between the $\mathrm{ABG}$ and $\mathrm{MH}$ stems, and the relationship with preoperative BMD. A total of 50 patients (24 ABG, $26 \mathrm{MH}$ ) completed the study.

Three months after THA there was a statistically significant BMD decrease in every Gruen zone that varied between $5.6 \%$ and $13.8 \%$ for the ABG prosthesis and between $3.8 \%$ and $8.7 \%$ for the $\mathrm{MH}$ prosthesis. Subsequently, in most zones BMD reached a plateau or showed a small recovery. However, BMD continued to fall in Gruen zones 1 and 7 in ABG patients and Gruen zone 1 in $\mathrm{MH}$ patients. Bone loss was less in every Gruen zone in $\mathrm{MH}$ patients compared with ABG with the largest difference $(10 \%, \mathrm{p}=0.018)$ in Gruen zone 7. After adjustment for multiple comparisons the relationship between periprosthetic bone loss and preoperative BMD was highly statistically significant for spine, hip and radius BMD.

This study showed differences between two different designs of HA-coated implant that confirmed that prosthesis design influences periprosthetic bone loss. The study also showed that bone quality at the time of operation is a major factor influencing bone loss around the femoral stem.

Keywords:

Bone mineral density - bone quality - Dual Energy Xray Absorptiometry - total hip arthroplasty - periprosthetic bone loss 


\section{INTRODUCTION}

Cementless fixation of the femoral stem has gone through a period of evaluation over the last two decades. The surface texture of the stem is an important factor influencing the success of total hip arthoplasty (THA). Two main types of surfaces have been used: porous and hydroxyapatite (HA) (1).

Despite these studies, periprosthetic bone loss following THA remains a major reason for concern. It can occur as a result of the reduction in load transmitted to bone, the so-called stress-shielding phenomenon. The varying pattern of stress shielding may explain why the effects of different types of prosthesis differ in different areas of the proximal femur (2-5). Bone loss may also occur as a result of an inflammatory reaction to small particles, such as those produced by the various wear modes. To varying degrees, both processes occur simultaneously in complex mechanical-biological systems such as joint replacements, and the adverse effects can be additive (6).

Other factors may affect the remodeling patterns after THA. These include patientrelated factors such as sex and the quality of the bone, and prosthesis-related factors such as design and the presence, type and extent of the coating.

Radiographs, although qualitatively indicating changes due to bone remodeling, have limited usefulness in quantitative evaluation of the amount of bone resorption (7). The evaluation of periprosthetic bone loss on radiographs is of questionable reliability since it may go unrecognized until $70 \%$ of the bone is lost (8). Dual Energy Xray Absorptiometry (DEXA) has been shown to be an accurate and precise tool for determining periprosthetic bone mineral density (BMD), and an acceptable coefficient of variation $(\mathrm{CV})$ can be achieved provided positioning and rotation of the hip are strictly controlled (9-11).

Previous studies of BMD changes following THA have shown that the most rapid bone loss occurs during the first 3-6 months after the operation and can vary between $20 \%$ and $50 \%$ depending on the type of implant used and the study methodology (1226). Few long-term prospective studies have used the initial postoperative periprosthetic BMD as the baseline value (19-26), and this is clearly an important requirement if the effect of the bone removed during the operation is to be excluded (19). Further studies are required to achieve a better understanding of the factors determining the pattern of bone remodeling following THA and to obtain improvements in prosthesis design as well as in overall durability.

In the present study we monitored the periprosthetic BMD of two different types of femoral implant as a function of time over a 3-year period as a means of evaluating the design. We also investigate the relationship between the periprosthetic bone loss following the THA and preoperative BMD at the lumbar spine, proximal femur and the distal radius. 


\section{MATERIAL AND METHODS}

\section{Patients}

A total of 60 patients ( 35 female and 25 male, mean age 63 years, range $46-75$ years) undergoing THA were prospectively randomized to one of two cementless stems. Patients received either the Anatomique Benoist Gerard (ABG) (Stryker, Newbury, UK) or the Mallory-Head (MH) (Biomet, Warsaw, Indiana, USA) femoral stem. Both the $\mathrm{ABG}$ and the $\mathrm{MH}$ stems are made of titanium alloy (Ti-6Al-4V) with a proximal HAcoating. The ABG stem has an anatomic press-fit, whereas the $\mathrm{MH}$ stem is straight and aims for three-point-fixation. Proximal loading of the femur to recreate near-normal bone stresses is the primary goal of both stems. There were 29 patients ( 18 female, 11 male) in the ABG group and 31 patients (17 female, 14 male) in the $\mathrm{MH}$ group. In all cases a $28 \mathrm{~mm}$ chromium-cobalt head was used. Surgery was performed using the direct lateral approach. Following their THA the patients were allowed to walk with crutches with partial weight bearing during the first 4 weeks, and then to progress to full weight bearing over the next 8 weeks.

\section{BMD MEASUREMENTS}

BMD measurements were performed using a QDR-2000 + DEXA bone densitometer (Hologic Inc, Bedford, MA). Preoperative scans were acquired of the posteroanterior (PA) (L1-L4) and lateral lumbar spine (L2-L4), the contralateral hip (femoral neck, trochanter, intertochanteric, total hip and Ward's triangle sites) and the non-dominant distal forearm (ultra-distal, mid, one-third and total radius sites). Postoperative DEXA scans were performed to measure BMD in periprosthetic bone at 10 days (treated as baseline for subsequent follow-up), 6 weeks, and 3, 6, 12, 24 and 36 months after THA. The scans were analysed using the manufacturer's metal exclusion software with a template to create 7 Gruen zones (figure (a.b) that was manually adjusted to the anatomy of

Figure 1

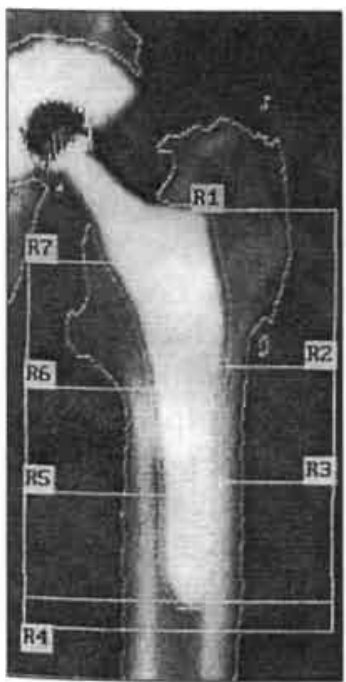

A

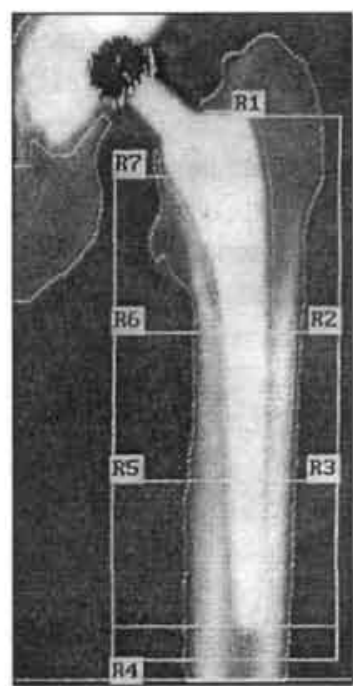

B
DEXA images of the Gruen zone analysis for regional periprosthetic bone mineral density measurements.

A - The Anatomique Benoist Gerard (ABG);

B - The Mallory-Head (MH) femoral stem. 
each individual. BMD was measured laterally (Gruen zones 1,2 and 3) and medially (Gruen zones 5, 6 and 7) around the stem of each prosthesis, and also $1 \mathrm{~cm}$ distally to the tip of the stem (Gruen zone 4). The seven Gruen zones are widely accepted for the radiologic and densitometric evaluation of THA (28). Measurements of all seven Gruen zones were combined to give the total periprosthetic BMD. The manufacturer's scan comparison software was used to transfer the Gruen zone regions of interest (ROI's) onto the follow-up scans of each individual with care taken in patient positioning and scan analysis to ensure that the area measured coincided as closely as possible with the baseline postoperative scan. The coefficient of variation (CV) of the BMD measurements varied between $1.4 \%$ and $4.1 \%$ according to the Gruen zone assessed, with an overall figure of $2.4 \%(10)$.

\section{Statistical Analysis}

Demographic variables and preoperative BMD measurements in the spine, hip and distal radius were compared using a two-tailed Students t-test. The differences between the $\mathrm{ABG}$ and $\mathrm{MH}$ groups were examined for men and women separately and for both sexes combined. Data for the $\mathrm{ABG}$ and $\mathrm{MH}$ groups were combined to examine the differences between men and women. The results of the postoperative follow-up scans of the periprosthetic bone were used to express the changes in BMD in each Gruen zone and the total ROI as a percentage of the BMD measured on the 10-day postoperative baseline scans. The statistical significance of the changes was assessed using a repeated measures analysis of variance and the p-values corrected for multiple comparisons using the Bonferroni method (28). Data for the percentage change at 6 weeks, 3, 6, 12, 24, and 36 months were plotted as a function of time and used to express the periprosthetic bone loss in terms of the area under the curve (AUC). Differences in bone loss between the $\mathrm{ABG}$ and $\mathrm{MH}$ patients for each Gruen zone and the total ROI were examined by comparing the respective AUC values using a two-tailed Students t-test.

The effect of preoperative BMD in the spine, hip and distal radius on periprosthetic bone loss was analysed by plotting the AUC for each Gruen zone against the baseline $\mathrm{BMD}$ and assessing the statistical significance of the regression coefficient. In this way the statistical significance of the relationship was evaluated individually for each periprosthetic ROI against baseline spine, hip and radius BMD measured in a total of eleven ROI's (PA spine, lateral spine, femoral neck, trochanter, intertrochanteric, total hip, Ward's triangle, ultra-distal, mid, one-third and total radius). The resulting p-values were then corrected for multiple comparisons using the Bonferroni method (28). To assess the relative significance of baseline $\mathrm{BMD}$, gender and the type of hip prosthesis as factors predictive of periprosthetic bone loss, multivariate regression analysis was performed with Gruen zone AUC as the dependent variable and gender, type of prosthesis and $\mathrm{BMD}$ at the PA spine, total hip or total radius as independent variables. For all statistical tests, a p-value of less than 0.05 after correction for multiple comparisons was taken as statistically significant. 


\section{RESULTS}

Three patients (1 ABG, $2 \mathrm{MH}$ ) died before the end of the three-year follow-up. A further six patients ( $3 \mathrm{ABG}, 3 \mathrm{MH}$ ) had incomplete DEXA follow-up data after their THA. Another ABG patient was withdrawn from the study because of early infection. The demographic data and results of the preoperative spine, hip and radius BMD measurements for the remaining 50 patients who completed the 3-year study are given in rable , which shows the data for men and women receiving the ABG and $\mathrm{MH}$ prostheses listed separately.

\section{Table 1}

Baseline demographic and bone mineral density (BMD) data (mean and SD) for patients receiving the Anatomique Benoist Girard (ABG) and Mallory-Head (MH) femoral stems. Data are given separately for men and women. NS = not statistically significant.

\begin{tabular}{|c|c|c|c|c|c|c|}
\hline & $\begin{array}{l}\text { ABG Women } \\
\mathrm{N}=15\end{array}$ & $\begin{array}{l}\text { ABG Men } \\
N=9\end{array}$ & $\begin{array}{l}\text { MH Women } \\
N=16\end{array}$ & $\begin{array}{l}\text { MH Men } \\
N=10\end{array}$ & $\begin{array}{l}\text { Statistical } \\
\text { significance } \\
\text { ABG vs MH }\end{array}$ & $\begin{array}{l}\text { Statistical } \\
\text { significance } \\
\text { Men vs Women }\end{array}$ \\
\hline Age (y) & $62,1(5.5)$ & $61.2(5.7)$ & $65.6(4.2)$ & $59.0(9.1)$ & NS & NS \\
\hline Weight $(\mathrm{kg})$ & $74.1(15.4)$ & $81.1(7.8)$ & $78.1(11.5)$ & $85.7(10.6)$ & NS & $P=0.029$ \\
\hline Height (cm) & $160.9(6.0)$ & $174.9(6.9)$ & $163.7(5.4)$ & $176.0(5.8)$ & NS & $P<0.001$ \\
\hline Body mass index $\left(\mathrm{kg} / \mathrm{m}^{\prime}\right)$ & $28.6(5.9)$ & $26.6(3.2)$ & $29.2(4.8)$ & $27.7(3.3)$ & NS & NS \\
\hline PA spine BMD $\left(\mathrm{g} / \mathrm{cm}^{\prime}\right)$ & $0.921(0.153)$ & $1.043(0.133)$ & $1.015(0.163)$ & $1.060(0.066)$ & NS & $P=0.032$ \\
\hline Femoral neck BMD $\left(\mathrm{g} / \mathrm{cm}^{\prime}\right)$ & $0.709(0.103)$ & $0.758(0.164)$ & $0.765(0.181)$ & $0.791(0.220)$ & NS & NS \\
\hline Total hip BMD (g/cm') & $0.783(0.131)$ & $0.930(0.175)$ & $0.817(0.120)$ & $0.904(0.107)$ & NS & $P=0.006$ \\
\hline Total forearm BMD $\left(\mathrm{g} / \mathrm{cm}^{\prime}\right)$ & $0.488(0.070)$ & $0.592(0.089)$ & $0.501(0.056)$ & $0.657(0.045)$ & NS & $P<0.001$ \\
\hline
\end{tabular}

When the data for both sexes were combined there was no statistically significant difference between the $\mathrm{ABG}$ or $\mathrm{MH}$ groups. (Table 1, column 6) However, there was a trend for $\mathrm{MH}$ patients to have higher preoperative $\mathrm{BMD}$ values than $\mathrm{ABG}$ patients with differences of $7 \%$ in PA spine BMD, $6 \%$ in femoral neck BMD, $2 \%$ in total hip BMD, and $7 \%$ in distal radius BMD. When data for both prostheses were combined and examined for differences by gender, as expected men were heavier and taller than women and had statistically significantly larger preoperative BMD values. (table 1, column $n$ ) The differences between men and women was $8 \%$ for PA spine BMD, $5 \%$ for femoral neck BMD, $14 \%$ for total hip BMD, and $23 \%$ for distal radius BMD.

The mean percentage postoperative changes in periprosthetic BMD for each of the 7 Gruen zones from 0 to 3 year after THA were plotted separately for both prostheses. (Figure 2a.b) The mean percentage change, the standard error of the mean (SEM) and the statistical significance of the change for each Gruen zone and for the total periprosthetic ROI are listed for the ABG (rable 2) and $\mathrm{MH}$ patients. (rable 3) By 3 months postoperatively there was a statistically significant decrease in BMD in every ROI with the exception of Gruen zone 2 in $\mathrm{MH}$ patients. The decrease varied between $5.6 \%$ and 
Figure $2 a, b, c$

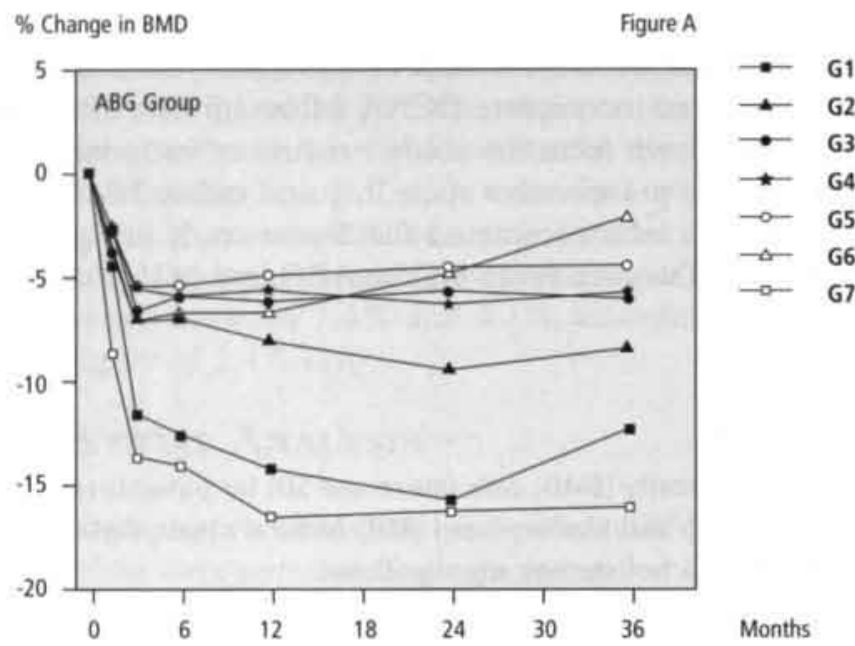

$\%$ Change in BMD

Figure B

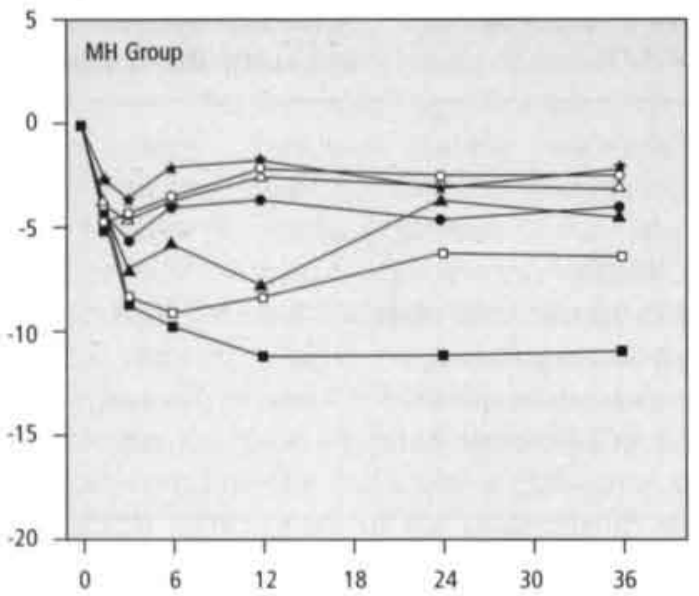

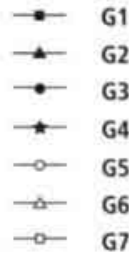

Mean percentage change in bone mineral density (BMD) as a function of time for each of the seven Gruen zones (G1-G7) for:

A - patients receiving the $A B G$ femoral stem;

B - patients receiving the $M H$ femoral stem;

$\mathrm{C}$ - the difference between the two stems (MH - ABG).

Months

$\%$ Change in BMD

Figure C

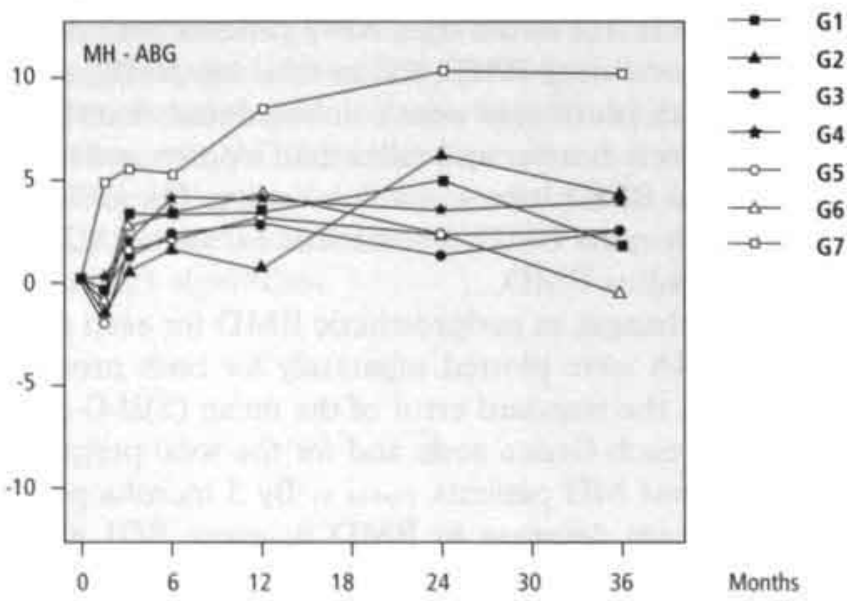


Table 2

Mean percentage change from baseline in BMD for the ABG femoral stem measured in 24 patients between 6 weeks and 3 year after THA. The final column lists the RMSE for the repeated measures model used to fit the data. NS = not statistically significant; $t=\mathrm{P}<0.05 ; \ddagger=\mathrm{P}<0.01 ;{ }^{*}=\mathrm{P}<0.001$. $\mathrm{P}$-values are those obtained after correction for multiple comparisons using the Bonferroni method.

\begin{tabular}{|c|c|c|c|c|c|c|c|}
\hline I & 6 weeks & 3 months & 6 months & 1 year & 2 years & 3 years & RMSE \\
\hline Gruen Zone 1 & -4.6 NS & $-11.8 \pm$ & $-12.8^{\circ}$ & $-14.5^{\circ}$ & $-15.9^{\circ}$ & $-12.6^{\circ}$ & 13.4 \\
\hline Gruen Zone 2 & $-2.6 \mathrm{NS}$ & $-7.1+$ & $-7.1+$ & $-8.2+$ & $-9.6 \neq$ & $8.6 \dagger$ & 11,9 \\
\hline Gruen Zone 3 & $-3.9 \mathrm{NS}$ & $6.8 \mp$ & -6.17 & $-6.3 \ddagger$ & $-5.8+$ & -6.27 & 8.0 \\
\hline Gruen Zone 4 & $-2.9 \mathrm{NS}$ & $-5.7 \pm$ & $-6.0 \neq$ & $-5.8 \pm$ & $-6.4^{\circ}$ & $-5.9 \pm$ & 6.7 \\
\hline Gruen Zone 5 & $-2.9 \mathrm{NS}$ & $-5.6 \neq$ & $-5.5 t$ & $-5.0 t$ & $-4.6 t$ & $-4.5 t$ & 7.6 \\
\hline Gruen Zone 6 & $-2.8 \mathrm{NS}$ & $-7.2 \pm$ & $-6.8 \neq$ & $-6.7 \pm$ & $-4.8 \mathrm{NS}$ & $-2.2 \mathrm{NS}$ & 9.0 \\
\hline Gruen Zone 7 & $-8.8 \dagger$ & $-13.8^{\circ}$ & $-14.3^{\circ}$ & $-16.8^{\circ}$ & $-16.5^{\circ}$ & $-16.3^{\circ}$ & 12.3 \\
\hline Total ROI & $-4.2 \mathrm{NS}$ & $-8.8^{*}$ & $-8.3^{\circ}$ & $-8.7^{\circ}$ & $8.5^{\circ}$ & $-7,4^{\circ}$ & 7.8 \\
\hline
\end{tabular}

Table 3

Mean percentage change from baseline in BMD for the MH femoral stem measured in 26 patients between 6 weeks and 3 year after THA. The final column lists the RMSE for the repeated measures model used to fit the data. NS = not statistically significant; $t=\mathrm{P}<0.05 ; \quad \neq=\mathrm{P}<0.01{ }^{*}=\mathrm{P}<0.001$. $\mathrm{P}$-values are those obtained after correction for multiple comparisons using the Bonferroni method.

\begin{tabular}{|c|c|c|c|c|c|c|c|}
\hline & 6 weeks & 3 months & 6 months & 1 year & 2 years & 3 years & RMSE \\
\hline Gruen Zone 1 & $-5.2 \mathrm{NS}$ & $-8.7 \pm$ & $-9.7 \pm$ & $-11.2^{\circ}$ & $-11.1^{*}$ & $-10.9^{*}$ & 11.4 \\
\hline Gruen Zone 2 & $-4.2 \mathrm{NS}$ & $-6.8 \mathrm{NS}$ & $-5.7 \mathrm{NS}$ & $-7.7 \mathrm{NS}$ & $-3.6 \mathrm{NS}$ & -4.4 NS & 16.0 \\
\hline Gruen Zone 3 & $-4.5 \mathrm{NS}$ & $-5.7 \neq$ & $-4.0 \mathrm{NS}$ & $-3.6 \mathrm{NS}$ & $-4.6 t$ & $-3,9$ NS & 8.2 \\
\hline Gruen Zone 4 & $-2.9+$ & $-3.8^{\circ}$ & $-2.0 \mathrm{NS}$ & -1.8 NS & $-2.9+$ & $-2.0 \mathrm{NS}$ & 4.3 \\
\hline Gruen Zone 5 & $-5.1 \neq$ & $-4.3 t$ & $-3.5 \mathrm{NS}$ & $-2.1 \mathrm{NS}$ & $-2.5 \mathrm{NS}$ & $-2.2 \mathrm{NS}$ & 6.3 \\
\hline Gruen Zone 6 & $3.9 \mathrm{NS}$ & $-4.6+$ & $-3.8 \mathrm{NS}$ & $-2.4 \mathrm{NS}$ & $-2.7 \mathrm{NS}$ & $-2.8 \mathrm{NS}$ & 7.0 \\
\hline Gruen Zone 7 & $-4.1 \mathrm{NS}$ & $-8.5 t$ & $-9.3 \pm$ & $-8.4 \dagger$ & $-6.2 \mathrm{NS}$ & $-6.3 \mathrm{NS}$ & 12.8 \\
\hline Total ROI & $-4.2 \ddagger$ & $-6.1^{\circ}$ & $-4.3^{\circ}$ & $-4.7^{\circ}$ & $-4.6 \neq$ & $-4.1 \neq$ & 5.4 \\
\hline
\end{tabular}

$13.8 \%$ for the ABG prosthesis and between $3.8 \%$ and $8.7 \%$ for the $\mathrm{MH}$ prosthesis. Subsequently, BMD at most sites either reached a plateau or showed a small recovery. However, only for Gruen zone 6 in the ABG patients was evidence for recovery at 3 years statistically significant ( $p=0.014)$. After 3 months, BMD continued to fall in Gruen zones 1 and 7 in ABG patients and in Gruen zone 1 in $\mathrm{MH}$ patients until a plateau was reached 12 months postoperatively. In both prostheses the BMD decrease at 3 years was largest in Gruen zones 1 and 7 , with mean losses of $12.6 \%$ and $16.3 \%$ respectively in ABG patients and $10.9 \%$ and $6.3 \%$ in $\mathrm{MH}$ patients. After 3 years the BMD loss remai- 
ned statistically significant in Gruen zones $1,2,3,4,5,7$ and the total ROI in ABG patients, but in $\mathrm{MH}$ patients was significant only for Gruen zone 1 and the total ROI.

The difference between the two prostheses in the bone loss in each Gruen zone is plotted in figure zc. While there was a strong trend for the BMD decrease to be smaller at every Gruen zone in $\mathrm{MH}$ compared with $\mathrm{ABG}$ patients, the difference was greatest for Gruen zone 7 with a mean difference of $10.0 \%$ at 3 years. The statistical significance of the differences between the two prostheses was examined by comparing the area under the curve (AUC) for the plots of percentage BMD loss against time. (tabte 4) Although this confirmed the trend to smaller losses in $\mathrm{MH}$ patients, the difference in AUC values

Table 4

Values of the area under the curve (AUC) and standard error of the mean for the 0 to $3 \mathrm{y}$ percentage bone loss in 7 Gruen zones and the total ROI for patients receiving the ABG and MH femoral stems. The final column gives the statistical significance of the difference in the AUC values between the two stems. NS = not statistically significant.

\begin{tabular}{|l|lll|}
\hline & ABG femoral stem & MH femoral stem & Statistical significance \\
\hline AUC Gruen Zone 1 & $-13.8(2.7)$ & $-10.5(2.2)$ & NS \\
AUC Gruen Zone 2 & $-8.0(2.3)$ & $-5.3(3.0)$ & NS \\
AUC Gruen Zone 3 & $-6.0(1.5)$ & $-4.1(1.4)$ & NS \\
AUC Gruen Zone 4 & $-5.9(1.4)$ & $-2.2(0.6)$ & $\mathrm{P}=0.020$ \\
AUC Gruen Zone 5 & $-4.8(1.5)$ & $-2.2(1.2)$ & NS \\
AUC Gruen Zone 6 & $-5.1(1.7)$ & $-2.4(1.2)$ & NS \\
AUC Gruen Zone 7 & $-15.5(2.2)$ & $-7.4(2.5)$ & $\mathrm{P}=0.018$ \\
AUC Total ROI & $-8.1(1.5)$ & $-4.5(0.9)$ & NS \\
\hline
\end{tabular}

between the two prostheses was statistically significant only for Gruen zone 4 ( $p=$ $0.020)$ and Gruen zone $7(\mathrm{p}=0.018)$.

The dependence of periprosthetic bone loss on preoperative PA spine, total hip and total radius BMD was examined by plotting the AUC for the total periprosthetic ROI against preoperative BMD. (Figure $3 \mathrm{~s} \cdot \mathrm{c})$ The data points are plotted separately for men and women in the ABG and $\mathrm{MH}$ groups. Overall, the relationship between periprosthetic bone loss for the total ROI and baseline BMD was highly statistically significant with correlation coefficients of $r=0.532(p<0.001), r=0.411(p=0.004)$ and $r=$ 0.497 ( $p<0.001$ ) for the PA spine, total hip and total radius BMD respectively. The relationship between periprosthetic bone loss and preoperative BMD was further investigated by examining the statistical significance of the relationship between AUC and BMD between each periprosthetic ROI and every BMD site in the spine, hip and distal radius, a total of 88 correlations. (tab) 5) The sign of the regression coefficient was positive (i.e. a higher preoperative BMD was associated with smaller bone loss) for all 88 relationships, and the coefficient was statistically significant for $51 / 88$ correlations. After adjustment for multiple comparisons, the relationship for the total periprosthetic ROI remained statistically significant for PA spine $(p=0.001)$, trochanter $(p=0.008)$, total hip $(p=0.045)$, ultradistal $(p=0.013)$, mid $(p=0.002)$, one-third $(p=0.019)$ and total radius $\mathrm{BMD}(\mathrm{p}=0.003)$. 
Figure $3 a, b, c$

Periprosthetic Bone Loss (Total ROI AUC) (\%)

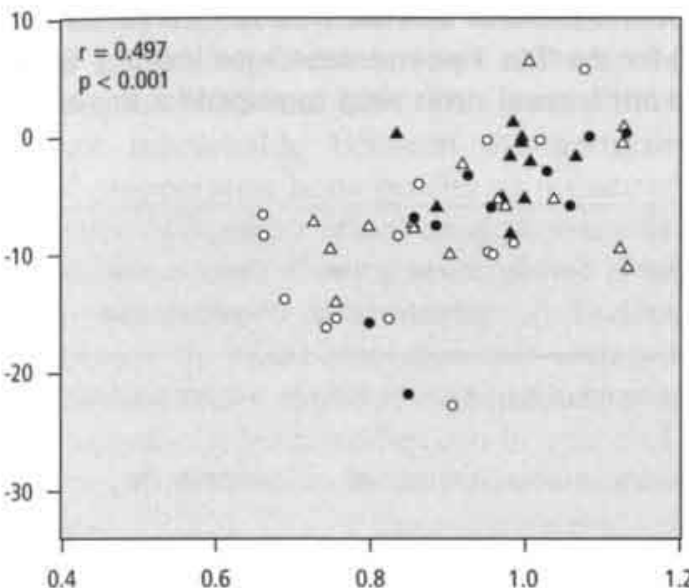

- ABG women

- $A B G$ men

$\triangle \mathrm{MH}$ women

^ MH men
Periprosthetic Bone Loss (Total ROI AUC) (\%)

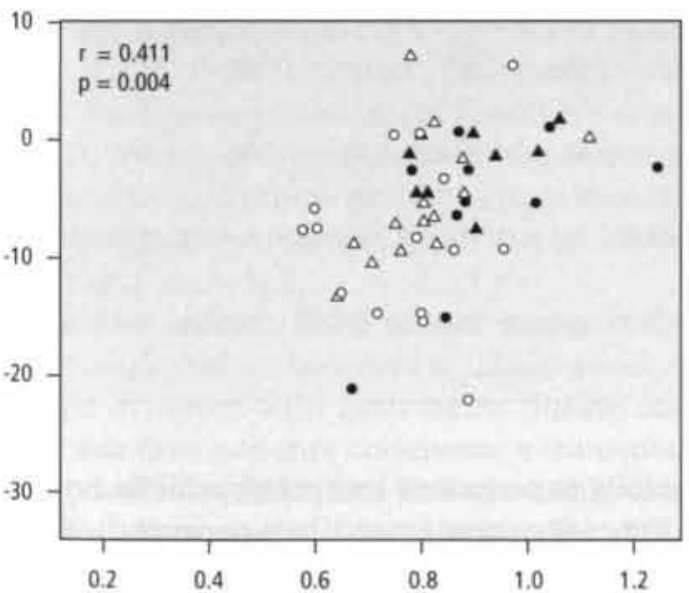

- ABG women

- $A B G$ men

$\triangle \mathrm{MH}$ women

$\star \mathrm{MH}$ men

Figure C

Periprosthetic Bone Loss (Total ROI AUC) (\%)

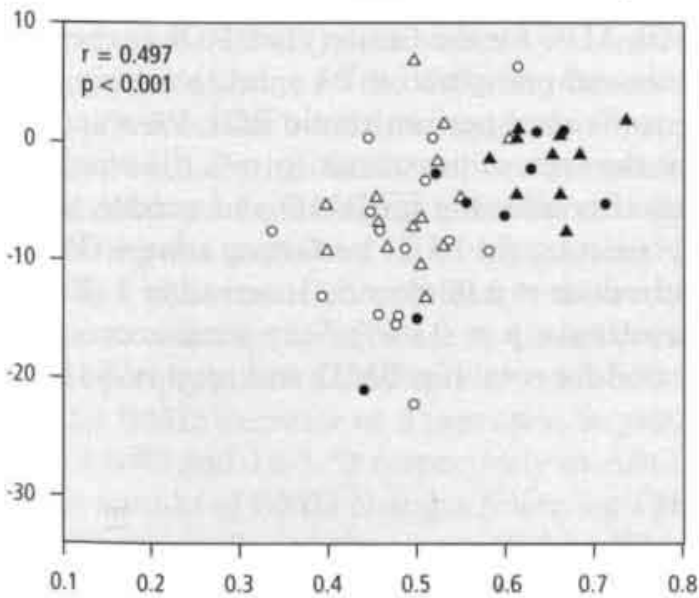

- ABG women

- ABG men

$\triangle \mathrm{MH}$ women

$\Delta$ MH men

Scatter plots showing postoperative bone loss represented by the area under the curve (AUC) of the plot of mean percentage change in BMD against time for the total periprosthetic region of interest (ROI) plotted against the preoperative BMD for:

A - the PA spine (L1-L4) ROI;

B - the total hip ROI;

C - the total radius $R O I$.

Total Hip BMD $\left(\mathrm{g} / \mathrm{cm}^{2}\right)$ 
Table 5

Statistical significance of the regression coefficients between baseline BMD at 11 different skeletal sites and the area under the curve (AUC) for the 0 to 3 y percentage bone loss in 7 Gruen zones and the total ROI. Data for the ABG and MH femoral stems were combined for this analysis. NS = not statistically significant.

\begin{tabular}{|c|c|c|c|c|c|c|c|c|c|c|c|}
\hline & PA Spine & $\begin{array}{l}\text { Lateral } \\
\text { Spine }\end{array}$ & $\begin{array}{l}\text { Femoral } \\
\text { Neck }\end{array}$ & Troch & $\begin{array}{l}\text { Inter } \\
\text { troch }\end{array}$ & Total hip & $\begin{array}{l}\text { Wards } \\
\text { triangle }\end{array}$ & $\begin{array}{l}\text { Ultra } \\
\text { distal }\end{array}$ & $\begin{array}{l}\text { Mid } \\
\text { forearm }\end{array}$ & $\begin{array}{l}\text { One } \\
\text { third }\end{array}$ & $\begin{array}{l}\text { Total } \\
\text { forearm }\end{array}$ \\
\hline $\begin{array}{l}\text { AUC Gruen } \\
\text { Zone } 1\end{array}$ & $P=0.006$ & $P=0.020$ & NS & $P=0.002$ & $P=0.045$ & $P=0.025$ & NS & $P<0.001$ & $P<0.001$ & $P=0.003$ & $P<0.001$ \\
\hline $\begin{array}{l}\text { AUC Gruen } \\
\text { Zone } 2\end{array}$ & NS & NS & $P=0.015$ & $P=0.003$ & $P=0.021$ & $P=0.008$ & $P=0.008$ & NS & $P=0.012$ & NS & $P=0.029$ \\
\hline $\begin{array}{l}\text { AUC Gruen } \\
\text { Zone } 3\end{array}$ & $P=0.003$ & NS & NS & $P=0.029$ & $P=0.049$ & NS & NS & NS & NS & NS & NS \\
\hline $\begin{array}{l}\text { AUC Gruen } \\
\text { Zone } 4\end{array}$ & $P=0.026$ & NS & NS & $P=0.026$ & $P=0.045$ & $P=0.041$ & NS & $P=0.023$ & $P=0.016$ & $P=0.025$ & $P=0.015$ \\
\hline $\begin{array}{l}\text { AUC Gruen } \\
\text { Zone } 5\end{array}$ & NS & NS & NS & NS & NS & NS & NS & NS & NS & NS & NS \\
\hline $\begin{array}{l}\text { AUC Gruen } \\
\text { Zone } 6\end{array}$ & $P=0.009$ & NS & $P=0.012$ & NS & NS & NS & $P=0.004$ & NS & NS & NS & NS \\
\hline $\begin{array}{l}\text { AUC Gruen } \\
\text { Zone } 7\end{array}$ & $P<0.001$ & NS & $P=0.011$ & $P=0.002$ & $P=0.007$ & $P=0.004$ & $P=0.018$ & $P<0.001$ & $P<0.001$ & $P=0.002$ & $P<0.001$ \\
\hline $\begin{array}{l}\text { AUC Total } \\
\text { ROI }\end{array}$ & $P<0.001$ & $P=0.048$ & $P=0.029$ & $P=0.001$ & $P=0.008$ & $P=0.004$ & $P=0.016$ & $P=0.001$ & $P<0.001$ & $P=0.002$ & $P<0.001$ \\
\hline
\end{tabular}

It is evident from nigure 3 that men generally experienced less periprosthetic bone loss. (rabie 1) Figure 2 shows that $\mathrm{MH}$ patients generally experienced less periprosthetic bone loss than ABG patients, and this was consistent with their trend to higher preoperative BMD values. (table ") To examine the relative significance of preoperative BMD, gender and the type of hip prosthesis as factors predictive of periprosthetic bone loss, multivariate regression analysis was performed with AUC for the Gruen zone ROI as the dependent variable and gender, type of prosthesis and preoperative PA spine, total hip or total radius BMD as independent variables. For the total periprosthetic ROI, PA spine BMD $(p=0.001)$ but not gender $(p=0.42)$ or the type of prosthesis $(p=0.13)$ was a significant factor in predicting AUC. However, after allowing for BMD and gender, the type of implant remained a significant factor predicting the AUC for Gruen zone 4 (PA spine BMD: $p=0.088$; gender: $p=0.99$; prosthesis: $p=0.036$ ) and Gruen zone 7 (PA spine BMD: $p=0.001$; gender: $p=0.076$; prosthesis: $p=0.038$ ). Very similar conclusions were reached when the analysis was repeated for total hip BMD and total radius BMD. 


\section{Discussion}

The study reported here was undertaken to investigate the differences in regional adaptive remodeling between two different designs of HA-coated titanium alloy hip prosthesis, the ABG and $\mathrm{MH}$. The study showed for the first time evidence of a highly significant relationship between the periprosthetic bone loss following THA and patients' preoperative bone quality as measured by the BMD at the spine, hip and distal forearm. Although a number of previous DEXA studies have investigated the periprosthetic bone loss following cementless THA, a precise comparison of the results is not always possible due to differences in study design. Study protocols that compare follow up periprosthetic BMD measurements with preoperative values or with the contralateral hip $(4,12-14,17)$ can lead to inaccurate assessment of periprosthetic BMD loss. Preoperatively, the involved hip can be stiff and painful and this may complicate correct positioning of the femur. Patient positioning is the most variable condition in the clinical setting $(10,15)$. Use of the contralateral side as a reference requires modified software (12) and may lead to bias since the BMD in the two limbs can differ by as much as $20 \%$ (29). Differences may be due to arthrosis elevating the BMD in certain regions (30) or due as a result of disuse bone demineralization (31). A change in BMD of the non-operated femur after THA may occur as a result of increased physical activity (16) and will lead to overestimation of the periprosthetic bone loss of the operated femur. The effect of the size and numbers of the ROI's must also be taken into consideration. Using large ROI's such as Gruen zones yields better precision than using smaller ROI's (10). In the present study these problems were avoided by using the initial postoperative BMD measurement as the baseline. With this procedure the effect of bone loss caused by operation is also excluded.

Bone loss around THA is well recognized and occurs with all types of implants, whether cemented or cementless. The present study showed that statistically significant bone loss occurred with both stems during the first 3 months following implantation. During this time patients underwent a transition from partial to full weight bearing, and the effects of immobilization and stress shielding explain the bone loss occurring during this period. Periprosthetic bone loss in the different Gruen zones varied between $5.6 \%$ and $13.8 \%$ for the ABG stem and between $3.8 \%$ and $8.7 \%$ for the MH stem. For both prostheses the bone loss was larger in Gruen zones 1 and 7 compared with Gruen zones 2 to 6 . This finding is similar to that reported in other studies (20-26) in which the initial postoperative BMD measurement was used as the baseline value and is explained by different types of bone in the different Gruen zones. Zones 1 and 7 have a higher percentage of trabecular bone than zones 2 to 6 which contain predominantly cortical bone. Compared with cortical bone, trabecular bone has a higher blood supply with more active metabolism and remodeling that make it more susceptible to bone loss (32).

Following the period of rapid loss during the first 3 months, bone mass in Gruen zones 2 to 6 either reached a plateau or showed a small trend towards recovery. However, bone mass continued to decrease in Gruen zones 1 and 7 in ABG patients and in Gruen 1 in $\mathrm{MH}$ patients until a plateau was reached 12 months postoperatively. For both prostheses the BMD decrease at 3 years was largest in Gruen zones 1 and 7, with mean losses of $12.6 \%$ and $16.3 \%$ respectively in ABG and $10.9 \%$ and $6.3 \%$ in $\mathrm{MH}$ patients. Previous studies of BMD changes following THA showed significant bone loss in Gruen zone 7. In the studies of Venesmaa (22) and Rosenthal (24), both of porous coated prostheses, bone loss in zone 7 after 2 years was $22.9 \%$ and $20.3 \%$ respectively. 
In the present study, HA-coated implants were used and bone loss in zone 7 at 2 years was $16.5 \%$ and $6.2 \%$ for the $\mathrm{ABG}$ and $\mathrm{MH}$ prostheses respectively. It seems that the HA- coating may offer more favorable bone remodeling in Gruen zone 7 than porous coating alone. This conclusion is consistent with the study of Tanzer et al. (25), who compared the differences in bone remodeling after cementless THA for porous and HAcoated prostheses and found that the HA-coated stem had significantly less periprosthetic bone loss than the uncoated stem after 2 years follow-up.

The pattern of bone remodeling observed in the different Gruen zones will reflect the local load transferred from the stem to periprosthetic bone. In the ABG stem, net bone loss continued to occur in Gruen zones 1 and 7 after 3 months and there was a further $3 \%$ decrease in BMD until a plateau was reached at 12 months. After that time, a balance between bone resorption and bone formation occurred, suggesting that the load transfer was sufficient to prevent any further postoperative bone loss. In comparison, the periprosthetic bone in Gruen zones 2 to 6 stabilized by 3 months. In one of these regions, Gruen zone 6, BMD increased progressively after the 3-month time point and the total recovery of $5 \%$ at the end of 3 years was statistically significant. These findings suggest that in the ABG stem the load transfer occurred mostly distally to Gruen zones 1 and 7 with more load distributed medially (mainly zone 6 and to a lesser extend zone 5) than laterally (zones 2 and 3). This evidence for augmented distal load transfer challenges the original design intention of the $\mathrm{ABG}$ prosthesis, and recently the stem was modified so that load transfer is only allowed to occur proximally.

In patients with the $\mathrm{MH}$ stem, net bone loss continued in Gruen zone 1 after 3 months with a further $2 \%$ BMD loss occurring until a plateau was reached at 12 months. In contrast, in Gruen zone $7 \mathrm{BMD}$ increased by $3 \%$ between 6 months and 3 years, although this increase was not statistically significant. During the same period, Gruen zones 2 to 6 all exhibited a small increase in BMD that averaged $2 \%$ by the end of 3 years after THA. In contrast with the ABG prosthesis, there was evidence of positive bone remodeling in Gruen zone 7. The small increase in Gruen zone 4 may indicate that there was load transfer occurring distally to the tip of the $\mathrm{MH}$ stem.

As is evident from figure $2 c$, there was a trend for the BMD decrease to be smaller in $\mathrm{MH}$ compared with $\mathrm{ABG}$ patients that was seen in every Gruen zone. However, when the AUC values were compared this trend was statistically significant only for Gruen zones 4 and 7 . The large difference of $10 \%$ in the 3 -year bone loss in Gruen zone 7 between the $\mathrm{MH}$ and $\mathrm{ABG}$ patients suggests that there was better proximal load transfer in zone 7 in $\mathrm{MH}$ patients. In contrast, the differences for Gruen zone 4 may indicate that load transfer is occurring at the tip of the stem in $\mathrm{MH}$ patients, an unwanted effect. These findings confirm that the design of the prosthesis can influence the loading pattern to periprosthetic bone and consequently affect the periprosthetic bone loss.

The preoperative BMD measurements in the lumbar spine, hip and radius showed a consistent although non-significant trend across all measurement sites for $\mathrm{MH}$ patients to have higher BMD values than ABG patients. When the data for both prostheses were combined and analysed for difference by gender, as expected the BMD differences between men and women were statistically significant, with an $8 \%$ difference at the PA spine, $5 \%$ at the femoral neck, $14 \%$ at the total hip and $23 \%$ at the distal radius. The difference between the genders is partly explained by the differences in bone size, with the men taller and heavier than the women, but is also related to the differences in hormonal status, with postmenopausal women experiencing 10-15\% greater bone loss due to aging than men $(33,34)$.

A striking finding of this study was the highly significant relationship between peri- 
prosthetic bone loss and the preoperative BMD measurements in the spine, hip and forearm, indicating an important relationship between bone loss following THA and patients' bone quality at the time of operation. When the relationship was evaluated for each periprosthetic ROI paired with each BMD site, the sign of the regression coefficient was positive (i.e. a higher preoperative BMD was associated with lower bone loss) for all 88 combinations shown in rable 5. That the statistical significance of the relationship was greater for some combinations of variables than others was due to the larger periprosthetic bone losses at some sites (for example, Gruen zones 1 and 7), the smaller RMSE of the periprosthetic BMD measurements at some sites (for example, Gruen zone 4 and the total ROI), and the better precision of the preoperative BMD measurements. Thus lateral spine BMD and some hip sites with poorer precision (for example, the femoral neck and Ward's triangle) showed weaker relationships than other BMD sites listed in table 5. No exclusions were made for patients with degenerative changes in the spine or arthrosis in the contralateral hip. This may explain why the forearm BMD measurements performed relatively well as indicators of preoperative bone quality, in contrast to the usual convention in bone densitometry measurements where spine and hip BMD are considered the most reliable indicators of skeletal status (35). Although rable s shows results for the $\mathrm{ABG}$ and $\mathrm{MH}$ patients combined, the relationship remained statistically significant when data for the two prostheses were analysed individually.

To compare the importance of preoperative BMD, gender and the design of the femoral stem as predictors of periprosthetic bone loss these variables were compared in multivariate regression analysis. This confirmed that preoperative BMD was the most important factor predicting bone loss following a femoral implant. However, for Gruen zones 4 and 7 prosthesis design remained a statistically significant factor influencing periprosthetic bone loss even after controlling for the effects of preoperative BMD and gender.

The relationship between periprosthetic bone loss and preoperative bone quality may have significant clinical implications for patients undergoing THA. For this reason we are currently investigating the use of bisphosphonate therapy for the prevention of periprosthetic bone loss $(36,37)$. Although the greater bone loss in patients with lower spine, hip or forearm BMD may not adversely affect the outcome for patients in the short and mid-term, preservation of femoral bone stock may be important in the longer term because a low femoral BMD can adversely affect the results of a subsequent revision. Greater femoral bone stock may be particularly advantageous in younger patients in whom a future revision is more likely.

\section{Conclusions}

In this study we investigated the differences in regional bone remodeling between patients receiving two different types of HA-coated titanium alloy hip prosthesis, the $\mathrm{ABG}$ and $\mathrm{MH}$. We were able to show differences in Gruen zones 4 and 7 that confirmed that prosthesis design influences the loading pattern to periprosthetic bone and affects the consequent bone loss. The study showed a highly significant relationship between periprosthetic bone loss and the preoperative BMD at the spine, hip and distal radius, suggesting that bone quality at the time of operation is the major factor influencing bone loss around the femoral stem. 


\section{REFERENCES}

1. Huo MH, Cook SM. (2001) What's new in hip arthroplasty. J Bone Joint Surg [Am] 83:1595-1610.

2. Huiskes R, Weinans $\mathbf{H}$, van Rietbergen $\mathbf{B}$. (1992) The relationship between stress shielding and bone resorption around total hip stems and effects of flexible materials. Clin Orthop 274:124-134.

3. Niinimaki T, Junila J, Jalovaara P. (2001) A proximal fixed anatomic stem reduces stress shielding. Int Orthop 25(2):85-88

4. Sychterz CJ, Engh CA. (1996) The influence of clinical factors on periprosthetic bone remodeling. Clin Orthop 322 285-292.

5. Bobyn JD, Mortimer ES, Glassman AH, Engh CA, Miller EJ, Brooks CE. (1992) Producing and avoiding stress shielding: Laboratory and clinical observations of noncemented total hip arthoplasty. Clin Orthop 274:79-96.

6. Schmalzried TP, Callaghan JJ. (1999) Current concepts review - wear in total hip and knee replacements. J Bone Joint Surg [Am] 81:115-136.

7. West J, Mayor MB, Collier JP. (1987) Potential errors inherent in quantitative densitometric analysis of orthopaedic radiographs. J Bone Joint Surg [Am] 69:58-63.

8. Engh CA Jr, McAuley JP, Sychterz CJ, Sacco ME, Engh CA Sr. (2000)

The accuracy and reproducibility of radiographic assessment of stress-shielding. A postmortem analysis. J Bone Joint Surg [Am] 82:1414-1420.

9. Smart RG, Barbagallo S, Slater GL. (1996) Measurement of periprosthetic bone density in hip arthroplasty using dual-energy $\mathrm{x}$-ray absorptiometry. Reproducibilty of Measurement J Arthroplasty 11: 445-452.

10. Rahmy AIA, Tonino AJ, Tan W. (2000) Precision of dual energy x-ray absorptiometry in determining peripros- thetic bone mineral density of the hydroxyapatite coated hip prosthesis. Hip Int 10:83-90.

11. Martini F, Lebherz C, Mayer F. (2000) Precision of the measurements of periprosthetic bone mineral density in hips wth custom made fermoral stem. J Bone Joint Surg [Br] 82 :1065-1071.

12. Kilgus D, Shimaoka E, Tipton J, Eberle R. (1993) Dual-energy x-ray absorptiometery measurement of bone mineral density around porous-coated cementless femoral implants. Methods and preliminary results. J Bone Joint Surg [Br] 75:279-287.

13. Marchetti ME, Steinberg GG, Greene JM, Jenis LG, Baran DT. (1996)

A prospective study of proximal femur bone mass following cemented and uncemented hip arthroplasty.

J Bone Miner Res 11:1033-1039.

14. McCarthy CK, Steinberg GG, Agren M, Leahey D, Wyman E, Baran DT. (1991) Quantifying bone loss from the proximal femur after total hip arthroplasty. J Bone Joint Surg [Br] 73:774-778.

15. Kiratli BJ, Checovich MM, MacBeath AA, Wilson MA, Heiber JP. (1996) Measurement of bone mineral density by dual-energy $\mathrm{x}$-ray absorptiometry in patients with with the Wisconsin hip, an uncemented femoral stem. J Arthroplasty 2:184-193.

16. Kroger H, Vanninen E, Overmyer M, Mietinen H, Rushton N, Suomalainen O. (1996) Periprosthetic bone loss and regional bone turnover in uncemented total hip arthroplasty: a prospective study using high resolution single photon emission tomography and dual-energy $\mathrm{x}$-ray absorptiometry J Bone Miner Res 12:487-492.

17. Trevisan C, Bigoni M, Randelli G, Marinoni EC, Peretti G, Ortolani S. (1997) periprosthetic bone density around a fully hydroxyapatite coated femoral stem.Clin Orthop 340:109-117. 
18. Spittlehouse AJ, Smith TW, Eastell A. (1998) Bone loss around 2 different types of hip prostheses. J Arthoplasty 16:422-427.

19. Kroger H, Miettinen H, Arnala I, Koski E, Rushton N, Suomalainen O. (1996) Evaluation of periprosthetic bone using dual-energy $x$-ray absorptiometry. Precision of the method and effect of operation on bone mineral density. J Bone Miner Res 10:1526-1530.

20. Rosenthall L,Bobyn JD, Tanzer M. (1999) Bone densitometry: influence of prosthetic design and hydroxyapatite coating on regional adaptive bone remodeling Inter Orthop 23:325-329.

21. Wixson RL, Stulberg SD, Van Flandern GJ, Puri L. (1977) Maintenance of proximal bone mass with an uncemented femoral stem analysis with dual energy x-ray absorptiometry. J Arthroplasty 4:365-372.

22. Venesmaa PK, Kroger HP, Miettinen HJ, Jurvelin JS,Suomalainen OT, Alhava EM. (2001) Monitoring of periprosthetic BMD after uncemented total hip arthroplasty with dual-energy x-ray absorptiometry - a 3-year follow-up study. J Bone Miner Res 16:1056-1061.

23. Sabo D, Reiter A, Simank HG, Thomsen M, Lukoschek M, Ewerbeck. (1997) Periprosthetic mineralization around cementless total hip endoprosthesis: Longitudinal study and cross-sectional study on titanium threaded acetabular cup and cementless Spotorno with dexa. Calcif Tissue Int 62:177-182.

24. Rosenthall L, Bobyn DJ, Brooks CE. (1999) Temporal changes of periprosthetic bone density with modular noncemented fermoral prosthesis. J Arthroplasty $14: 71-76$.

25. Tanzer M, Kantor S, Rosenthall L. (2001) Femoral remodeling after porous coated total hip arthroplasty with and without hydroxyapatite tricalcium phosphate coating: a prospective randomized trial. J Arthoplasty 16:522-528.
26. Nishii T, Sugano N, Masuhara K, Shibuya T, Ochi T, Tamura S. (1977) Longitudinal evaluation of time related bone remodeling after cementless total hip arthroplasty. Clin Orthop 339:121-131.

27. Gruen TA, McNeice GM, Amstutz HC. (1979) "Modes of failure" of cemented stem-type femoral component. A radiographic analysis of loosening. Clin Orthop 141:17-27.

28. Altman DG. (1991) Practical statistics for medical research. London; Chapman Hall:210-212.

29. Hall ML, Heavens J, Ell P. (1991) Variation between femurs as measuerd by dual-energy x-ray absorptiometry. Eur J Nucl Med 18:38-40.

30. Nevitt MC, Lane MN, Scott JC, Hochberg MC, Pressman AR, Geneant HK, Cummings SR. (1995)

Radiographic osteoarthritis of the hip and bone mineral density. Arthritis Rheum 38:907-916.

31. LeBlanc A, Schneider V, Kerbs J, Evans H, Ajhingran S, Johnson P. (1987) Spinal bone density after five weeks of bed rest. Calcif Tissue Int 41:259-261.

32. Rodan GA. (1992) Introduction to bone biology. Bone 13: S3-S6.

33. Riggs BL,Melton LJ. (1986) Involutional osteoporosis. N Eng J Med 314: 1676-1686.

34. Mazess RB, Barden HS, Eberle RW, Denton MD. (1994) Age changes of spine density in posterior-anterior and lateral projections in normal women. Calcif Tissue Int 56:201-205.

35. Marshall D, Johnell O, Wedel H. (1996) Meta-analysis of how well measures of bone mineral density predict occurrence of osteoporotic fractures. $\mathrm{Br}$ Med J 312: 1254-1259.

36. HoskingsD, Chilvers CE, Christiansen C. (1998) Prevention of bone loss in postmenopausal women under 60 years of age. Early postmenopausal intervention cohort study group. N Engl J Med 338:485-492.

37. Tonino RP, Meunier PJ, Emkey R. (2000) Skeletal benefits of alendronate: 7- 
DEXA STUDY OF THE MALLORY-HEAD FEMORAL PROTHESIS

year treatment of postmenopausal

osteoporotic women. J Clin Endocrinol

Metab 85:3109-3115. 
$\overline{178}$ 


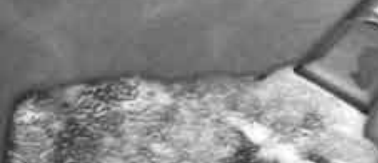

CHAPTER

Discussion AND CONCLUSIONS

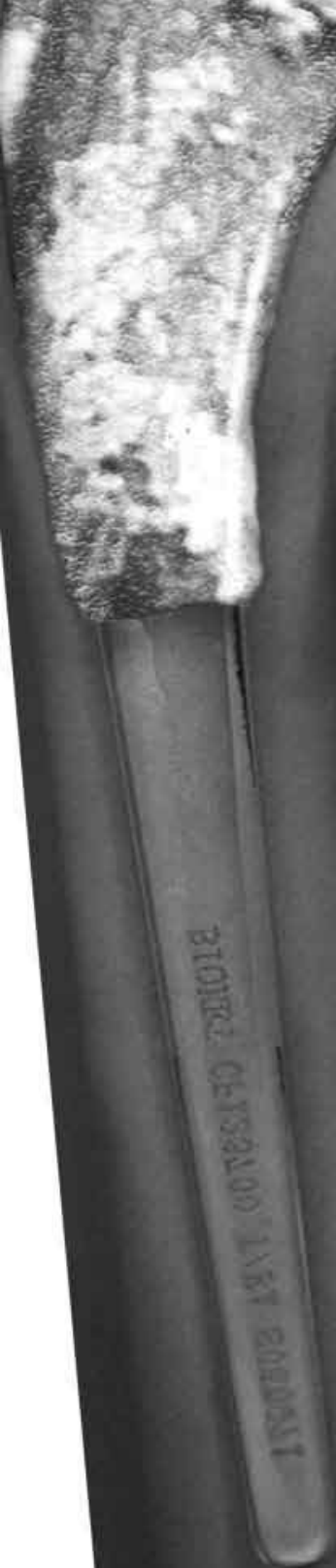


DISCUSSION AND CONCLUSIONS 


\section{THE MODIFIED "OXFORD HEUP SCORE"}

In this thesis the clinical results and radiologic remodeling patterns of the MalloryHead HA-coated femoral prosthesis are described. Although the preoperative scores were measured by the Harris Hip Score and specific questions about pain, limping and the use of walking aids, postoperatively also a patient oriented score system, the 12 item questionnaire, was used. This necessitated the validation of this into Dutch translated modified "Oxford Heup Score", since it is insufficient solely to translate a questionnaire into a foreign language, without validating the translated version. $(1,2)$ The two added questions about "the use of walking aids" and "problems because of the hip with sexual activity" were positively answered before the operation by more than half of the patients. This illustrates the importance of these items for total hip arthroplasty patients and therefore these questions should be included in a disease specific questionnaire for total hip arthroplasty patients. Although the internal consistency dropped a little by the low correlation between the question about "problems because of the hip with sexual activity" and the total score, we think that it is an item that is often forgotten in the evaluation of THA patients, especially the females.

This research has proven that the modified OHS is a useful instrument to judge the result of a total hip arthroplasty from the patient's point of view. The use of the modified OHS has many advantages. Firstly for the patient, since specific problems can be evaluated. Secondly for the surgeon, since the questionnaire can be a guidance in the conversation with the patient. Thirdly, patients can be followed in time easier, since this questionnaire can be sent and returned by mail. Moreover, in the comparison between the primary, dysplasia and revision cases no significant difference was found in their Harris Hip Scores, but the modified "Oxford Heup Score" was able to discriminate the outcome differences between these groups. This suggests that the modified "Oxford Heup Score" is a more sensitive instrument than the Harris Hip Score.

\section{STUdies Concerning THE Mallory-HeAd FEMORAL PROSTHESIS}

\section{SuRVival}

The pain relief $(93 \%, 97 \%$ and $89 \%)$ and stem survival $(98.7 \%, 100 \%$ and $100 \%)$ in the three groups were similar to the same and several other cementless prostheses. Remarkably, since these studies only described primary cementless hip replacements and this study also included dysplasia and revision cases. (3-12). The survival rate in the dysplasia group of $95.3 \%$ for the total hip arthroplasty is approximately the same as Mulliken et al. (13) described for primary total hip replacement with the same prosthesis in a cohort of non-dysplastic patients after a shorter period of follow up (3.7 years). The stem survival in our series is however $100 \%$ up till now. We did not see the need for a specially designed dysplasia prosthesis in our study group, although it contained merely Crowe class I and II dysplastic hips (48 patients versus 15 patients in class III and IV). (14) In more severely deformed femora these specially designed prostheses can be helpful. The Mallory-Head femoral stem is a relatively slender prosthesis that can be used in this group of patients with a relatively high percentage of hyperanteverted, champagne 
flute formed femora. The proximal configuration of a dysplastic femur (larger AP diameter than mediolateral) will cause less problems with this prosthesis since it aims for three-point-fixation by insertion of a straight stem in a curved femur.

In the revision cases, we showed better results in our study compared with the proximally porous coated revision procedures in literature. (15-21) These authors describe loosening and rerevision rates above $10 \%$ but they studied the use of proximally porous coated in more extensively (class 3 and worse) damaged femora, so this is not a fair comparison. Woolson and Delaney (21) however, noted $48 \%$ of their prostheses subsiding in a study population with only class 1 and 2 femoral defects, a study population comparable to our study. We do not recommend the use of proximally porous coated prostheses in these grossly damaged femora, but use calcar replacing or distal fixation prostheses instead. Specially designed revision prostheses with longer stems and an extensive porous coating have been engineered to bypass the damaged part of the femur and to provide stability by distal fixation. The osseointegration of a proximally HA-coated hip prosthesis is very reliable in mildly damaged femora (up to class $3 \mathrm{~A}$ according to Paprosky) in revision cases irrespective of factors such as age, sex, weight, activity and diagnosis. These mildly damaged femora can be treated more or less the same as primary hip replacement with the same results in terms of survival.

\section{Clinical Results}

The functional results depend on the status of the soft tissues: the more a patient is operated before the index operation, the more problems were seen in the functional result after total hip arthroplasty. This is true especially for the dysplasia and the revision patients. Compared with the standard primary and dysplastic primary cases of this study, hip function (limping and the use of walking aids) was not as good in our revision cases. These differences in functionality could be explained by the fact that revision and dysplasia patients have had multiple operations before. They may have experienced difficulties in reattaching the damaged abductors, which resulted in limping even before the index operation. The dysplastic group scores lower than the standard primary group (although not significantly in the chapter in this thesis concerning the comparison of the primary and the dysplasia patients). The reason for a relatively high percentage of patients limping $(20 \%)$ or using a crutch or cane when walking more than half an hour $(16 \%)$ is fourfold. Firstly, the abductor strenght is slightly reduced in dysplastic patients. Secondly, eight out of the ten patients who complained about limping had had multiple previous hip surgery even further compromising abductor strength. The relation between the use of walking aids and limping and the number of previous operations is described in chapter 8 . Thirdly, there are the cases with concomitant morbidity such as vascular claudicatio and a femoral fracture. Fourthly, we did not succeed to obtain perfectly equal leg length in all patients, although the differences were within $1 \mathrm{~cm}$ of the contralateral leg. Nevertheless it is remarkable that Mulliken et al. (13) noted exactly the same percentage for limping in his series with "normal" primary procedures. Paavilainen et al. (22) described a limp in respectively $17 \%$ and $18 \%$ in two dysplasia groups, of which the first consisted of relatively mild cases (Crowe class I and II) and the other of relatively severe cases (Crowe class III and IV). Seven of their sixty patients (12\%) still used a walking aid after the operation, compared to $14 \%$ (10/63 hips or $7 / 50$ patients) in our series. That the dysplastic primary group had a poor function before the operation and reached a postoperative functional level almost comparable to standard primaries can be explained by the reorientation of the center of rotation and the tensioning of 
the abductor muscles. The functionality of the hip (limping and the use of walking aids) in the revision cases is less good than in the mentioned primary and dysplasia procedures. Studies with the same prosthesis $(11,12)$ (but without the HA-coating and also primary replacements) also show better results in terms of function, but pain relief and survival are comparable. These differences in functionality can be explained in the same way as in the dysplasia patients: by multiple surgery and less function of the abductor muscles, resulting in limping even before the index operation. Preoperatively, all patients had a limp and postoperatively $36 \%$ of the patients still limped and $41 \%$ used walking aids regularly. Moreover revision patients are recommended to use walking aids after their operation, especially when they are limping or feeling they are unstable when walking. In the cited studies about functionality after total hip arthroplasty the doctor's opinion about limping was used, where we used the patient's opinion.

\section{RADIOLOGIC RESULTS}

The radiographic osseointegration is characterized by a specific pattern of remodeling in the proximal femur. Positive bone remodeling in the form of endosteal bone apposition in Gruen zones 2 and 6 suggests that the transfer from stem to femoral bone occurs in this area and that the prosthesis is securely bonded there. When transferring stresses from the proximal to the distal prosthesis, a slow process of bone resorption (negative bone remodeling) in the region of the lesser and greater trochanter should be expected. We could not detect any sign of femoral resorption or atrophy in our study which is explained by the fact that a substantial percentage of the bone mineral content has to be resorbed before it is visual on plain radiographs. The DEXA study in chapter 9 , providing more information about bone mineral density changes next to this prosthesis, showed this proximal bone loss.

Radiographic bone remodeling around the stem in the different groups showed after 6 years $30 \%$ to $52 \%$ of cortical hypertrophy in Gruen zone 3 and $5 ; 5 \%$ to $22 \%$ of spotwelding in Gruen zone 2 and 6 and $29 \%$ to $39 \%$ of spot-welding in Gruen zone 3 and 5 and $13 \%$ to $20 \%$ of reactive line formation in Gruen zone 4 . These phenomena have also been described in the radiologic analysis of the Mallory-Head prosthesis by Mulliken et al. (13) and Mallory and Mitchell (12) and are also seen in various other cementless prostheses with different percentages varying from study to study, even with the same prosthesis. The fact that also zones 3 and 5 showed endosteal spot-welding suggests a more distal bone ongrowth and load transfer than in the area of the HA-coating alone. In fact, after 6 years most of the bone apposition occurs adjacent to that part of the femoral stem where the HA coating ends, the so-called transitional zone. We would have expected the apposition to occur more proximally since the coating was present only on the proximal one third of the stem. Instead we found that the region in which the most prominent cancellous and cortical densifications were observed gradually shifted from proximally in Gruen zones 2 and 6 to more distally in these same zones. Formation of new bone in the area near the lower edge of HA-coatings was predicted by Huiskes et al. (23) using finite element analysis. The explanation was that particularly in this area endosteal stress concentrations are caused by the abrupt transition from a bonded to a loose interface. These same phenomena have been observed by Tonino et al. for the cementless ABG prosthesis. (24)

We found a positive correlation between tight femoral canal fit and cortical hypertrophy in Gruen zone 3 and 5 ( $p<0.0001$ ), while the correlation between tight femoral canal fit and spot-welding in Gruen zone 2 and $6(p<0.0001)$ and 3 and 5 (p < 
0.002 ) were negative. So spot-welding can be a sign of fixation of a prosthesis (25), but it is rather a sign of stress transfer. The morphology of the positive bone remodeling around the stem, with either endosteal bone formation or periosteal bone formation, was dependent on the way the stem filled the medullary canal. The radiologic phenomena are in our opinion not prosthesis-dependent but femoral canal fit dependent. We showed that in a less tightly fitted prosthesis spot-welding is in essence the endosteal equivalent of cortical hypertrophy. This was also seen in the dysplastic primary cases and the cases in which the primary stem was used as a revision stem. This concept of femoral canal fit predicting the radiologic remodeling pattern was statistically proven in the chapter comparing the three groups. It appeared to occur independently of other factors such as type of patient, stem size, the shape of the femoral canal or osteoporosis. Parameters as femoral morphometrics, grade of osteoporosis, stem size and operative group can still be of influence on the remodeling pattern. However, the design of this study is not suitable to study the possibility that femoral canal fit may act as an intermediate factor for the above mentioned factors. Since the grading of osteoporosis according to Singh is not very reliable, this is a weak point in this study. In the DEXA study osteoporotic patients lost more bone and had a worse recovery than non-osteoporotic patients. Femoral canal fit was not significantly different between these groups. Indirectly, one can conclude that osteoporosis is not the most important item in the quality of bone remodeling, but is the most important factor in the quantity of remodeling.

The low frequency of thigh pain, seen in the first generation cementless stems, has also been shown with the same prosthesis $(11,12)$, although in those series no HAcoating was used. In the first two years of follow up the percentage of thigh pain was higher than in further follow up. This might be explained by a mismatch in stiffness between the femur and the prosthesis. In the two years following implantation a remodeling process of the femur will eradicate this mismatch by reaching an equilibrium between bone loss and bone gain, a process shown by the DEXA study in this thesis. In the studies here reported however, no significant relation was found between thigh pain and radiologic remodeling phenomena such as cancellous densifications, cortical hypertrophy or reactive line formation.

The studied relationship between the femoral canal fit and the radiologic results, suggesting that radiologic appearance is caused by operation technique, was never reported before. The proposed relation between cortical thickening and reactive line formation and thigh pain (26) was not found in this study. We conclude that the fixation scale proposed by Engh et al. (25), in which endosteal spot-welds are rated positive for bone ingrowth and cortical thickenings are rated negative, is not appropriate for a proximally coated, tapered, titanium stem as the Mallory-Head prosthesis, but might be appropriate for an extensively coated, non-tapered cobalt-chrome prosthesis as the AML prosthesis.

Finite element analysis has confirmed that the Mallory-Head stem (and possibly all cementless designs) creates a press-fit mechanical interface in the proximal portion of the femur that results in deformation. (27-32) In the interface, contact pressures between two components of dissimilar modulus, the bone and the prosthesis, produce deformation. The bone exhibits visco-elastic behavior, which limits the effectiveness of the press-fit by relaxing the contact pressures at the interface. Elastic recoil occurs about the prosthesis, leaving the proximal portion of the component unsupported. This diminishes load transfer and eventually results in stress shielding of proximal bone and distal hypertrophy of metaphyseal bone. The taper provides mechanical dynamics that become operational as proximal support of the prosthesis diminishes in the presence of 
visco-elastic relaxation. The tapered geometry allows the prosthesis to subside into a tighter relationship with the bone, unhindered in the absence of a tight distal fit. Proximal load-sharing is maintained as subsidence continues until the prosthesis reaches a new position of stability.

On this basis Mallory et al. defined the radiographic requirements for a well-fixed stem (33), but they admit that the radiographic assessment of a cementless stem remains difficult. They consider the following seven radiographic characteristics attributes of a well-fixed, stable, cementless tapered femoral component: the presence of calcar remodeling and endosteal bone formation and the absence of cortical hypertrophy, pedestal formation, proximal stress shielding, radiolucencies and distal osteolysis. Also others noted that Engh's fixation scale is not applicable very well to proximally porous coated, tapered, titanium stems. (34-36) In this thesis however, the radiologic remodeling phenomena are dependent of femoral canal fit. The presence of cortical hypertrophy, for instance, is not related to thigh pain or other clinical items and is seen quite often in well-fixed femoral components. The development of a reactive line or a pedestal in Gruen zone 4 reflects the distal non-ingrowth and the proximal loading of the bone by this tapered stem while the tip of the stem is flexible within the femoral canal. Theoretically, tight femoral canal fit can lead to less possibility to subside and less proximal load sharing and thus proximal bone resorption. In the studies presented in this thesis no evidence could be found for more proximal bone resorption in case of a tight femoral canal fit. The DEXA study has a follow up that is too short to draw conclusions about this item, but future follow up might show this relation. Up till 3 years no relation could be demonstrated between tight fit of the prosthesis and increased BMD loss. Theoretically, one should overream the diaphysis, widen the diaphysis to obtain good proximal fit and fill and allow for subsidence.

The use of a titanium plasma-sprayed HA-coated femoral prosthesis leads to a tight bondage between the metaphyseal bone and the prosthesis creating a barrier for PEdebris migrating distally. That this seal in combination with the HA-coating is effective is shown by patients with marked PE-wear without any sign of proximal or distal bone resorption. Yee et al. (37) were not able to show a difference in using a HA-coating or not on the Mallory-Head femoral prosthesis. However their (and our own) follow up length (4.4-4.9 years) might be too short to judge the extra effect of HA with respect to longevity of the prosthesis. It has been shown by others that a HA-coated femoral stem may prevent peri implant particle migration (38-43) and has superior potential in sealing the proximal femur over the use of cement (41). The bone ongrowth even occurs in a damaged and sclerotic proximal femur, as in revision operations is often the case as a result of bone resorption and relative movement between bone and the loosened implant.

The extra value of an additional (and more expensive) layer of hydroxyapatite on the porous coating cannot be proven with the studies here presented. Longer follow up of HA-coated versus non-HA-coated stems will be necessary to prove that the larger surface of ingrowth into the prosthesis will have clinical benifits, in terms of even less aseptic loosening and bone loss. In DEXA studies one can see that the use of HA-coatings has led to less initial bone loss. In the studies of Venesmaa (44) and Rosenthal $(45,46)$, both of porous coated prostheses, bone loss in zone 7 after 2 years was $22.9 \%$ and $20.3 \%$ respectively. In the present study, HA-coated implants were used and bone loss in zone 7 at 2 years was $16.5 \%$ and $6.2 \%$ for the $A B G$ and $M H$ prostheses respectively. It seems that HA-coating may offer more favorable bone remodeling in Gruen zone 7 than porous coating alone. This conclusion is consistent with the study of Tanzer et al. (47), 
who compared the differences in bone remodeling after cementless THA for porous and HA coated prostheses and found that the HA coated stem had significantly less periprosthetic bone loss than the uncoated stem after 2 years follow-up.

\section{Bone Mineral Density Results}

Although only $70.2 \%$ of the primary group had a normal bone stock by using the modified Singh index this did not compromise clinical success and osseointegration: no correlation existed between an osteoporotic grade of the Singh index and thigh pain or the overall result, although in one severly osteoporotic patient the stem failed to osseointegrate.

The DEXA study showed that statistically significant bone loss occurred in all seven Gruen zones during the first 3 months following implantation. Periprosthetic bone loss in the different Gruen zones varied between $5.6 \%$ and $13.8 \%$ for the ABG stem and between $3.8 \%$ and $8.7 \%$ for the MH stem. For both prostheses the bone loss was larger in Gruen zones 1 and 7 compared with Gruen zones 2 to 6 . This is explained by different types of bone in the different Gruen zones. Zones 1 and 7 have a higher percentage of trabecular bone than zones 2 to 6 which contain predominantly cortical bone. Compared with cortical bone, trabecular bone has a higher blood supply with more active metabolism and remodeling that makes it more susceptible to bone loss.

In patients with the $\mathrm{MH}$ stem, net bone loss continued in Gruen zone 1 after 3 months with a further $2 \%$ BMD loss occurring until a plateau was reached at 12 months. After that time, a balance between bone resorption and bone formation occurred, suggesting that the load transfer was sufficient to prevent any further postoperative bone loss. There was evidence of positive bone remodeling in the zone 7 region. There was also a small increase in Gruen zone 4.

In the ABG stem, the periprosthetic bone in Gruen zone 6 increased progressively after the 3-month time point and the total recovery reached $5 \%$ at the end of 3 years. This is also the region in which in the radiological studies the cancellous densifications develop during the first years of follow up. These findings suggest that in the ABG stem the load transfer occurred mostly distally to zones 1 and 7, whereas the Mallory-Head stem has more proximal stress transfer, although in zone 4 also evidence exists of BMD increase. The large difference of $10 \%$ in the 3-year bone loss in Gruen zone 7 between the $\mathrm{MH}$ and $\mathrm{ABG}$ patients suggests that there was better proximal load transfer in zone 7 in $\mathrm{MH}$ patients. In contrast, the differences for Gruen zone 4 may indicate that load transfer is occurring to the tip of the stem in $\mathrm{MH}$ patients, an unwanted effect. This reflects the design rational of the Mallory-Head stem: three point fixation. These findings confirm that the design of the prosthesis can influence the loading pattern to periprosthetic bone and consequently affect the periprosthetic bone loss. As a remark on these results one can argue that the Gruen zones in the Mallory-Head prosthesis are larger than in the ABG prosthesis. As a consequence, more cortical bone is included in the proximal zones in the $\mathrm{MH}$ group, which makes this zone less susceptible to bone loss in the $\mathrm{MH}$ group compared to the ABG group.

A striking finding of this study was the highly significant relationship between periprosthetic bone loss and the preoperative BMD measurements in the spine, hip and forearm, indicating an important relationship between bone loss following THA and the patient's bone quality at the time of operation. In fact, the preoperative bone mass was of more influence on the remodeling process than the design of the prosthesis. A lower initial bone loss might be better in the long run for clinical outcome. Clinical implica- 
tions of this increased bone loss could not be demonstrated with this follow up, but in the long run this augmented bone loss can lead to a more difficult revision. Since uncemented prostheses are used in the younger and active patients, probably needing a revision at a later stage of their life, it is an item to remember.

Future developments might lead to identification of osteoporotic patients before performing a cementless total hip arthroplasty. Maybe young patients that are indicated to receive a cementless hip implant because of their age, but who are not suitable because of low preoperative bone mineral density, should receive alendronate to improve the bone stock before the operation and to prevent future bone loss after the operation.

\section{FURTHER FOLLOW UP}

During the preparation of this thesis the follow up of the original group of 200 hips in 170 patients from the Rijnland Hospital in Leiderdorp increased. In chapter 5, 6, 7, and 8 it was a mean follow up of 6 years and at the end of 2003 this had increased to 7 to 12 years with a mean of 9.2 years.

Up to the end of 200311 patients (with 13 hips included) died of unrelated causes. Two stem revisions were performed (described in chapter 5 ). The number of acetabular revisions grew from 12 ( 8 primary patients in chapter 5 and 4 revision patients in chapter 7) to 20 during the recent years. In the cases with PE wear, no signs of femoral bone loss was seen.

The stem survival percentage remained $98.7 \%$ with a $95 \%$ confidence interval of $3.6 \%$ for 10 years survival and of $6.4 \%$ for 13 years survival. 


\section{Conclusions}

The relevance of these mid-term studies of the HA-coated Mallory-Head prosthesis, knowing that recently longer-term results were published $(33,48,49)$ exists in the fact that essentially all studies of this prosthesis concern the non-HA-coated version. This series of studies is the only one studying the HA-coated version.

In the meta-analysis performed by Mallory et al. (33) 17 papers met their inclusion criteria of a minimal follow up of 5 years and a bi- or tri-planar tapering of the prosthesis. A total of 1853 tapered total hip arthroplasties was reviewed. They concluded that a tapered prosthesis, in general and the Mallory-Head prosthesis in particular, leads to a low incidence of thigh pain and an extremely low incidence of revision for aseptic loosening. The results obtained in the studies presented in this thesis match with the literature on tapered designs and the non-HA-coated Mallory-Head stem.

Having presented the studies on the translation and validation of the Dutch modified Oxford Hip Score, the clinical and radiological results of the standard HA-coated Mallory-Head femoral implant in primary, dysplasia and revision cases and the comparison of these groups and the prospective randomized DEXA study between the Mallory-Head and the ABG implant, I conclude:

1 The modified Oxford Hip Score is a useful instrument to investigate and present the results of total hip replacement. It appears to have a higher sensitivity than the traditional hip scores from Harris and Merle d'Aubigné.

2 The Mallory-Head HA-coated femoral prosthesis has very good clinical and radiologic results and an excellent survival after a mean of 6 years follow up in pri mary, dys-plasia as well as revision cases. These results match the literature results for comparable patient groups with other cementless or cemented designs.

3 The radiologic appearance of the remodeling processes around the Mallory-Head HA-coated femoral prosthesis is a reflection of the fitting of the stem in the femoral canal and not of the size of the component and/or the diameter or the form of the femoral canal. These radiologic parameters have no clinical implications.

4 The Mallory-Head HA-coated femoral prosthesis shows such a stress redistribution that in zone 7 even a recovery of the initial bone mineral density loss is seen. The fact that also bone gain is seen in zone 4 , must be seen as a result of distal stress transfer and is an unwanted effect. Osteoporotic patients remodel worse after total hip arthroplasty: they have more bone loss and the recovery is less than in nonostoporotic patients. In total hip arthroplasty with a cementless femoral component the preoperative bone mineral density is of more influence on the postoperative bone mineral density than the design of the prosthesis. 


\section{REFERENCES}

1. Guillemin F, Bombardier C,

Beaton D. (1993) Cross-cultural adaptation of health-related quality of life measures: literature review and proposed guidelines [see comments]. J Clin Epidemiol 46(12):1417-1432.

2. Guyatt GH. (1993) The philosophy of health related quality of life translation. Qual Life Res 2(6):461-5.

3. Tonino AJ, Rahmy AIA. (2000) The International ABG Study Group. The hydroxyapatite-ABG hip system. J Arthroplasty 11:534-542.

4. Hellman EJ, Capello WN, Feinberg JR. (1999) Omnifit cementless total hip arthroplasty. A 10 year average follow up. Clin Orthop 364:164-174.

5. D'Antonio JA, Capello WN, Jaffe WL. (1992) Hydroxylapatite-coated hip implants: multicentre three year clinical and roentgenographic results. Clin Orthop 285: 102-115.

6. Geesink RGT, Hoefnagels NHM. (1995) Six-year results of hydroxyaptitecoated total hip replacement.

J Bone Joint Surg [Br] 77:534-547.

7. Ang KC, Das De S, Goh JCH, Low SL, Bose K. (1997)

Periprosthetic bone remodelling after cementless total hip replacement. A prospective comparison of two different implant designs. J Bone Joint Surg [Br] 79:675-679.

8. Bourne RB, Rorabeck CH, Ghazal ME, Lee MH. (1994) Pain in the thigh following total hip replacement with a porous coated anatomic prosthesis for osteoarthrosis. J Bone Joint Surg [Am] 76:1464-1470.

9. Engh CA, Bobyn JD, Glassman AH. (1987) Porous coated hip replace ment. The factors governing bone ingrowth, stress shielding and clincal results. J Bone Joint Surg [Br] 69:44-55.

10. Malchau H, Herberts $\mathbf{P}$, Ahnfelt $L$. (1993) Prognosis of total hip replacement in Sweden. Acta Orthop Scand 64:497506.

11. Mulliken BD, Bourne RB, Rorabeck CH, Nayak N. (1996)

A tapered titanium femoral stem inserted without cement in a total hip arthroplasty. J Bone Joint Surg [Am] 78:1214- 1225.

12. Mallory TH, Mitchell MB. (1990) Results of total hip replacement using porous coating as a fixation mode. Sem Arthroplasty 1:70.

13. Mulliken BD, Bourne RB, Rorabeck CH, Nayak N. (1996) A tapered titanium femoral stem inserted without cement in a total hip arthroplasty. Radiologic evalu ation and stability. J Bone Joint Surg [Am] 78:1214.

14. Crowe JF, Mani VJ, Ranawat CS. (1979) Total hip arthroplasty in congenital dislocation and dysplasia of the hip.

J Bone Joint Surg [Am] 61:15-23.

15. Berry DJ, Harmsen S, Ilstrup D, Lewallen DG, Cabanela ME. (1995) Survivorship of uncemented proximally porous coated-femoral components. Clin Orthop 319:168-177.

16. Head WC, Wagner RA, Emerson jr RH, Malinin TI. (1994) Revision total hip arthroplasty in the deficient femur with aproximal load bearing prosthesis. Clin Orthop 298:119-126.

17. Hedley AK, Gruen TA, Ruoff DP. (1988) Revision of failed total hip arthroplasties with uncemented porous coated anatomic components. Clin Orthop 235:75-90.

18. Malkani AL, Lewallen DG, Cabanela ME, Walrichs SL. (1996) Femoral component revision using an uncemented, proximally coated, long-stem prosthesis. J Arthroplasty 11:411-418.

19. Mulliken BD, Rorabeck CH, Bourne RB. (1996) Uncemented revision total hip arthroplasty: a 4- to 6-year review. Clin Orthop 325:156-162.

20. Peters CL, Rivero DP, Kull LR, 
Jacobs JJ, Rosenberg AG, Galante JO. (1995) Revision total hip arthroplasty without cement: subsidence of proximally porous coated femoral components. J Bone Joint Surg 67-A:1217-1226.

21. Woolson ST, Delaney TJ. (1994)

Failure of proximally porous coated femoral prostheses in revision total hip arthroplasty. J Arthroplasty 10 (suppl): S22-S28.

22. Paavilainen T, Hoikka V, Paavolainen P. (1993) Cementless total hip arthroplasty for congenitally dislocated or dysplastic hips. Technique for replacement with a straight femoral component. Clin Orthop 297:71.

23. Huiskes R, Weinans H, Dalstra $\mathbf{M}$. (1989) Adaptive bone remodelling and biomechanical design considerations. Orthopaedics 12:1255-1267.

24. Tonino AJ, Rahmy AIA. (2000) The international ABG study group. The hydroxyapatite-ABG hip system. 5- to 7-years results from an international multicentre study. J Arthroplasty 15(3): 274 .

25. Engh CA, Massin P, Suthers KE. (1990): Roentgenographic assessment of the biologic fixation of porous-surfaced femoral components. Clin Orthop 257:107.

26. Whiteside LA. (1989) The effect of stem fit on bone hypertrophy and pain relief in cementless total hip arthroplasty. Clin Orthop 138-47

27. Mallory TH, Head WC, Lombardi AV jr. (1997) Tapered design for the cementless total hip arthroplasty femoral component. Clin Orthop 344:172-178.

28. Mallory TH, Head WC, Lombardi AV jr, Emerson RH jr, Eberle RW, Mitchell MB. (1996) Clinical and radio graphic outcome of a cementless, titanium, plasma spray-coated total hip arthroplasty femoral component. Justification for continuance of use. J Arthroplasty 11:653660 .

29. Vresilovic EJ, Hozack WJ, Rothman RH. (1994) Radiographic assessment of cementless femoral components. Cor- relation with intraoperative mechanical stability. J Arthroplasty 9:137-141.

30. Camino TC. (1993) Design optimization of the Mallory-Head prosthesis using the finite element method. Master of Science dissertation. The Ohio State University, Columbus, Ohio.

31. Lakes RS, Katz JL, Sternstein SS. (1979) Visco-elastic properties of wet cortical bone - I. Torsional and biaxial studies. J Biomech 12:657-678.

32. Lakes RS, Katz JL. (1979) Visco-elastic properties of wet cortical bone - II. Relaxation mechanisms. J Biomech 12:679-687.

33. Mallory TH, Lombardi AV, Leith JR, Fujita H, Hartman JF, Capps SG, Kefauver CA, Adams JB, Vorys GC. (2002) Why a taper? J Bone Joint Surg [Am] 84;suppl 2:81-9.

34. McLaughlin JR, Lee KR. (1997) Total hip arthroplasty with an uncemented femoral component. Excellent results at ten-year follow-up. J Bone Joint Surg [Br] 79:900-907.

35. Pellegrini VD jr, Hughes SS, Evarts CM. (1992) A collarless cobalt-chrome femoral component in uncemented total hip arthroplasty. Five- to eight-year follow up. J Bone Joint Surg [Br] 74:814821.

36. Reigstad A, Rokkum M, Bye K, Brandt M. (1993) Femoral remodelling after arthroplasty of the hip. Prospective randomized 5-year comparison of 120 cemented/uncemented cases of arthrosis. Acat Orthop Scand 64:411-416.

37. Yee AJM, Kreder HK, Bookman I, Davey JR. (1999) A randomised trial of hydroxyapatite coated prostheses in total hip arthroplasty. Clin Orthop 366:120.

38. Capello WN, D'Antonio JA, Manley MT, Feinberg JR. (1998) Hydroxyapatite in total hip arthroplasty. Clinical results and critical issues. Clin Orthop 355:200211.

39. Coathup MJ, Blunn GW, Flynn N, Williams C, Thomas NP. (2001) A comparison of bone remodelling around 
hydroxyapatite-coated porous-coated and grit-blasted hip replacements retrieved at post-mortem. J Bone Joint Surg [Br] 83:118.

40. Hellman EJ, Capello WN, Feinberg JR. (1999) Omnifit cementless total hip arthroplasty. A 10 year average follow up. Clin Orthop 364:164-174.

41. Kadoya Y, Kobayashi A, Ohashi H. (1998) Wear and osteolysis in total joint replacements. Acta Orthop Scand 278:1.

42. Rahbek O, Overgaard S, Søballe K, Bunger C. (1996) Hydroxyapatite coating might prevent peri-implant particle migration: a pilot study in dogs. Acta Orthop Scand 67(suppl 267):58-9.

43. Rahbek O, Overgaard S, Lind M, Bendix, Bunger C, Søballe K. (2001) Sealing effect of hydroxyapatite coating on peri-implant migration of particles. An experimental study in dogs. J Bone Joint Surg [Br] 83:441-447.

44. Venesmaa PK, Kroger HP, Miettinen HJ, Jurvelin JS, Suomalainen OT, Alhava EM. (2001) Monitoring of periprosthetic BMD after uncemented total hip arthroplasty with dual-energy $\mathrm{x}$-ray absorptiometry. A 3-year follow-up study.
J Bone Miner Res 16;1056-61.

45. Rosenthall L, Bobyn JD, Tanzer M. (1999) Bone densitometry: influence of prosthetic design and hydroxyapatite coating on regional adaptive bone remodelling. Int Orthop 23(6);325-9.

46. Rosenthall L, Bobyn DJ, Brooks CE. (1999) Temporal changes of periprosthetic bone density with modular noncemented fermoral prosthesis. J Arthroplasty 14;71-6.

47. Tanzer M, Kantor S, Rosenthall L. (2001) Fermoral remodeling after porouscoated total hip arthroplasty with and without hydroxyapatite tricalcium phosphate couting: a prospective randomized trial. J Arthoplasty 16;522-8.

48. Mallory TH, Lombardi AV, Leith JR, Fujita H, Hartman JF, Capps SG, Kefauver CA, Adams JB, Vorys GC. (2001) Minimal 10-year results of a tapered cementless femoral component in total hip arthroplasty. J Arthroplasty 16(8), suppl 1:49-54.

49. Bourne RB, Rorabeck CH, Patterson JJ, Guerin J. (2001) Tapered titanium cementless total hip replacements. A 10- to 13-year follow up study. Clin Orthop 393:112-20. 


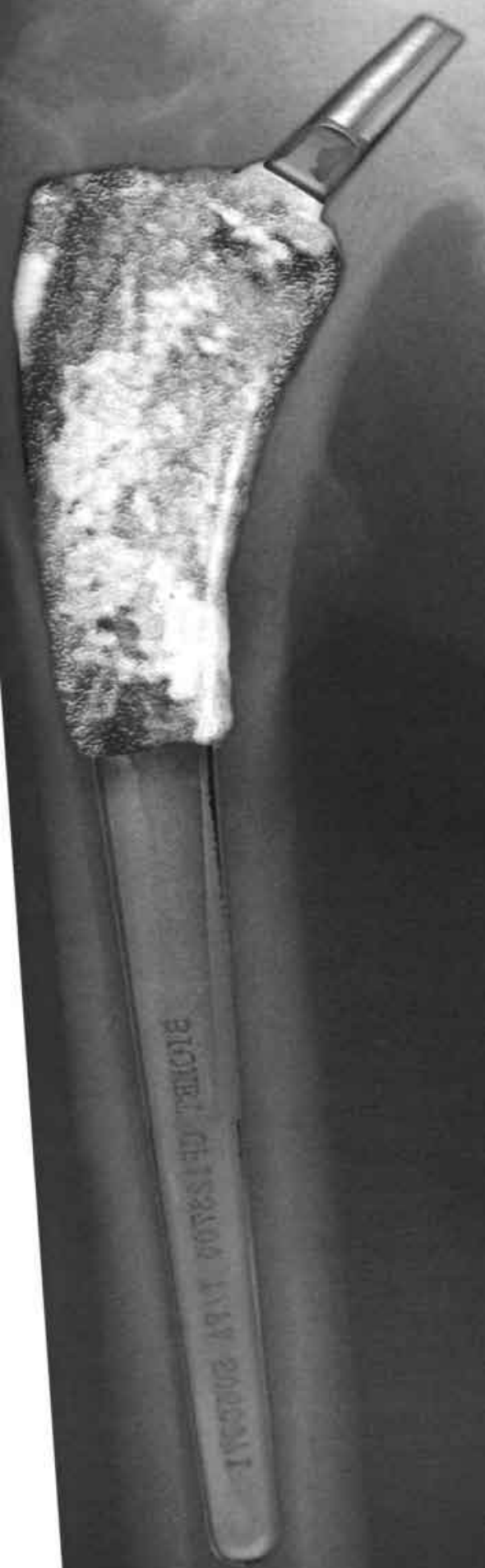

CHAPTER

\section{SUMMARY IN ENGLISH}


SUMMARY IN ENGLISH 


\section{SUMMARY IN ENGLISH}

Total hip arthroplasty has become one of the most commonly performed procedures in the orthopaedic practice. Periprosthetic bone loss is one of the most common complications of total hip replacement. Bone loss can be due to adaptive bone remodeling and osteolysis because of polyethylene wear products. In this thesis the first is studied more intensively. The implantation of a stem in the femoral canal radically alters the stress distribution in the femur and this alteration in the local mechanical situation results in changes of the bony architecture. This thesis contains studies about the patient outcome, the radiologic and the bony remodeling behavior of the cementless porous and hydroxyapatite coated femoral prosthesis according to Mallory-Head (Biomet, Warsaw, Indiana, USA).

\section{MODIFIED "OXFORD HEUP SCORE"}

Chapter 3 presents the validation and translation of the modified "Oxford Heup Score": a questionnaire tailored to the Dutch situation and language based on the 12item questionnaire by Dawson et al. We added two specific hip items, "the need for walking aids" and "sexual problems because of the hip", four general items on overal satisfaction and one question about patient classification. The 14 hip specific items were scored, each from 1 (least difficulties) to 5 (most difficulties). The Dutch version (the modified "Oxford Heup Score") was tested on psychometric quality in a multicenter prospective study.

The psychometric results of the modified "Oxford Heup Score" proved to be adequate. In the first postoperative year, the score was very sensitive for changes; in the second year it did not changed significantly. The two added hip specific questions were both filled out positively by more than $50 \%$ of the patients and fit therefore perfectly in this hip specific patient outcome questionnaire

The Dutch modified "Oxford Heup Score" proves to be an appropriate instrument to assess the outcome of total hip replacement from the patient's perspective. Together with the judgement of the surgeon it provides useful insights into the question whether this operation has been a success or not. In our opinion this score reflects the patients' opinion about his or her total hip prosthesis better than the more known doctors' opinion based scores such as the Harris Hip Score or the Merle d'Aubigné score.

\section{The Mallory-Head PRosthesis}

In chapter 4 the rational design and the known literature of the Mallory-Head cementless prosthesis are presented. It is a straight titanium, double tapered prosthesis with a proximal porous and hydroxyapatite coating. The 10 to 13 years results are published in 2001 and 2002 by Mallory et al. and Bourne et al. and are excellent.

\section{Primary RESUlts}

Chapter 5 presents the results of a study of 152 hips in 126 patients with the MalloryHead HA-coated double tapered straight femoral prosthesis. The follow up period was 4.2 to 9.6 years. All but two prostheses showed osseointegration. The mean Harris Hip Score increased from 40 to 92 points and $97 \%$ of the patients had no or only mild pain. 
Limping and the use of walking aids decreased substantially after the operation. The morphology of positive bone remodeling with either endosteal bone formation or periosteal bone formation was correlated with the stem fit in the medullary canal $(p=0.0001)$. Negative bone remodeling features could not be demonstrated. There was no correlation between the clinical parameters and the radiologic phenomena. The above mentioned functional results combined with a survival rate of $98.7 \%$ after 6.4 years leads to the conclusion that this prosthesis produces excellent results in primary total hip arthroplasty.

\section{DYSPLASIA RESUlTS}

In chapter 6 we studied 63 cementless Mallory-Head prostheses that were used in primary total hip arthroplasty in 50 patients with osteoarthritic hips due to congenital hip dysplasia. The patients were followed for a mean period of 75.1 (range $44-110$ ) months. Clinical and radiologic analysis were performed.

The mean Harris Hip Score increased from 42 to 90 points; $97 \%$ of the patients had no or only mild pain, while limping decreased from $90 \%$ to $20 \%$. Complications were marginal: no infections, one habitual dislocation, one peroperative fracture of the femur and one transient ischiadic nerve palsy.

Radiographically no subsidence of the prosthesis nor any atrophy of the proximal femur could be detected. No correlations were found between the radiologic phenomena and the clinical outcome, but the tightness of the fit of the prosthesis had a definitive influence on the radiographic bone remodeling pattern.

We concluded that the cementless Mallory-Head HA-coated femoral prosthesis showed excellent clinical and radiologic mid term results in osteoarthritic hip dysplasia patients. There was no need for the use of a specially designed dysplasia femoral prosthesis.

\section{REVISION RESULTS}

In chapter 7 we prospectively studied 48 hips in 47 patients with a mean age of 59.6 years and reviewed the results after a mean period of follow up of 6.1 (range 4 - 9.3) years following revision arthroplasty for aseptic loosening using a primary HA-coated femoral stem. 1.8 Previous operations per patient were performed, ranging from 1 to 8 , all patients had a femoral defect class 1 or 2 according to Paprosky.

Clinical outcome was good with a mean increase of the Harris Hip Score from 39 to 90 points. Pain was absent in $89 \%$, a limp was present in $36 \%$ and $41 \%$ used a walking aid. There were 5 re-operations: 4 recurrent dislocations and 1 progressive PE wear necessitated cup revision. At 6 years, 39\% cancellous densifications were seen, especially in non-tightly fitted prostheses, mainly in zone 2 and 6 . Cortical thickening was seen in $30 \%$, especially in tightly-fitted prostheses, mainly in zone 3 and 5 . These differences in radiologic behavior were significant and were not related with various clinical parameters. These phenomena started to appear from 6 months onwards with increasing frequency with longer follow up. The stem survival up till 6.1 years is $100 \%$, no stem is pending revision at the latest follow up.

We concluded that the primary Mallory-Head HA-coated femoral prosthesis is a suitable prosthesis to use in revision procedures with a lower class femoral defect. 


\section{COMPARISON OF THE GROUPS}

The aim of the study presented in chapter 8 was to describe the differences in clinical and radiologic behavior of the Mallory-Head femoral stem in different operation groups. The radiologic reactions around femoral prostheses have very variable incidences in literature. Even with identical prostheses in different studies the reactions are very different. These percentages are described as features of the prosthesis or its osseointegration. We also tested the hypothesis that the radiologic reactions were influenced by the tightness of the fit of the prosthesis in the femoral canal and can thus be predicted, irrespective of operative group, stem size, grade of osteoporosis and femoral morphometry.

The clinical results in all three groups are slightly favourable for the standard primary group, but in terms of survival and radiologic behavior the groups were comparable. Non-tight femoral fit significantly influenced the development of cancellous densification, but osteoporosis also contributed. Only femoral canal fit significantly influenced the development of cortical thickening independently of other parameters. There was no correlation between clinical parameters and the radiologic phenomena in either of the groups.

\section{DEXA STUDY}

The DEXA study, chapter 9, showed that statistically significant bone loss occurred in all seven Gruen zones during the first 3 months following implantation. For both the ABG and the Mallory-Head prosthesis the bone loss was larger in Gruen zones 1 and 7 compared with Gruen zones 2 to 6 . Following the period of rapid loss during the first 3 months, bone mass in Gruen zones 2 to 6 either reached a plateau or showed a small but non-significant trend towards recovery. However, bone mass continued to decrease in Gruen zones 1 and 7 in ABG patients and in Gruen 1 in Mallory-Head patients until a plateau was reached 12 months postoperatively. For both prostheses at 3 years the BMD decrease was largest in Gruen zones 1 and 7, with mean losses of $12.6 \%$ and $16.3 \%$ respectively in ABG and $10.9 \%$ and $6.3 \%$ in Mallory-Head patients.

The pattern of bone remodeling observed in the different Gruen zones will reflect the local load transferred from the stem to periprosthetic bone. The findings suggest that in the ABG stem the load transfer occurred mostly distally to Gruen zones 1 and 7 with more load distributed medially than laterally. In patients with the Mallory-Head stem, compared to the $\mathrm{ABG}$ prosthesis, there was evidence of positive bone remodeling in the zone 7 region. The large difference of $10 \%$ in the 3-year bone loss in Gruen zone 7 between the Mallory-Head and ABG patients suggests that there was better proximal load transfer in zone 7 in Mallory-Head patients. In contrast, the differences for Gruen zone 4 may indicate that load transfer is occurring at the tip of the stem in $\mathrm{MH}$ patients, an unwanted effect. These findings confirm that the design of the prosthesis can influence the loading pattern to periprosthetic bone and consequently affect the periprosthetic bone loss.

A striking finding of this study was the highly significant relationship between periprosthetic bone loss and the preoperative BMD measurements in the spine, hip and forearm, indicating an important relationship between bone loss following THA and the patient's bone quality at the time of operation. 


\section{Discussion AND CONCLUSIONS}

The Mallory-Head femoral prosthesis with a proximal hydroxyapatite coating has excellent clinical results in standard primary, dysplastic primary and low grade revision cases. The results are slightly favourable for the standard primary group, but in terms of survival and radiologic behavior the groups were comparable. One can argue about the fact that most dysplasia cases in our study had only slightly deformed femora and the same can be said from the revision cases. The studies do not show that in every heavily deformed femur (dysplasia or revision) the standard Mallory-Head proximally HAcoated stem can be used. Most cases in a normal practice are like the cases we described and therefore we can draw the conclusion that in the hands of non-inventors, in a standard hospital, the results with this prosthesis are excellent. Even in some less ordinary cases with really abnormal femora an excellent result can be obtained. In higher class femoral deficiencies in revisions we advise not to use this standard prosthesis, but use a calcar replacing stem or a stem that is designed for distal fixation.

The remodeling is characterized by the absence of proximal bone loss and the existance of a distally progressing ossifying front: not only the proximal hydroxyapatite coated part of the prosthesis is integrated into the femoral bone but in later follow up also the more distal uncoated parts of the stem show osseointegration. This is not according to the idea with which the prosthesis was designed. Therefore it is not logical that with the existance of positive bone remodeling in the midstem regions, negative proximal bone remodeling is absent.

The pattern of remodeling is identical in all three operation groups, irrespective of the femoral morphometry, sex, age, or other patient related factors. The femoral fit is the most influencing factor in predicting radiologic changes, such as cortical thickening, endostel spotwelding and reactive line formation at the tip of the stem. The influence of osteoporosis or the hypothesis that femoral fit acts as an intermediating factor could not be excluded definitively using radiographs.

Since femoral fit is a predicting factor in the radiologic remodeling pattern, one might conclude that with a good metaphyseal fit and a non-tight canal fit less distal ingrowth will happen, which will lead to less positive remodeling in the mid-stem regions and thus less negative remodeling in the proximal zones. A more tapering and less long prosthesis might lead to higher bone densities and less bone loss by diminished stress shielding to the distal end of the stem.

The weaknesses of plain radiographs in demonstrating bone density changes around a femoral prosthesis were demonstrated by the use of a DEXA study. From plain radiographs one might conclude that no proximal bone loss occurs, but with DEXA this loss is visible from the beginning. DEXA also makes the relation between remodeling and pre-existent osteoporosis visible: pre-existent osteoporosis leads to more intense bone loss and less complete remodeling and is a more important factor in predicting postoperative bone loss than the design of the prosthesis.

Future developments in this field of orthopaedics may be that before implantation of a femoral prosthesis, bone density will be measured and when osteoporosis is diagnosed, alendronate will be used to optimise bone density before surgery. 


\section{(SAMENVATTING SUMA IN DUTCH}

\section{HET NEDERLANDS)}


SUMMARY IN DUTCH 


\section{SUMMARY IN DUTCH (SAmenvatTing IN HEt NederLANDS)}

De totale heup arthroplastiek is tegenwoordig een van de meest verrichte operaties in de orthopaedische praktijk. Botverlies rondom een prothese is een van de meest voorkomende complicaties van een totale heup vervanging. Dit botverlies kan een gevolg zijn van adaptieve remodellering of door debris door slijtage van polyethyleen. In dit proefschrift wordt het eerstgenoemde mechanisme bestudeerd. De implantatie van een gesteelde prothese in het mergkanaal van het femur verandert de belastingsverdeling in het femur ingrijpend. Deze verandering van de lokale mechanische situatie leidt tot aanpassingen van de architectuur van het bot.

Dit proefschrift bevat studies over de patiënt gerelateerde uitkomsten, de radiologische resultaten en de veranderingen in de architectuur van het femur rondom de cementloze, femorale heupprothese met een proximale poreuze en hydroxyapatiet coating volgens Mallory-Head (Biomet, Warsaw, Indiana, USA).

\section{DE GEMODIFICEERDE "OXFORD HEUP SCORE"}

Hoofdstuk 3 behandelt het proces van vertalen en valideren van de gemodificeerde "Oxford Heup Score": een vragenlijst aangepast aan de Nederlandse situatie en taal, gebaseerd op de "12-item questionnaire" van Dawson et al. Een tweetal vragen werd toegevoegd: "het gebruik van stok of kruk" en "sexuele problemen vanwege de heup". Ook werden 4 algemene vragen over tevredenheid en een vraag over de Charnley klasse van de patiënt toegevoegd. De 14 heup specifieke vragen werden van 1 (minste problemen) tot 5 (meeste problemen) gescoord. De Nederlandstalige versie (de gemodificeerde "Oxford Heup Score") werd vervolgens getest op zijn psychometrische kwaliteiten in een multicenter prospectieve studie.

De psychometrische kwaliteiten van de gemodificeerde "Oxford Heup Score" bleken adequaat te zijn. In het eerste jaar na de operatie was de score zeer gevoelig voor veranderingen; in het tweede jaar veranderde de score niet veel. De twee toegevoegde vragen werden beide door meer dan $50 \%$ van de ondervraagden positief beantwoord. Daarom past dit tweetal vragen in een heup specifieke vragenlijst.

De gemodificeerde "Oxford Heup Score" heeft bewezen een goed instrument te zijn om de uitkomsten van totale heupvervanging te beoordelen vanuit het gezichtspunt van de patiënt. Samen met de beoordeling van de chirurg geeft deze score inzichten in de vraag waarom een nieuwe heup succesvol is of niet. Naar de mening van de auteurs wordt de mening van de patiënt over zijn of haar heup beter weergegeven met deze score dan met de bekende op de mening van de arts gebaseerde scoresystemen als de Harris Hip Score of de Merle d'Aubigné score.

\section{De Mallory-Head Prothese}

In hoofdstuk 4 wordt het design en de literatuur aangaande de Mallory-Head cementloze prothese gepresenteerd. Het betreft een rechte titanium, dubbel taps toelopende prothese met een proximale poreuze en hydroxyapatiet coating. De 10 tot 13 jaars resultaten zijn in 2001 en 2002 gepubliceerd door Mallory et al. en Bourne et al. en zijn zeer goed. 


\section{RESUltaten IN DE PRIMAIRE GROEP}

Hoofdstuk 5 behandelt de resultaten van een studie van 152 heupen van 126 patiënten met de Mallory-Head femoral heupprothese. De follow up bedroeg 4,2 tot 9,6 jaar. Op twee na alle protheses vertoonden botingroei. De gemiddelde Harris Hip Score steeg van 40 naar 92 punten en $97 \%$ van de patiënten had geen of slechts milde pijn. Manklopen en het gebruik van stok of kruk verminderde aanzienlijk na de operatie. De morfologie van de positieve bot remodellering met ofwel endostale botvorming ofwel periostale botvorming was gecorreleerd aan de vulling van het mergkanaal door de steel van de prothese $(p=0.0001)$. Negatieve botremodellering werd niet waargenomen. Er was geen correlatie tussen de radiologische verschijnselen en de klinische resultaten. De hierboven genoemde functionele resultaten gecombineerd met een overleving van $98.7 \%$ na 6,4 jaar leidt tot de conclusie dat deze prothese zeer goede resultaten geeft bij primaire heupvervanging.

\section{RESULTATEN IN DE DYSPLASIE GROEP}

In hoofdstuk 6 werden de resultaten op klinisch en radiologisch gebied bestudeerd van 63 cementloze Mallory-Head prothesen die werden gebruikt voor een primaire totale heupvervanging bij 50 patiënten met coxarthrose op basis van congenitale heupdysplasie. De patiënten werden gevolgd gedurende gemiddeld 75,1 (44-110) maanden. De klinische en radiologische resultaten werden ook hier beoordeeld.

De gemiddelde Harris Hip Score steeg van 42 naar 90 punten; $97 \%$ van hen had geen of slechts milde pijn, terwijl manklopen verminderde van $90 \%$ naar $20 \%$. Het aantal complicaties was marginaal: geen infecties, één patiënt met habituele luxaties, één peroperatieve femurfractuur en één voorbijgaande neuropraxie van de $n$. ischiadicus.

Radiologisch kon geen inzakking van de prothese worden gezien, noch een verlies van botmassa in het proximale femur. Er werden geen correlaties waargenomen tussen de klinische en de radiologische parameters, maar de mate van vulling van het mergkanaal door de prothese bleek ook hier een zekere invloed te hebben op het radiologische remodelleringspatroon.

Uit deze studie werd geconcludeerd dat de cementloze Mallory-Head HA-gecoate femorale heupprothese excellente klinische en radiologische middellange termijns resultaten liet zien in deze groep met dysplasie patiënten. Er werd geen noodzaak gezien voor een speciaal ontwikkelde dysplasie prothese.

\section{RESUltaten IN DE REVISIE GROEP}

In hoofdstuk 7 werden prospectief 48 heupen van 47 patiënten met een gemiddelde leeftijd van 59,6 jaar onderzocht. De resultaten werden beoordeeld na een gemiddelde periode van $6,1(4-9,3)$ jaar na een revisie heup arthroplastiek voor aseptische loslating gebruik makende van de primaire HA-gecoate femursteel. 1.8 eerdere operaties per patiënt werden verricht, variërend van 1 tot 8 . Alle patiënten hadden een femoraal defect dat werd geclassificeerd volgens Paprosky als klasse 1 of 2 . Het klinische resultaat was goed met een stijging van de Harris Hip Score van 39 naar 90 punten. Pijn was afwezig bij $89 \%$, manklopen bleef aanwezig bij $36 \%$ van de patiënten en $41 \%$ maakte nog steeds gebruik van een wandelstok.

Er waren 5 reoperaties: 4 in verband met recidiverende luxaties en éen voor een 
progressieve slijtage van de polyethyleen liner van de cup. Bij een follow up van 6 jaar was er in $39 \%$ van de gevallen sprake van cancelleuze verdichtingen, met name bij niet strak passende prothesen en vooral in zone 2 en 6 . Corticale verdikkingen werden in $30 \%$ van de gevallen gezien, voornamelijk bij strak passende prothesen met name in zone 3 en 5 . Deze verschillen in radiologisch gedrag waren significant en konden niet worden gerelateerd aan klinische parameters. Deze fenomenen ontstonden voor het eerst rond de $6^{\mathrm{c}}$ maand van de follow up en de frequentie ervan steeg met het groeien van de lengte van de follow up. De survival van de femurprothese tot aan 6,1 jaar is $100 \%$ en geen van de prothesen is gepland voor revisie.

De conclusie luidt dat de primair bedoelde Mallory-Head HA-gecoate femorale heupprothese ook met goed gevolg gebruikt kan worden voor revisie patiënten, met name die met klasse 1 of 2 femoraal defect,

\section{VERGELIJKING VAN DE GROEPEN}

Het doel van de in hoofdstuk 8 gepresenteerde studie is het vergelijken van de klinische en radiologische resultaten van de Mallory-Head femorale heupprothese in de verschillende operatiegroepen. Gezien het feit dat de radiologische reacties rondom de protheses variëren in frequentie, niet alleen bij verschillende protheses, maar ook bij dezelfde protheses in andere studies, is het onwaarschijnlijk dat deze verschillen een gevolg zijn van het design van de prothese. Daarom werd de hypothese getest dat deze verschillen afhankelijk zijn van de vulling van de prothese in het mergkanaal van het femur en dat de verschillen dus konden worden voorspeld onafhankelijk van de operatiegroep, de dikte van de prothese, de mate van osteoporose of de vorm van het femur.

De klinische resultaten zijn marginaal beter in de standaard primaire groep, maar wat betreft de survival van de prothese zijn er geen verschillen. Een niet strakke vulling van het mergkanaal beïnvloedde de ontwikkeling van endostale botvorming significant, maar hierin droeg ook de mate van osteoporose bij. Wat betreft de ontwikkeling van corticale verdikkingen was de vulling van het femorale mergkanaal de enige factor die een significante invloed had. Er werd geen correlatie gevonden tussen de klinische en de radiologische parameters in alle groepen.

\section{DEXA}

De DEXA studie gepresenteerd in hoofdstuk 9 laat zien dat een statistisch significant botverlies optreedt in de eerste drie maanden na de implantatie van een heupprothese. Voor zowel de ABG als de Mallory-Head prothese geldt dat het botverlies groter is in de zones 1 en 7 vergeleken met 2 en 6 . Na deze periode van snel botverlies ontstaat er in zone 2 en 6 een plateau of is er zelfs een niet significante trend van herstel van botmassa zichtbaar. De botmassa bleef echter verminderen in zone 1 en 7 bij de ABG patiënten en in zone 1 bij de Mallory-Head patiënten, totdat een plateau werd bereikt op 12 maanden postoperatief. Voor beide prothesen was na 3 jaar het verlies van botmassa het grootst in zones 1 en 7, met gemiddelde verliezen voor de ABG prothese van $12.6 \%$ en $16.3 \%$ respectievelijk en voor de Mallory-Head prothese van $10.9 \%$ en $6.3 \%$.

Het patroon van botremodellering in de diverse Gruen zones is een uiting van de lokale belasting van het omliggende bot door de prothese. De bevindingen suggereren dat bij de ABG prothese de belasting van het bot meer naar distaal van zones 1 en 7 gaat, met een hogere belasting mediaal dan lateraal. Voor de Mallory-Head prothese geldt dat, in vergelijking met de ABG prothese, er een teken was van positieve botremodellering in 
zone 7. Het grote verschil van $10 \%$ in de 3 jaars resultaten in deze zone suggereert een betere belasting van het proximale bot door de Mallory-Head prothese. Daarentegen is het verschil in zone 4 een bewijs voor belasting van het bot distaal van de steel in de Mallory-Head groep. Dit is een niet gewenst effect. Deze bevindingen bevestigen dat het design van de prothese het belastingspatroon van het periprosthetische bot kan beïnvloeden en daardoor kan leiden tot verlies van botmassa. Een belangrijke andere bevinding is de zeer significante relatie tussen het periprosthetische botverlies en de preoperatieve botdichtheid in de wervels, de heup en de onderarm. Dit wijst op een belangrijke relatie tussen het botverlies na een totale heupprothese en de kwaliteit van het bot ten tijde van de operatie.

\section{DiscusSIE EN CONCLUSIES}

De Mallory-Head femorale heupprothese met een proximale hydroxyapatiet coating heeft zeer goede resultaten bij gebruik in primaire, dysplasie en relatief eenvoudige revisie patiënten. De resultaten zijn licht in het voordeel van de standaard primaire groep, maar met betrekking tot de survival van de prothese en de radiologische remodellerings fenomenen zijn zij identiek. Men kan discussiëren over het feit dat de meeste dysplasie en revisie patiënten een minder afwijkend femur hadden wat betreft morphologie en mate van osteoporose. De hier gepresenteerde studies bewijzen niet dat in elk, hoe zwaar gedeformeerd ook, femur de standaard Mallory-Head proximaal HA-gecoate prothese gebruikt kan worden. De meeste gevallen in de dagelijkse praktijk zijn gevallen zoals hier beschreven, en van daaruit kan men de conclusie trekken dat in de handen van niet-ontwerpers van deze prothese, in een standaard ziekenhuis, de resultaten van deze prothese zeer goed zijn. Zelfs in enkele minder vaak voorkomende gevallen met een echt abnormale vorm of kwaliteit van het femur kan een zeer goed resultaat worden behaald. Bij revisies met ernstige femurdefecten wordt de standaard prothese niet geadviseerd, maar kan een calcar vervangende steel of een distaal gefixeerde steel worden gebruikt.

Radiologisch wordt de remodellering gekarakteriseerd door de afwezigheid van proximaal botverlies en de aanwezigheid van een distaal voortgaand ossificerend front: niet alleen het hydroxyapatiet gecoate gedeelte van de prothese is in het femur geïntegreerd, maar ook bij langere follow up de meer distaal gelegen ongecoate delen van de prothese. Dit is niet in overeenstemming met wat het design beoogde. Het is echter niet logisch dat bij een aanwezige positieve botombouw in het midden van de steel er geen proximale negatieve botombouw aanwezig is. Het patroon van botombouw is identiek in alle drie de groepen, ongeacht de vorm van het femur, geslacht, leeftijd of andere patiënt gerelateerde factoren. De vulling van het mergkanaal van het femur is de meest invloedrijke factor in het voorspellen van radiologische veranderingen, zoals corticale verdikkingen, endostale verdichtingen en reactieve lijn formatie aan het einde van de steel. De invloed van osteoporose, dat als intermediair kan werken, kan niet door middel van Röntgenfoto's worden uitgesloten, maar lijkt wel degelijk van belang.

Omdat femorale vulling de voorspellende factor is in het radiologische remodelleringsproces, zou met een goede metafysaire passing en een niet strakke diafysaire passing minder distale ingroei aanwezig zijn, hetgeen tot minder positieve botombouw in de diafysaire zones en meer positieve botombouw in de proximale zones zou kunnen leiden. Een meer getaperde en minder lange prothese zouden kunnen leiden to hogere proximale botmassa's en minder botverlies door minder krachtengeleiding naar het eind van de steel.

De zwakheden van de standaard Röntgenfoto's bij de bestudering van veranderingen 
in botdichtheid rondom een femorale heupprothese werden duidelijk gedemonstreerd door de DEXA studie. Waar op de conventionele opnames geen proximaal botverlies aanwezig leek te zijn, was dit overduidelijk op de DEXA scan vanaf het eerste moment aanwezig. DEXA maakt ook de relatie tussen remodellering en pre-existente osteoporose zichtbaar: pre-existente osteoporose leidt tot een groter periprosthetisch botverlies en een veel lager herstel van de botdichtheid. Ook is osteoporose een belangrijkere factor in het voorspellen van periprosthetisch botverlies dan het design van de prothese.

Toekomstige onwikkelingen in dit gedeelte van de orthopaedie zouden kunnen zijn dat voorafgaand aan de plaatsing van een femurprothese, de botdichtheid wordt gemeten en wanneer osteoporose wordt gediagnostiseerd, alendronaat gebruikt zal worden om de botdichtheid te optimaliseren voordat wordt overgegaan tot plaatsing van de prothese. 


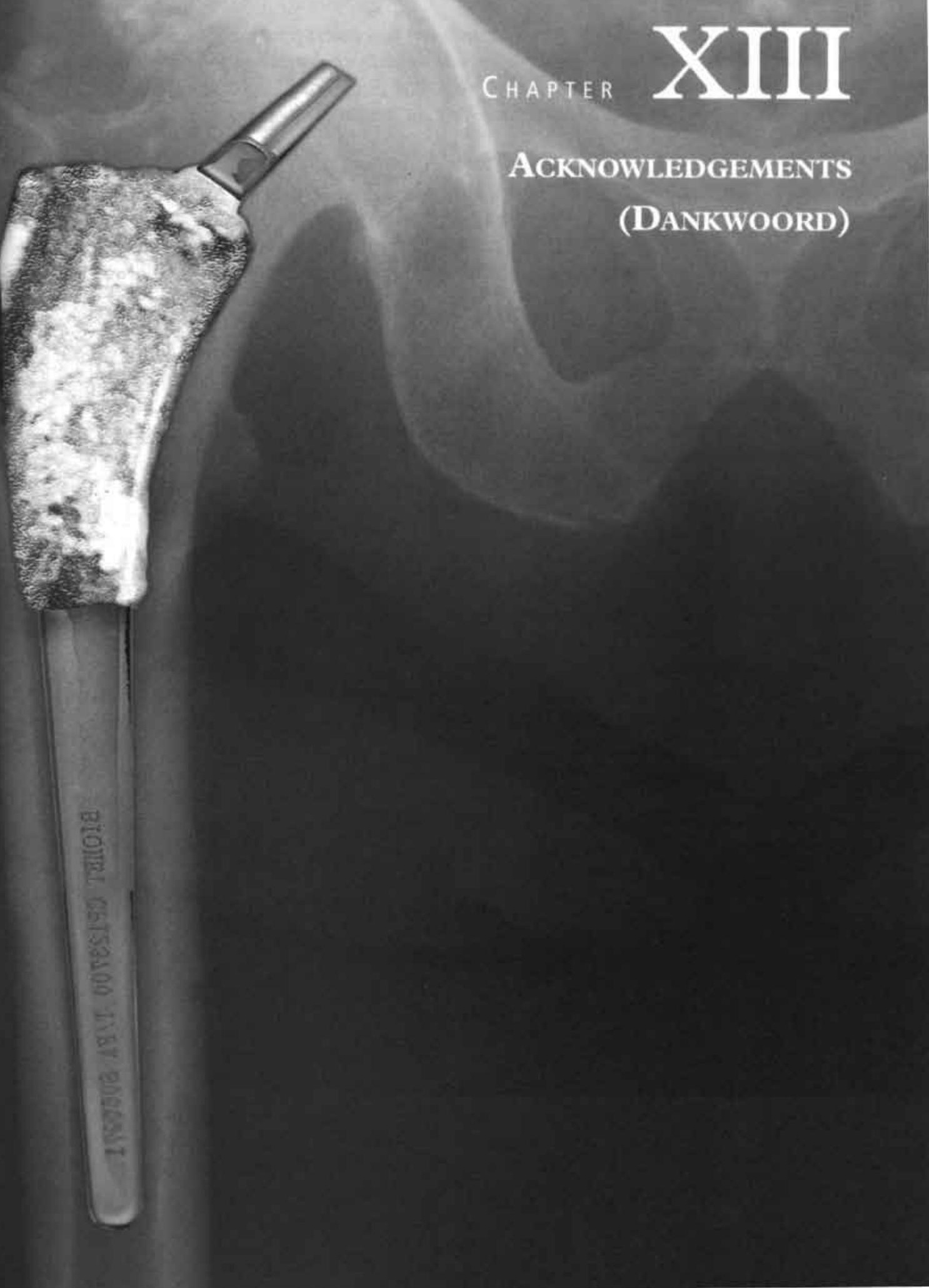


DANKWOORD 


\section{DANKWOORD}

De problemen bij het uitspreken van een dankwoord zijn veelvuldig: met wie te beginnen, dank alleen voor het proefschrift of dank voor de algehele vorming, familie en vrienden of alleen medici, etc. Naar mijn mening is dit een gelegenheid om allen die mij gemaakt hebben tot wat ik nu ben, met als wetenschappelijk resultaat dit proefschrift, te bedanken.

$\mathrm{Pa}$ en ma, bedankt voor de opvoeding van dat soms "eigenwijze jong". Door die opvoeding met veel duidelijkheid ben ik in staat geweest enkele tegenslagen te doorstaan en kon ik dit onderzoek doorzetten en bundelen tot een boekje. Zoals jullie uiteraard weten ben ik een man van niet al te veel woorden, maar in dat ene woord zit een hele boel verscholen. Bedankt.

Vivian, mijn vrouw. Al die zondagen en "vrije" avonden die opgingen aan het onderzoek en het computergebeuren. Ik weet dat je beter weet, al leek het er soms op, alsof ik met die computer was getrouwd! En dan ook nog eens het constante verhuizen voor de goede zaak: een opleiding tot orthopaedisch chirurg. Ook in moeilijke tijden was je in staat te relativeren en bleef je constant bij me. Ik beloof je dat het grote genieten nu eindelijk zal gaan beginnen en ook al zal onderzoek een deel blijven uitmaken van mijn professie, een verschuiving van prioriteiten lijkt nu wel op zijn plaats. Wederom slechts één woord, waar ook meerdere woorden mijn dank niet kunnen uitdrukken. Bedankt.

Professor Geesink, beste Ruud, beste promotor. Tijdens mijn academische stage maakte ik de afspraak om eens te praten over een promotie. Je was verbaasd dat er al een aantal artikelen af was en het wachten was op acceptatie door de tijdschriften. Het tijdspad daarna heb je fraai voor mij uitgezet en je duidelijke visie met betrekking tot het smeden van een geheel van de afzonderlijke artikelen was onmisbaar. Het resultaat is een promotie net na de afronding van mijn opleiding.

Evert van Langelaan, beste co-promotor, als AGNIO ben ik bij jou begonnen in Leiderdorp. Je hebt gestaan aan de basis van mijn orthopaedie carrière, je hebt genereus een deel van je patiëntenmateriaal aangeboden ter adoptie door mij. Ik zie ons nog staan tijdens het wassen voor de operaties: zeurend en klagend over een opleidingsplaats en het daarbij behorende onderzoek. Wat begon als een onderzoekje om in opleiding te komen is nu uitgemond in een proefschrift.

Alfons Tonino, beste co-promotor, mijn opleider en schrijver van diverse tijdspaden voor dit proefschrift. Steeds bleek er weer een ander hoofdstuk te zijn en een ander onderzoek dan je had gedacht, maar uiteindelijk is er toch iets moois ontstaan. Ik weet dat de promotie door jou twee jaar geleden al gepland was, maar dit is toch ook niet slecht?

Mede-auteurs vanuit de diverse ziekenhuizen in Nederland. Bedankt voor jullie expertise op de diverse vlakken. Enkelen wil ik bij naam noemen:

Ali Rahmy, je maakte mij enthousiast voor het botdichtheidsonderzoek bij heupprothesiologie. Uit het feit dat drie van de zes proefschrift gerelateerde stellingen uit ons DEXA-artikel zijn voortgekomen, blijkt de waarde van dit deel van het proefschrift. 
Nicolette Hoefnagels, het brein achter de vertaling en validering van de Oxford Heup Score. Met dit instrument kwam er toch een extra dimensie in het naonderzoek van de heuppatiënten.

Judith Sluimer, Arnold Kester en Riekie de Vet, mijn steunen op het statistische vlak. Zeker bij het herschrijven van artikelen en beantwoorden van opmerkingen door de statistisch geinteresseerde reviewers waren jullie onmisbaar.

Zonder jullie hulp zou er nooit een fraaie constructie zijn ontstaan.

Collega's tijdens de (voor)opleiding. Iedere keer dat ik bezig was met eigen onderzoek, dat ik weg was voor een praatje op een congres: jullie deden mijn taken en stelden je flexibel op. Zonder jullie flexibiliteit was dit boekje niet mogelijk geweest.

Alle patiënten die meewerkten door de vragenlijsten in te vullen en netjes hun foto's jaarlijks kwamen maken: een response rate op de vraag foto's te komen maken en een vragenlijst in te vullen van hoog in de $90 \%$ zelfs na gemiddeld 6 jaar is niet niets. Zonder jullie was er uiteraard geen onderzoek en proefschrift geweest.

De mensen bij Biomet Nederland B.V., voorheen Ortomed die mijn vragen over het Mallory-Head gebeuren snel en vakkundig beantwoorden. Ook was er altijd medewerking om weer eens een verhaaltje te vertellen op een congres. Op deze wijze kom je nog eens ergens, hetgeen de niet onprettige kant van onderzoek doen is.

Die mensen van de industrie die ondanks het feit dat het om een concurrerend produkt gaat, toch hun deel van de sponsorgelden leverden en wezenlijke bijdrages leveren aan mijn opleiding: eigenlijk onbegrijpelijk, maar voor een assistent in opleiding in de tijden van belastingherzieningen niet te missen.

Leden van de leescommissie, bedankt voor de opmerkingen van diverse aard. Deze opmerkingen verduidelijken de discussies en de conclusies.

Mijn paranymphen, Guido Dekkers en Will Meijers, bedankt dat jullie tijd konden vrij maken van een drukke praktijk om mij bij te staan in de organisatie en verwezenlijking van deze promotie. 



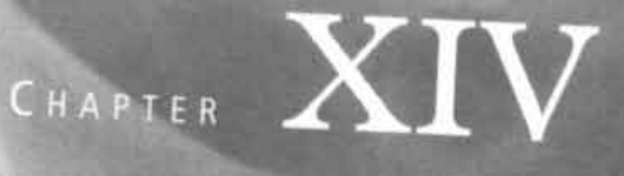

\section{Curriculum vitaE}




\section{Curriculum vitae}

Taco Gosens werd geboren op 19 april 1970 in Zwartewaal, Zuid-Holland. De lagere school werd aldaar gevolgd en de middelbare scholing werd gevolgd aan de Rijksscholengemeenschap in Brielle. Vervolgens studeerde hij geneeskunde aan de Erasmus Universiteit te Rotterdam. Gedurende 1992 en 1993 werkte hij als student assistent op de afdeling Anatomie en verrichtte hij, naast het geven van onderwijs, onderzoek. Hierna werden de reguliere co-schappen aangevuld met traumatologie, orthopaedie en sportgeneeskunde, zodat op 19 januari 1996 het artsexamen kon worden afgelegd.

De orthopaedische loopbaan begon in Leiderdorp waar hij als AGNIO kennis maakte met het vak onder de bezielende leiding van dr. E.J. van Langelaan. Tijdens deze periode werd de basis gelegd voor dit proefschrift en er zouden nog vele contacten met deze thuisbasis in het wilde Westen volgen.

De vooropleiding werd gevolgd in de Isala klinieken, lokatie Sophia in Zwolle (dr. W. van Rooijen en dr. J.E. de Vries). Daar werd een dusdanige ruimte gegeven voor onderzoek dat voordrachten en later ook publicaties over femurfracturen en supracondylaire humerusfracturen bij kinderen, een luxerende kophalsprothese en luxatiefracturen van de schouder bij epileptici konden worden geschreven.

Van het wijze Oosten werd in december 1999 de weg vervolgd naar het diepe Zuiden. In het Atrium Medisch Centrum te Heerlen werd het orthopaedisch gedeelte van de opleiding gestart onder dr. A.J. Tonino en dr. H.H. de Boer. Het onderzoek uit Leiderdorp kon worden voortgezet in Heerlen, omdat door de goede contacten tussen Leiderdorp en Heerlen het DEXA onderzoeksprotocol reeds was gestart. Tijdens de Heerlense periode werd intensief geparticipeerd in de Plexus Brachialis Werkgroep.

De laatste 2 maanden van het tweede jaar orthopaedie werden aangegrepen om de chirurgie van de bovenste extremiteit nader te bestuderen. Dit kon in het City Hospital in Nottingham onder auspiciën van Prof. W.A. Wallace en Mr. L. Neumann.

Het interessegebied kinderorthopaedie werd in het Academisch Ziekenhuis Maastricht verder uitgebouwd onder leiding van prof. dr. R.G.T. Geesink en dr. S.K. Bulstra.

Het laatste jaar van de opleiding, ondertussen onder leiding van dr. I.C. Heyligers, werd weer in Heerlen gevolgd en de laatste scherpe kantjes werden weggeslepen van zowel het proefschrift als de assistent in opleiding.

De opleiding werd met goed gevolg afgesloten eind november 2003 waarna hij per 1 januari 2004 ging werken in het St. Elisabeth Ziekenhuis in Tilburg. Hij vormt hier een maatschap met M. Bonnet, dr. J. de Waal Malefijt, J.J. Caron en C.H. Diekerhof.

De auteur is gelukkig getrouwd met Vivian en heeft een zoon, Rik, die op de eerste werkdag in Tilburg werd geboren. 